\title{
Comparison of Approaches to Category Partition Specifications, Selection Criteria, and the Impact of the 'Error' and 'Single' Annotations using Industrial Case Studies
}

\section{by}

\author{
Biraq Hussein
}

A thesis submitted to the Faculty of Graduate and Postdoctoral Affairs in partial fulfillment of the requirements for the degree of

Master of Applied Science

in

Electrical and Computer Engineering

Carleton University

Ottawa, Ontario

(C) 2018, Biraq Hussein 


\begin{abstract}
Given the significance of software testing, many methods such as black box testing have been introduced in order to make testing as efficient as possible. Experimental evidence is required to attest to the validity of such methods. In this thesis, we conducted experiments on twenty four test suites generated from two case studies targeting a real industrial system for generating financial reports. The experiments aim to evaluate the effectiveness of different Category Partition (CP) specifications on the same problem as well as that of the 'Single' and 'Error' constraints on the same CP specifications. The experiments also evaluate the effectiveness of the three selection criteria of Base-Choice, Each-Choice, and Pair-Wise. The effectiveness is measured in terms of cost, which is the number of generated test cases, fault detection of errors created by mutating code under test, and code coverage using Visual Studio.
\end{abstract}




\section{Acknowledgements}

I would first like to thank my wife, Mays, whose patience and support had made this work possible. I would also like to thank my parents for their ongoing encouragement. Many thanks go to my supervisor, Professor Yvan Labiche, for his insightful suggestions and remarks in perfecting this work. 
Table of Contents

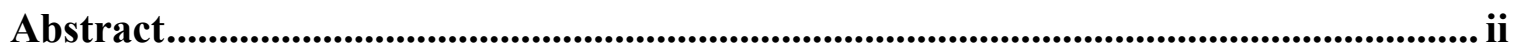

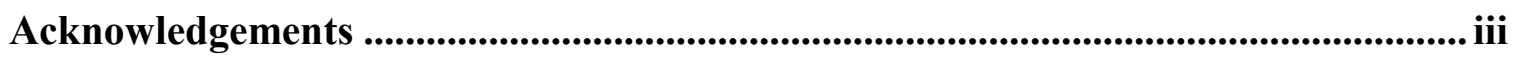

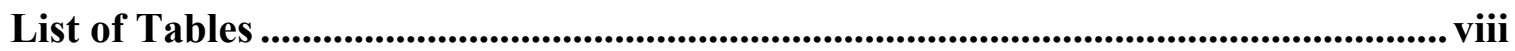

List of Illustrations................................................................................................................ $\mathrm{x}$

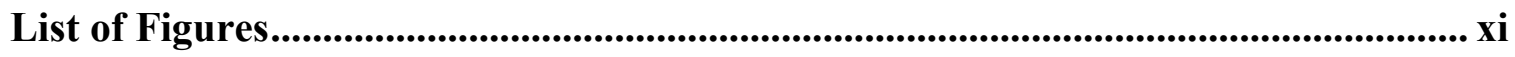

List of Listings .......................................................................................................................... xii

Chapter 1 Introduction........................................................................................... 1

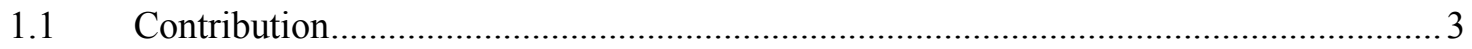

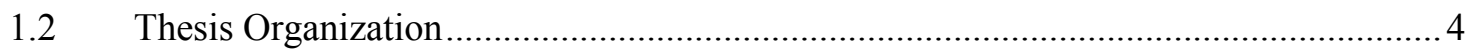

Chapter 2 Related Work ......................................................................................................... 5

Chapter 3 Experiment Design.................................................................................................. 7

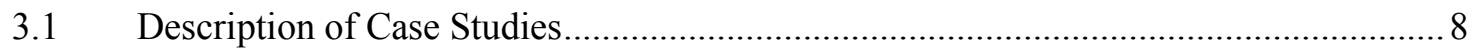

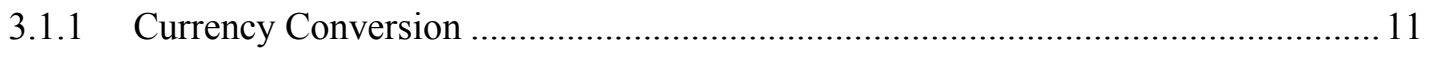

3.1.1.1 Technical Description of the System Under Test (SUT) .............................. 13

3.1.1.2 First (Preliminary) CP Specifications ....................................................... 14

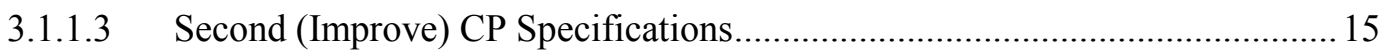

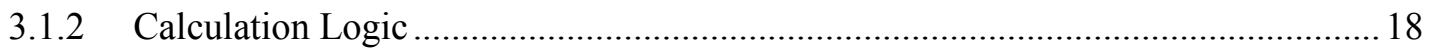

3.1.2.1 Technical Description of the System Under Test (SUT) ...............................2 21

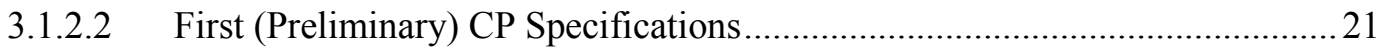

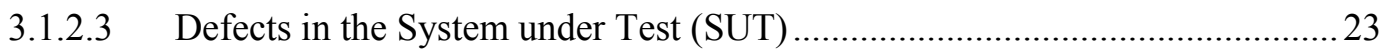

3.1.2.4 Second (Improved) CP Specifications....................................................... 23

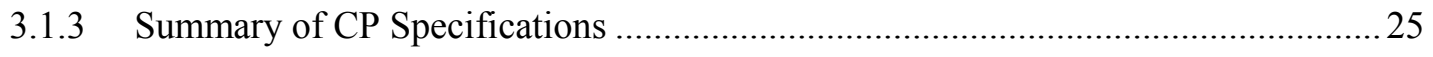

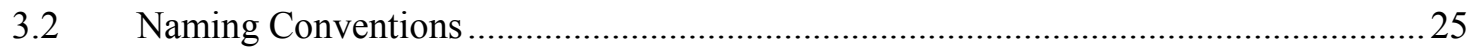




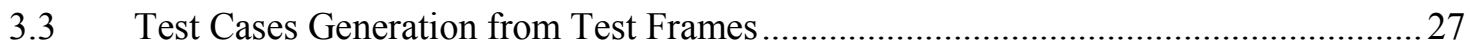

3.3.1 Test Inputs for the Currency Conversion Case Study ….....................................28

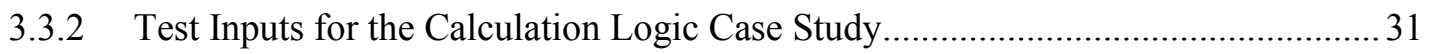

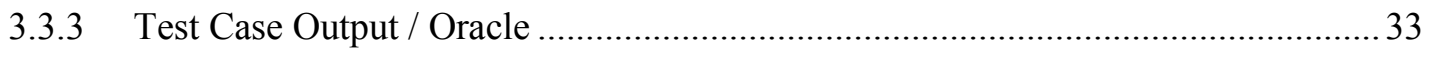

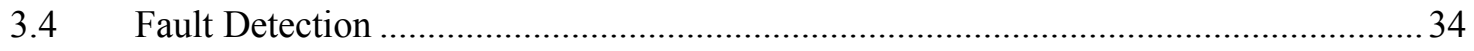

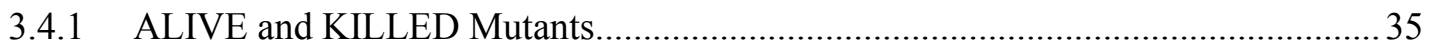

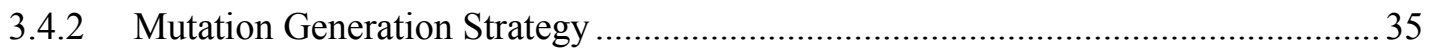

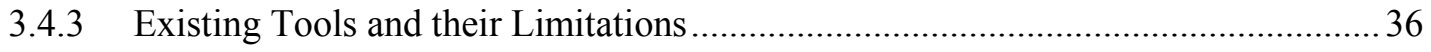

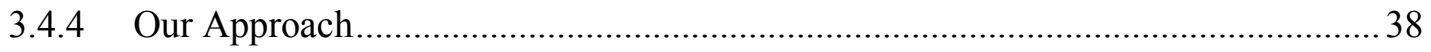

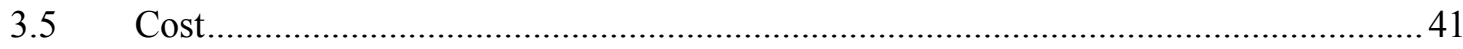

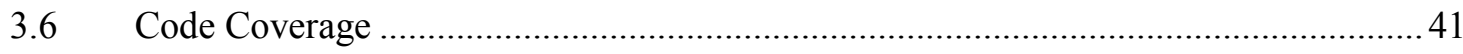

Chapter 4 Results and Discussion ...................................................................... 43

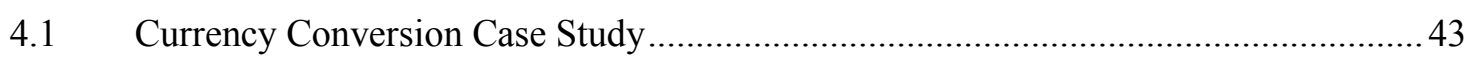

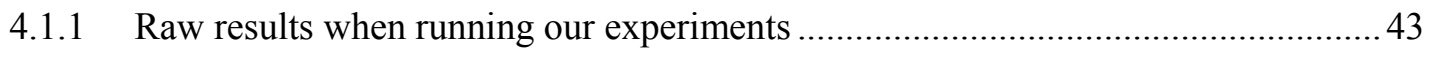

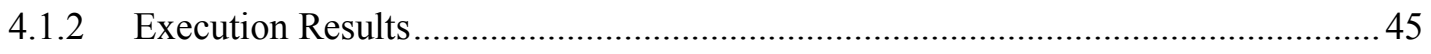

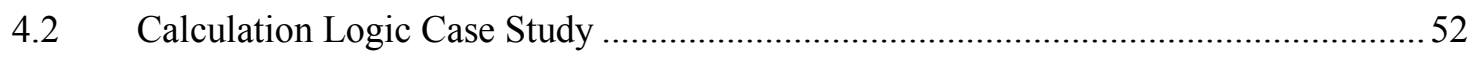

4.2.1 Raw results when running our experiments ...................................................52

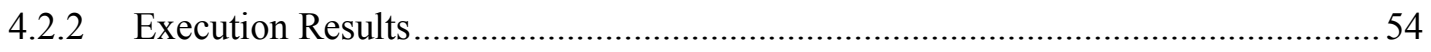

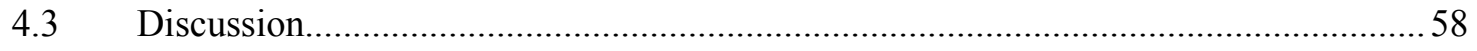

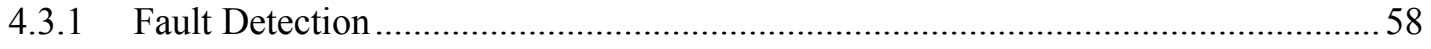

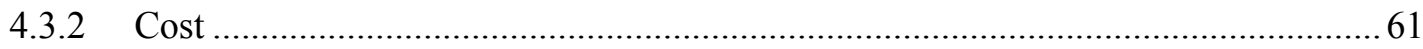

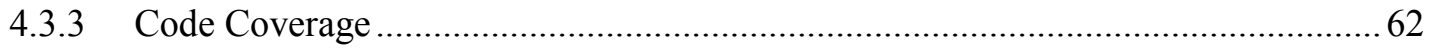

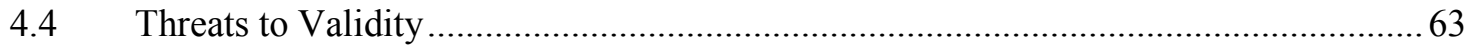

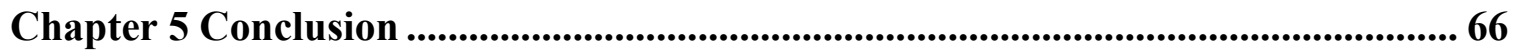

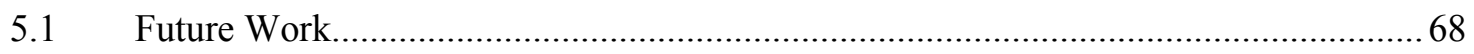


References...................................................................................................................................... 69

Appendices........................................................................................................................ 72

Appendix A Currency Conversion Case Study (First Approach) ............................................ 73

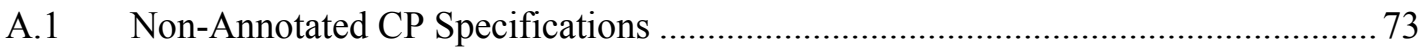

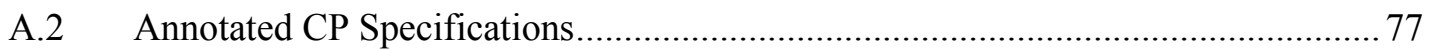

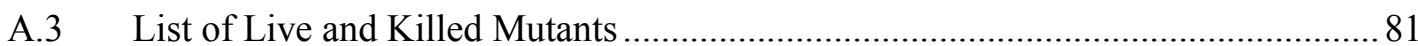

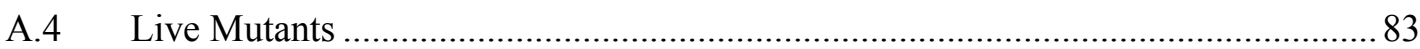

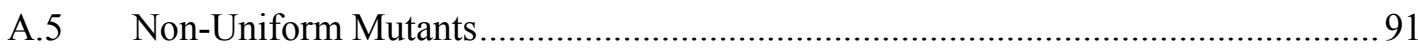

Appendix B Currency Conversion Case Study (Second Approach) ….................................. 92

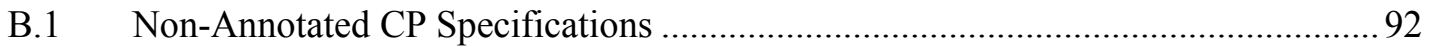

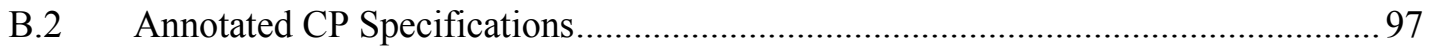

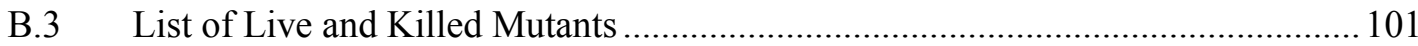

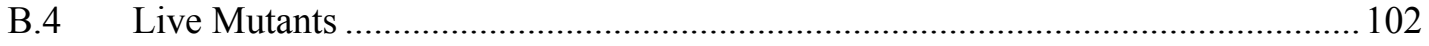

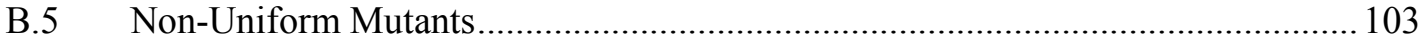

Appendix C Calculation Logic Case Study (First Approach) ............................................. 106

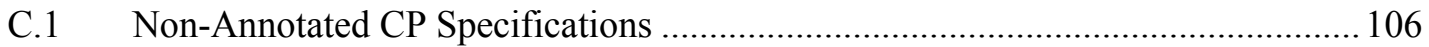

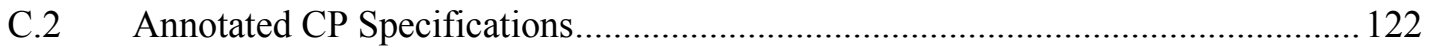

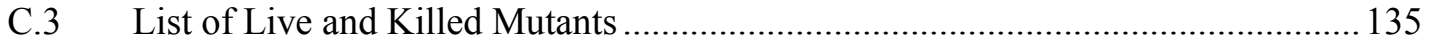

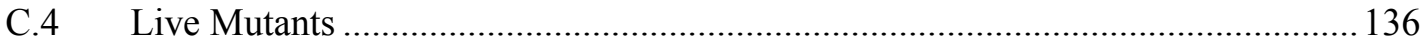

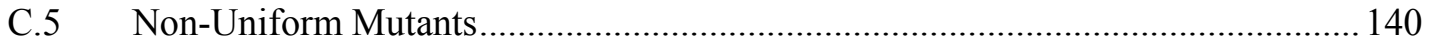

Appendix D Calculation Logic Case Study (Second Approach) .......................................... 141

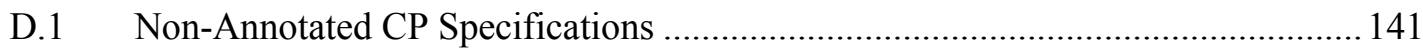

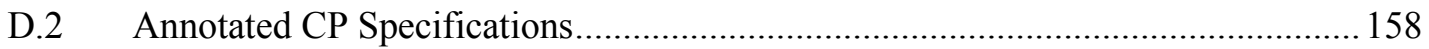

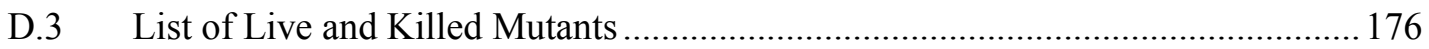

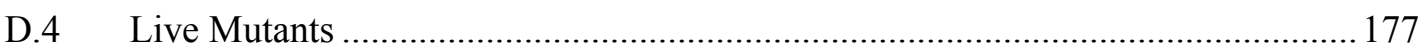

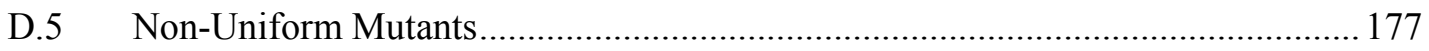




\section{List of Tables}

Table 1 - The (Non-)Annotated CP Specifications of the First Approach ...................... 15

Table 2 - The (Non-)Annotated CP Specifications of the Second Approach ................... 18

Table 3 - Table of Calculated Values ......................................................................... 20

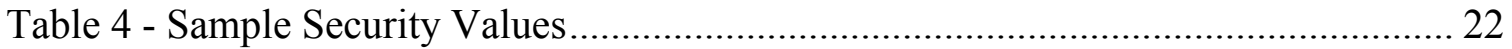

Table 5 - The (Non-)Annotated CP Specifications of the First Approach ..................... 23

Table 6 - The (Non-)Annotated CP Specifications of the Second Approach ................... 25

Table 7 - Summary of all CP Specifications............................................................. 25

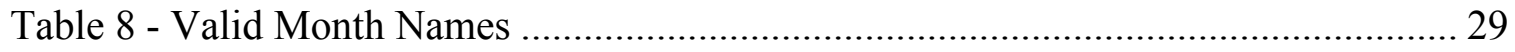

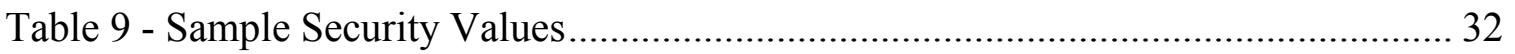

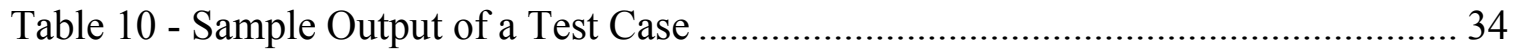

Table 11 - Code Mutation Operators (Standard and Object Operators) .......................... 40

Table 12 - Rates_1 Case Study - Number of Frames and Test Cases............................ 44

Table 13 - Rates_2 Case Study - Number of Frames and Test Cases.............................. 44

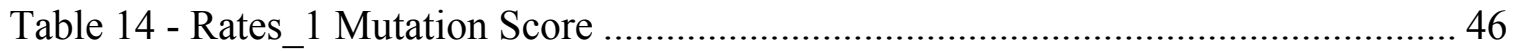

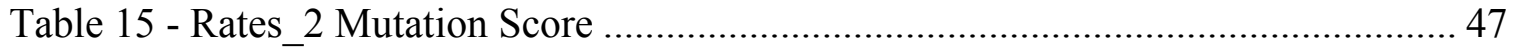

Table 16 - Calc_1 Case Study - Number of Frames and Test Cases .............................. 53

Table 17 - Calc_2 Case Study - Number of Frames and Test Cases ............................. 53

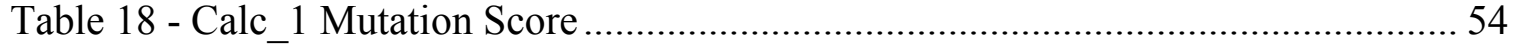

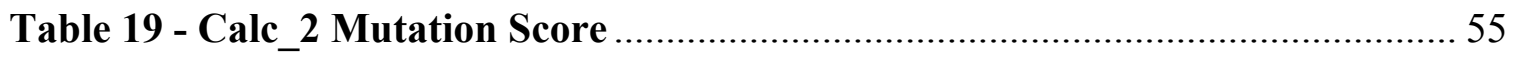

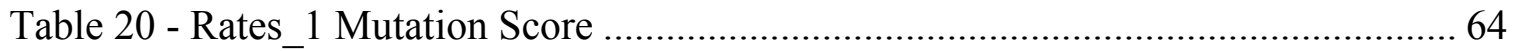

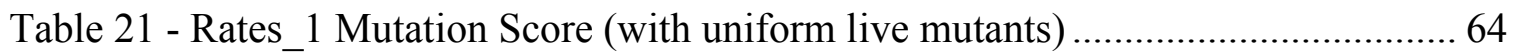

Table 22 - Base-Choice Test Cases (Non-Annotated Rates_1) ..................................... 75 
Table 23 - Each-Choice Test Cases (Non-Annotated Rates_1) .................................... 75

Table 24 - Pair-Wise Test Cases (Non-Annotated Rates_1) ........................................ 77

Table 25 - Base-Choice Test Cases (Annotated Rates_1) ........................................... 79

Table 26 - Each-Choice Test Cases (Annotated Rates_1) ........................................... 80

Table 27 - Pair-Wise Test Cases (Annotated Rates_1).............................................. 81

Table 28 - List of all mutants for the Rates_1 case study ......................................... 83

Table 29 - Base-Choice Test Cases (Non-Annotated Rates_2) .................................... 93

Table 30 - Each-Choice Test Cases (Non-Annotated Rates_2) ..................................... 94

Table 31 - Pair-Wise Test Cases (Non-Annotated Rates_2) ........................................ 96

Table 32 - Base-Choice Test Cases (Annotated Rates_2) ............................................ 98

Table 33 - Each-Choice Test Cases (Annotated Rates_2) ........................................... 99

Table 34 - Pair-Wise Test Cases (Annotated Rates_2).............................................. 100

Table 35 - List of all mutants for the Rates_2 case study ......................................... 102

Table 36 - Subset of live mutants in Rates_1 killed in Rates_2 .................................. 103 


\section{List of Illustrations}

Illustration 1 - Flow chart of the of the conversion process ...................................... 13

Illustration 2 - Alive and Killed Mutants (Rates_1) ................................................... 45

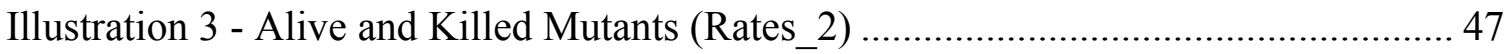

Illustration 4 - Code Coverage Percentage for Rates_ 1 ............................................... 51

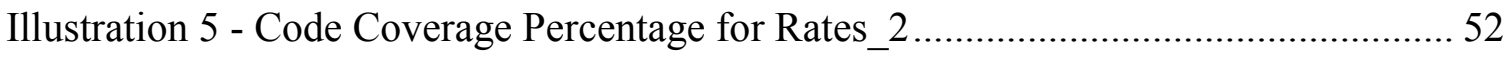

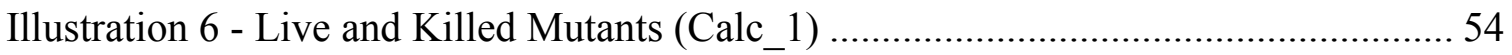

Illustration 7 - Live and Killed Mutants (Calc_2) ....................................................... 55

Illustration 8 - Code Coverage Percentage for Calc_1 ….......................................... 56

Illustration 9 - Code Coverage Percentage for Calc_2 ............................................... 56 


\section{List of Figures}

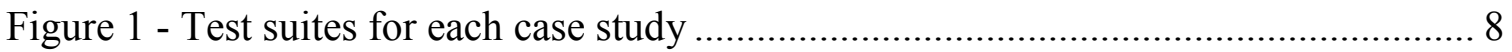

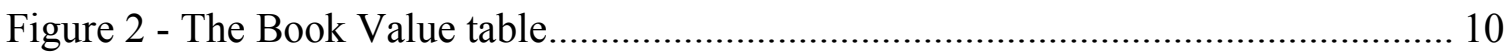

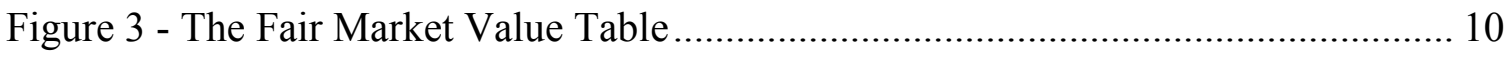

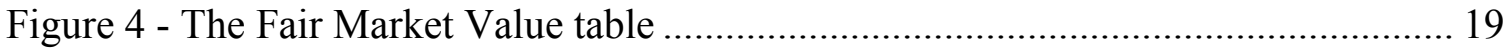

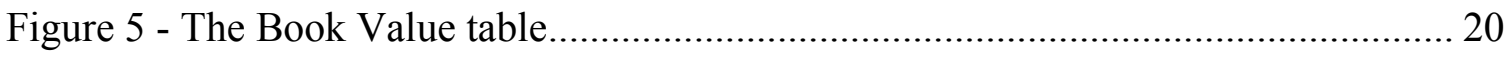

Figure 6 - Selected mutation operators in the CREAM tool....................................... 41 


\section{List of Listings}

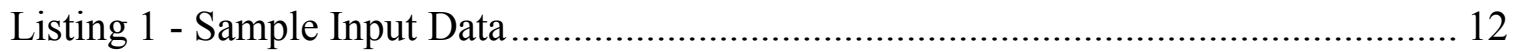




\section{Chapter 1 Introduction}

Software testing constitutes a significant part of the software development life cycle. It is meant to ensure that software products do their best in meeting certain quality standards [1]. Untested or poorly tested software products can be damaging to the end-user as well as the manufacturer. Moreover, the testing process itself can be costly from a time and resources perspective. Thus, any good care taken during the initial planning of testing will pay off in the form of more efficient testing.

Given the need for efficient testing, several testing methods and techniques have been devised to achieve this goal. Black box testing is one such method. More precisely, one technique of black box testing is the Category Partition (CP) technique. This technique relies on the specification of the system under test to derive input without having to be aware of the implementation details of the system.

The Category Partition technique approaches testing a system by first identifying its input parameters and their characteristics. A characteristic is defining a feature of an input parameter such as the length of a string input value. Next, choices or blocks are identified from a characteristic. For example, a zero-length string is one possible choice under the length characteristic. Choices can then be combined to construct test frameworks which dictate the specification of test case inputs. Sometimes, choices cannot be logically combined. This is where constraints are used to determine what combination of choices is valid. Constraints are essentially properties of choices which determine the choice's ability to be combined with another choice. For example, a choice sometimes cannot, or must, be combined with another one. Therefore, such constrains are used to specify feasibility of choice combinations. 
Another purpose of constraints is to reduce the number of test frames especially when it is deemed sufficient to use a choice, or a set thereof, only once for instance. Two special constraints are the 'Single' and 'Error' constraints. A choice is tagged with the 'Single' constraint to indicate that having this choice in a single combination with other choices would suffice. Tagging a choice with the 'Error' constraint indicates that using this choice in any combination with other choices would result in an error. Once characteristics, choices, and constraints are in place, selecting choices to make up frameworks can begin based a certain selection criterion. Since the work in this thesis uses the Melba [2] tool to generate test frameworks, we will be using the selection criteria provided by this tool which are the main ones being discussed in the literature. Melba provides the ability to select choices based on three selection criteria, namely the base choice, the each choice, and the pair wise selection criteria. The mechanism used by these criteria to combine choices is outside the scope of this work, but the reader can refer to section 4.1 of Ammann and Offutt's textbook [3] for more details.

Deriving characteristics and choices may not always be an easy task. The authors in reference [3] refer to this process as Input Domain Modeling (IDM) and identify two approaches to it: interface-based and functionality-based. The interface-based approach is straightforward in the sense that it considers each input parameter on its own to derive its characteristics and choices. This approach is reported by Ammann and Offutt [3] to produce tests that are "surprisingly good". On the other hand, the second approach considers the system under test as a whole and "allows the tester to 
incorporate some semantics and domain knowledge into the IDM" [3]. In our work, we use both approaches to IDM.

In our work, we attempt to address the following three research questions:

1 How can differently created CP specifications impact testing?

2 What is the impact of using and discarding the 'Single' and 'Error' constraints on a CP specification?

3 What is the impact of using different selection criteria in testing?

In each of the two case studies, to address the first question, we will first attempt a preliminary and seemingly simple approach to creating a $\mathrm{CP}$ specification, and then a more carefully thought out one. To address the second research question, we attempt to evaluate the impact of introducing and completely eliminating the 'Single' and 'Error' constraints on all previously created CP specifications. For the third research question, we use different selection criteria to combine choices and evaluate each criterion's impact. The three criteria are known in the literature as Base-Choice, Each-Choice and Pair-wise selection criteria. The evaluation is performed experimentally based on cost, or the number of test frames, fault detection, and code coverage.

\subsection{Contribution}

The contribution of this thesis comes from the experimental value or evidence obtained by conducting two case studies on a real industrial system and experimentally evaluating:

1. Different CP specifications for the same system under test; 
2. The presence and absence of the 'Single' and 'Error' constraints on the same CP specifications;

3. The selection criteria used to combine choice for constructing test frames.

\subsection{Thesis Organization}

From this point forward, this thesis is structured to have the following sections:

1. Chapter 2 discusses related work.

2. Chapter 3 discusses the experiment design which contains subsections describing the case studies, test case generation, fault detection, and code coverage.

3. Chapter 4 presents the results of each case study as well as a discussion on the results.

4. Chapter 5 is about the conclusion and possible future work. 


\section{Chapter 2 Related Work}

Sadeghi's work [4] added tool support to Melba, which is what we are working with, to enable the automatic generation of test frames using the selection criteria basechoice, each-choice, and pair-wise. It also presents experimental work through five academic case studies on the comparison of these selection criteria. Our work is similar to this in terms of comparing the selection criteria, but our comparison is done on case studies performed on a real industrial system. Another difference is that the work does not research the impact of different CP specifications nor that of the 'Single' and 'Error' constraints.

The authors in reference [5] report on experimenting with three academic case studies using CP specifications with and without the 'Single' and 'Error' constraints. Test frames in the case studies are constructed using the Melba tool. This work shows that specifying the 'Single' and 'Error' choices results in getting better coverage than when not specifying them. The paper emphasizes on the tester's expertise and knowledge to carefully place constraints to achieve better results. However, there is no discussion on the impact of different CP specifications.

For a closer look at another work done on the 'Error' and 'Single' annotations, Khalsa, Labiche, and Johanna [6] present an experimental evaluation of the 'Single' and 'Error' annotations performed on a set of three case studies, two academic and one industrial. The paper only uses the Each Choice and Pair Wise selection criteria. It also discusses the impact of adding and discarding the 'Single' and 'Error' annotations to CP specifications on 12 experiments where the first six use constraints amongst choice while 
the rest do not. However, it does not compare different approaches to constructing CP specifications.

In their work [7], Tse, Sau-Fun, and Fei-Chang discuss types and amounts of mistakes made by software testers in the process of identifying categories and choices. This is done by conducting "several case studies using three commercial specifications written primarily in an informal manner." The studies discuss the effect of the tester's experience as well as the futility of providing a checklist in order to detect missing and/or problematic categories and choices. The study found that generally a tester's experience, despite an ad hoc approach to identify categories and choice, is a factor in producing $\mathrm{CP}$ specifications with better quality. This conclusion does seem to be a common sense knowledge that is proven by Tse et al, which is what we also strive to show through our work.

In summary, the contribution made by this work comes from conducting case studies on an industrial system in order to provide experimental evidence on the impact on differently created CP specifications, the impact of discarding and enforcing the 'Single' and 'Error' annotations, and the impact of different test selection criteria (namely, the base choice, the each choice, and the pair wise criteria). But also, our work is similar in a sense to previous ones and it has the value of contributing, or maybe invalidating, evidence made in support of the related work presented above. 


\section{Chapter 3 Experiment Design}

In this work, we have designed two case studies derived from a real system in a financial institution. The system is responsible for generating financial reports for clients based on input data in the form of XML. For each case study, we will construct two CP specification models. The first model is a preliminary one that is derived from a first look at the requirements and thus may not be fully thought out. The second, improved model is also derived from the requirements in addition to the tester's expertise and familiarity with the system under test.

We will experiment on each model in the presence and absence of the 'Single' and 'Error' annotations. This will result in two versions for each model: an annotated model and a non-annotated model. Furthermore, to construct test frames from each model, we will use three selection criteria: Base-Choice, Each-Choice, and Pair-Wise.

Constraints that are used to determine feasibility of combining choices or reduce the number of test frames were not used in this work for two reasons. First, the CP specifications that were developed did not need such constraints in the sense that no unfeasible combinations of choices were observed. Second, the resulting number of test frames was relatively manageable and we did not need to reduce it and consequently enforce such constraints.

The above will therefore create twelve test suites for each case study because each one will have a preliminary and an improved CP specifications model, and each model will have a version with and without the 'Single' and 'Error' annotations, and three selection criteria will be used to construct test frames from each further resulting model. This is a total of twelve test suites per case study. Figure 1 shows the breakdown of these 
test suites: "annotated" means that the CP specification uses the 'Single' and 'Error' annotations.

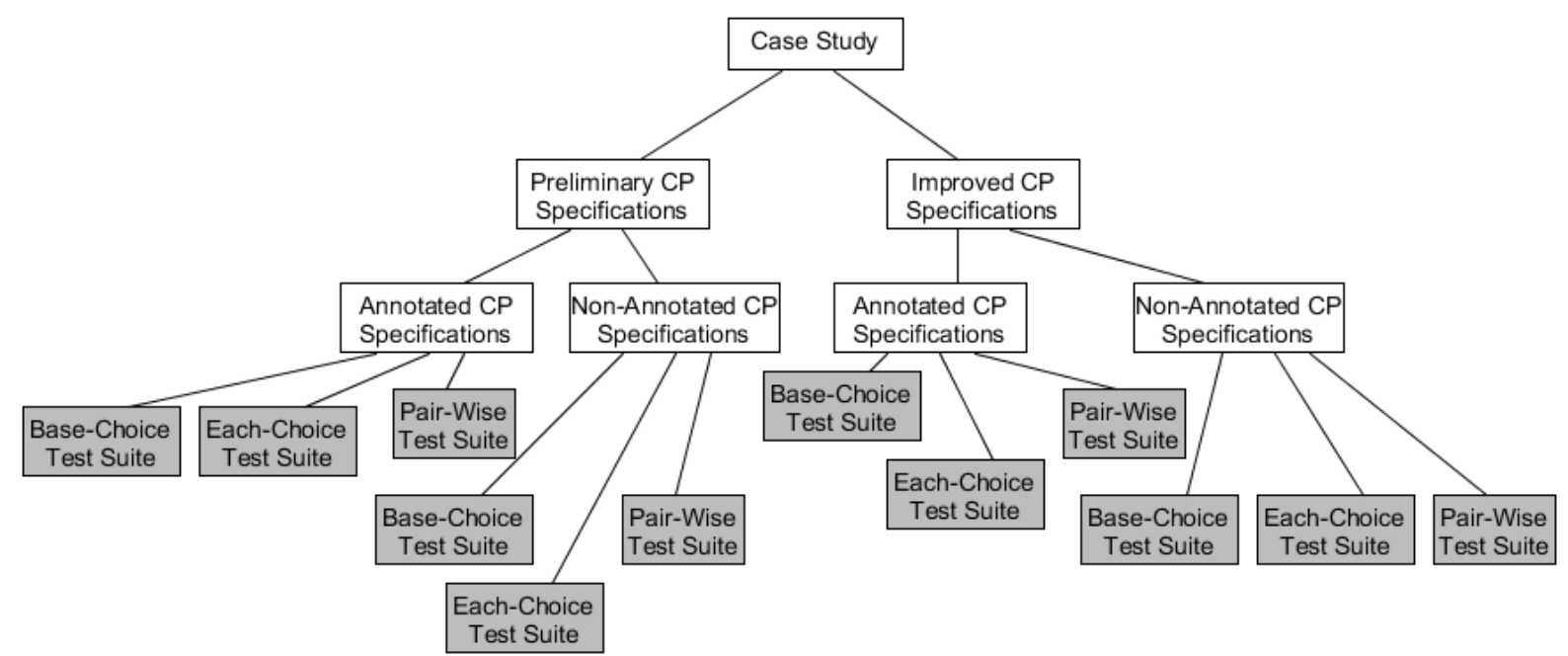

Figure 1 - Test suites for each case study

\subsection{Description of Case Studies}

The case studies in this paper are focused around a financial report for foreign income which is generated from holding foreign investments. The report is produced annually and shows the book value ${ }^{1}(\mathrm{BV})$ and market value ${ }^{2}$ (MV) of a security ${ }^{3}$ for each month during which the security is owned by the client. For example, if a client bought a foreign security in January and kept it for the rest of the year, the report should show the book value and market value of the security for each month from time of purchase (January in this case). However, if a security is sold, say in May, the report only shows

\footnotetext{
${ }^{1}$ Book value is the value of a security upon the time of purchase, which is also referred to as Investment Closing Book Value and denoted as BV henceforward.

${ }^{2}$ Market value is the current market value of a security, which is also referred to as Investment Closing Market Value and denoted as MV henceforward.

3 A security is a certificate or other financial instrument that has monetary value and can be traded. [http://whatis.techtarget.com/definition/security-finance]
} 
information about the security for the first five months of the year (i.e., duration of ownership of the security). In addition to the BV and MV of a security, the report also displays the Income Earned ${ }^{4}$ and Capital Gain ${ }^{5}$ made on the security during the year.

The report consists of two tables. The first table is the Book Value table which shows only the monthly book values of securities. This value is to remain consistent during the period of owning the security. The second table is the Fair Market Value (or Market Value for short) table which shows the monthly market values of the securities as well as the annual income earned and capital gain of each security. Securities in both tables are grouped by the country of incorporation (i.e., country of origin). For example, Canadian securities have their country of incorporation as 'Canada', and American securities as 'USA'.

Figure 2 shows a Book Value table which holds the security's name, BV for each month, and the account number it belongs to as well as the conversion rate (which is outside our scope of concern for now). Figure 3 shows a Market Value table which holds the security's name, MV for each month, income earned value, capital gain/loss value, and the account number it belongs to. In both tables, securities are grouped by their country of incorporation. For each group, totals are calculated as indicated in sub-total sections.

A client can own multiple securities under the same investment account. Accounts and securities can have the same or different currencies. The currency of a security is

\footnotetext{
${ }^{4}$ The Income Eared is the income made on the security as a result of selling it or parts of it.

${ }^{5}$ The Capital Gain is the income made on the security due to "increase in value that gives it a higher worth than the purchase price" [Investopedia.com]
} 
referred to as 'CurrencyCode', and that of the account as 'AccountCurrency'. Values for the currency fields are expected to be either 'CAD' or 'USD' for now.

\begin{tabular}{|c|c|c|c|c|c|c|c|c|c|c|c|c|c|c|}
\hline Security Name/Nom du titre & $\begin{array}{l}\text { Jan./ } \\
\text { Janv. }\end{array}$ & $\begin{array}{l}\text { Feb./ } \\
\text { Févr. }\end{array}$ & $\begin{array}{l}\text { Mar./ } \\
\text { Mars }\end{array}$ & $\begin{array}{l}\text { Apr./ } \\
\text { Avril }\end{array}$ & $\begin{array}{l}\text { May/ } \\
\text { Mai }\end{array}$ & $\begin{array}{l}\text { June/ } \\
\text { Juin }\end{array}$ & $\begin{array}{l}\text { July/ } \\
\text { Juillet }\end{array}$ & $\begin{array}{l}\text { Aug./ } \\
\text { Août }\end{array}$ & $\begin{array}{l}\text { Sept./ } \\
\text { Sept. }\end{array}$ & $\begin{array}{l}\text { Oct./ } \\
\text { Oct. }\end{array}$ & $\begin{array}{l}\text { Nov./ } \\
\text { Nov. }\end{array}$ & $\begin{array}{l}\text { Dec./ } \\
\text { Déc. }\end{array}$ & $\begin{array}{l}\text { Account } \\
\text { Number/Numéro de } \\
\text { compte }\end{array}$ & FX Rate/Taux (\%) \\
\hline SEC 5 & - & - & - & - & - & - & - & - & 33 & 33 & 33 & - & 1234.700 & - \\
\hline SEC 6 & - & - & - & - & - & - & 70 & 70 & 70 & 70 & 70 & 70 & 1234.700 & - \\
\hline SEC 7 & 10 & 10 & 10 & 10 & 10 & 10 & 10 & 10 & 10 & 10 & 10 & 10 & 1234.700 & - \\
\hline $\begin{array}{l}\text { Sub-Total/Sous-total } \\
\text { USA }\end{array}$ & 20 & 20 & 20 & 10 & 10 & 10 & 80 & 80 & 113 & 113 & 113 & 80 & & \\
\hline \multicolumn{15}{|l|}{ Country/Pays: CHINA } \\
\hline SEC 8 & 10 & 10 & 10 & 10 & 10 & 10 & 10 & 10 & 10 & 10 & 10 & 10 & 1234.700 & - \\
\hline $\operatorname{SEC} 9$ & 10 & 10 & 10 & 10 & 10 & 10 & 10 & 10 & 10 & 10 & 10 & 10 & 1234.700 & - \\
\hline $\begin{array}{l}\text { Sub-Total/Sous-total } \\
\text { CHINA }\end{array}$ & 20 & 20 & 20 & 20 & 20 & 20 & 20 & 20 & 20 & 20 & 20 & 20 & & \\
\hline $\begin{array}{l}\text { Total for the month } \\
\text { Total pour le mois }\end{array}$ & 650 & 650 & 650 & 540 & 540 & 540 & 110 & 110 & 143 & 143 & 143 & 110 & & \\
\hline
\end{tabular}

\section{Figure 2 - The Book Value table}

\begin{tabular}{|c|c|c|c|c|c|c|c|c|c|c|c|c|c|c|c|}
\hline$\frac{\text { Security Name }}{\text { Nom du titre }}$ & $\begin{array}{l}\text { Jan./ } \\
\text { Janv. }\end{array}$ & $\begin{array}{l}\text { Feb./ } \\
\text { Févr. }\end{array}$ & $\begin{array}{l}\text { Mar./ } \\
\text { Mars }\end{array}$ & $\begin{array}{l}\text { Apr./ } \\
\text { Avril }\end{array}$ & $\begin{array}{l}\text { May/ } \\
\text { Mai }\end{array}$ & $\begin{array}{l}\text { June/ } \\
\text { Juin }\end{array}$ & $\begin{array}{l}\text { July/ } \\
\text { Juillet }\end{array}$ & $\begin{array}{l}\text { Aug./ } \\
\text { Août }\end{array}$ & $\begin{array}{l}\text { Sept./ } \\
\text { Sept. }\end{array}$ & $\begin{array}{l}\text { Oct./ } \\
\text { Oct. }\end{array}$ & $\begin{array}{l}\text { Nov. } \\
\text { Nov. }\end{array}$ & $\begin{array}{l}\text { Dec./ } \\
\text { Déc. }\end{array}$ & $\begin{array}{l}\text { Income } \\
\text { earned/(loss) } \\
\text { by security } \\
\text { Revenu gagné } \\
\text { (perdu) par } \\
\text { titre }\end{array}$ & \begin{tabular}{|l|} 
Capital \\
gain/ \\
(loss) by \\
security \\
Gain \\
(perte) en \\
capital par \\
titre
\end{tabular} & $\begin{array}{l}\text { Account Number } \\
\text { Numéro de compte }\end{array}$ \\
\hline $\begin{array}{l}\text { Sub-Total/Sous-total } \\
\text { CANADA }\end{array}$ & 1,233 & 2,466 & 355 & 44 & 66 & 3,344 & 22 & 33 & 11 & 22 & 33 & 33 & 1,425 & 996 & \\
\hline \multicolumn{16}{|l|}{ Country/Pays: USA } \\
\hline SEC 4 & 100 & 200 & 300 & - & - & - & - & - & - & - & - & - & 669 & 432 & 1234.700 \\
\hline SEC 5 & - & - & - & - & - & - & - & - & 100 & 200 & 300 & - & 69 & 89 & 1234.700 \\
\hline SEC 6 & - & - & - & - & - & - & 100 & 200 & 100 & 200 & 300 & 300 & 96 & 5 & 1234.700 \\
\hline SEC 7 & 100 & 200 & 100 & 200 & 300 & 100 & 200 & 300 & 100 & 200 & 300 & 300 & 99 & 6 & 1234.700 \\
\hline $\begin{array}{l}\text { Sub-Total/Sous-total } \\
\text { USA }\end{array}$ & 200 & 400 & 400 & 200 & 300 & 100 & 300 & 500 & 300 & 600 & 900 & 600 & 933 & 532 & \\
\hline \multicolumn{16}{|l|}{ Country/Pays: CHINA } \\
\hline SEC 8 & 100 & 200 & 100 & 200 & 300 & 100 & 200 & 300 & 100 & 200 & 300 & 300 & 629 & 100 & 1234.700 \\
\hline SEC 9 & 100 & 200 & 100 & 200 & 300 & 100 & 200 & 300 & 100 & 200 & 300 & 300 & 10 & 965 & 1234.700 \\
\hline $\begin{array}{l}\text { Sub-Total/Sous-total } \\
\text { CHINA }\end{array}$ & 200 & 400 & 200 & 400 & 600 & 200 & 400 & 600 & 200 & 400 & 600 & 600 & 639 & 1,065 & \\
\hline $\begin{array}{l}\text { Total for the month } \\
\text { Total pour le mois }\end{array}$ & 1,633 & 3,266 & 955 & 644 & 966 & 3,644 & 722 & 1,133 & 511 & 1,022 & 1,533 & 1,233 & 2,997 & 2,593 & \\
\hline
\end{tabular}

\section{Figure 3 - The Fair Market Value Table}

Since this financial report (as presented in Figure 2 and Figure 3 collectively) is for foreign securities, values are sometimes expected to be reported in US dollars, so the report needs to convert these amounts to Canadian dollars by applying a given conversion rate and following certain conversion rules. This conversion process is the subject of the 
first case study. Also, the report groups the securities by country of incorporation and performs certain calculations to report on certain amounts. This calculation logic is the subject of the second case study.

\subsubsection{Currency Conversion}

Among the many requirements of the system under test is that BV and MV of a security must be displayed in Canadian dollar. However, the original data processed by the system may be in either Canadian or US dollar. Therefore, amounts in US dollar must be converted to Canadian whereas Canadian amounts remain unchanged.

Converted BV and MV are calculated based on conversion or exchange rates provided for each month of the reporting year. Rates are provided by an external source and merged with the input data.

For example, if we have a security whose 'CurrencyCode' and 'AccountCurrency' are both 'USD' and are also given conversion rates (i.e., rates to convert from USD to CAD) for each, or only some, month of the year, then the BV and MV of this security have to be converted. The input data is represented in Listing 1. 


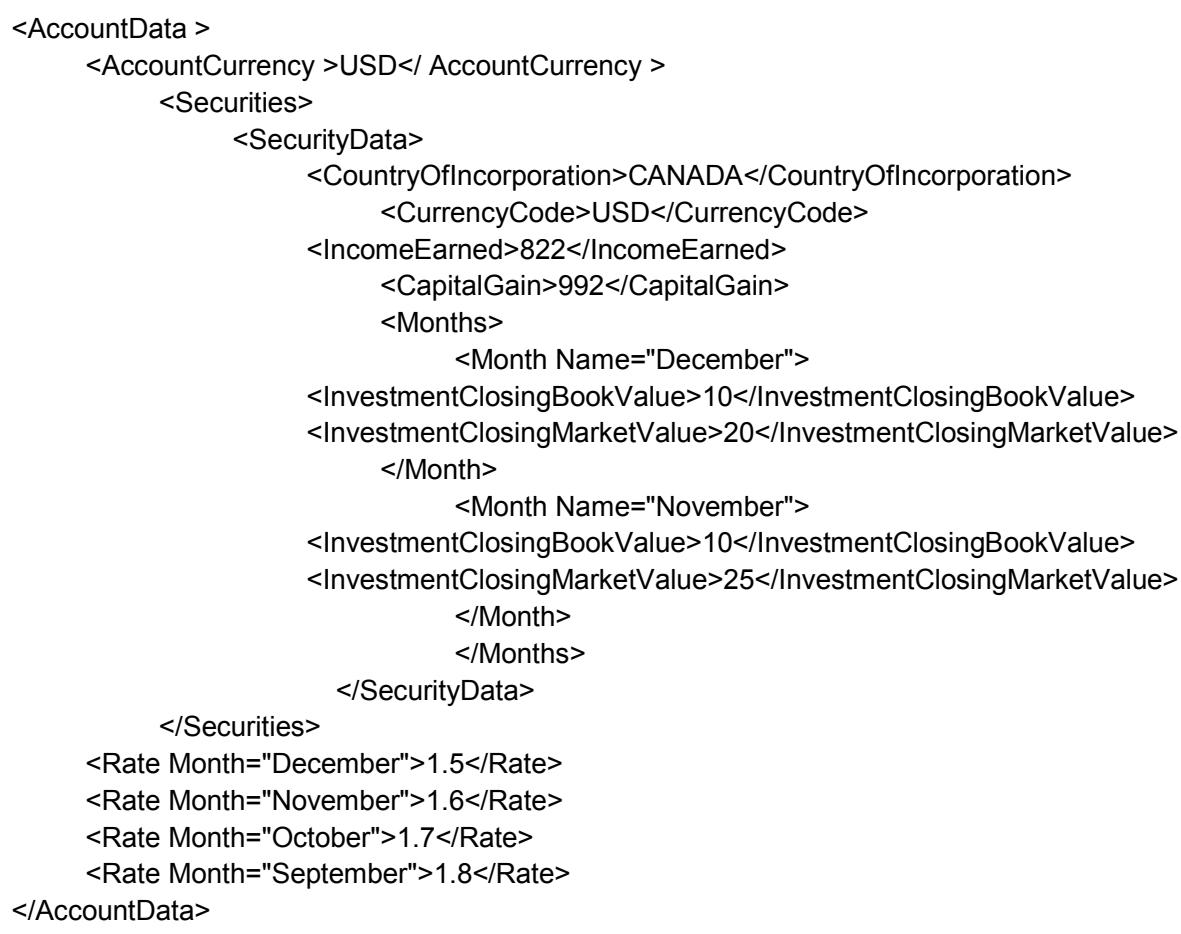

\section{Listing 1 - Sample Input Data}

The above input sample shows that this security has a CurrencyCode (line 6) and AccountCurrency (line 2) of USD. It also shows that it has BV and MV for the months of November (lines 15 and 16) and December (lines 11 and 12). Also, we are provided with conversion rates for the months of September, October, November, and December (line numbers 23, 34, 25, and 26).

Given the above input data, the conversion logic goes as follows:

- Convert the BV (10) by multiplying it by the average conversion rate obtained from the provided months: $1.5,1.6,1.7$ and 1.8 .

- Convert the MV for December by multiplying it by 1.5 and the MV for November by 1.6 because these are the conversion rates for December and November respectively.

The following flow chart shows the conversion logic: 


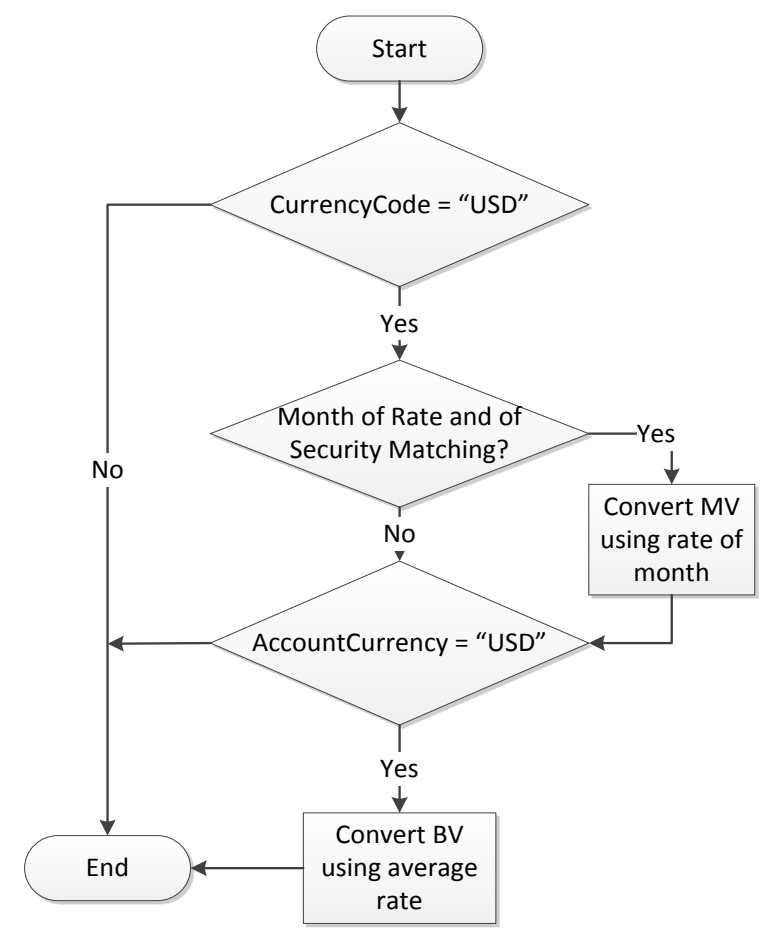

\section{Illustration 1 - Flow chart of the of the conversion process}

Table 1 and Table 2 represent the CP specifications of the first and second approach respectively. Each table shows the annotated and non-annotated version of the $\mathrm{CP}$ specification. In each column, the first non-indented line represents the input parameter, the bulleted line under the input parameter is the category name, and the remaining lines represent choices.

\subsubsection{Technical Description of the System Under Test (SUT)}

The system under test is written in the $\mathrm{CH}$ language. The part of the system that is the subject of this case study is a class consisting of 63 lines of code. This number was obtained using Visual Studio's Code Metrics feature which provides the number of lines along with other metrics. The code is withheld for confidentiality reasons. 


\subsubsection{First (Preliminary) CP Specifications}

Deriving the first $\mathrm{CP}$ specification should not require extensive knowledge and effort from the tester. The idea is that by simply reading the logic of the case study and considering its inputs as provided in Listing 1, the tester should be able to come up with input parameter as seen in Table 1.

By simply looking at the XML input data sample, see Listing 1, we can see that there are seven values which are:

- CurrencyCode

- Name (Name of the month under $<$ Month Name="December" $>$ )

- InvestmentClosingBookValue

- InvestmentClosingMarketValue

- AccountCurrency

- Month (Month of rate under $<$ Rate Month="December" $>$ )

- Rate value(s) (exchange rate value for a specific month under $<$ Rate Month="December" $>1.5<$ Rate $>$ )

As a first attempt, we can use all the values above as input parameters. This approach is pretty straightforward in the sense that it blindly enumerates the parameters used in the conversion process without giving much consideration to their semantics. 


\begin{tabular}{|c|c|}
\hline CP Specification & Annotated CP Specification \\
\hline $\begin{array}{l}\text { CurrencyCode } \\
\text { - IsUSD: } \\
\bullet \quad \text { True[base] } \\
\text { - False }\end{array}$ & $\begin{array}{l}\text { CurrencyCode } \\
\bullet \quad \text { IsUSD: } \\
\qquad \quad \text { True[base] } \\
\bullet \quad \text { False [Error] }\end{array}$ \\
\hline $\begin{array}{l}\text { AccountCurrency } \\
\qquad \quad \text { IsUSD: } \\
\qquad \quad \text { True[base] } \\
\text { - False }\end{array}$ & $\begin{array}{l}\text { AccountCurrency } \\
\qquad \quad \text { IsUSD: } \\
\qquad \text { True[base] } \\
\qquad \quad \text { False [Error] }\end{array}$ \\
\hline $\begin{array}{l}\text { RateMonthName } \\
\qquad \quad \text { IsValidName } \\
\bullet \quad \text { True [base] } \\
\text { - False }\end{array}$ & $\begin{array}{l}\text { RateMonthName } \\
\qquad \quad \text { IsValidName } \\
\bullet \quad \text { True [base] } \\
\bullet \quad \text { False [single] }\end{array}$ \\
\hline $\begin{array}{l}\text { ExchangeRate } \\
\bullet \quad \text { Range } \\
\bullet \quad \text { LargerThanZero [base] } \\
\bullet \quad \text { LessThanOrEqualToZero }\end{array}$ & $\begin{array}{l}\text { ExchangeRate } \\
\qquad \quad \text { Range } \\
\bullet \quad \text { LargerThanZero [base] } \\
\bullet \quad \text { LessThanOrEqualToZero }\end{array}$ \\
\hline $\begin{array}{l}\text { SecurityMonthName } \\
\qquad \quad \text { IsValidName } \\
\bullet \quad \text { True [base] } \\
\bullet \quad \text { False }\end{array}$ & $\begin{array}{l}\text { SecurityMonthName } \\
\bullet \quad \text { IsValidName } \\
\bullet \quad \text { True [base] } \\
\bullet \quad \text { False [Single] }\end{array}$ \\
\hline $\begin{array}{l}\text { BV } \\
\text { - Range } \\
\qquad \quad \text { LargerThanZero [base] } \\
\bullet \quad \text { LessThanOrEqualToZero }\end{array}$ & $\begin{array}{l}\text { BV } \\
\qquad \quad \text { Range } \\
\qquad \quad \text { LargerThanZero [base] } \\
\bullet \quad \text { LessThanOrEqualToZero }\end{array}$ \\
\hline $\begin{array}{c}\text { MV } \\
\qquad \text { Range } \\
\bullet \quad \text { LargerThanZero [base] } \\
\bullet \quad \text { LessThanOrEqualToZero }\end{array}$ & $\begin{array}{c}\text { MV } \\
\qquad \quad \text { Range } \\
\bullet \quad \text { LargerThanZero [base] } \\
\bullet \quad \text { LessThanOrEqualToZero }\end{array}$ \\
\hline
\end{tabular}

Table 1 - The (Non-)Annotated CP Specifications of the First Approach

\subsubsection{Second (Improve) CP Specifications}

Deriving the second CP specification requires, in addition to understanding the case study's logic, more knowledge of the code behind the SUT too. In this approach, we consider the entire problem from a different perspective in an attempt to refine the selection of the input parameters.

At first, we know that the input parameters 'CurrencyCode' and 'AccountCurrency' control the logic flow of the process. Therefore, we need these two input parameters in our refined CP specifications. We also know that the conversion is applied to the MV value if the value of the AccountCurrency parameter is 'USD' and to the BV value if 
both AccountCurrency and CurrencyCode are both 'USD'. Therefore, the value 'USD' should be specially considered in the CP specification as all other values will cause a system error. There is an exception if the value is 'CAD' which causes no conversion and no error either. Note that the behavior of the 'CAD' was not explicitly mentioned in the description of the case study. This is something that we found while inspecting the XML input validation mechanism in the code. This is an example where the tester's familiarity with code behind the system under test can impact testing. Therefore, values for the CurrencyCode and AccountCurrency parameters are of three choices:

- Those that trigger a conversion (only 'USD')

- Those that do not cause a system error nor trigger a conversion (only 'CAD')

- Those that cause a system error right off the start (i.e. all other values except 'USD' and 'CAD')

Thus, we now have two input parameters: CurrencyCode and AccountCurrency which have only one category whose choices are IsUSD, IsCAD, and Other.

Also, we are trying to see if the correct conversion rate is applied to the BV and MV values. The correct conversion rate for MV is selected based on the month name of both the $\mathrm{BV}$ and $\mathrm{MV}$ values. Therefore, the month name of the $\mathrm{BV}$ and $\mathrm{MV}$ is a potential input parameter. What is also important about the month name is whether it matches the rate's month. In other words, given that the conversion rate consists of a month name and a numeric value representing the exchange rate for the month, this month name and the month of the MV and BV must match in order to trigger a conversion; this is of course when earlier conversion conditions are established. This gives us our third input 
parameter SecurityMonthlyValue with one category of IsMatchingMonthInRates to indicate whether the value of the BV and MV match a month name in the provided rates.

Moreover, we will consider a rate (consisting of a month and an exchange rate) as one input parameter. This way we can have multiple rates to enable us to test the conversions based on an average rate. In the first approach, this was no possible because we only relied on the individual values (month name and exchange rate) of the conversion rate. Having multiple conversion rates is necessary in order to allows us to see how the average of these rates is calculated and applied. This gives us our third input parameter Rates with one category of Count whose choices are Zero and MoreThanOne. The Zero choice allows us to observe the behavior of the system when no rates are provided at all, and the MoreThanOne choice when one or more rates are provided. Based on the above, we can have the following four input parameters:

\section{CurrencyCode}

2. AccountCurrency

3. SecurityMonthlyValue

4. Rate

We note we have fewer input parameters than the first approach. This makes the CP specification less cumbersome to manage and more comprehensible. Also, we have to notice the nature of the input parameters in the sense that they may not assume a single value but can rather be multi-valued. For example, the 'Rates' input parameter consists of a month name and a number representing the exchange rate of the month. Therefore, when creating the test cases, we need to come up with multiple values (i.e., month name and exchange rate value) for such complex input parameters. Furthermore, choosing an 
input type in Melba for such input parameters is not straightforward because Melba only deals with primitive input types.

\begin{tabular}{|c|c|}
\hline CP Specification & Annotated CP Specification \\
\hline $\begin{array}{l}\text { CurrencyCode } \\
\qquad \quad \text { Value: } \\
\text { - USD [base] } \\
\text { • CAD } \\
\text { - Other }\end{array}$ & $\begin{array}{l}\text { CurrencyCode } \\
\qquad \quad \text { Value: } \\
\qquad \quad \text { USD [base] } \\
\text { - CAD [Single] } \\
\text { - Other [Error] }\end{array}$ \\
\hline $\begin{array}{l}\text { AccountCurrency } \\
\bullet \quad \text { Value: } \\
\bullet \quad \text { USD [base] } \\
\bullet \quad \text { CAD } \\
\bullet \text { Other } \\
\text { SecurityMonthlyValue } \\
\bullet \quad \text { IsMatchingMonthInRates } \\
\text { • True [base] } \\
\bullet \quad \text { False }\end{array}$ & $\begin{array}{l}\text { AccountCurrency } \\
\text { - Value: } \\
\text { • USD [base] } \\
\text { • CAD [Single] } \\
\text { • Other [Error] } \\
\text { SecurityMonthlyValue } \\
\text { - IsMatchingMonthInRates } \\
\text { • True [base] } \\
\text { - False [Single] }\end{array}$ \\
\hline 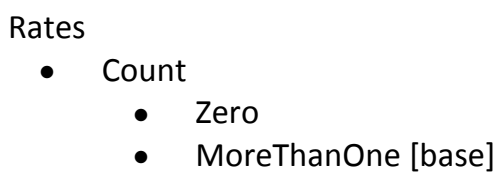 & $\begin{array}{ll}\text { Rates } & \\
- & \text { Count } \\
& \bullet \quad \text { Zero [Single] } \\
& \bullet \quad \text { MoreThanOne [base] }\end{array}$ \\
\hline
\end{tabular}

Table 2 - The (Non-)Annotated CP Specifications of the Second Approach

\subsubsection{Calculation Logic}

This case study addresses testing the calculation logic on the report. Contrary to the logic in the previous case study which deals with only one security, the calculation logic deals with multiple securities. It groups securities by their country of incorporation (i.e., country of origin) and performs certain calculations as follows:

- Securities are to be grouped by country.

- The Maximum Cost comes from the highest summed up value of all BVs of all securities.

- For a given country, the maximum fair market value during the year is the highest value that comes from summing up all MVs of all securities of the given country.

- For a given country, the fair market value at year end comes from summing up the December MVs values of all securities of the given country. 
- For a given country, the foreign income earned or loss comes from summing up all income earned values of all securities of the given country.

- For a given country, the capital gain/loss comes from summing up all the capital gain values of all securities of the given country.

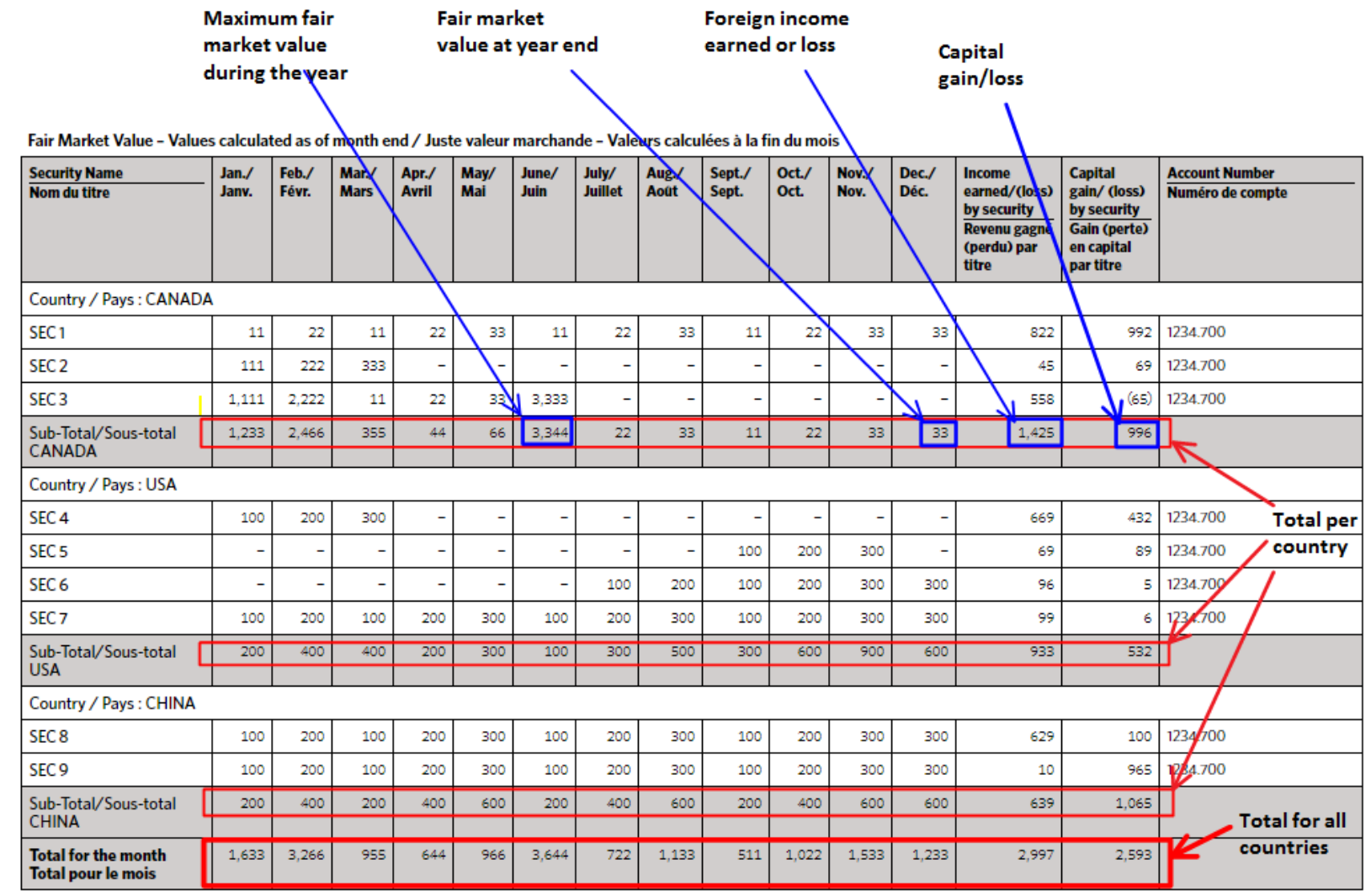

Figure 4 - The Fair Market Value table 


\begin{tabular}{|c|c|c|c|c|c|c|c|c|c|c|c|c|c|c|}
\hline \multirow{2}{*}{$\begin{array}{l}\text { Book Value (Cost amount) } \\
\text { Security Name/Nom du titre }\end{array}$} & \multicolumn{14}{|c|}{ Values calculated as of month end / Valeur comptable - Valeurs calculées à la fin du mois } \\
\hline & $\begin{array}{l}\text { Jan./ } \\
\text { Janv. }\end{array}$ & $\begin{array}{l}\text { Feb./ } \\
\text { Févr. }\end{array}$ & $\begin{array}{l}\text { Mar// } \\
\text { Mars }\end{array}$ & $\begin{array}{l}\text { Apr// } \\
\text { Avril }\end{array}$ & $\begin{array}{l}\text { May/ } \\
\text { Mai }\end{array}$ & \begin{tabular}{|l} 
June/ \\
Juin
\end{tabular} & $\begin{array}{l}\text { July/ } \\
\text { Juillet }\end{array}$ & $\begin{array}{l}\text { Aug./ } \\
\text { Aoat }\end{array}$ & $\begin{array}{l}\text { Sept./ } \\
\text { Sept. }\end{array}$ & $\begin{array}{l}\text { Oct./ } \\
\text { Oct. }\end{array}$ & \begin{tabular}{|l} 
Nov./ \\
Nov.
\end{tabular} & $\begin{array}{l}\text { Dec./ } \\
\text { Déc. }\end{array}$ & $\begin{array}{l}\text { Account Number/Numéro de } \\
\text { compte }\end{array}$ & FX Rate/Taux (\%) \\
\hline \multicolumn{15}{|l|}{ Country / Pays : CANADA } \\
\hline SEC 1 & 10 & 10 & 10 & 10 & 10 & 10 & 10 & 10 & 10 & 10 & 10 & 10 & 1234.700 & - \\
\hline SEC 2 & 100 & 100 & 100 & - & - & - & - & - & - & - & - & - & 1234.700 & - \\
\hline SEC 3 & 500 & 500 & 500 & 500 & 500 & 500 & - & - & - & - & - & - & 1234.700 & - \\
\hline $\begin{array}{l}\text { Sub-Total/Sous-total } \\
\text { CANADA }\end{array}$ & 610 & 610 & 610 & 510 & 510 & 510 & 10 & 10 & 10 & 10 & 10 & 10 & & \\
\hline \multicolumn{15}{|l|}{ Country / Pays : USA } \\
\hline SEC 4 & 10 & 10 & 10 & - & - & - & - & - & - & - & - & - & 1234.700 & - \\
\hline SEC 5 & - & - & - & - & - & - & - & - & 33 & 33 & 33 & - & 1234.700 & - \\
\hline SEC 6 & - & - & - & - & - & - & 70 & 70 & 70 & 70 & 70 & 70 & 1234.700 & - \\
\hline SEC 7 & 10 & 10 & 10 & 10 & 10 & 10 & 10 & 10 & 10 & 10 & 10 & 10 & 1234.700 & - \\
\hline $\begin{array}{l}\text { Sub-Total/Sous-total } \\
\text { USA }\end{array}$ & 20 & 20 & 20 & 10 & 10 & 10 & 80 & 80 & 113 & 113 & 113 & 80 & & \\
\hline \multicolumn{15}{|l|}{ Country/Pays: CHINA } \\
\hline SEC 8 & 10 & 10 & 10 & 10 & 10 & 10 & 10 & 10 & 10 & 10 & 10 & 10 & 1234.700 & - \\
\hline SEC 9 & 10 & 10 & 10 & 10 & 10 & 10 & 10 & 10 & 10 & 10 & 10 & 10 & 1234.700 & - \\
\hline $\begin{array}{l}\text { Sub-Total/Sous-total } \\
\text { CHINA }\end{array}$ & p & 20 & 20 & 20 & 20 & 20 & 20 & 20 & 20 & 20 & 20 & 20 & & \\
\hline $\begin{array}{l}\text { Total for the month } \\
\text { Total pour le mois }\end{array}$ & 650 & 650 & 650 & 540 & 540 & 540 & 110 & 110 & 143 & 143 & 143 & 110 & & \\
\hline
\end{tabular}

Figure 5 - The Book Value table

Figure 5 shows the Book Value table and indicates the Maximum Cost amount.

Given the description above and Figure 4 and Figure 5, the values should be reported as represented in Table 3.

\begin{tabular}{|l|l|l|l|l|l|}
\hline $\begin{array}{l}\text { Grouping } \\
\text { Countries }\end{array}$ & $\begin{array}{l}\text { Maximum } \\
\text { Cost }\end{array}$ & $\begin{array}{l}\text { Maximum fair } \\
\text { market value }\end{array}$ & $\begin{array}{l}\text { Fair market } \\
\text { value at year } \\
\text { end }\end{array}$ & $\begin{array}{l}\text { Foreign income } \\
\text { earned or loss }\end{array}$ & $\begin{array}{l}\text { Capital } \\
\text { gain/loss }\end{array}$ \\
\hline CANADA & \multirow{2}{*}{650} & 3344 & 33 & 1425 & 996 \\
\hline USA & 900 & 600 & 933 & 532 \\
\hline CHINA & 600 & 600 & 639 & 1065 \\
\hline
\end{tabular}

\section{Table 3 - Table of Calculated Values}

Figure 4 shows the Fair Market Value table with securities grouped by country and indicates the values to be calculated. The input data is also in the form of an XML file and is similar to Listing 1 for the previous case study except that now we have multiple 'SecurityData' elements under the parent 'Securities' element. 
For this case study, our input parameters are more complex than simply being of primitive type. In deriving the input parameters, we followed a method defined by Ammann and Offutt [3] as the "functionality-based input domain modeling" which attempts to "identify characteristics that correspond to the intended functionality of the system under test rather than using the actual interface". We consider the parameters characteristics of a set of securities which is to constitute the test case input. However, it may be worth reminding that a security consists of a country of incorporation, BV, MV, income earned value, and capital gain value. A sample security is presented in Table 4, where the first column is the country of incorporation, the columns from Jan to Dec represent the BVs in the first row and MVs in the second row, and the last two columns represent the income earned and capital gain values.

\subsubsection{Technical Description of the System Under Test (SUT)}

The system under test is written in the $\mathrm{C} \#$ language. The part of the system that is the subject of this case study is a class consisting of 82 lines of code. This number was obtained using Visual Studio's Code Metrics feature which provides the number of lines along with other metrics. The code is withheld for confidentiality reasons.

\subsubsection{First (Preliminary) CP Specifications}

The first CP specification in this case study is derived by simply considering the logic and case study description above. We chose here to consider the country of a security as one of the input parameters (CountryOfSecurity). This input parameter targets the country of incorporations in all securities, not only an individual one. We 
added only one category to this input parameter named Value whose choices which affect the country of incorporation $(\mathrm{CI})$ for the input set of securities:

- DifferentForAll: different CI values for all securities.

- SameForAll: same CI values for all securities.

- Empty: empty CI values for all securities.

- Missing: missing CI values for all securities. That is, the XML element CountryOfIncorporation, see Listing 1, is not provided as opposed to being present and empty (previous choice).

The second input parameter (AllValuesPresent) was chosen to indicate whether all values of a security (such as the monthly BV and MV, income earned, and capital gain) are present or not. If the choice is True, it means each security in the input set of securities have all BV and MV from January to December as well as the income earned and capital gain values. If the choice is False, it means all securities only have some of their BV, MV, capital gain, and income earned values. The resulting CP specification can be seen in Table 5 .

\begin{tabular}{|c|c|c|c|c|c|c|c|c|c|c|c|c|c|c|}
\hline \begin{tabular}{|l} 
E \\
音 \\
它
\end{tabular} & 胥 & $\begin{array}{l}0 \\
0 \\
1\end{array}$ & $\begin{array}{l}\bar{D} \\
\overline{0} \\
\Sigma \\
\Sigma\end{array}$ & $\overline{u^{\prime}}$ & $\stackrel{\vec{\sigma}}{\Sigma}$ & 号 & 齐 & 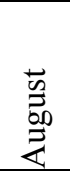 & $\begin{array}{l}0 \\
0\end{array}$ & $\ddot{0}$ & z & $\stackrel{\mathscr{\Perp}}{ }$ & 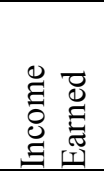 & 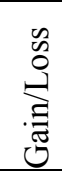 \\
\hline \multirow{2}{*}{ Canada } & 10 & 10 & 10 & 10 & 10 & 10 & 10 & 10 & 10 & 10 & 10 & 10 & \multirow{2}{*}{60} & \multirow{2}{*}{30} \\
\hline & & & & & & 40 & 45 & 34 & 22 & 34 & 87 & 77 & & \\
\hline
\end{tabular}

Table 4 - Sample Security Values 


\begin{tabular}{|c|c|}
\hline CP Specification & Annotated CP Specification \\
\hline CountryOfSecurity & CountryOfSecurity \\
\hline - Value & - Value \\
\hline - DifferentForAll & ○ DifferentForAll \\
\hline ○ SameForAll & ○ SameForAll \\
\hline$\circ$ Empty & $\circ \quad$ Empty [Single] \\
\hline ○ Missing & $\circ \quad$ Missing [Error] \\
\hline $\begin{array}{l}\text { AllValuesPresent } \\
\text { - Value }\end{array}$ & $\begin{array}{l}\text { AllValuesPresent } \\
\text { - Value }\end{array}$ \\
\hline$\circ$ False [base] & $\circ$ False [base] \\
\hline$\circ$ True & ○ True \\
\hline
\end{tabular}

Table 5 - The (Non-)Annotated CP Specifications of the First Approach

\subsubsection{Defects in the System under Test (SUT)}

In the course of this work we found two defects in the system under test. For confidentiality reasons, we cannot reveal the nature of these defects, but we will refer to them as D1 and D2.

\subsubsection{Second (Improved) CP Specifications}

The defect 'D1' and 'D2' were part of our consideration in creating an improved CP specification. We wanted the new $\mathrm{CP}$ to be able to create test cases where these two defects can be found.

The first input parameter in the second CP specification was kept the same in the sense that it addresses all the countries in a set of securities. However, its categories were adjusted to include more scenarios. The 'Casing' category is meant to indicate whether securities of the same country of incorporation all have the country name spelled with the same case (i.e., consistent casing or otherwise). The 'Similarity' category is meant to indicate whether the country of incorporation for all securities is the same. The 'HaveEmpty' and 'HaveMissing' categories are to indicate whether at least one security has an empty country or a missing country respectively. 
The 'AllValuesPresent' from the first approach is removed because we see no value in it. The reason is that the logic loops through the monthly values. Therefore, running this logic 12 times or only once is the same in the sense that it is run already regardless of the number of times. In light of this information and the 'D2' defect, we chose to make the second input parameter address the position of the highest occurring summed up value. We want this parameter to give us specifications as to where the highest summed up value can occur. Thus, the categories of this parameters are 'OtherMonths', which means the highest summed up value can be in any month that is not December, 'December' to indicate the highest value is in the month of December, or 'IncomeEarnedOrCapitalGain' to indicate that the highest value is either in the income earned or the capital gain value.

Notice that even though the highest summed up value can occur under any month, we created two choices: OtherMonths to indicate the occurrence of such a value under months January to November, and December if the value occurs under the month of December. The reason for this is that the summed value under December is also reported as the fair market value at year end and, in the case that it is the highest summed up value, can also be the maximum fair market value during the year. We therefore wanted to test how the system reports the highest summed value under December and other months too. The resulting CP specification can be seen in Table 6 . 


\begin{tabular}{|c|c|}
\hline \multirow[t]{2}{*}{ CP Specification } & Annotated CP Specification \\
\hline & Countries \\
\hline - Casing & - Casing \\
\hline$\circ$ Consistent [base] & $\circ$ Consistent [base] \\
\hline ○ Inconsistent & ○ Inconsistent [Single] \\
\hline - Similarity & - Similarity \\
\hline$\circ$ False [base] & $\circ$ False [base] \\
\hline - True & ○ True [Single] \\
\hline - HaveEmpty & - HaveEmpty \\
\hline$\circ \quad$ False [base] & $\circ \quad$ False [base] \\
\hline O True & $\circ$ True [single] \\
\hline - HaveMissing & - HaveMissing \\
\hline$\circ$ False [base] & $\circ$ False [base] \\
\hline ○ True & - True [Error] \\
\hline SecurityValue & SecurityValue \\
\hline - PlaceOfHighestSummedUpValue & - PlaceOfHighestSummedUpValue \\
\hline $\begin{array}{ll}\circ & \text { OtherMonths [base] } \\
\circ & \text { December }\end{array}$ & $\begin{array}{ll}\circ & \text { OtherMonths [base] } \\
\circ & \text { December }\end{array}$ \\
\hline - IncomeEarnedOrCapitalGain & - IncomeEarnedOrCapitalGain [Single] \\
\hline
\end{tabular}

Table 6 - The (Non-)Annotated CP Specifications of the Second Approach

\subsubsection{Summary of CP Specifications}

Table 7 presents a summary of all the CP specifications in this study. For the names of the case studies, please refer to the next section on Naming Conventions" in order to understand what the names represent.

\begin{tabular}{|c|c|c|c|c|c|}
\hline Case Study & $\begin{array}{c}\text { Number Of } \\
\text { Parameters }\end{array}$ & $\begin{array}{c}\text { Number of } \\
\text { Categories }\end{array}$ & $\begin{array}{c}\text { Number of } \\
\text { Choices }\end{array}$ & $\begin{array}{c}\text { Single } \\
\text { Constraints }\end{array}$ & $\begin{array}{c}\text { Error } \\
\text { Constraints }\end{array}$ \\
\hline Rates_1 & 7 & 7 & 14 & 0 & 0 \\
\hline Rates_1_Ann & 7 & 7 & 14 & 2 & 2 \\
\hline Rates_2 & 4 & 4 & 10 & 0 & 0 \\
\hline Rates_2_Ann & 4 & 4 & 10 & 4 & 2 \\
\hline Calc_1 & 2 & 2 & 6 & 0 & 0 \\
\hline Calc_1_Ann & 2 & 2 & 6 & 1 & 1 \\
\hline Cal_2 & 2 & 5 & 11 & 0 & 0 \\
\hline Calc_2_Ann & 2 & 5 & 11 & 4 & 1 \\
\hline
\end{tabular}

Table 7 - Summary of all CP Specifications

\subsection{Naming Conventions}

To refer to any of the case studies, we will be using a short name. 'Rates' will be used for the Currency Conversion case study and 'Calc' will be used for the Calculation 
Logic case study. Similarly, each approach to creating CP specifications will be shorthanded as follows:

- 'Rates_1' will refer to the first CP specification on the Rates case study;

- 'Rates_2' will refer to the second CP specification on the Rates case study;

- 'Calc_1' will refer to the first CP specification on the Calc case study;

- 'Calc_2' will refer to the second CP specification on the Calc case study.

- The 'Ann' suffix is optional and will be used to refer to the CP specification that is to be annotated with the 'Single' and 'Error' constraints.

Moreover, the generated test suites will also be shorthanded as follows:

$$
<\text { case_study_shorthand }>\text { _ }<\text { selection_criterion }>\text { [_Ann] }
$$

Where:

- case_study_shorthand: is the short for the CP specification name and approach, such as Rates_2;

- selection_criterion: is either BC for Base-Choice, EC for Each-Choice, or PW for Paire-Wise;

- Ann: is an option suffix for annotated CP specs.

For example, Rates_1_BC would be the name of the test suite obtained from the Currency Logic case study's first CP specification using the Base-Choice selection criterion.

Continuing on the same convention, we propose the following naming convention for each test case:

$\left.\left.<c a s e_{-} s t u d y \_s h o r t n a m e\right\rangle_{-}<C P_{-} a p p r o a c h\right\rangle_{-} T C_{-}<t e s t$ frame_number $\rangle_{-}$ $<$ test_case_number>_<selection_criterion $>$ [ Ann]

Where: 
- <case_study_shortname $>$ refers to either Rates or Calc;

- $\quad<$ CP_approach $>$ refers to either the first or second approach on either case study;

- $\quad \mathbf{T C}$ is just a shorthand for Test Case;

- <test_frame_number $>$ refers to the number of the test frames in a list of test frames;

- $\quad<$ test_case_number $>$ refers to the test case generated from the test frame. A test frame can have many test cases generated from it;

- $<$ selection_criterion $>$ refers to the selection criterion used to generate test frames. This value can be BC for base-choice, EC for each-choice, or PW for pair-wise;

Ann is an optional suffix meant for test cases generated from $\mathrm{CP}$ specifications having the 'Single' and 'Error' annotations.

\subsection{Test Cases Generation from Test Frames}

Test cases for the case studies in this manuscript are derived from the test frames that are generated by Melba for each CP specification. Test case values are generated manually using the author's common sense and knowledge of the system. In this section, we will describe how we generated input values for the case studies (sections 3.3.1 and 3.3.2) and conclude by describing the test case output/oracle (section 3.3.3). Generally, the number of test cases equals the number of generated test frames in our experimentation. However, for some frames where, for example, a value is expected to be less than or equal to zero, we added an extra test case representing either the 'strictly less than zero' or 'equal to zero' conditions. This is especially true for the Rates_1 case study, but even in this case, we still used the number of frames as the measure for cost for 
two reasons: The number of test cases did not exceed the number of test frames by a large amount; We only added one or two extra test cases to the suite.

A test case took a very short time to run which was 1 to 10 milliseconds. Therefore, an extra test case did not have considerable impact on the test suite.

Though test case values were generated randomly, we made sure such values are realistic and reasonable. The assumption that such values are realistic and reasonable comes from the fact that such values are typical in the input domain of the system under test.

\subsubsection{Test Inputs for the Currency Conversion Case Study}

For the Rates_1 case study, two CP specifications were generated. They are very similar to each other except that one of them is annotated with the 'Single' and 'Error' constraints. Since both the annotated and non-annotated CP specifications have the same input parameters, categories, and choices, we are going to explain how test case inputs are generated for only one.

For the CurrencyCode and AccountCurrency input parameters, we have only one category (IsUSD) which can assume a Boolean value of either 'true' or 'false'. If a test frame specifies a 'true' choice, the test case input value is set to 'USD', and if it specifies a 'false' choice, any string other than 'USD' is used. In the latter case, we used a randomly and manually generated string consisting of two capital case characters such 'AA', 'BB', and so on.

The 'RateMonthName' input parameter also has one category that can assume a Boolean value of either 'true' or 'false'. If a test frame specifies a 'true' choice, the test case input value is selected randomly from Table 8 , and if it is 'false' it is any value that 
is not in the table of valid month names. In the latter case, we simply used a misspelled month name such as 'Decembbber' for 'December'.

\begin{tabular}{|l|}
\hline Valid Month Names \\
\hline January \\
February \\
March \\
April \\
May \\
June \\
July \\
August \\
September \\
October \\
November \\
December \\
\hline
\end{tabular}

\section{Table 8 - Valid Month Names}

The ExchangeRate input parameter has one category with two choices, namely LargerThanZero and LessThanOrEqualToZero. If a test frame specifies the LargerThanZero choice, then we select any value that is larger than zero, and if LessThanOrEqualToZero any value that is less than or equal to zero. Note that for the ExchangeRate input parameter, the values selected in our testing were based on our understanding or what a reasonable conversion rate should be. For example, 1.5 is a more reasonable and realistic value than 13456322 which still satisfies the LargerThanZero choice but is quite unrealistic to use in testing. For the purposes of our experimentation, we used randomly selected numbers whose absolute value is larger than 1.0 and less than 2.0 with single decimal point such as 1.2 or 1.5 .

The SecurityMonthName has only one category, IsValidName, of a Boolean type and results in two choices of either 'true' or 'false'. If a test frame specifies a 'true' choice, then the test input value is selected from Table 8 , and if it specifies a 'false' choice then the value is any value that is not in the table of valid month names. As in the 
case with the RateMonthName input parameter above, we simply used a misspelled month name, such as 'Decembbber' for 'December', if the choice specifies 'false'.

Note that if choices under the RatesMonthName and SecurityMonthName are set to 'true', we select the same month for both. Selecting different, but valid, months from Table 8 does not trigger the conversion logic in the test case.

Both the BV and MV input parameters have a single category name 'Range' which holds two choices, either LargerThanZero or LessThanOrEqualToZero. These are treated just like the case for the ExchangeRate parameter above.

Note that for the purposes of our testing, we selected relatively small values by limiting ourselves to double-digit integers as we saw no value in using very large numbers. This is specifically applied in the case of creating values for BV and MV because the logic truncates any decimals before and after processing these values. For example, if an input value to a test case is 3.9 , it is treated as 3 . The same is applied to output values. We therefore do not need to worry about rounding values.

Similar to the case of the Rates_1 case study, the Rates_2 also produced two similar CP specifications; only one of them is annotated with the 'Single' and 'Error' constraints. Therefore, we will only describe how test case inputs are generated for the non-annotated CP specification.

Both the CurrencyCode and AccountCurrency input parameters have one category which encompasses three choices: USD, CAD, and Other. When a test frame specifies USD or CAD, the test input value will be set to a string value of 'USD' or 'CAD' respectively. If the Other choice is used by a test frame, the test case input value will be assigned any string that is not 'USD' nor 'CAD'. As pointed out earlier for similar input 
parameters, we used a randomly and manually generated string consisting of two characters such as 'AA' or 'BB' and so on.

For the SecurityMontlyValue, we have only one category which is IsMatchingMonthInRates. This category is of a Boolean type. If a test frame specifies the 'true' choice, the test case input value will be selected from Table 8 in addition to having to satisfy the condition that the selected month must also exist (and be the same) in the provided set of rates. If no rate is provided, then any month name can be selected from the table.

For the Rates input parameter, there exists only one category named Count. This category contains two choices which are named Zero and MoreThanOne. If a test frame specifies the Zero choice, then no rate is provided. If MoreThanOne is specified, more than one rate is provided. Rates is a multi-valued input parameter which needs to be assigned a month name and a conversion rate. The month name comes from Table 8 while the conversion rate is a float value which, for the purposes of our testing, is chosen to be anything between 1.0 to 2.0. It is needless to say that the conversion rate values can be any valid number, with or without a decimal, but we chose to use more realistic values to convert USD currency to CAD.

\subsubsection{Test Inputs for the Calculation Logic Case Study}

A sample test case input would consist of many securities whose values are specified by the input parameters in the Calculation Logic case study. 


\begin{tabular}{|c|c|c|c|c|c|c|c|c|c|c|c|c|c|c|}
\hline $\begin{array}{l}\stackrel{\Xi}{\Xi} \\
\stackrel{\Xi}{0}\end{array}$ & ్ㅗ & $\begin{array}{l}0 \\
0 \\
\end{array}$ & $\begin{array}{l}\overline{0} \\
\overline{0} \\
\bar{z}\end{array}$ & $\overline{\bar{a}}$ & $\sum^{\mathrm{I}}$ & $\Xi$ & 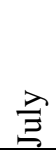 & 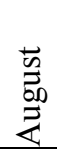 & 苛 & 0 & z & ̊̈ & 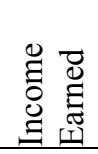 & 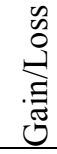 \\
\hline \multirow{2}{*}{ Canada } & 10 & 10 & 10 & 10 & 10 & 10 & 10 & 10 & 10 & 10 & 10 & 10 & \multirow{2}{*}{60} & \multirow{2}{*}{30} \\
\hline & 21 & 22 & 23 & 25 & 22 & 40 & 45 & 34 & 22 & 34 & 87 & 77 & & \\
\hline
\end{tabular}

Table 9 - Sample Security Values

For the Cal_1 case study, we have two input parameters: CountryOfSecurity and AllValuesPresent. The CountryOfSecurity input parameter has one category named Value which contains four choices: DifferentForAll, SameForAll, Empty, and Missing. In a set of securities, this input parameter attempts to classify whether the securities have different countries (DifferentForAll choice), the same country (SameForAll choice), no country is provided for any security (Empty choice), missing country for all (Missing choice) which basically means the XML input element is missing as opposed to being present but with no value (i.e. Empty).

The AllValuesPresent input parameter has one category named Value and contains two choices: False and True. This input parameter is meant to indicate whether all values are present (i.e. the True choice) or only some of them are (i.e. the False choice). For the False choice, we do not have any further constraint as to what value type (BV, MV, income earned, or capital gain) is present or missing. This is left to the tester's discretion.

For the Calc_2 case study, we also have two input parameters which represent characteristics of the system under test. The input parameters are Countries and SecurityValue. The Countries input parameter represents the countries in the set of input securities and it has four categories: Casing (case sensitivity of the country name), Similarity (whether all securities have the same country), HaveEmpty (whether there exists a security in the input set that has an empty country name), HaveMissing (whether 
a country is missing the country XML element all together). The second input parameter is the SecurityValue and it has one category: PlaceOfHighestSummedUpValue. This category does not impact the BV value of a given security. It is only meant to address the MV, income earned, and capital gain values. The PlaceOfHighestSummedUpValue category is meant to indicate where the highest summed up value occurs for each set of securities constituting the test input. For example, given a set of securities, the highest summed up value can come from adding up all MVs under the months of July (or any other month other than December) and is defined by the OtherMonths choice. The highest summed up value can also come from adding up all MVs under December and is defined by the December choice, or from adding up all income earned or capital gain values and is defined by the IncomeEarnedOrCapitalGain choice.

\subsubsection{Test Case Output / Oracle}

For each test case, we have an expected output and an actual one. The expected output is what the tester expects the output should be based on his/her knowledge of the system's behavior. The actual output, on the other hand, is what the system actually produces. The expected and actual outputs should always match if the tester fully understands the system's behavior and there is no fault.

Test cases where the expected output and actual output mismatch need to be investigated as this may be an indication of either lack of understanding of the system's behavior or an actual defect in the system. In our test cases, found in tables in the appendices, we specify the expected output and mark the actual output as 'Same' to indicate that the actual value produced by the test output matches (i.e., equals) the expected value. 
Moreover, the reader can refer to the description of the case studies in sections 3.1.1 and 3.1.2 in order to understand how the expected output is calculated for any of the case studies. In the Currency Conversion case study, the reader can refer to section 3.3.1 in order to find out how test inputs are created and based on the logic presented in section 3.1.1, the reader can calculate the expected output. Given a test case input and our understanding of the logic in the Currency Conversion case study, we can manually calculate the expected BV and MV. The actual values are what the system under test actually produces for the BV and MV.

The Calculation Logic case study produces a set of values represented in Table 10 as a sample output of a test case. Table 10 represents the output of a set of securities whose countries of incorporation are Canada, USA, China, and Mexico.

\begin{tabular}{|l|l|l|l|l|l|}
\hline $\begin{array}{l}\text { Grouping } \\
\text { Countries }\end{array}$ & \multirow{2}{*}{$\begin{array}{l}\text { Maximum } \\
\text { Cost }\end{array}$} & $\begin{array}{l}\text { Maximum fair } \\
\text { market value }\end{array}$ & $\begin{array}{l}\text { Fair market } \\
\text { value at year } \\
\text { end }\end{array}$ & $\begin{array}{l}\text { Foreign income } \\
\text { earned or loss }\end{array}$ & $\begin{array}{l}\text { Capital } \\
\text { gain/loss }\end{array}$ \\
\cline { 1 - 3 } CANADA & \multirow{2}{*}{26} & 171 & 77 & 81 & 88 \\
\hline USA & 118 & 88 & 85 & 97 \\
\hline CHINA & & 132 & 0 & 84 & 58 \\
\hline MEXICO & & 54 & 33 & 45 & 30 \\
\hline
\end{tabular}

\section{Table 10 - Sample Output of a Test Case}

Given a test case input, the values in Table 10 can be calculated manually according to the logic presented in section 3.1.2. The test case input in the Calculation Logic case study is, as stated earlier in section 3.3.2, a set of securities. Each security consists of the BVs, MVs, the income earned value, and the capital gain value.

\subsection{Fault Detection}

Fault detection is one of our measures to evaluate a test suite. An efficient test suite should be able, to a certain degree, to detect faulty behavior. Our strategy for seeding faults in the program will follow the well-known method of mutation testing. This is a 
method in which errors are deliberately introduced in the code under test to produce what is known as mutated versions of the code, also known as mutants. If the test, when run against the mutant, can produce an output different than that of the original code, the test is said to have distinguished the mutant from the original code [8].

\subsubsection{ALIVE and KILLED Mutants}

Mutants can either be considered alive or killed when a test suite is run against the mutated code. When run against a mutated code, if all the tests in a test suite passed, a mutant would be considered alive. If only a single test, any test, failed, the mutant would be considered killed because the tests were able to identify it. The ability to identify mutants presupposes that all tests pass against the original un-mutated code or otherwise they (i.e., tests) cannot be used in mutation testing. Equivalent mutants, which are syntactically different from the original code and yet semantically equivalent, were excluded from our analysis because such mutants cannot be killed by any test input. At the end of each appendix in this manuscript, there is a section called 'Live Mutants' which explains why certain mutants remain live throughout testing.

\subsubsection{Mutation Generation Strategy}

Our first attempt at devising a strategy to generating mutants was to search for a tool that can mutate and compile $\mathrm{C \#}$ code as well as invoke a predefined test suite against it. Unfortunately, all the tools we found fell short of achieving this goal. Some tools were able to mutate the code, but not run tests against it. Other tools just failed to run while others made good progress to only fail half way through the run due to unknown reasons. The following section briefly touches upon the tool we tried in the course of this work and their pros and cons. 


\subsubsection{Existing Tools and their Limitations}

Visual Mutator [9] is a Visual Studio extension. This means it can be run as part of the Visual Studio IDE which is a very good convenience. The tool ran successfully but started to fail as tests were augmented.

Pros:

1 User interface nicely integrated with the Visual Studio IDE.

2 Ease of use to quickly get up and running with the tool.

3 The user can specify to the test method what to run during mutation as opposed to blindly running all tests it finds.

4 It uses XML to report results which can be easily consumed by other services to parse for further data.

5 Ability to easily select type of mutation and its quantity. For example, the user can specify how many mutants per operator can be used.

6 It can run in a multi-threaded mode to save time.

Cons:

1 It only works with Visual Studio 2013 Professional which does not have code coverage analysis.

2 All tests written using the Microsoft Unit Test Framework must be converted to NUnit Tests.

3 As more tests were added, the tool started to crash and became unreliable.

Ninja Turtles [10] is run through the command line. The user needs to specify the class to be mutated, preceded by its namespace, the method to be mutated, and the DLL file of the unit test project. It seems that because of the many DLL files involved in the system 
under test, the tool never ran successfully and always threw an exception of type System.Reflection.ReflectionTypeLoadException. In fact, this error was not even shown by running the tool from the command line, and we had to debug its code to find out about it.

Pros:

\section{Open source}

2 Command line availability to allow further automation

Cons:

1 Limited documentation on issues.

2 It mutates one method at a time which is an inconvenient if there is a large number of methods to be mutated.

3 Exceptions/Errors are not clearly described in command-line mode.

CREAM is a GUI-based stand-alone tool [11]. The user selects the solution (set of projects containing the system under test as well as the unit tests), sets up few configuration values such as the output location of mutated code and mutation operators, and starts the mutation run. Once mutants are available, the user can start the tests from another wizard where the mutants' location and test file (DLL) have to be specified. Given that we have to deal with twelve test suites per case study, this tool expected each test suite in its own solution which include the unit tests and a copy of the system under test. Separating test suites in their own solutions was considered a huge management task especially when a change was done to the system under test, because it now has to be done in twelve separate places. This approach posed a great threat because of its high probability of error. 
Pros:

1 Nice user interface that is easy to follow.

2 It successfully mutates code and stores mutated copy in a separate location.

3 It successfully runs tests against and brings back results.

Cons:

1 Inability to specify individual unit tests to run which resulted in blindly running all tests.

\subsubsection{Our Approach}

Given the limitations above, we set out to find our way of conducting mutation testing leveraging as much advantages/features from the tools we worked with. Basically, we want to be able to do the following:

1. Mutate certain code files (classes);

2. Compile the system under test (SUT) with the new mutated file(s);

3. Target a specific test suite to run against the mutated SUT;

4. Report back on the results.

Since (1) is already done for us by the CREAM tool (which stored mutants files on disk), we only have to find a way to do the rest of the tasks. To achieve this goal, a tool is created to collect all mutant files created by CREAM and do the following for each one of them:

1 Inject the mutant file in the SUT;

2 Compile the SUT; 
3 Invoke MSTest $^{6}$ to run a particular test suite against the SUT;

4 Collect the test results as a .trx file (which is really an XML file);

5 Parse the .trx file to extract information on each unit test in the test suite;

6 Report the end result for all mutation runs in a text file.

The resulting file contains information on mutants that failed to compile, alive and killed mutants, the total number of passing and failing tests per mutant, an overall number of live and killed mutants, and start to finish time for the whole mutation testing process. Note that this is a custom tool made for the purpose of this manuscript only to compensate for what is missing in other tools.

The following table shows the description of the mutant types generated by the CREAM tool. The descriptions are those provided by the CREAM tool itself. Table 11 lists standard and object operators. Standard operators mutate logical and arithmetic operators whereas object operators mutant object-related code such as changing an object reference, changing a method's argument, and so on.

\footnotetext{
${ }^{6}$ MSTest is a Visual Studio's tool used to invoke unit tests through the command line prompt. In our work, test frames were implemented as unit test projects. MSTest was kicked off and passed these test projects (test suites) in order to execute the unit tests.
} 


\begin{tabular}{|c|c|}
\hline Operation & Description \\
\hline $\mathrm{ABS}$ & Absolute \\
\hline AOR & Arithmetic Operator Replacement \\
\hline ASR & Assignment Operator Replacement \\
\hline LCR & Logical Condition Replacement \\
\hline LOR & Logical Operator Replacement \\
\hline ROR & Relational Operator Replacement \\
\hline UOI & Unary Operator Inversion \\
\hline UOR & Unary Operator Replacement \\
\hline DMC & Delegate Method Change \\
\hline HER & Exception Handler Remover \\
\hline EOA & Reference assignment and content assignment Replacement \\
\hline $\mathrm{EOC}$ & Reference Comparison and Content Comparison Remover \\
\hline EXS & Exception Swallowing \\
\hline IHD & Hiding Variable Declaration \\
\hline IHI & Hiding Variable Insertion \\
\hline IOD & Overriding Method Deletion \\
\hline IOK & Override/New Keyword Substitution \\
\hline IOP & Override Method's Calling Position Change \\
\hline IPC & Explicit Call of Parent's Constructor Deletion \\
\hline ISK & Base Keyword Deletion \\
\hline JID & Delete Field Initialization \\
\hline JTD & Base Keyword Deletion \\
\hline $\mathrm{OAO}$ & Argument Order Change \\
\hline OMR & Overloading Method Content Change \\
\hline PRM & Property Replacement with Member Field \\
\hline PRV & Reference Assignment with Compatible Type \\
\hline
\end{tabular}

Table 11 - Code Mutation Operators (Standard and Object Operators)

Note that in the CREAM tool, even if the user selects to use all mutant operators as in

Figure 6, the tool will only apply a mutation operator if it can be applied to the code. For example, if no delegate methods are used, the DMC operator will not be applied. 


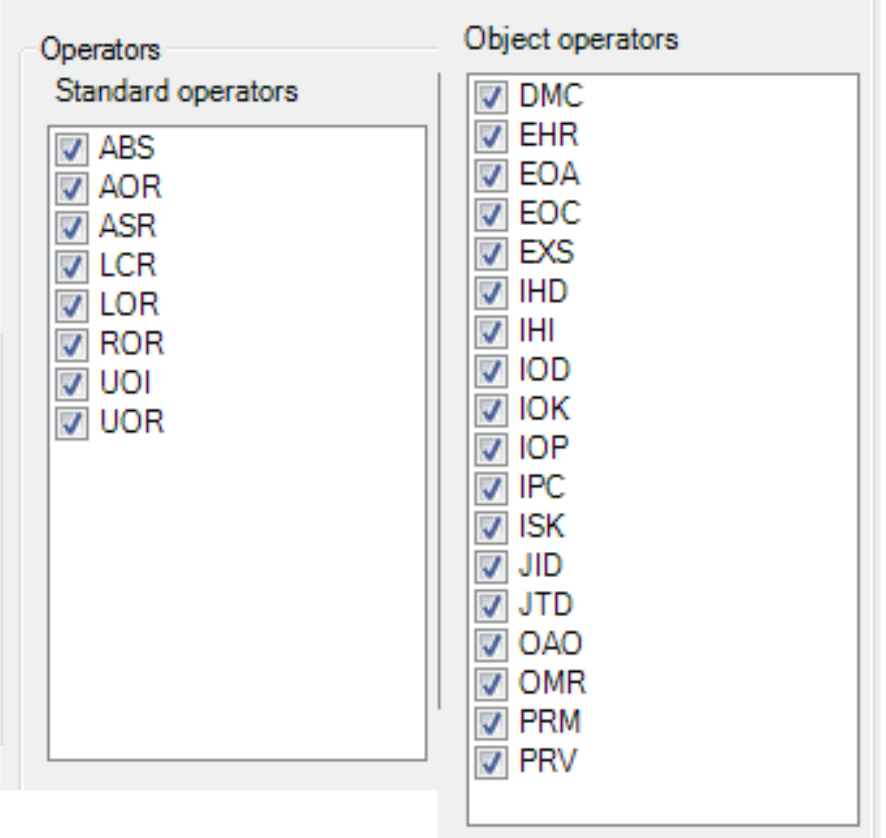

\section{Figure 6 - Selected mutation operators in the CREAM tool}

\subsection{Cost}

Cost of a test suite is one of the measurements we use to evaluate the effectiveness of a test suite. Cost might be a very loose concept in this context as it could involve for example time, resources, number of tests and possibly other factors. For the purposes of keeping things simple, we will use the number of generated test frames, that is the number of test cases, as our indicator of cost.

\subsection{Code Coverage}

Code coverage is basically the amount of code covered by executing a test. It is one of the measurements we use to determine a test suite's efficiency. Since our test suites are built in Visual Studio, we will use its built-in functionality to analyze code coverage for test cases. Visual Studio uses color coding for code coverage. The default colors are as follows (note this could be changed in the Visual Studio): 
1 Light-blue background is used for covered lines of code.

2 Red background for uncovered lines of code.

3 Beige background for partially covered lines of code. This is code which the compiler finds unnecessary to execute completely. For example, the second operand of the short-circuited AND operator is evaluated only if the first operand is true. If the first operand is false, the entire condition is false and thus the compiler does not need to evaluate the second operand. We also observed this behavior in ternary if-statements.

Code coverage in Visual Studio in measured in blocks. A block is "a piece of code with exactly one entry and exit point". A block is considered covered if it is executed at least once by running a test suite. Multiple passes through a code block has no impact on the code coverage result. This means that whether a loop is executed once or $n$ times, the results are the same [12]: the loop body is a block that is covered. This coverage criterion is often also called node coverage (because a block is essentially a node in the control flow graph representing the code). 


\section{Chapter 4 Results and Discussion}

In this chapter, we present and discuss the results of the experiments on both case studies. As indicated earlier, each case study generated twelve test suites. Mutation testing was performed against each test suite and results were captured. Also, code coverage analysis was conducted against each suite and results were captured. In the next sections, we present those results in detail for each case study. But first, it is worth mentioning that some mutants were consistently left alive, or killed, by all test suites. We will call such mutants uniform mutants. In other words, these are mutant that exhibit consistent state (either killed or alive) under all test suites. More specifically, the phrase uniform alive mutants will be used for those mutants that remained consistently alive, and uniform killed mutants will be used for those that were consistently killed. By contrast, mutants that exhibit no such uniformity will be called non-uniform mutants. Also, in our discussion we will exclude uniform alive mutants because they are not killed by any input, so it makes no sense to include them in the discussion.

\subsection{Currency Conversion Case Study}

In this section, we will first discuss the CP specifications, test suites, and generated mutants. Then we move on to discussing execution results in a subsequent subsection.

\subsubsection{Raw results when running our experiments}

In the first approach for this case study (i.e., Rates_1), which represents the preliminary approach to this case study (refer to Appendix A ), we have seven input parameters, seven categories, and fourteen choices for both the non-annotated and the annotated CP specifications. The base-choice, each-choice, and pair-wise selection 
criteria were tried on both CP specifications to generated test frames and test cases as shown in Table 12 (where the number of test cases is in parentheses). The annotated CP specification has two 'Single' and two 'Error' annotations. Since in our experiment, each test frame leads to the creation of at least one test case, the numbers in the tables below are the number of test frames (our measure of cost) as well as the number of test cases.

\begin{tabular}{|c|c|c|c|}
\hline \multirow{2}{*}{ CP Specifications } & \multicolumn{3}{|c|}{ Number of Test Frames } \\
\cline { 2 - 4 } & Base Choice & Each Choice & Pair Wise \\
\hline Non-Annotated & $8(8)$ & $2(2)$ & $6(10)$ \\
\hline Annotated & $8(8)$ & $6(6)$ & $7(11)$ \\
\hline
\end{tabular}

\section{Table 12 - Rates_1 Case Study - Number of Frames and Test Cases}

In the second approach (i.e., Rates_2), which is the improved approach to this case study (refer to Appendix B ), we have four input parameters, four categories, and 10 choices for the non-annotated and annotated CP specs. Again, all three selection criteria were tried on both $\mathrm{CP}$ specifications to generate test frames and test cases as shown in Table 13 (where the number of test cases is in parentheses). The annotated CP specification has four 'Single' and two 'Error' annotations.

\begin{tabular}{|c|c|c|c|}
\hline \multirow{2}{*}{ CP Specifications } & \multicolumn{3}{|c|}{ Number of Test Frames } \\
\cline { 2 - 4 } & Base Choice & Each Choice & Pair Wise \\
\hline Non-Annotated & $5(7)$ & $3(3)$ & $9(9)$ \\
\hline Annotated & $6(6)$ & $5(5)$ & $5(5)$ \\
\hline
\end{tabular}

\section{Table 13 - Rates_2 Case Study - Number of Frames and Test Cases}

Table 12 and Table 13 represent the number of test cases for the Rates_1 and Rates_2 cases studies. Though in some test suites, the number of test cases is larger than the number of test frames, we still used the number of test frames as the measure for cost for the reasoning stated earlier in section 3.3. 
The mutation tool [11] only created 81 mutants produced by mutating the code of the system under test. The mutants were used in both case studies (Rates_1 and Rates_2) since they use the same code targeted by the mutation tool. Ten of those mutants could not be compiled. The change that led to mutants failing to compile involved placing the ' $\sim$ ' parameter [13] in front of a double type value which violated compilation rules in .NET. Therefore, only 71 mutants were successfully compiled in order to experiment with.

\subsubsection{Execution Results}

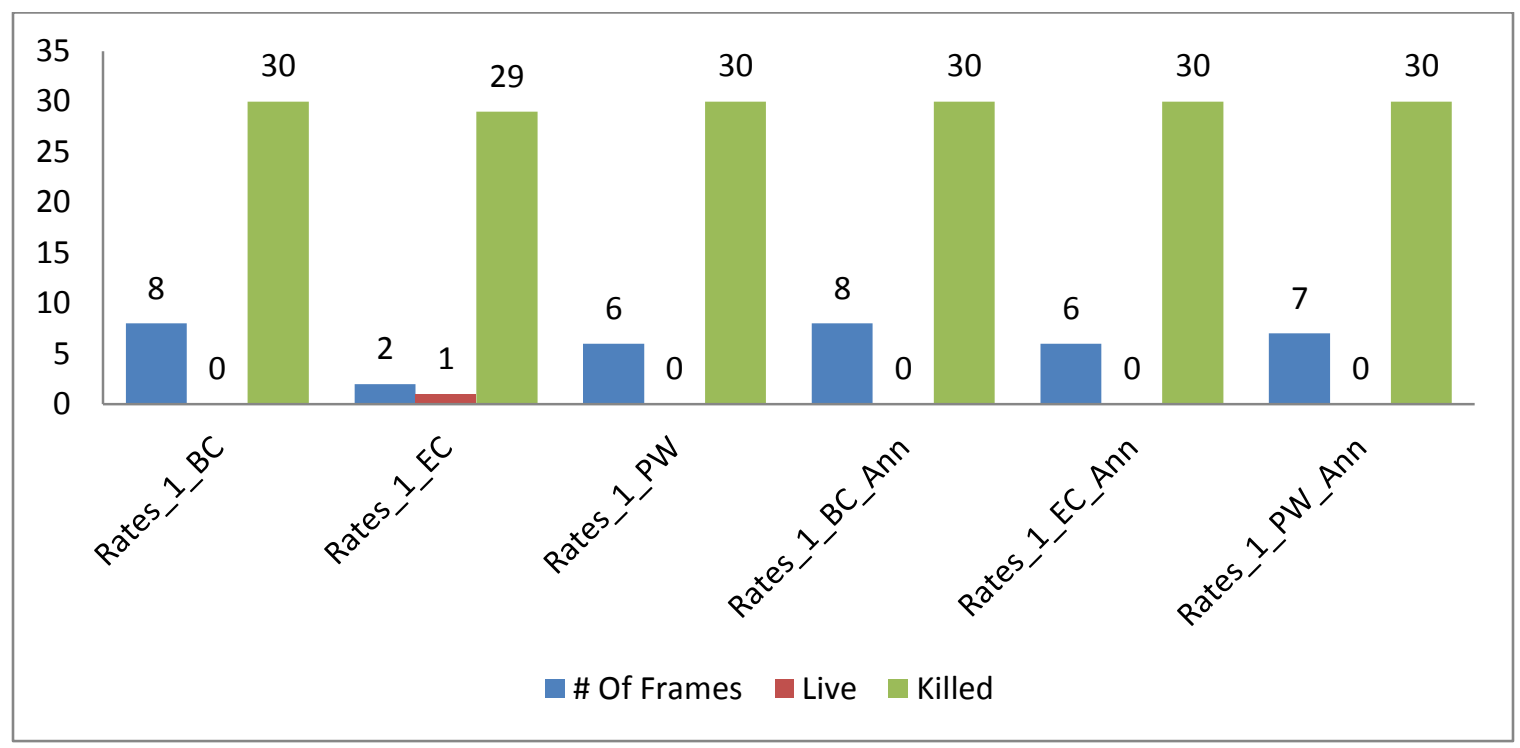

\section{Illustration 2 - Alive and Killed Mutants (Rates_1)}

Illustration 2 shows the mutation testing results, along with the number of frames, on the annotated and non-annotated CP specifications for Rates_1. Note that the naming in the illustration follows the naming convention in section 3.2.

In Rates_1, we found 41 uniform alive mutants which we excluded from the analysis. This leaves only 30 mutants for the analysis. 


\begin{tabular}{|l|l|l|}
\hline Test Suite & Test Frames & Mutation Score (\%) \\
\hline Rates_1_BC & 8 & 100 \\
\hline Rates_1_EC & 2 & 96.6 \\
\hline Rates_1_PW & 6 & 100 \\
\hline Rates_1_BC_Ann & 8 & 100 \\
\hline Rates_1_EC_Ann & 6 & 100 \\
\hline Rates_1_PW_Ann & 7 & 100 \\
\hline
\end{tabular}

\section{Table 14 - Rates_1 Mutation Score}

In the Rates_1 test suites, UOI10 is a non-uniform mutant. It is killed by all test suites except the Rates_1_EC suite. The mutant negated the value of the exchange rate of the month in the Converusdsecurity () method. The only two test cases in the Rates_1_EC test suite do not have input that reached this code. The first test case Rates_1_TC_1_1_EC contained invalid months which resulted in the execution skipping the mutated code. The second test case Rates_1_TC_2_1_EC contained invalid CurrencyCode and AccountCode values which failed the validation up front and caused an error. One possible test case input for this first test case could have caught this mutant is the following:

\begin{tabular}{|l|l|l|l|}
\hline $\begin{array}{l}\text { Test Case } \\
\text { Name }\end{array}$ & Test Case Value & Expected output & Actual Output \\
\hline Rates_1_TC_1_2_EC & USD,USD,AprilAB,1.2,AprilAB,10,20 & BV=12, MV=24 & Same \\
\hline
\end{tabular}

This test input would fit under the first test frame in the sense that both months are invalid, but if they both contained the same wrong value, a very unlikely occurrence, the mutated code would be executed and the test case would fail. 


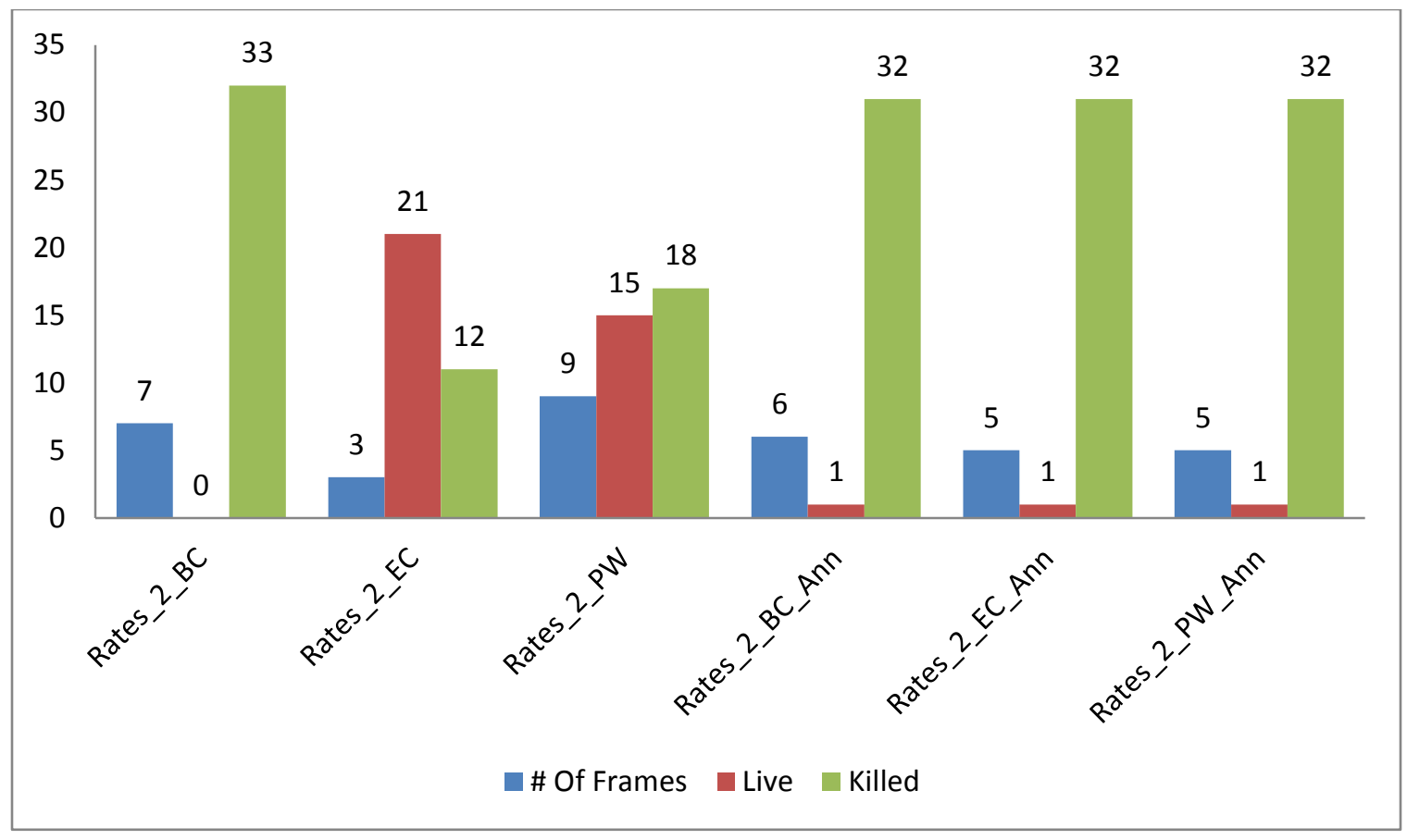

\section{Illustration 3 - Alive and Killed Mutants (Rates_2)}

In Rates_2, we found, and excluded from the analysis, 38 uniform alive mutants which are the same as those found previously in Rates_1 except for three which have been added to the analysis (see A.4 and B.4 in the appendices). Therefore, 33 mutants were left for analysis.

\begin{tabular}{|l|l|l|}
\hline Test Suite & Test Frames & Mutation Score (\%) \\
\hline Rates_2_BC & 7 & 100 \\
\hline Rates_2_EC & 3 & 34.34 \\
\hline Rates_2_PW & 9 & 53.1 \\
\hline Rates_2_BC_Ann & 6 & 96.9 \\
\hline Rates_2_EC_Ann & 5 & 96.9 \\
\hline Rates_2_PW_Ann & 5 & 96.9 \\
\hline
\end{tabular}

\section{Table 15 - Rates_2 Mutation Score}

In the Rates_2 test suites, we observed a spike in non-uniform live mutants (see section B.5 in the Appendices for details on these mutants). Also, Illustration 3 shows the spike in the non-uniform mutants in test suites Rates_2_EC and Rates_2_PW. Compared to only one non-uniform mutant in Rates_1 test suites, twenty two (22) non- 
uniform mutants were found by all Rates_2 test suites. The rest of this section will discuss such mutants.

Below are the results of all Rates_2 test suites for the first set of non-uniform mutants.

\begin{tabular}{|l|l|l|l|l|l|l|}
\hline $\begin{array}{l}\text { Mutation } \\
\text { Name }\end{array}$ & $\begin{array}{l}\text { Rates_2 } \\
\text { BC }\end{array}$ & $\begin{array}{l}\text { Rates_2- } \\
\text { EC }\end{array}$ & $\begin{array}{l}\text { Rates_2 } \\
\text { PW }\end{array}$ & $\begin{array}{l}\text { Rates_2_- } \\
\text { BC_Ann }\end{array}$ & $\begin{array}{l}\text { Rates_2_- } \\
\text { EC_Ann }\end{array}$ & $\begin{array}{l}\text { Rates_2_ } \\
\text { PW_Ann }\end{array}$ \\
\hline AOR1 & KILLED & LIVE & LIVE & KILLED & KILLED & KILLED \\
\hline AOR2 & KILLED & LIVE & LIVE & KILLED & KILLED & KILLED \\
\hline AOR3 & KILLED & LIVE & LIVE & KILLED & KILLED & KILLED \\
\hline AOR4 & KILLED & LIVE & LIVE & KILLED & KILLED & KILLED \\
\hline ASR1 & KILLED & LIVE & LIVE & KILLED & KILLED & KILLED \\
\hline ASR2 & KILLED & LIVE & LIVE & KILLED & KILLED & KILLED \\
\hline ASR3 & KILLED & LIVE & LIVE & KILLED & KILLED & KILLED \\
\hline ASR4 & KILLED & LIVE & LIVE & KILLED & KILLED & KILLED \\
\hline
\end{tabular}

AOR1 to AOR4 and ASR1 to ASR4 were left alive by the Rates_2_EC and Rates_2_PW test suites because no possible input values in these two suites led to executing the method where these mutants were seeded. Contrary to the previous observation, whereby a different test input selection for an existing test frame could have killed a mutant, here, we believe the combination of choices is responsible for leaving some mutants alive. See Appendix B.5 for details of mutated code.

All Rates_2_Ann test suites left non-uniform mutant LOR3 alive.

To reach LOR3, i.e., to first reach the method where LOR3 is seeded and then trigger the mutated statement, a test case input must be such that no rates are provided. None of the test suites in Rates_2_Ann met this condition. There are test cases that provided no rates, but their other inputs, which are the CurrencyCode and AccountCurrency, did not trigger the logic to reach this method.

Below are the results of all Rates_2 test suites on the non-uniform PRV1 mutant.

\begin{tabular}{|l|l|l|l|l|l|l|}
\hline $\begin{array}{l}\text { Mutation } \\
\text { Name }\end{array}$ & Rates_2_ & $\begin{array}{l}\text { Rates_2 } \\
\text { EC }\end{array}$ & $\begin{array}{l}\text { Rates_2_ } \\
\text { PW }\end{array}$ & $\begin{array}{l}\text { Rates_2_ } \\
\text { BC_Ann }\end{array}$ & $\begin{array}{l}\text { Rates_2_ } \\
\text { EC_Ann }\end{array}$ & $\begin{array}{l}\text { Rates_2_ } \\
\text { PW_Ann }\end{array}$ \\
\hline
\end{tabular}




\begin{tabular}{|l|l|l|l|l|l|l|}
\hline PRV1 & KILLED & LIVE & LIVE & KILLED & KILLED & KILLED \\
\hline
\end{tabular}

Only test cases Rates_2_EC_TC_3_1 and Rates_2_PW_TC_2_1 in Rate_2_EC and Rates_2_PW respectively reached the method where this mutant is seeded, but they both had zero number of rates. Therefore, this mutant remains alive for the same reason as AOR1 to AOR4 and ASR1 to ASR4.

UOI10 was left alive by Rates_2_EC only because, again, no rates were provided which meant no rate value could be found in the 'rates' dictionary variable. If found and used, the rate would have been negated and failed the test case leading to killing the mutant.

\begin{tabular}{|l|l|l|l|l|l|l|}
\hline $\begin{array}{l}\text { Mutation } \\
\text { Name }\end{array}$ & $\begin{array}{l}\text { Rates_2 } \\
\text { BC }\end{array}$ & $\begin{array}{l}\text { Rates_2_ } \\
\text { EC }\end{array}$ & $\begin{array}{l}\text { Rates_2_ } \\
\text { PW }\end{array}$ & $\begin{array}{l}\text { Rates_2_ } \\
\text { BC_Ann }\end{array}$ & $\begin{array}{l}\text { Rates_2_ } \\
\text { EC_Ann }\end{array}$ & $\begin{array}{l}\text { Rates_2_ } \\
\text { PW_Ann }\end{array}$ \\
\hline UOI10 & KILLED & LIVE & KILLED & KILLED & KILLED & KILLED \\
\hline
\end{tabular}

The mutant UOI13, UOI36, and UOI39 were left alive by both test suites Rates_2_EC and Rates_2_PW for the same reasons as previously mentioned. They all target the method GetAverageConversionRates () which returns successfully before even reaching the mutated code. However, note that UOI36 and UOI39 mutate the first lines of the method which get executed but mutants have no impact because having zero number of rates causes the method to return the value ' 1.0 ' as the average rate anyway.

\begin{tabular}{|l|l|l|l|l|l|l|}
\hline $\begin{array}{l}\text { Mutation } \\
\text { Name }\end{array}$ & $\begin{array}{l}\text { Rates_2 } \\
\text { BC }\end{array}$ & $\begin{array}{l}\text { Rates_2_ } \\
\text { EC }\end{array}$ & $\begin{array}{l}\text { Rates_2_ } \\
\text { PW }\end{array}$ & $\begin{array}{l}\text { Rates_2_ } \\
\text { BC_Ann }\end{array}$ & $\begin{array}{l}\text { Rates_2_ } \\
\text { EC_Ann }\end{array}$ & $\begin{array}{l}\text { Rates_2_ } \\
\text { PW_Ann }\end{array}$ \\
\hline UOI13 & KILLED & LIVE & LIVE & KILLED & KILLED & KILLED \\
\hline UOI36 & KILLED & LIVE & LIVE & KILLED & KILLED & KILLED \\
\hline UOI39 & KILLED & LIVE & LIVE & KILLED & KILLED & KILLED \\
\hline
\end{tabular}

UOI41 was left alive by the Rates_2_EC test suite because the only test case in this suite which triggered the mutated logic provides no rates which automatically set the 
average rate to 1.0, so regardless of whether the mutant gets executed or not, it has no impact on the outcome of the test suite.

\begin{tabular}{|l|l|l|l|l|l|l|}
\hline $\begin{array}{l}\text { Mutation } \\
\text { Name }\end{array}$ & $\begin{array}{l}\text { Rates_2_ } \\
\text { BC }\end{array}$ & $\begin{array}{l}\text { Rates_2_ } \\
\text { EC }\end{array}$ & $\begin{array}{l}\text { Rates_2_ } \\
\text { PW }\end{array}$ & $\begin{array}{l}\text { Rates_2_ } \\
\text { BC_Ann }\end{array}$ & $\begin{array}{l}\text { Rates_2_ } \\
\text { EC_Ann }\end{array}$ & $\begin{array}{l}\text { Rates_2_ } \\
\text { PW_Ann }\end{array}$ \\
\hline UOI41 & KILLED & LIVE & KILLED & KILLED & KILLED & KILLED \\
\hline
\end{tabular}

UOI42 changed the logic around setting the AccoutCurrency. In both suites Rates_2_EC and Rates_2_PW, the only test cases that triggered the conversion logic were Rate_2_TC_3_1_EC and Rates_2_TC_2_1_PW respectively. Both provided zero number of rates which should result in no conversion. Therefore, whether this no conversion was due to the value of AccountCurrency or the fact that no rates were provided, the end result is the same which led to the mutant remaining alive.

\begin{tabular}{|l|l|l|l|l|l|l|}
\hline $\begin{array}{l}\text { Mutation } \\
\text { Name }\end{array}$ & $\begin{array}{l}\text { Rates_2 } \\
\text { BC }\end{array}$ & $\begin{array}{l}\text { Rates_2 } \\
\text { EC }\end{array}$ & $\begin{array}{l}\text { Rates_2_ } \\
\text { PW }\end{array}$ & $\begin{array}{l}\text { Rates_2_ } \\
\text { BC_Ann }\end{array}$ & $\begin{array}{l}\text { Rates_2_ } \\
\text { EC_Ann }\end{array}$ & $\begin{array}{l}\text { Rates_2_ } \\
\text { PW_Ann }\end{array}$ \\
\hline UOI42 & KILLED & LIVE & LIVE & KILLED & KILLED & KILLED \\
\hline
\end{tabular}

UOI43 remained alive in Rates_2_EC only for the same reason as previously discussed in that the only test case that triggered the conversion logic had zero number of rates and expected no conversion to occur. So whether the mutant executed or not, it had no impact on the output of the test case.

\begin{tabular}{|l|l|l|l|l|l|l|}
\hline $\begin{array}{l}\text { Mutation } \\
\text { Name }\end{array}$ & $\begin{array}{l}\text { Rates_2_ } \\
\text { BC }\end{array}$ & $\begin{array}{l}\text { Rates_2_ } \\
\text { EC }\end{array}$ & $\begin{array}{l}\text { Rates_2_ } \\
\text { PW }\end{array}$ & $\begin{array}{l}\text { Rates_2_ } \\
\text { BC_Ann }\end{array}$ & $\begin{array}{l}\text { Rates_2_ } \\
\text { EC_Ann }\end{array}$ & $\begin{array}{l}\text { Rates_2_ } \\
\text { PW_Ann }\end{array}$ \\
\hline UOI43 & KILLED & LIVE & KILLED & KILLED & KILLED & KILLED \\
\hline
\end{tabular}

UOI44, and UOI47 and UOI52 mutated the logic around setting the Currencycode (UOI44 and UOI47) and AccountCurrency (UOI52). However, theses mutants remained alive only in Rates_2_EC because again the test case that 
triggered the conversion logic passed in zero rates and was expecting no conversion to occur.

\begin{tabular}{|l|l|l|l|l|l|l|}
\hline $\begin{array}{l}\text { Mutation } \\
\text { Name }\end{array}$ & $\begin{array}{l}\text { Rates_2 } \\
\text { BC }\end{array}$ & $\begin{array}{l}\text { Rates_2_ } \\
\text { EC }\end{array}$ & $\begin{array}{l}\text { Rates_2_ } \\
\text { PW }\end{array}$ & $\begin{array}{l}\text { Rates_2 } \\
\text { BC_Ann }\end{array}$ & $\begin{array}{l}\text { Rates_2 } \\
\text { EC_Ann }\end{array}$ & $\begin{array}{l}\text { Rates_2_ } \\
\text { PW_Ann }\end{array}$ \\
\hline UOI44 & KILLED & LIVE & KILLED & KILLED & KILLED & KILLED \\
\hline UOI47 & KILLED & LIVE & KILLED & KILLED & KILLED & KILLED \\
\hline UOI52 & KILLED & LIVE & KILLED & KILLED & KILLED & KILLED \\
\hline
\end{tabular}

UOR2 and UOR3 mutated the code of the GetAverageConversionRate() and remained alive only in Rates_2_EC which, for the same reason as abovementioned, provided zero number of rates and resulted in the method returning successfully and thus passing all test cases.

\begin{tabular}{|l|l|l|l|l|l|l|}
\hline $\begin{array}{l}\text { Mutation } \\
\text { Name }\end{array}$ & $\begin{array}{l}\text { Rates_2 } \\
\text { BC }\end{array}$ & $\begin{array}{l}\text { Rates_2 } \\
\text { EC }\end{array}$ & $\begin{array}{l}\text { Rates_2 } \\
\text { PW }\end{array}$ & $\begin{array}{l}\text { Rates_2_ } \\
\text { BC_Ann }\end{array}$ & $\begin{array}{l}\text { Rates_2_ } \\
\text { EC_Ann }\end{array}$ & $\begin{array}{l}\text { Rates_2_ } \\
\text { PW_Ann }\end{array}$ \\
\hline UOR2 & KILLED & LIVE & LIVE & KILLED & KILLED & KILLED \\
\hline UOR3 & KILLED & LIVE & LIVE & KILLED & KILLED & KILLED \\
\hline
\end{tabular}

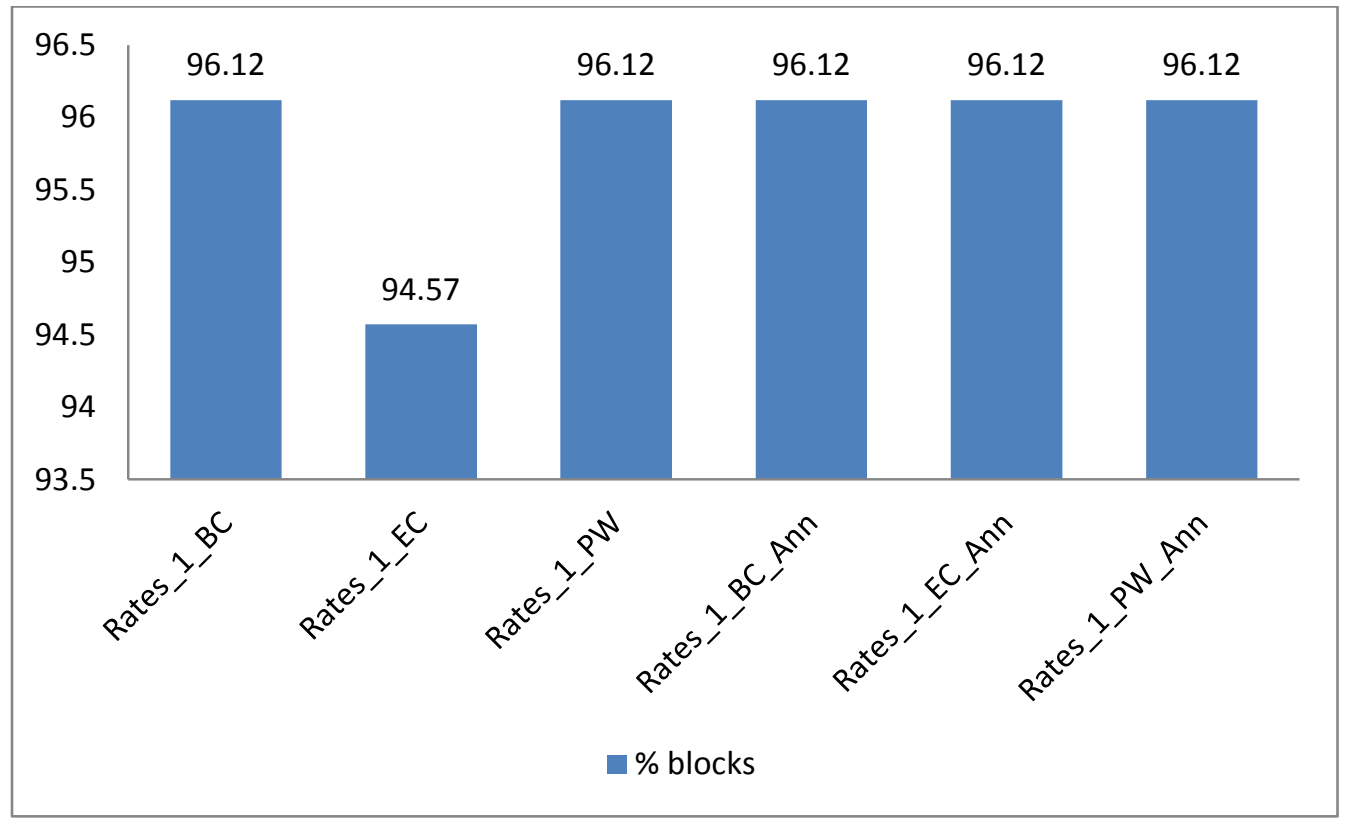

\section{Illustration 4 - Code Coverage Percentage for Rates_1}




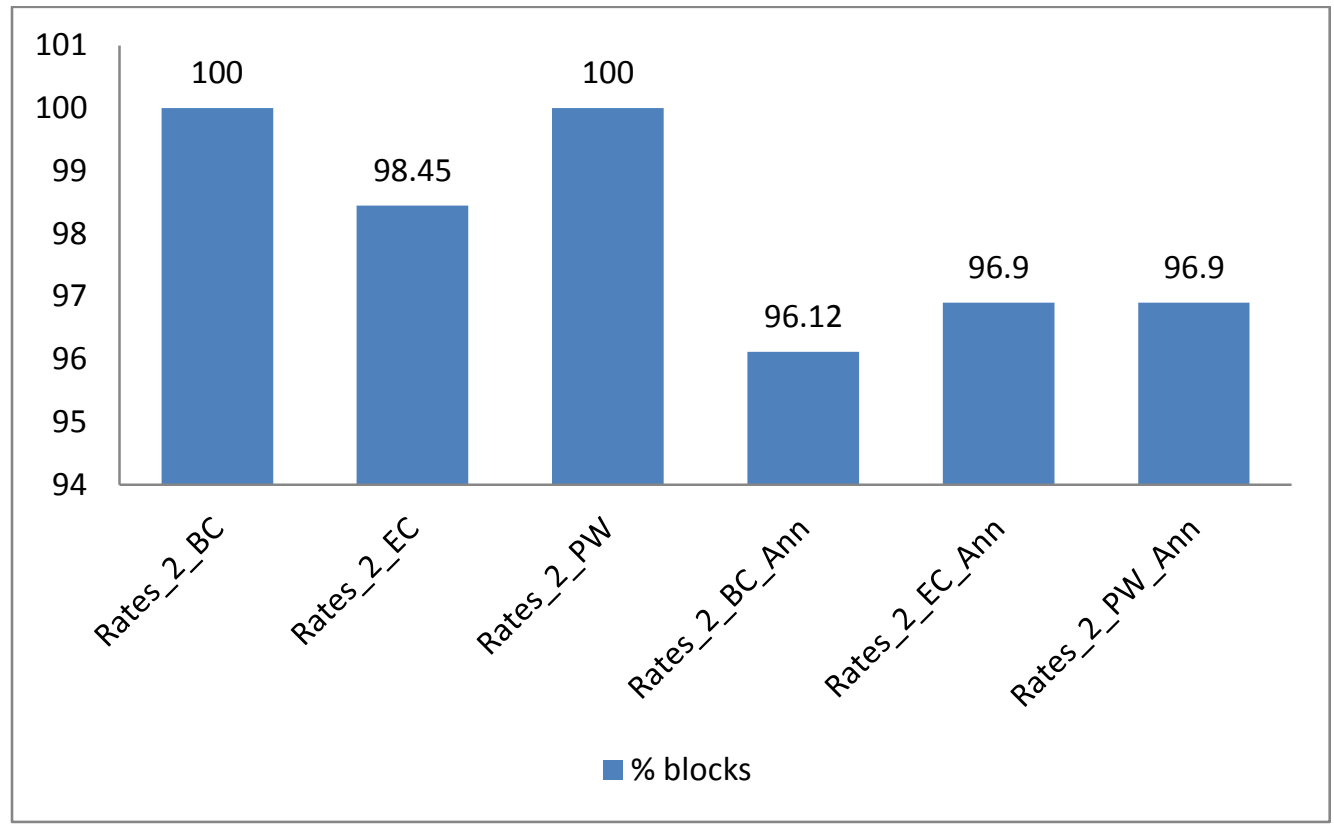

\section{Illustration 5 - Code Coverage Percentage for Rates_2}

Illustration 4 and Illustration 5 show the percentage of code coverage (measured in blocks [12]) against the T1135ExtractRecord class for Rates_1 and Rates_2 respectively

\subsection{Calculation Logic Case Study}

In this section, we will first discuss the $\mathrm{CP}$ specifications, test suites, and generated mutants. Then we move on to discussing execution results in a subsequent subsection.

\subsubsection{Raw results when running our experiments}

In the first approach (i.e., Calc_1), which represents the preliminary approach to this case study (refer to Appendix C ), there are two input parameters, two categories, and six choices for both the annotated and non-annotated CP specifications. All three selection criteria were tried on both $\mathrm{CP}$ specifications. See Table 16 below for details on the generated number of test frames and test cases (indicated in parentheses). The annotated approach has one 'Error' and one 'Single' constraints. 


\begin{tabular}{|c|c|c|c|}
\hline \multirow{2}{*}{ CP Specifications } & \multicolumn{3}{|c|}{ Number of Test Frames } \\
\cline { 2 - 4 } & Base Choice & Each Choice & Pair Wise \\
\hline Non-Annotated & $5(5)$ & $4(4)$ & $8(8)$ \\
\hline Annotated & $5(5)$ & $4(4)$ & $6(6)$ \\
\hline
\end{tabular}

\section{Table 16 - Calc_1 Case Study - Number of Frames and Test Cases}

In the second approach to this case study (Calc_2), which represents the improved approach to this case study (refer to Appendix D ), there are two input parameters, five categories, and eleven choices for the annotated and non-annotated CP specifications. Also, all three selection criteria were tried in both CP specifications. See Table 17 below for details on the generated number of test frames and test cases (indicated in parentheses). The annotated approached has four 'Single' constraints and one 'Error' constraint.

\begin{tabular}{|c|c|c|c|}
\hline \multirow{2}{*}{ CP Specifications } & \multicolumn{3}{|c|}{ Number of Test Frames } \\
\cline { 2 - 4 } & Base Choice & Each Choice & Pair Wise \\
\hline Non-Annotated & $7(7)$ & $3(3)$ & $6(6)$ \\
\hline Annotated & $7(7)$ & $5(5)$ & $5(5)$ \\
\hline
\end{tabular}

\section{Table 17 - Calc_2 Case Study - Number of Frames and Test Cases}

The mutation tool [11] used in this experiment created 27 mutants generated by mutating the code of the system under test. The reason for this relatively small number of mutants is, we believe, because the core mathematical operations, such as finding the sum and maximum values on security values, are not done directly in the code we are testing. These operations are done through extension methods associated with data collections in the .NET framework. For example, to find the sum of values in a given collection of numbers (such as an array), the programmer can utilize the 'Sum' extension method on the collection instead of writing her own algorithm to do so. Unlike some of the mutants in the previous case study, all mutants successfully compile in this case study. We therefore ended up using all of them in the experiment in addition to two 
manually created mutants ${ }^{7}$. Therefore, we have 29 mutants for experimentation.

Uniform alive mutants in this case study across both approaches (i.e. Calc_1 and Calc_2) were 13 and had been excluded from the analysis. This leaves only 16 out of the original 29 mutants.

\subsubsection{Execution Results}

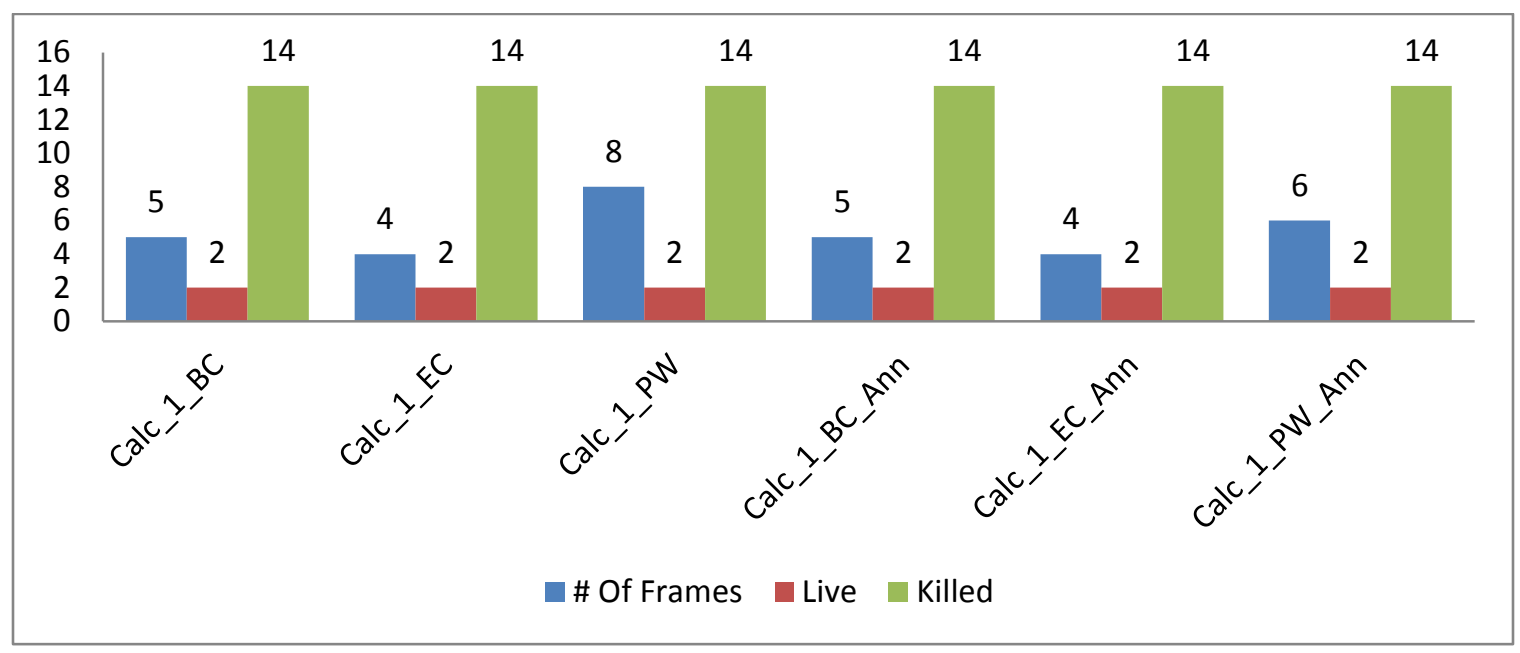

\section{Illustration 6 - Live and Killed Mutants (Calc_1)}

\begin{tabular}{|l|l|l|}
\hline Test Suite & Test Frames & Mutation Score (\%) \\
\hline Calc_1_BC & 5 & 87.5 \\
\hline Calc_1_EC & 4 & 87.5 \\
\hline Calc_1_PW & 8 & 87.5 \\
\hline Calc_1_BC_Ann & 5 & 87.5 \\
\hline Calc_1_EC_Ann & 4 & 87.5 \\
\hline Calc_1_PW_Ann & 6 & 87.5 \\
\hline
\end{tabular}

\section{Table 18 - Calc_1 Mutation Score}

Illustration 6 presents the number of live and killed mutants compared to the number of test frames. The number of alive and killed mutants is the same across all test suites. See section C. 3 for more details on the number of killed and live mutants. All

\footnotetext{
${ }^{7}$ Two manually created mutants were added to the ones created by the mutation tool. These mutants are real defects in the code that were encountered during the course of this work (see section 3.3.2 for more details). We chose to add them to our list of automatically generated mutants for fault detection analysis.
} 
mutants were uniform (whether alive or killed) across the annotated and non-annotated approaches as well as across the selection criteria. Mutants that remained uniform alive were D1 and D2. These are the manually injected mutants. Had the test cases provided the proper input, these two mutants would have been killed as well by the generated test frames. A set of securities with the same country, yet spelled with a different case, could have killed D1. And for any set of securities of the same country, we could have killed D2 if the highest summed up value of MV had occurred in either the income earned or capital gain value. Test case input to kill D1 and D2 were not explicitly specified by the CP specifications in Calc_1, but the CP specifications did not prevent such input either. For more details, please refer to Appendix section C.4.

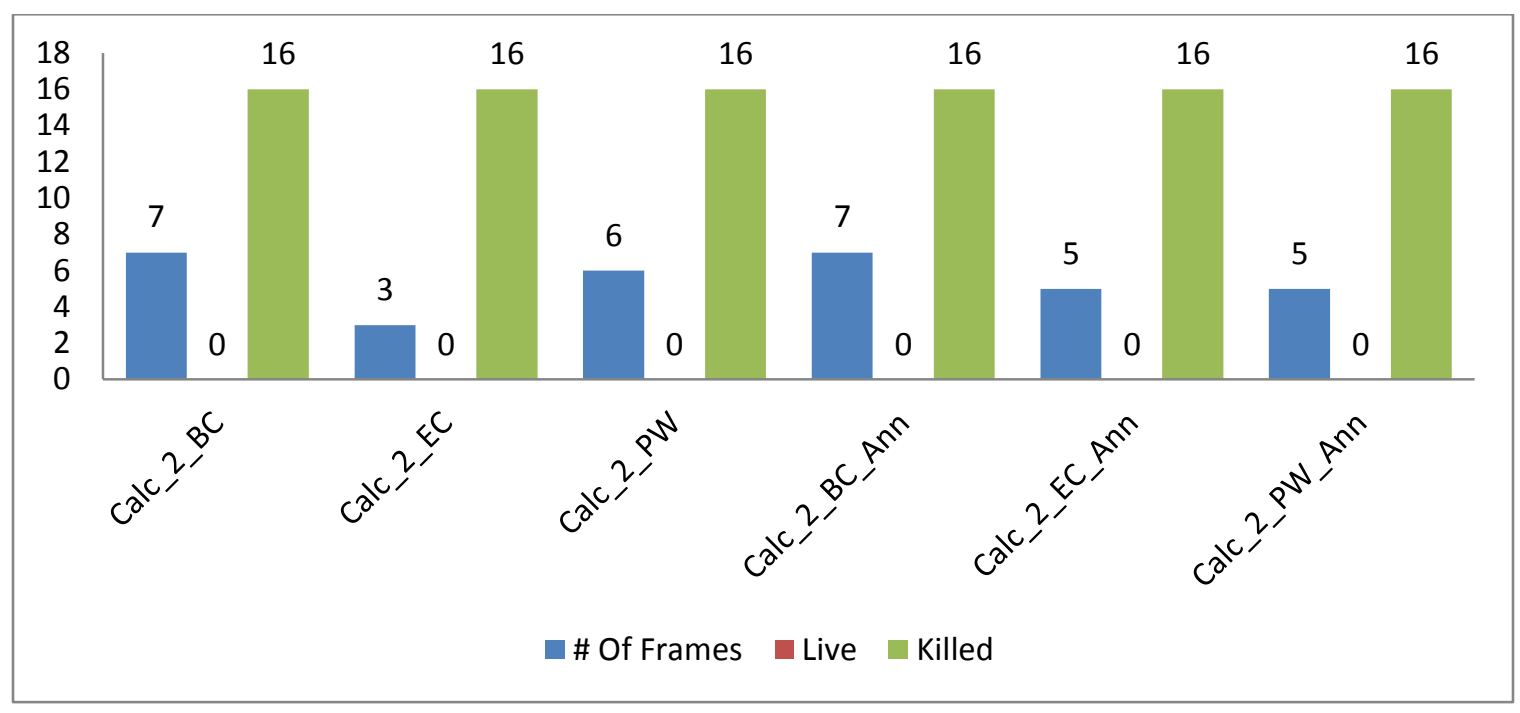

\section{Illustration 7 - Live and Killed Mutants (Calc_2)}

\begin{tabular}{|l|l|l|}
\hline Test Suite & Test Frames & Mutation Score (\%) \\
\hline Calc_2_BC & 7 & 100 \\
\hline Calc_2_EC & 3 & 100 \\
\hline Calc_2_PW & 6 & 100 \\
\hline Calc_2_BC_Ann & 7 & 100 \\
\hline Calc_2_EC_Ann & 5 & 100 \\
\hline Calc_2_PW_Ann & 5 & 100 \\
\hline
\end{tabular}

Table 19 - Calc_2 Mutation Score 


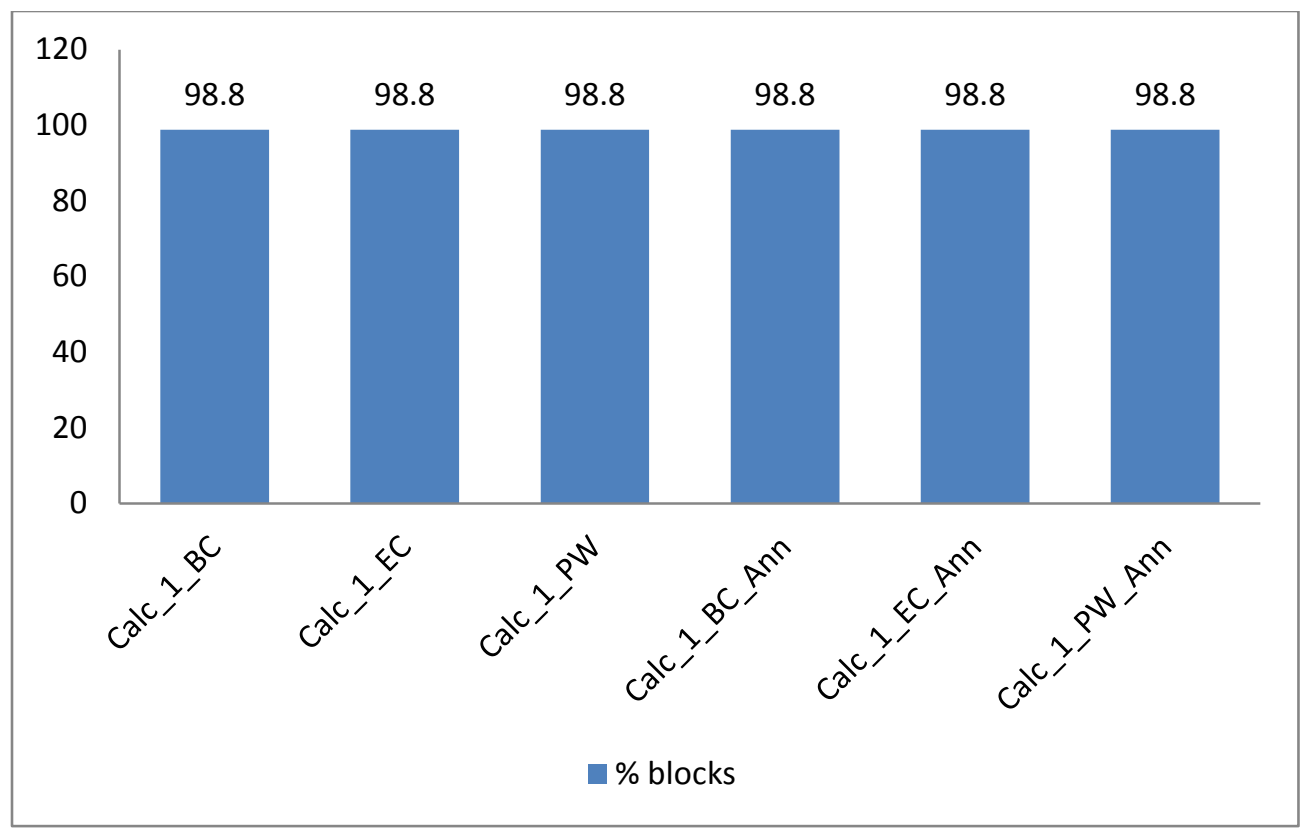

\section{Illustration 8 - Code Coverage Percentage for Calc_1}

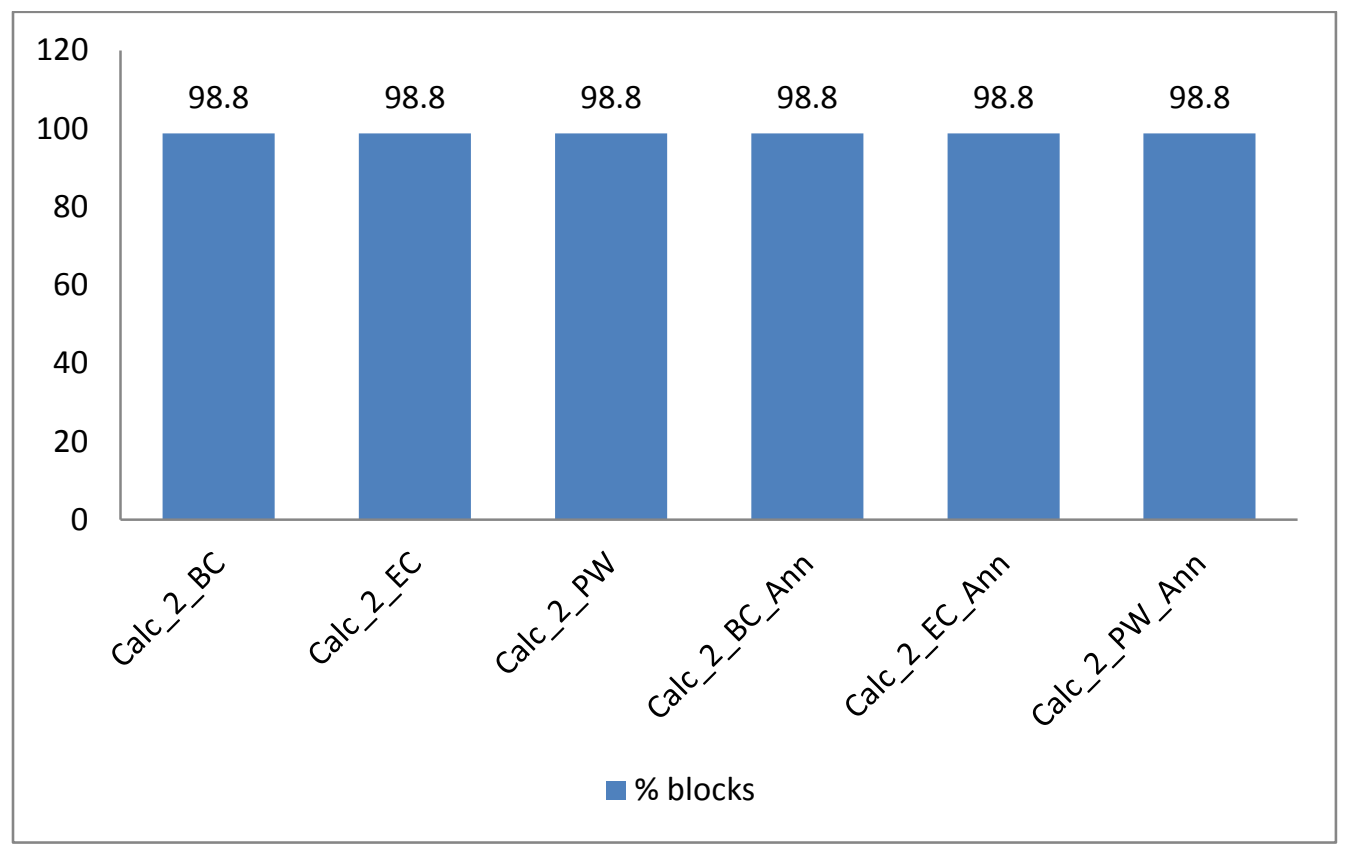

\section{Illustration 9 - Code Coverage Percentage for Calc_2}

Illustration 8 and Illustration 9 show the percentage of code coverage (in blocks [12]) against the code of the T1135BundleCalculator class for both cases studies.

However, in this case study, it was impossible to achieve $100 \%$ code coverage because 
some parts of the code check for conditions that were not possible to satisfy not because of the CP specifications, choices combinations, or test input, but because of the other unrelated initialization code. For example, the only non-covered lines were the following:

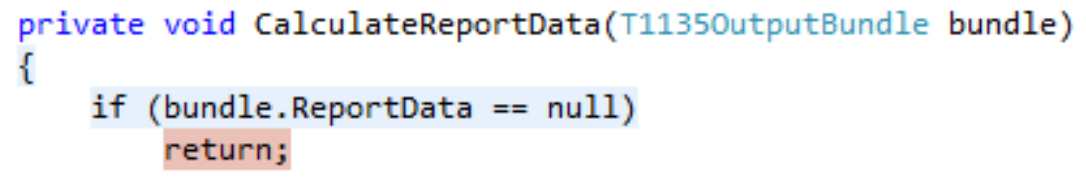

And private void CalculateMonthlySubtotalsPerCountry(T11350utputBundle bundle) \{

It was impossible to cover the first line because in the constructor of the T11350utputBundle class, the class member ReportData is always initialized to a new instance. This made it impossible for this variable to be null by any given input and therefore the condition checking for its null state is never met. This statement is essentially dead code and any mutant applied to it is therefore an equivalent mutant.

For the second line, the T1135BundleCalculator class always converts the passed in argument of type OutputBundle to type T11350utputBundle. We would have to pass in a parameter type that is not convertible to T11350utputBundle to fail the cast (causes it to be Null) in order to hit the condition shown above which was not doable and therefore this condition could not be met. Other than the above two lines, everything else was covered which created the highest coverage percentage of $98.8 \%$. 


\subsection{Discussion}

\subsubsection{Fault Detection}

By observing the two case studies in this work, we noticed that mutants remained alive because they belong to one of the categories below:

1 Mutants that cause no behavior change in the system under test remain alive (i.e, equivalent mutants). For example, in the Rates case study, mutants UOI11, UOI14, and UOI23 add the '+' unary operator to variables of numeric type which has no effect on whether the value is negative or positive as per [14]. More specifically, this makes $\mathrm{x}=5$ and $\mathrm{x}=+5$ equivalent to $\mathrm{x}=5$, and $\mathrm{x}=+(-5)$ always equivalent to $\mathrm{x}=-5$. This unary operator seems to have no impact on the value.

2 Mutants that cause a behavior change in the system but the change is not part of what is being used to assess whether a test case passes or fails. For example, mutants UOI4, UOI45, and UOI46 in the Rates case study introduce a change to the logic calculating the Income Earned and Capital Gain values. These values are not used in the currency conversion process in the Rates case study. Other examples of such mutants are UOI3, UOI3, and UOI4 in the Calc case study. Therefore, whether those irrelevant values change or not, no impact is observed on the behavior of the system under test.

3 Mutants that change the system behavior and impact areas under test but they do not get executed because the input values of the test cases directed the execution flow in a way such that the mutant was not reached. Further to this point, such mutants fall under two sub-categories: 
- Mutants that are not executed because no possible input could lead to executing the mutated code (dead code).

- Mutants that could be executed if test case input was more carefully thought out. Examples of such mutant are UOI10 in the Rates_2 case study and D1 and D2 in the Calc_1 case study.

Mutant uniformity can be exhibited in the context of different selection criteria such as the LOR3 in Rates_2 and AOR1 to AOR4 in Rates_2_Ann, in the context of annotated and non-annotated CP specifications such as AOR1 to AOR4 in Rates_1, or in the context of different approaches to creating the $\mathrm{CP}$ specifications such as the $\mathrm{EOC} 1$ and EOC2 mutants. Mutant uniformity over a certain context does not give much room for comparison. For example, if a mutant is consistently killed or left alive under all different selection criteria, one cannot determine, solely based on the output from this mutant, which selection criterion is better than the other. The last sections in the appendix of each case study list uniform live and non-uniform mutants.

Regarding the first research question on the impact of differently created $\mathrm{CP}$, the preliminary approaches to creating the $\mathrm{CP}$ specification either performed better or equally to the improved approached. Contrary to what is expected, the improved CP specification (see the Currency Conversion case study) actually performed poorly and some of its test suites (Rates_2_EC) scored as low as $34.34 \%$ mutation score. This may be attributed to the significantly smaller number of test frames provided by the each choice criterion in Rates_2_EC. The smaller number of frames is due to the nature of the each-choice criterion which is satisfied as long as each choice is used at least once in at least one test case [3]. However, the expectation that the improved CP specification 
would kill more mutants holds in the case of the Calculation Logic case study where the Calc_2 approach was able to kill all automatically generated mutants in addition to the manually created ones.

Regarding the second research question on the impact of adding or discarding the 'Single' and 'Error' annotations, the annotated approaches performed either better or equally to their non-annotated counterpart. The each choice and pair wise selection criteria performed noticeably poorly in the Rates_2 case study while their annotated counterparts performed as good as the base choice. The reason for this poor performance is that the each choice criterion did not produce a test frame that includes all base choice which would guarantee a full execution of the test code. The same reason goes for the pair wise criterion which performed slightly better than each choice and only produced one test frame that executed a little more code.

Regarding the third question on the impact of different test selection criteria, the base choice selection criterion performed the best compared to each choice and pair wise. This is regardless of whether the base choice criterion was part of the preliminary or improved approach or whether it was part of the annotated or non-annotated CP specifications. We also observed that the each choice criterion, except in the case of Rates_2, performed quite well given the small number of test frames it produced compared to other selection criteria. The pair wise criterion's performance was equal to the each choice's except that it produced significantly more test frames than each choice especially in the non-annotated CP specifications. 


\subsubsection{Cost}

Regarding the third research question on the impact on cost of different selection criteria, the each choice criterion is the most effective in that it always produced the least number of test frames compared to other selection criteria. This is regardless of the $\mathrm{CP}$ specification's quality or whether it is annotated with the 'Single' and 'Error' constraints. The base choice and pair wise criteria scored very closely where the base choice criterion was more expensive in 5 out of 8 times than the pair wise criterion. We believe that this variation between the base choice and pair wise criteria is attributable to the nondeterminism of test frames constriction as well as the requirements of each criterion for test frame construction (the difference in the number of frames between the two criteria is utmost three). Regarding the second research question on the impact of the 'Single' and 'Error' annotations on a CP specification, we observed that adding the 'Error' and 'Single' annotations do not necessarily reduce the number of test frames although this may seem counterintuitive as one would think that adding constraints should limit the number of combinations of test frames and consequently produce fewer test frames. This finding is also in agreement with what others [6] established. However, the selection criteria in annotated CP specifications collectively produce fewer test frames than the corresponding non-annotated CP specifications. This is true except in the Rates_1 case study where the annotated CP specifications produced more test frames, we could not find an explanation for such a behavior except that test frames are non-deterministically created by Melba (using CASA).

Regarding the first research question on the impact of differently created CP specifications, we observed that selection criteria in the improved CP specifications 
collectively produce fewer test frames. However, this observation will need to be further confirmed with more experimental evidence as it may not be always true. Also, since the approaches to create $\mathrm{CP}$ specifications are different, it is natural that the number of the resulting categories and choices become different too. Therefore, we suggest that comparing different CP specifications based on cost, number of test frames, may not be ideal since these specifications have different numbers of categories and choices which makes the number of test frames inevitably different for both.

\subsubsection{Code Coverage}

Regarding the first research question on the impact of differently created CP specifications, we observed that an improved approach to creating CP specifications either improves code coverage or sustains it at the same level. We suggest that the improvement in code coverage is due to that extra care exercised in creating the improved CP specifications which resulted in executing more code in the system under test.

Observing no impact to code coverage in this context is particularly true in the case of the Calculation Logic case study where the coverage results remained consistent at $98.8 \%$ in all test suites.

Regarding the second research question on the impact of adding and discarding the 'Single' and 'Error' annotations, the annotated CP specification, especially for the Rates_2 case study, resulted in less coverage for all selection criteria. This may be attributed to the fact that the annotated $\mathrm{CP}$ specifications produced fewer test frames and hence prevented the tests from executing every possible path. Moreover, contrary to the claim made by others [6] that the 'Error' annotations can contribute to code coverage, we observed the opposite. We particularly noted that in the case of the Rates_2_BC and 
Rates_2_PW which achieved 100\% coverage while their annotated counterparts only achieved $96.12 \%$ and $96.9 \%$ respectively.

Regarding the third research question on the impact of different test selection criteria, we observed that the each choice criterion covered the least amount of code compared to other criteria (except for Rates_2_BC_Ann). This again may have been caused by the fact that the each choice criterion also produced fewer test frames and hence executed less test code. The base choice and pair wise criteria were almost equal in code coverage in both case studies.

\subsection{Threats to Validity}

As per Malhotra [15], several types of validity threats may be posed against an experiment.

Internal validity is concerned with how strongly we can affirm that an outcome is caused only by the independent variable in our experiment and not something else. We believe that threats to this validity are minimized because we have conducted 12 different test suites in each case study and testing was carefully conducted. We also were very careful in isolating the part of the system targeted for testing and defining its XML input to make sure the input is similar to that provided under a real world scenario. Issues due to the input selection method, for example, were reported and discussed in earlier sections. Randomness in generating input values while also maintaining the reasonable and realistic characteristics of these values should not change the outcome in the sense that such values will always trigger the same control flows.

Moreover, we did not account for uniform live mutants in our analysis for calculating mutation score. This has been mentioned at the very beginning of this chapter. 
Accounting for such mutants would of course impact our results. However, results would only be proportionately impacted such that the conclusions about comparing annotated and non-annotated $\mathrm{CP}$ specifications as well as different selection criteria would still be valid. For example, out of the 71 mutants in the Rates_1 case study, 41 were uniform live mutants and consequently excluded from the analysis. Mutation scores for the Rates_1 case study after removing those mutants are recorded in Table 20.

\begin{tabular}{|l|l|l|}
\hline Test Suite & Test Frames & Mutation Score (\%) \\
\hline Rates_1_BC & 8 & 100 \\
\hline Rates_1_EC & 2 & 96.6 \\
\hline Rates_1_PW & 6 & 100 \\
\hline Rates_1_BC_Ann & 8 & 100 \\
\hline Rates_1_EC_Ann & 6 & 100 \\
\hline Rates_1_PW_Ann & 7 & 100 \\
\hline
\end{tabular}

Table 20 - Rates_1 Mutation Score

If we were to include uniform live mutants in the analysis, the results would be as presented in Table 21.

\begin{tabular}{|l|l|l|}
\hline Test Suite & Test Frames & Mutation Score (\%) \\
\hline Rates_1_BC & 8 & 42 \\
\hline Rates_1_EC & 2 & 40.1 \\
\hline Rates_1_PW & 6 & 42 \\
\hline Rates_1_BC_Ann & 8 & 42 \\
\hline Rates_1_EC_Ann & 6 & 42 \\
\hline Rates_1_PW_Ann & 7 & 42 \\
\hline
\end{tabular}

\section{Table 21 - Rates_1 Mutation Score (with uniform live mutants)}

As seen in the above mutation score tables, the results change proportionately for all test criteria and the annotated and non-annotated $\mathrm{CP}$ specifications. This proportionate change does not invalidate our earlier conclusion. However, more case studies from other or similar industrial fields should be conducted in order to attain more confidence in results. 
External validity is concerned the ability to extend the results of a study to situations with different conditions and settings. Threats to such ability are considered external threats. In our case, the case studies address industrial financial system that uses XML input. We believe this threat is reduced due to the fact that we created more than one CP specification for each case study. Also, another threat under this category would be the size of the system. More specifically, if the number of input parameters grows significantly more than what we have in this work, generating the number of test frames through CASA may pose an issue. For instance, in the Rates_1_EC_Ann case study which has seven (7) input parameters, CASA was run eight times and it provided the following numbers of frames: $5,6,6,5,5,6,5,5$. With a larger number of input parameters, this non-determinism can probably have a larger impact. Therefore, we believe that more case studies need to be conducted against systems of different sizes and industrial uses in order to attain more confidence and further mitigate this threat.

There are also construct validity threats which are concerned with "the gap, if any, between the theoretical concepts and the actual representation of the concepts." In our case this would be how accurately mutation testing measures a CP specification's effectiveness at detecting faults. However, authors [16] seem to suggest that "carefully selected mutation can provide a good indication of the fault detection ability" which reduces this type of threat in our work. In addition to automatically generated mutants, we added two manually created one which should further mitigate this threat. However, further research is probably needed on how manually created mutants affects the fault detection ability of a testing approach. 


\section{Chapter 5 Conclusion}

The value of this work comes from the contribution it makes to existing empirical evidence available thus far on comparing selection criteria, assessing the impact of the 'Single' and 'Error' annotation of a CP specification, and how differing approaches to creating $\mathrm{CP}$ specifications can have an impact on testing. The fact that we have twentyfour (24) test suites derived from an industrial real-world system in the financial sector provides us with empirical evidence from a perspective different than that commonly found in purely academic case studies.

We have two case studies and in each we attempted two different approaches to creating a $\mathrm{CP}$ specification. The first approach is a preliminary one relying on deriving input variables found at a first glance at the system under test while the second (improved) approach incorporates more domain knowledge and uses the tester's familiarity with the system under test and his intimate knowledge of its working details. The purpose of this practice was to observe how poorly derived CP specifications can impact testing results compared to more diligently derived specifications. Also, we looked at the impact of forcing and ignoring the 'Single' and 'Error' annotations on each $\mathrm{CP}$ specification in addition to the impact of the selection criteria used in constructing test frames.

To measure the results of our experiment, we used cost, code coverage, and mutation score to assess and compare test suites. Our cost measure relies on the number of test frames generated by a test suite where a high number of test frames means more cost. For code coverage, we used Visual Studio's built-in functionality to measure code coverage using the all-blocks coverage criterion. And for mutation score, we used the 
CREAM tool to mutate the code under test. However, since all mutation tools we tried in the course of this work did not satisfy our needs, we had to resort to our own way of injecting mutants, already created by CREAM, in the test code and run test suites against them. After that, we captured our results for each case study and presented a discussion of the results.

The main findings in our work can be summarized in the following:

1 A preliminary and simple $\mathrm{CP}$ specification derived from quickly identifiable input parameters can be very powerful in fault detection. This is especially true for detecting simple and automatically generated mutants.

2 A carefully derived CP specification can either improve code coverage or maintain it at the same level compared to a preliminary CP specification.

3 A CP specification annotated with the 'Single' and 'Error' constraints can kill most or all mutants. This is regardless of whether a CP specification was derived from a preliminary or an improved approached.

4 The Each Choice selection criterion was the worst criterion in detecting faults. This is due to the fact that this criterion is satisfied by the least number of test frames so long as every choice occurs once in a test frame. However, this criterion was also the cheapest (i.e., the least number of test frames).

5 The Base Choice criterion was very effective at detecting faults and attaining very high code coverage percentage. However, it was generally (5 out of 8 times) more expensive than the Each Choice and Pair Wise criteria.

6 Annotating a CP specification with the 'Single' and 'Error' constraints does not necessarily reduce the number of test frames. However, it makes the test frames 
more focused by limiting the selection of choices to those of interest as much as possible.

\subsection{Future Work}

Since this work is done using the .NET testing framework, we feel that more work could be done to address the lacking of mutation testing in .NET. There are tools that we came across during our experimentation, but they were not satisfactory. Therefore, this area is one place for further work to improve mutation testing in .NET.

More experimental work should be done in the area of comparing test selection criteria and probably more varied types of industrial systems from different fields (such as health care, embedded systems) should be used in order to reach more firm results.

Also, the Melba tool we used in this work needs more user interface improvements. The UI of the tool at least needs re-work in order to become more user friendly. Also, being able to input multi-values input parameters (such as the Rates input parameter in the Currency Conversion case study) would be a good enhancement to Melba if it could recognize it. Moreover, a web-based version of the tool that allows users to save and later resume inputting $\mathrm{CP}$ specifications would be beneficial. Such online accessibility can open up the tool to a wider community of users and spare users the hassle of having to install and configure the tool locally. 


\section{References}

[1] S. Desikan and G. Ramesh, Software Testing: Principles and Practices, Dorling Kindersley (India), 2006.

[2] L. C. Briand, Y. Labiche, N. T. Spido and Z. Bawar, "Using machine learning to refine Category-Partition test specifications and test suites," Information and Software Technology, vol. 15, no. 11, pp. 1551-1564, 2009.

[3] P. Ammann and J. Offutt, Introduction to Software Testing, Cambridge University Press, 2008.

[4] F. Rafsanjani Sadeghi, Comparison of coverage criteria for the category partition method using automatically generated test suites with melba, Ottawa: Carleton University, 2012.

[5] S. K. Khalsa and Y. Labiche, "Getting more in less: The power of single/error annotations in category partition," in 2015 IEEE International Symposium on Software Reliability Engineering Workshops (ISSREW), 2015.

[6] S. Khalsa, Y. Labhiche and N. Johanna, "The power of single and error annotations in category partition testing: an experimental evaluation," in Proceedings of the 20th International Conference on evaluation and assessment in software engineering, Ottawa, 2016.

[7] T. H. Tse, S.-F. Tang and F.-C. Kuo, "Contributions of tester experience and a checklist guideline to the identification of categories and choices for software testing," Software Quality Journal, vol. 19, no. 1, p. 141-163, 2011.

[8] J. J. Marciniak, Encylopedia of Software Engineering, vol. 1, New York: John Wiley 
\& Sons Inc., 2002, p. 76.

[9] Institute of Computer Science, Warsaw University of Technology, "Visual Mutator .NET Mutation Testing," 2016. [Online]. Available:

https://visualmutator.github.io/web/.

[10] NinjaTurtles .NET Mutation Testing, [Online]. Available: http://www.mutationtesting.net/.

[11] A. Szustek and M. Rudnik, "CREAM Creator of Mutants," 2011. [Online]. Available: http://galera.ii.pw.edu.pl/ adr/CREAM/index.php.

[12] Microsoft, "Using Code Coverage to Determine How Much Code is being Tested," 2018. [Online]. Available: https://msdn.microsoft.com/en-us/library/dd537628.aspx.

[13] Microsoft, " Operator," [Online]. Available: https://msdn.microsoft.com/enus/library/d2bd4x66(v=vs.120).aspx.

[14] Microsoft, "+ Operator (C\# Reference)," 2015. [Online]. Available: https://docs.microsoft.com/en-us/dotnet/csharp/languagereference/operators/addition-operator.

[15] R. Malhotra, Empirical Research in Software Engineering: Concepts, Analysis, and Applications, CRC Press, 2016.

[16] J. Andrews, L. Briand and Y. Labiche, "Is mutation an appropriate tool for testing experiments?," ICSE '05 Proceedings of the 27th international conference on Software engineering, pp. 402-411, 2005.

[17] Y. Jia and M. Harman, "Higher Order Mutation Testing," Information and Software Technology, vol. 51, no. 10, pp. 1379-1393, 2009. 
Appendices 


\section{Appendix A Currency Conversion Case Study (First Approach)}

\section{A.1 Non-Annotated CP Specifications}

CurrencyCode

- IsUSD:

- True[base]

- False

AccountCurrency

- IsUSD:

- True[base]

- False

RateMonthName

- IsValidName

- True [base]

- False

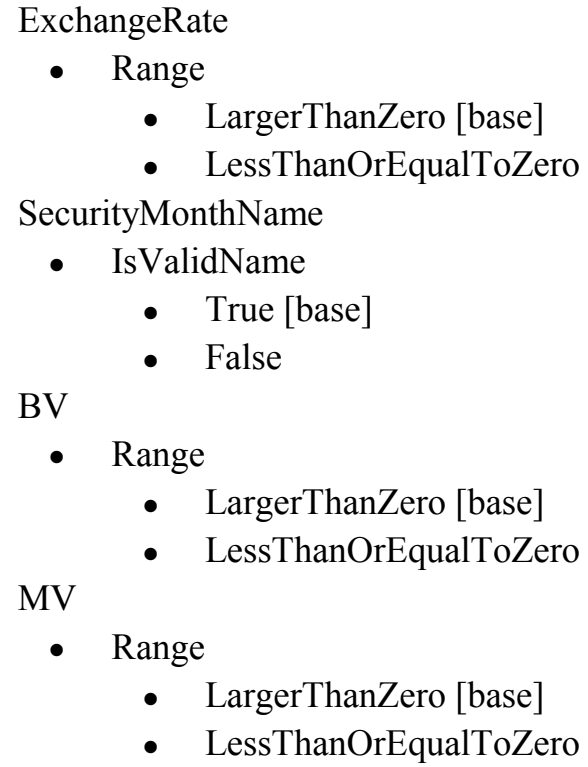

From the requirements, we know that the conversion logic will not be triggered unless both input parameters AccountCurrency and CurrencyCode have values of 'USD'. This is why we are giving weight to the value 'USD' in creating the categories and blocks for AccountCurrency and CurrencyCode. For the month names, the creation of the categories and blocks was based on whether a month name is valid. This is only an approach that seems to make sense based on common knowledge of the names of months in the year, and not any specific understanding of this problem. For the remaining numeric values, again without relying on problem-specific understanding, we choose to create the categories and blocks based on whether values are equal to, larger than, or smaller than zero.

Also, we can have test cases where AccountCurrency and CurrencyCode have different values other than 'USD' to test whether the conversion logic is triggered. This 
helps us achieve robustness testing where we are interested in seeing the system's behavior with unexpected input values.

\section{Base-Choice Frames and Test Cases}

Frame 1:

AccountCurrency.IsUSD.True

CurrencyCode.IsUSD.True

RateMonthName.IsValidName.True

ExchnageRate.Range.LargerThanZero

SeurityMonthName.IsValidName.True

BV.Range.LargerThanZero

MV.Range.LargerThanZero

Frame 2:

AccountCurrency.IsUSD.False

CurrencyCode.IsUSD.True

RateMonthName.IsValidName.True

ExchnageRate.Range.LargerThanZero

SeurityMonthName.IsValidName.True

BV.Range.LargerThanZero

MV.Range.LargerThanZero

Frame 3:

AccountCurrency.IsUSD.True

CurrencyCode.IsUSD.False

RateMonthName.IsValidName.True

ExchnageRate.Range.LargerThanZero

SeurityMonthName.IsValidName.True

BV.Range.LargerThanZero

MV.Range.LargerThanZero
Frame 4:

AccountCurrency.IsUSD.True

CurrencyCode.IsUSD.True

RateMonthName.IsValidName.False

ExchnageRate.Range.LargerThanZero

SeurityMonthName.IsValidName.True

BV.Range.LargerThanZero

MV.Range.LargerThanZero

Frame 5:

AccountCurrency.IsUSD.True

CurrencyCode.IsUSD.True

RateMonthName.IsValidName.True

ExchnageRate.Range.LessThanOrEqualToZero

SeurityMonthName.IsValidName.True

BV.Range.LargerThanZero

MV.Range.LargerThanZero

Frame 6:

AccountCurrency.IsUSD.True

CurrencyCode.IsUSD.True

RateMonthName.IsValidName.True

ExchnageRate.Range.LargerThanZero

SeurityMonthName.IsValidName.False

BV.Range.LargerThanZero

MV.Range.LargerThanZero 
Frame 7:

AccountCurrency.IsUSD.True

CurrencyCode.IsUSD.True

RateMonthName.IsValidName.True

ExchnageRate.Range.LargerThanZero

SeurityMonthName.IsValidName.True

BV.Range.LessThanOrEqualToZero

MV.Range.LargerThanZero
Frame 8:

AccountCurrency.IsUSD.True

CurrencyCode.IsUSD.True

RateMonthName.Is ValidName.True

ExchnageRate.Range.LargerThanZero

SeurityMonthName.IsValidName.True

BV.Range.LargerThanZero

MV.Range.LessThanOrEqualToZero

\begin{tabular}{|l|l|l|l|}
\hline Test Case Name & Test Case Value & Expected output & Actual output \\
\hline Rates_1_TC_1_1_BC & USD,USD,May,1.2,May,10,20 & BV=12, MV=24 & Same \\
\hline Rates_1_TC_2_1_BC & USD,AA,May,1.2,May,10,20 & Error & Same \\
\hline Rates_1_TC_3_1_BC & AA,USD,May,1.5,May,10,20 & Error & Same \\
\hline Rates_1_TC_4_1_BC & USD,USD,Mayee,1.5,May, 10, 20 & BV=15, MV=20 & Same \\
\hline Rates_1_TC_5_1_BC & USD,USD,May,-1.5,May,10,20 & BV=-15, MV=-30 & Same \\
\hline Rates_1_TC_6_1_BC & USD,USD,May,1.5,Mayee,10,20 & BV=15, MV=20 & Same \\
\hline Rates_1_TC_7_1_BC & USD,USD,May,1.5,May,-10,20 & BV $=-15, \mathrm{MV}=30$ & Same \\
\hline Rates_1_TC_8_1_BC & USD,USD, May,1.5,May, 10, -20 & BV=15, MV=-30 & Same \\
\hline
\end{tabular}

\section{Table 22 - Base-Choice Test Cases (Non-Annotated Rates_1)}

\section{Each-Choice Frames and Test Cases}

Frame 1:

AccountCurrency.IsUSD.True

CurrencyCode.IsUSD.True

RateMonthName.IsValidName.False

ExchnageRate.Range.LargerThanZero

SeurityMonthName.IsValidName.False

BV.Range.LargerThanZero

MV.Range.LargerThanZero
Frame 2:

AccountCurrency.IsUSD.False

CurrencyCode.IsUSD.False

RateMonthName.IsValidName.True

ExchnageRate.Range.Less ThanOrEqualToZero

SeurityMonthName.IsValidName.True

BV.Range.LessThanOrEqualToZero

MV.Range.LessThanOrEqualToZero

\begin{tabular}{|l|l|l|l|}
\hline Test Case Name & Test Case Value & Expected output & Actual Output \\
\hline Rates_1_TC_1_1_EC & USD,USD,AprilAB,1.2,AprilCD,10,20 & BV=12, MV=20 & Same \\
\hline Rates_1_TC_2_1_EC & AA,BB,April,-1.2,April,-10,-20 & Error & Same \\
\hline
\end{tabular}

Table 23 - Each-Choice Test Cases (Non-Annotated Rates_1) 


\section{Pair-Wise Frames and Test Cases}

Frame 1:

CurrencyCode.IsUSD.True;

AccountCurrency.IsUSD.True

RateMonthName.IsValidName.False

ExchnageRate.Range.LessThanOrEqualToZero

SeurityMonthName.IsValidName.True

BV.Range.LargerThanZero

MV.Range.LargerThanZero

Frame 2

CurrencyCode.IsUSD.False

AccountCurrency.IsUSD.False

RateMonthName.IsValidName.True

ExchnageRate.Range.LessThanOrEqualToZero

SeurityMonthName.IsValidName.True

BV.Range.LessThanOrEqualToZero

MV.Range.LessThanOrEqualToZero

Frame 3

CurrencyCode.IsUSD.False

AccountCurrency.IsUSD.False

RateMonthName.IsValidName.False

ExchnageRate.Range.LargerThanZero

SeurityMonthName.Is ValidName.False

BV.Range.LargerThanZero

MV.Range.LargerThanZero
Frame 4

CurrencyCode.IsUSD.True

AccountCurrency.IsUSD.True

RateMonthName.IsValidName.True

ExchnageRate.Range.LargerThanZero

SeurityMonthName.IsValidName.True

BV.Range.LargerThanZero

MV.Range.LessThanOrEqualToZero

Frame 5

CurrencyCode.IsUSD.True

AccountCurrency.IsUSD.False

RateMonthName.IsValidName.True

ExchnageRate.Range.LargerThanZero

SeurityMonthName.IsValidName.False

BV.Range.LessThanOrEqualToZero

MV.Range.LargerThanZero

Frame 6

CurrencyCode.IsUSD.False

AccountCurrency.IsUSD.True

RateMonthName.Is ValidName.False

ExchnageRate.Range.Less ThanOrEqualToZero

SeurityMonthName.Is ValidName.False

BV.Range.LessThanOrEqualToZero

MV.Range.LessThanOrEqualToZero 


\begin{tabular}{|l|l|l|l|}
\hline Test Case Name & Test Case Value & Expected output & Actual output \\
\hline Rates_1_TC_1_1_PW & USD,USD,Decembber,0,December,10,20 & BV=0, MV=20 & Same \\
\hline Rates_1_TC_1_2_PW & USD,USD,Decembber,-1.5, December,10,20 & BV=-5, MV=20 & Same \\
\hline Rates_1_TC_2_1_PW & AA,BB,December,1.5,December,10,20 & Error & Same \\
\hline Rates_1_TC_3_1_PW & AA,BB,Decembbber,1.5,Decmmbr,10,20 & Error & Same \\
\hline Rates_1_TC_3_2_PW & AA,BB, Decer,1.5,Decer,10,20 & Error & Same \\
\hline Rates_1_TC_4_1_PW & USD,USD,December,1.5,December,10,20 & BV=15, MV=30 & Same \\
\hline Rates_1_TC_4_2_PW & USD,USD,December,1.5,December,12.35,22.30 & BV=18, MV=33 & Same \\
\hline Rates_1_TC_5_1_PW & USD,AA, December,1.5,Decr, 0, 20 & Error & Same \\
\hline Rates_1_TC_5_2_PW & USD AA, ,December,1.5,Decr, -10,20 & Error & Same \\
\hline Rates_1_TC_6_1_PW & BB,USD, Decr,0,Deeecr, 0,0 & Error & Same \\
\hline
\end{tabular}

Table 24 - Pair-Wise Test Cases (Non-Annotated Rates_1)

\section{A.2 Annotated CP Specifications}

CurrencyCode

- IsUSD:

- True[base]

- False [Error]

AccountCurrency

- IsUSD:

- True[base]

- False [Error]

RateMonthName

- IsValidName

- True [base]

- False [single]
ExchangeRate

- Range

- LargerThanZero [base]

- LessThanOrEqualToZero

SecurityMonthName

- IsValidName

- True [base]

- False [Single]

BV

- Range

- LargerThanZero [base]

- LessThanOrEqualToZero

MV

- Range

- LargerThanZero [base]

- LessThanOrEqualToZero 


\section{Base-Choice Frames and Test Cases}

Frame 1:

CurrencyCode.Value.USD

AccountCurrency.Value.USD

SecurityMonthlyValue.IsMatchingMonthInRates

.True

Rates.Count.MoreThanOne

Frame 2:

CurrencyCode.Value.CAD

AccountCurrency.Value.USD

SecurityMonthlyValue.IsMatchingMonthInRates

.True

Rates.Count.MoreThanOne

Frame 3:

CurrencyCode.Value.Other

AccountCurrency.Value.USD

SecurityMonthlyValue.IsMatchingMonthInRates

.True

Rates.Count.MoreThanOne

Frame 4:

CurrencyCode.Value.USD

AccountCurrency.Value.CAD

SecurityMonthlyValue.IsMatchingMonthInRates

.True

Rates.Count.MoreThanOne
Frame 5:

CurrencyCode.Value.USD

AccountCurrency.Value.Other

SecurityMonthlyValue.IsMatchingMonthInRates

.True

Rates.Count.MoreThanOne

Frame 6:

CurrencyCode.Value.USD

AccountCurrency.Value.USD

SecurityMonthlyValue.IsMatchingMonthInRates

.False

Rates.Count.MoreThanOne

Frame 7:

CurrencyCode.Value.USD

AccountCurrency.Value.USD

SecurityMonthlyValue.IsMatchingMonthInRates

.True

Rates.Count.Zero 


\begin{tabular}{|l|l|l|l|}
\hline Test Case Name & Test Case Value & Expected output & Actual Output \\
\hline Rates_1_TC_1_1_BC_Ann & USD,USD,May,1.5,May,10,20 & BV=15, MV=30 & Same \\
\hline Rates_1_TC_2_1_BC_Ann & USD,USD,May,-1.5, May,10,20 & BV=-15, MV=-30 & Same \\
\hline Rates_1_TC_3_1_BC_Ann & USD,USD,May,1.5,May,-10,20 & BV=-15, MV=30 & Same \\
\hline Rates_1_TC_4_1_BC_Ann & USD,USD,May,1.5,May,10,-20 & BV=15, MV=-20 & Same \\
\hline Rates_1_TC_5_1_BC_Ann & USD,USD,MayAB,1.5,May,10,20 & BV=15, MV=20 & Same \\
\hline Rates_1_TC_6_1_BC_Ann & USD,USD,May,1.5,MayAB,12.35,22.30 & BV =18, MV=22 & Same \\
\hline Rates_1_TC_7_1_BC_Ann & AA,USD, May,1.5,May, 10,20 & Error & Same \\
\hline Rates_1_TC_8_1_BC_Ann & USD,BB,May,1.5,May,10,20 & Error & Same \\
\hline
\end{tabular}

Table 25 - Base-Choice Test Cases (Annotated Rates_1)

\section{Each-Choice Frames and Test Cases}

Frame 1:

AccountCurrency.IsUSD.True

CurrencyCode.IsUSD.True

RateMonthName.IsValidName.True

ExchnageRate.Range.LargerThanZero

SeurityMonthName.IsValidName.True

BV.Range.LessThanOrEqualToZero

MV.Range.LargerThanZero

Frame 2:

AccountCurrency.IsUSD.True

CurrencyCode.IsUSD.True

RateMonthName.IsValidName.True

ExchnageRate.Range.LessThanOrEqualToZero

SeurityMonthName.IsValidName.True

BV.Range.LargerThanZero

MV.Range.LessThanOrEqualToZero
Frame 3:

AccountCurrency.IsUSD.True

CurrencyCode.IsUSD.True

RateMonthName.IsValidName.True

ExchnageRate.Range.LessThanOrEqualToZero

SeurityMonthName.IsValidName.False

BV.Range.LessThanOrEqualToZero

MV.Range.LessThanOrEqualToZero

Frame 4:

AccountCurrency.IsUSD.True

CurrencyCode.IsUSD.True

RateMonthName.IsValidName.False

ExchnageRate.Range.LargerThanZero

SeurityMonthName.IsValidName.True

BV.Range.LargerThanZero

MV.Range.LargerThanZero

Frame 5:

AccountCurrency.IsUSD.False

Frame 6:

CurrencyCode.IsUSD.False 


\begin{tabular}{|l|l|l|l|}
\hline Test Case Name & Test Case Value & Expected output & $\begin{array}{l}\text { Actual } \\
\text { Output }\end{array}$ \\
\hline Rates_1_TC_1_1_EC_Ann & USD,USD,April,1.5,April,10,20 & BV=15, MV=20 & Same \\
\hline Rates_1_TC_2_1_EC_Ann & USD,USD,April,-1.5,April,10,20 & $\mathrm{BV}=-15, \mathrm{MV}=-30$ & Same \\
\hline Rates_1_TC_3_1_EC_Ann & USD,USD,April,0,AprilAB,10,20 & $\mathrm{BV}=0, \mathrm{MV}=20$ & Same \\
\hline Rates_1_TC_4_1_EC_Ann & USD,USD,AprilAB,1.5,April,10,20 & $\mathrm{BV}=15, \mathrm{MV}=20$ & Same \\
\hline Rates_1_TC_5_1_EC_Ann & AA,USD, April,1.5, April, 10,20 & Error & Same \\
\hline Rates_1_TC_6_1_EC_Ann & USD,BB, April,1.5, April,10,20 & Error & Same \\
\hline
\end{tabular}

\section{Table 26 - Each-Choice Test Cases (Annotated Rates_1)}

\section{Pair-Wise Frames and Test Cases}

Frame: 1

AccountCurrency.IsCADorUSD.True

CurrencyCode.IsCADorUSD.True

RateMonthName.IsValidName.True

ExchnageRate.Range.LessThanOrEqualToZero

SeurityMonthName.IsValidName.True

BV.Range.LessThanOrEqualToZero

MV.Range.LessThanOrEqualToZero

Frame: 2

AccountCurrency.IsCADorUSD.True

CurrencyCode.IsCADorUSD.True

RateMonthName.IsValidName.True

ExchnageRate.Range.LargerThanZero

SeurityMonthName.IsValidName.True

BV.Range.LessThanOrEqualToZero

MV.Range.LargerThanZero

Frame: 3

AccountCurrency.IsCADorUSD.True

CurrencyCode.IsCADorUSD.True

RateMonthName.IsValidName.True

ExchnageRate.Range.LessThanOrEqualToZero

SeurityMonthName.Is ValidName.True

BV.Range.LargerThanZero
MV.Range.LargerThanZero

Frame: 4

AccountCurrency.IsCADorUSD.True

CurrencyCode.IsCADorUSD.True

RateMonthName.IsValidName.True

ExchnageRate.Range.LargerThanZero

SeurityMonthName.IsValidName.True

BV.Range.LargerThanZero

MV.Range.LessThanOrEqualToZero

Frame: 5

AccountCurrency.IsCADorUSD.True

CurrencyCode.IsCADorUSD.True

RateMonthName.IsValidName.False

ExchnageRate.Range.LargerThanZero

SeurityMonthName.IsValidName.False

BV.Range.LessThanOrEqualToZero

MV.Range.LargerThanZero

Frame: 6

AccountCurrency.IsCADorUSD.False

Frame: 7

CurrencyCode.IsCADorUSD.False 


\begin{tabular}{|l|l|l|l|}
\hline Test Case Name & Test Case Value & Expected output & Actual Output \\
\hline Rates_1_TC_1_1_PW_Ann & USD,USD,March,0,March,-10,-20 & $\mathrm{BV}=0, \mathrm{MV}=0$ & Same \\
\hline Rates_1_TC_1_2_PW_Ann & USD,USD,March,-1.5, March,-10,-20 & $\mathrm{BV}=15, \mathrm{MV}=30$ & Same \\
\hline Rates_1_TC_2_1_PW_Ann & USD,USD,December,1.5,December,-10,20 & $\mathrm{BV}=-15, \mathrm{MV}=30$ & Same \\
\hline Rates_1_TC_3_1_PW_Ann & USD,USD,May,-1.5,May,10,20 & $\mathrm{BV}=-15, \mathrm{MV}=-20$ & Same \\
\hline Rates_1_TC_4_1_PW_Ann & USD,USD,May,1.5,May,10,-20 & $\mathrm{BV}=15, \mathrm{MV}=-30$ & Same \\
\hline Rates_1_TC_4_2_PW_Ann & USD,USD,May,1.5,May,12.35,-22.30 & $\mathrm{BV}=18, \mathrm{MV}=-33$ & Same \\
\hline Rates_1_TC_5_1_PW_Ann & USD,USD, Dec,1.5,Decr, 0, 20 & $\mathrm{BV}=0, \mathrm{MV}=20$ & Same \\
\hline Rates_1_TC_5_2_PW_Ann & USD,USD,Decr,1.5,Decr, -10,20 & $\mathrm{BV}=-15, \mathrm{MV}=20$ & Same \\
\hline Rates_1_TC_5_3_PW_Ann & USD,USD,Decr,1.5,Decr,-10,20 & $\mathrm{BV}=-15, \mathrm{MV}=30$ & Same \\
\hline Rates_1_TC_6_1_PW_Ann & BB,USD, Decr,0,Deeecr, 0,0 & Error & Same \\
\hline Rates_1_TC_7_1_PW_Ann & USD,BB, Decr,0,Deeecr, 0, 0 & Error & Same \\
\hline
\end{tabular}

Table 27 - Pair-Wise Test Cases (Annotated Rates_1)

\section{A.3 List of Live and Killed Mutants}

\begin{tabular}{|l|l|l|l|l|l|l|}
\hline $\begin{array}{l}\text { Mutatio } \\
\text { n Name }\end{array}$ & $\begin{array}{l}\text { Rates_1 } \\
\text { BC }\end{array}$ & $\begin{array}{l}\text { Rates_1 } \\
\text { EC }\end{array}$ & $\begin{array}{l}\text { Rates_1 } \\
\text { PW }\end{array}$ & $\begin{array}{l}\text { Rates_1 } \\
\text { BC_Ann }\end{array}$ & $\begin{array}{l}\text { Rates_1_- } \\
\text { EC_Ann }\end{array}$ & $\begin{array}{l}\text { Rate_1_- } \\
\text { PW_Ann }\end{array}$ \\
\hline AOR1 & KILLED & KILLED & KILLED & KILLED & KILLED & KILLED \\
\hline AOR2 & KILLED & KILLED & KILLED & KILLED & KILLED & KILLED \\
\hline AOR3 & LIVE & LIVE & LIVE & LIVE & LIVE & LIVE \\
\hline AOR4 & KILLED & KILLED & KILLED & KILLED & KILLED & KILLED \\
\hline ASR1 & KILLED & KILLED & KILLED & KILLED & KILLED & KILLED \\
\hline ASR2 & LIVE & LIVE & LIVE & LIVE & LIVE & LIVE \\
\hline ASR3 & KILLED & KILLED & KILLED & KILLED & KILLED & KILLED \\
\hline ASR4 & KILLED & KILLED & KILLED & KILLED & KILLED & KILLED \\
\hline EOC1 & LIVE & LIVE & LIVE & LIVE & LIVE & LIVE \\
\hline EOC2 & LIVE & LIVE & LIVE & LIVE & LIVE & LIVE \\
\hline EOC3 & LIVE & LIVE & LIVE & LIVE & LIVE & LIVE \\
\hline EOC4 & LIVE & LIVE & LIVE & LIVE & LIVE & LIVE \\
\hline EOC5 & LIVE & LIVE & LIVE & LIVE & LIVE & LIVE \\
\hline EOC6 & LIVE & LIVE & LIVE & LIVE & LIVE & LIVE \\
\hline IOP1 & LIVE & LIVE & LIVE & LIVE & LIVE & LIVE \\
\hline IOP2 & LIVE & LIVE & LIVE & LIVE & LIVE & LIVE \\
\hline IOP3 & LIVE & LIVE & LIVE & LIVE & LIVE & LIVE \\
\hline IOP4 & LIVE & LIVE & LIVE & LIVE & LIVE & LIVE \\
\hline JTD1 & LIVE & LIVE & LIVE & LIVE & LIVE & LIVE \\
\hline LOR1 & LIVE & LIVE & LIVE & LIVE & LIVE & LIVE \\
\hline
\end{tabular}




\begin{tabular}{|c|c|c|c|c|c|c|}
\hline $\begin{array}{l}\text { Mutatio } \\
\text { n Name }\end{array}$ & $\begin{array}{l}\text { Rates_1 } \\
\text { BC }\end{array}$ & $\begin{array}{l}\text { Rates_1 } \\
\text { EC }\end{array}$ & $\begin{array}{l}\text { Rates_1 } \\
\text { _PW }\end{array}$ & $\begin{array}{l}\text { Rates_1_- } \\
\text { BC_Ann }\end{array}$ & $\begin{array}{l}\text { Rates_1_- } \\
\text { EC_Ann }\end{array}$ & $\begin{array}{l}\text { Rates_1_ } \\
\text { PW_Ann }\end{array}$ \\
\hline LOR2 & LIVE & LIVE & LIVE & LIVE & LIVE & LIVE \\
\hline LOR3 & LIVE & LIVE & LIVE & LIVE & LIVE & LIVE \\
\hline LOR4 & LIVE & LIVE & LIVE & LIVE & LIVE & LIVE \\
\hline PRV1 & KILLED & KILLED & KILLED & KILLED & KILLED & KILLED \\
\hline UOI1 & KILLED & KILLED & KILLED & KILLED & KILLED & KILLED \\
\hline UOI10 & KILLED & LIVE & KILLED & KILLED & KILLED & KILLED \\
\hline UOI11 & LIVE & LIVE & LIVE & LIVE & LIVE & LIVE \\
\hline UOI13 & KILLED & KILLED & KILLED & KILLED & KILLED & KILLED \\
\hline UOI14 & LIVE & LIVE & LIVE & LIVE & LIVE & LIVE \\
\hline UOI16 & LIVE & LIVE & LIVE & LIVE & LIVE & LIVE \\
\hline UOI17 & LIVE & LIVE & LIVE & LIVE & LIVE & LIVE \\
\hline UOI19 & KILLED & KILLED & KILLED & KILLED & KILLED & KILLED \\
\hline UOI2 & LIVE & LIVE & LIVE & LIVE & LIVE & LIVE \\
\hline UOI20 & LIVE & LIVE & LIVE & LIVE & LIVE & LIVE \\
\hline UOI21 & KILLED & KILLED & KILLED & KILLED & KILLED & KILLED \\
\hline UOI22 & KILLED & KILLED & KILLED & KILLED & KILLED & KILLED \\
\hline UOI23 & LIVE & LIVE & LIVE & LIVE & LIVE & LIVE \\
\hline UOI25 & KILLED & KILLED & KILLED & KILLED & KILLED & KILLED \\
\hline UOI26 & LIVE & LIVE & LIVE & LIVE & LIVE & LIVE \\
\hline UOI28 & KILLED & KILLED & KILLED & KILLED & KILLED & KILLED \\
\hline UOI29 & LIVE & LIVE & LIVE & LIVE & LIVE & LIVE \\
\hline UOI31 & KILLED & KILLED & KILLED & KILLED & KILLED & KILLED \\
\hline UOI32 & LIVE & LIVE & LIVE & LIVE & LIVE & LIVE \\
\hline UOI34 & LIVE & LIVE & LIVE & LIVE & LIVE & LIVE \\
\hline UOI35 & LIVE & LIVE & LIVE & LIVE & LIVE & LIVE \\
\hline UOI36 & KILLED & KILLED & KILLED & KILLED & KILLED & KILLED \\
\hline UOI37 & LIVE & LIVE & LIVE & LIVE & LIVE & LIVE \\
\hline UOI38 & LIVE & LIVE & LIVE & LIVE & LIVE & LIVE \\
\hline UOI39 & KILLED & KILLED & KILLED & KILLED & KILLED & KILLED \\
\hline UOI4 & LIVE & LIVE & LIVE & LIVE & LIVE & LIVE \\
\hline UOI40 & KILLED & KILLED & KILLED & KILLED & KILLED & KILLED \\
\hline UOI41 & KILLED & KILLED & KILLED & KILLED & KILLED & KILLED \\
\hline UOI42 & KILLED & KILLED & KILLED & KILLED & KILLED & KILLED \\
\hline UOI43 & KILLED & KILLED & KILLED & KILLED & KILLED & KILLED \\
\hline UOI44 & KILLED & KILLED & KILLED & KILLED & KILLED & KILLED \\
\hline UOI45 & LIVE & LIVE & LIVE & LIVE & LIVE & LIVE \\
\hline UOI46 & LIVE & LIVE & LIVE & LIVE & LIVE & LIVE \\
\hline UOI47 & KILLED & KILLED & KILLED & KILLED & KILLED & KILLED \\
\hline UOI48 & LIVE & LIVE & LIVE & LIVE & LIVE & LIVE \\
\hline UOI49 & LIVE & LIVE & LIVE & LIVE & LIVE & LIVE \\
\hline
\end{tabular}




\begin{tabular}{|l|l|l|l|l|l|l|}
\hline $\begin{array}{l}\text { Mutatio } \\
\text { n Name }\end{array}$ & $\begin{array}{l}\text { Rates_1 } \\
\text { BC }\end{array}$ & $\begin{array}{l}\text { Rates_1 } \\
\text { EC }\end{array}$ & $\begin{array}{l}\text { Rates_1 } \\
\text { PW }\end{array}$ & $\begin{array}{l}\text { Rates_1_ } \\
\text { BC_Ann }\end{array}$ & $\begin{array}{l}\text { Rates_1_ } \\
\text { EC_Ann }\end{array}$ & $\begin{array}{l}\text { Rates_1_ } \\
\text { PW_Ann }\end{array}$ \\
\hline UOI5 & LIVE & LIVE & LIVE & LIVE & LIVE & LIVE \\
\hline UOI50 & LIVE & LIVE & LIVE & LIVE & LIVE & LIVE \\
\hline UOI51 & KILLED & KILLED & KILLED & KILLED & KILLED & KILLED \\
\hline UOI52 & KILLED & KILLED & KILLED & KILLED & KILLED & KILLED \\
\hline UOI53 & KILLED & KILLED & KILLED & KILLED & KILLED & KILLED \\
\hline UOI7 & LIVE & LIVE & LIVE & LIVE & LIVE & LIVE \\
\hline UOI8 & LIVE & LIVE & LIVE & LIVE & LIVE & LIVE \\
\hline UOR1 & LIVE & LIVE & LIVE & LIVE & LIVE & LIVE \\
\hline UOR2 & KILLED & KILLED & KILLED & KILLED & KILLED & KILLED \\
\hline UOR3 & KILLED & KILLED & KILLED & KILLED & KILLED & KILLED \\
\hline
\end{tabular}

Table 28 - List of all mutants for the Rates_1 case study

\section{A.4 Live Mutants}

\section{AOR3}

Original Code

Mutated Code

return (averageRate / divisor);

return (averageRate ${ }^{*}$ divisor);

\begin{tabular}{|ll|}
\hline ASR2 & Mutated Code \\
\hline Original Code & averageRate $=$ rate; \\
\hline averageRate $+=$ rate; & \\
\hline
\end{tabular}

AOR3 and ASR2 did not get killed by any of the test suite in the first approach. The reason is because we do not use more than one conversion rate in this approach. In AOR3 the value of the 'divisor' variable is always 1 which makes no difference in either the division or multiplication. The code in the ASR2 mutant is only executed once which make original and mutated version behave similarly.

\section{EOC1}

Original Code

Mutated Code

if (secCurrency == "USD")

if (secCurrency.Equals("USD")) 


\section{EOC2}

Original Code Mutated Code

if (rates $==$ null $\mid$ rates. Count $==0$ ) _logger.Warn(string.Format("No conversion rates found for account $\{0\}$, this.D(rAcctNbr));

if (rates. Equals(null) | rates. Count == 0) _logger.Warn(string.Format("No conversion rates found for account $\{0\} "$, this.DIrAcctNbr));

\section{EOC3}

Original Code Mutated Code

if (rates == null $\mid$ rates. Count $==0$ ) _logger.Warn(string.Format("No conversion rates found for account $\{0\}$ ", this.D(rAcctNbr)); if (rates == null | rates.Count.Equals(0)) _logger.Warn(string.Format("No conversion rates found for account $\{0\} "$, this.DirAcctNbr));

\section{EOC4}

Original Code Mutated Code

if (accountCurrency == "USD") if (accountCurrency.Equals("USD"))

\section{EOC5}

Original Code Mutated Code

if (rates $==$ null $\mid$ rates. Count $==0$ ) if (rates. Equals(null) | rates. Count == 0)

\section{EOC6}

Original Code Mutated Code

if (rates $==$ null $\mid$ rates. Count $==0$ ) if (rates $==$ null $\mid$ rates.Count.Equals(0))

EOC1 to EOC6 involve changing the '==' to 'Equals'. Without going any deeper in into the meanings of these operator, they general behave the same which explains mutants involving such changes do not get killed.

\begin{tabular}{|ll|}
\hline IOP1 & Mutated Code \\
\hline Original Code & //pull convertion rates for this account \\
\hline base.Initialize(xmIDoc); & $\begin{array}{l}\text { XmINodeList rates = } \\
\text { xmlDoc.SelectNodes("AccountData/Rate"); } \\
\text { //pull convertion rates for this account }\end{array}$ \\
$\begin{array}{l}\text { XmINodeList rates = } \\
\text { xmIDoc.SelectNodes("AccountData/Rate"); }\end{array}$ & base.Initialize(xmIDoc); \\
\hline
\end{tabular}




\begin{tabular}{|c|c|}
\hline Original Code & Mutated Code \\
\hline base.Initialize(xmIDoc); & //pull convertion rates for this account \\
\hline //pull convertion rates for this account & $\begin{array}{l}\text { XmlNodeList rates = } \\
\text { xmIDoc.SelectNodes("AccountData/Rate"); }\end{array}$ \\
\hline $\begin{array}{l}\text { XmINodeList rates = } \\
\text { xmIDoc.SelectNodes("AccountData/Rate"); } \\
\text { if(rates != null) } \\
\quad \text { rates = new Dictionary<string, double }>() ;\end{array}$ & $\begin{array}{l}\quad \text { if(rates } !=\text { null }) \\
\text { rates = new Dictionary<string, double }>() \text {; } \\
\text { base.Initialize }(x m \mid D o c)\end{array}$ \\
\hline
\end{tabular}

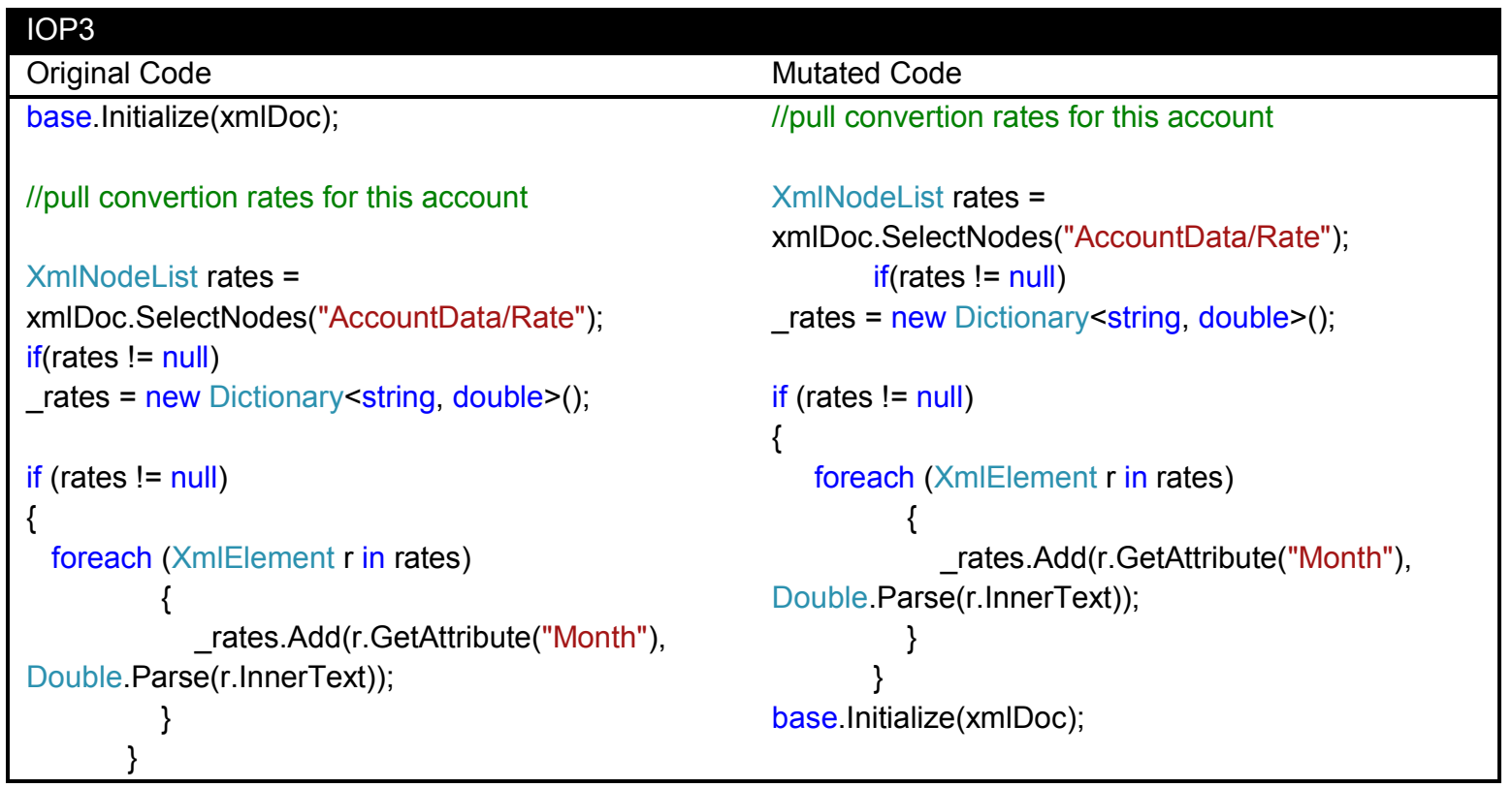

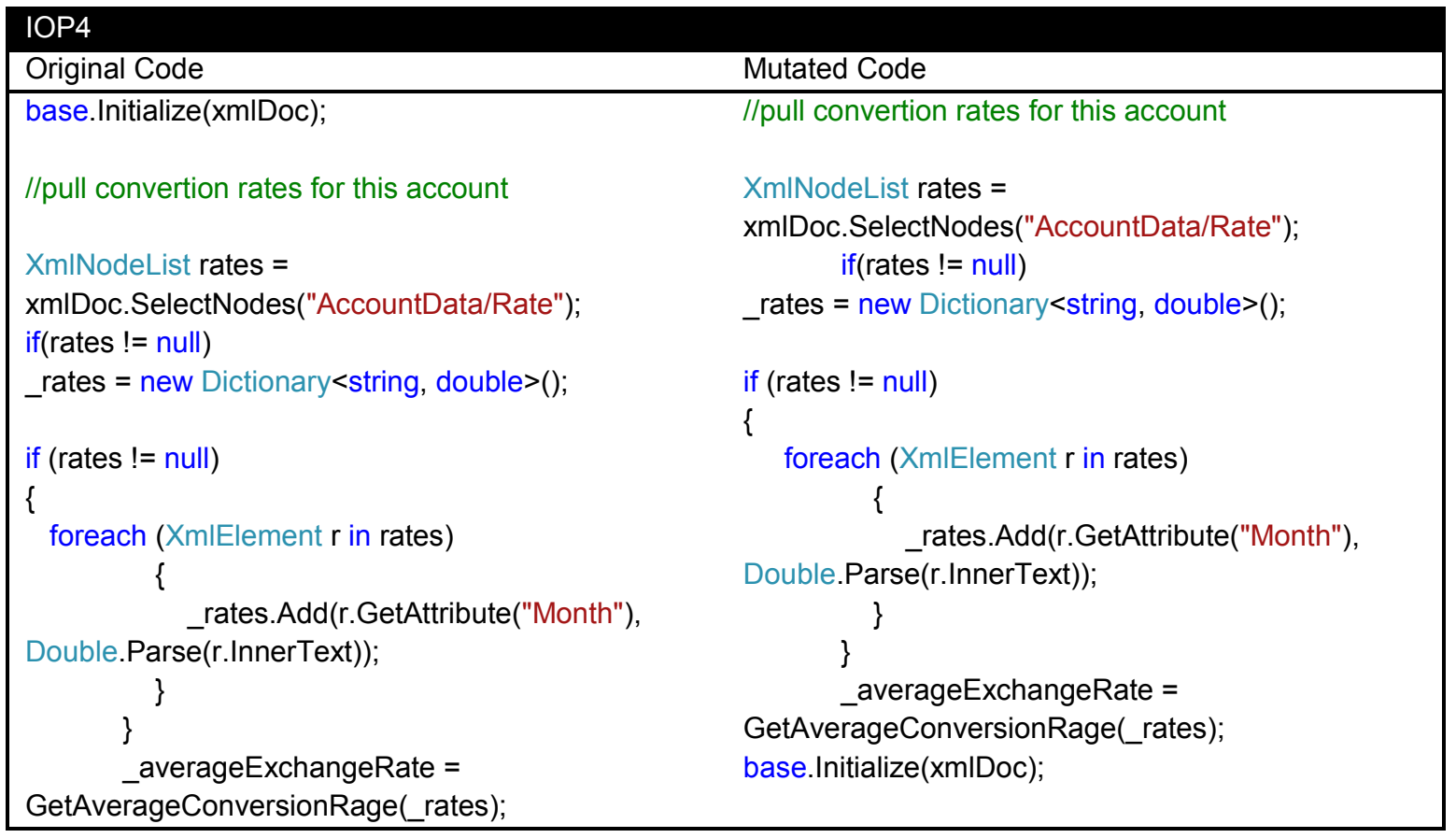


IOP1 to IOP4 involve moving a call to a parent method (base.Initialize(xmlDoc) in this case). This call has no impact on the logic because it merely involves reading values from the 'xmlDoc' variable which are used in other areas of the system under test.

Therefore, the position of this call does not impact the logic we are studying and hence mutants remain live.

\begin{tabular}{|ll|}
\hline JTD1 & Mutated Code \\
\hline Original Code & TransformedXmIData = transformedXml.OuterXml; \\
\hline $\begin{array}{l}\text { this. TransformedXmIData = } \\
\text { transformedXml.OuterXml; }\end{array}$ & \\
\hline
\end{tabular}

JDT1 involves removing the 'this' operator from the property TransfomedXmlData.

Referencing a property by either using its name directly or preceding it with the 'this' operator is the same.

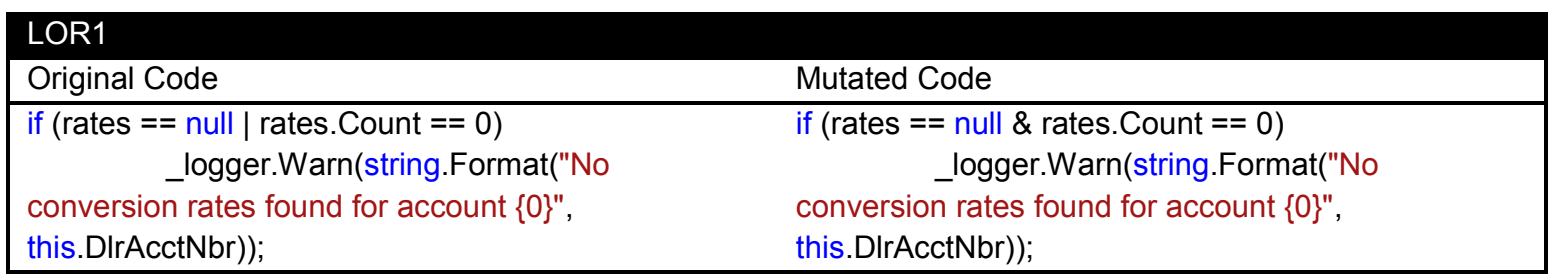

\begin{tabular}{|c|c|}
\hline LOR2 & \\
\hline Original Code & Mutated Code \\
\hline if $($ rates $==$ null $\mid$ rates. Count $==0$ ) & if $($ rates $==$ null $\wedge$ rates. Count $==0)$ \\
\hline _logger.Warn(string.Format("No & _logger.Warn(string.Format("No \\
\hline conversion rates found for account $\{0\} "$, & conversion rates found for account $\{0\} "$, \\
\hline this.DlrAcctNbr)); & this.DIrAcctNbr)); \\
\hline
\end{tabular}

\begin{tabular}{|c|c|}
\hline Original Code & Mutated Code \\
\hline $\begin{aligned} \text { if }(\text { rates }= & =\text { null } \mid \text { rates. Count }==0) \\
& \text { return } 1.0 ;\end{aligned}$ & $\begin{aligned} \text { if }(\text { rates }= & =\text { null } \& \text { rates. Count }==0) \\
& \text { return } 1.0 ;\end{aligned}$ \\
\hline
\end{tabular}

\begin{tabular}{|ll|}
\hline LOR4 & Mutated Code \\
\hline Original Code & if (rates $==$ null ${ }^{\wedge}$ rates. Count $\left.==0\right)$ \\
\hline $\begin{array}{l}\text { if }(\text { rates }==\text { null } \mid \text { rates. Count }==0) \\
\text { return } 1.0 ;\end{array}$ & return \\
\hline
\end{tabular}

LOR1 and LOR2 are in the ConvertUSDSecurity method and LOR3 and LOR4 are in the GetAverageConversionRate metho. In these methods, the 'rates' variable is passed fully 
initialized already which makes 'rates $==$ null' always false. Also, in this approach we always have one conversion rate which makes 'rates.Count $==0$ ' always false. Therfore, replacing '|' with '\&' (LOR1 and LOR3) or '^’ (XOR operator in LOR2 and) will always return false when both Boolean values are similar (false in this case). This explains why

LOR1 to LOR4 remain live.

\section{UOI11}

Original Code Mutated Code

if (rates.ContainsKey(monthOfSecurity)) if (rates.ContainsKey(monthOfSecurity)) exchangeRate $=$ rates[monthOfSecurity]; $\quad$ exchangeRate $=+$ rates[monthOfSecurity];

\section{UOI14}

Original Code

Mutated Code

averageRate += rate; averageRate $+=+$ rate;

\section{UOI16}

Original Code

Mutated Code

double val = 0.0; double val = -0.0 ;

\section{UOI17}

Original Code

Mutated Code

double val $=0.0$;

double val $=+0.0$;

\section{UOI2}

Original Code

_averageExchangeRate $=$

Mutated Code

GetAverageConversionRage(_rates); _averageExchangeRate $=$ +GetAverageConversionRage(_rates);

\section{UOI20}

Original Code

Mutated Code

double exchangeRate $=1$;

double exchangeRate $=+1$;

\section{UOI23}

Original Code

Mutated Code

double newBookValue $=$

Double.Parse(bookValue.InnerText) *

averageExchangeRate;

double newBookValue $=$

+Double.Parse(bookValue.InnerText) *

_averageExchangeRate;

\section{UOI26}

Original Code

Mutated Code

double newBookValue $=$

Double.Parse(bookValue.InnerText) *

double newBookValue $=$

Double.Parse(bookValue.InnerText) *

averageExchangeRate;

+_averageExchangeRate; 


\section{UOI29}

Original Code

double newMarketValue $=$

Double.Parse(marketValue.InnerText) *

exchangeRate;
Mutated Code

double newMarketValue $=$

+Double.Parse(marketValue.InnerText) * exchangeRate;

\section{UOI32}

Original Code

Mutated Code

double newMarketValue $=$

double newMarketValue $=$

Double.Parse(marketValue.InnerText) *

Double.Parse(marketValue.InnerText) *

exchangeRate;

+exchangeRate;

UOI11 to UOI32 all involve adding the unary operator '+', except UOI16 which uses the

'-' unary operator on value of 0 and produces no impact, which returns the value of the

operand regardless of whether it is positive or negative. That is, +1 returns 1 and $+(-1)$

returns -1 as per [14].

\section{UOI34}

Original Code

Mutated Code

double averageRate $=0$; double averageRate $=-0$;

\section{UOI35}

Original Code Mutated Code

double averageRate $=0 ; \quad$ double averageRate $=+0$;

\section{UOI37}

Original Code

Mutated Code

int divisor $=0$; int divisor $=-0$;

\section{UOI38}

Original Code

Mutated Code

int divisor $=0$

int divisor $=+0$;

UOI34 to UOI38 above use the unary operators '+' and '-' on a value of zero which has absolutely no impact on its value. Therefore, these mutants remain live

\section{UOI4}

Original Code

Mutated Code

if (sec.SelectSingleNode("IncomeEarned") != null)

val $=$

if (sec.SelectSingleNode("IncomeEarned") != null)

Double.Parse(sec.SelectSingleNode("IncomeEarned val $=$ -

").InnerText);

Double.Parse(sec.SelectSingleNode("IncomeEarned ").InnerText); 
UOI4 uses the unary operator on the 'IncomeEarned' values which is not part of our logic in this case study. Therefore, this mutant remains live.

\begin{tabular}{|ll|}
\hline UOI45 & Mutated Code \\
\hline Original Code & if (!sec.SelectSingleNode("IncomeEarned") != null) \\
\hline if (sec.SelectSingleNode("IncomeEarned")!= null) & val = \\
val = & $\begin{array}{l}\text { Double.Parse(sec.SelectSingleNode("IncomeEarned } \\
\text { Double.Parse(sec.SelectSingleNode("IncomeEarned } \\
\text { ").InnerText); }\end{array}$ \\
\hline
\end{tabular}

\begin{tabular}{|ll|}
\hline UOI46 & \\
\hline Original Code & Mutated Code \\
\hline if (sec.SelectSingleNode("CapitalGain")!= null) & if (!sec.SelectSingleNode("CapitalGain") != null) \\
val = & val = \\
Double.Parse(sec.SelectSingleNode("CapitalGain").I & Double.Parse(sec.SelectSingleNode("CapitalGain").I \\
nnerText); & nnerText); \\
\hline
\end{tabular}

UOI45 and UOI46 change logic around getting values for the IncomeEarend and CapitalGain variables which are not part of the logic in this case study. Therefore, these mutants remain live.

\begin{tabular}{|c|c|}
\hline \multicolumn{2}{|l|}{ UOI48 } \\
\hline Original Code & Mutated Code \\
\hline if (!averageRateSet) & if (!(!averageRateSet)) \\
\hline \multicolumn{2}{|l|}{ UOI49 } \\
\hline Original Code & Mutated Code \\
\hline $\begin{array}{l}\text { if } \\
\text { (transformedXml.SelectSingleNode("/TaxSlip/Accou } \\
\text { ntData/AverageExchangeRate") != null) }\end{array}$ & $\begin{array}{l}\text { if } \\
\text { (!(transformedXml.SelectSingleNode("/TaxSlip/Acco } \\
\text { untData/AverageExchangeRate") != null)) }\end{array}$ \\
\hline $\begin{array}{l}\text { transformedXml.SelectSingleNode("/TaxSlip/Accoun } \\
\text { tData/AverageExchangeRate").InnerText = } \\
\text { _averageExchangeRate.ToString(); }\end{array}$ & $\begin{array}{l}\text { transformedXml.SelectSingleNode("/TaxSlip/Accoun } \\
\text { tData/AverageExchangeRate").InnerText = } \\
\text { _averageExchangeRate.ToString(); }\end{array}$ \\
\hline
\end{tabular}

UOI48 and UOI49 touch the logic for setting the AvergaExchangeRate element in the XML data. The mutant results in not setting this value which comes from the precalculated average rate. However, this value is set in the XML for later processing components in the system which is not part of this case study. But for the purposes of 
this case study, whether this XML is set or not, it has no impact on it. Therefore, these two mutants remain live.

\begin{tabular}{|c|c|}
\hline Original Code & Mutated Code \\
\hline $\begin{array}{l}\text { if (sec.SelectSingleNode("IncomeEarned") != null) } \\
\text { val = }\end{array}$ & $\begin{array}{l}\text { if (sec.SelectSingleNode("IncomeEarned") != null) } \\
\text { val = }\end{array}$ \\
\hline $\begin{array}{l}\text { Double.Parse(sec.SelectSingleNode("IncomeEarne } \\
\text { d").InnerText); }\end{array}$ & $\begin{array}{l}\text { +Double.Parse(sec.SelectSingleNode("IncomeEarne } \\
\text { d").InnerText); }\end{array}$ \\
\hline
\end{tabular}

As in UOI45 and UOI46, UOI5 has no impact on this case study because it deals with the IncomeEarned value which is outside the scope of this case study.

\begin{tabular}{|c|c|}
\hline Ol50 & \\
\hline Original Code & Mutated Code \\
\hline $\begin{array}{l}\text { if (rates == null | rates.Count }==0 \text { ) } \\
\quad \text { logger.Warn(string.Format("No } \\
\text { conversion rates found for account }\{0\} ", \\
\text { this.DlrAcctNbr)); }\end{array}$ & $\begin{array}{l}\text { if }(\text { ! }(\text { rates }==\text { null | rates.Count }==0) \text { ) } \\
\text { logger.Warn(string.Format("No } \\
\text { conversion rates found for account }\{0\} ", \\
\text { this.DlrAcctNbr)); }\end{array}$ \\
\hline
\end{tabular}

UOI50 executes the body of the if-statement whereas the original code does not.

However, the mutant does not cause any tests to fail because the change in behavior does not impact what the tests are looking for. Therefore, this mutant remains live.

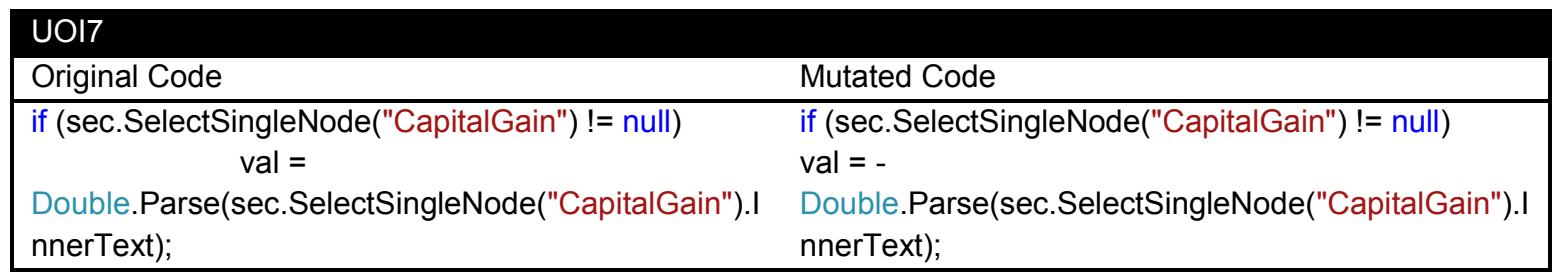

\begin{tabular}{ll} 
UOI8 & Mutated Code \\
\hline Original Code & if (sec.SelectSingleNode("CapitalGain") != null) \\
\hline $\begin{array}{ll}\text { if (sec.SelectSingleNode("CapitalGain")!= null) } \\
\text { val = }\end{array}$ & $\begin{array}{l}\text { val = } \\
\text { Double.Parse(sec.SelectSingleNode("CapitalGain"). }\end{array}$ \\
$\begin{array}{ll}\text { +Double.Parse(sec.SelectSingleNode("CapitalGain"). } \\
\text { InnerText); }\end{array}$
\end{tabular}

UOI7 and UOI8 introduce changes to the CapitalGain variable which is not in the scope of this case study.

\begin{tabular}{|ll|}
\hline UOR1 & \\
\hline Original Code & Mutated Code \\
\hline divisor++; & ++ divisor; \\
\hline
\end{tabular}


UOR1 changes a post-increment operator on the 'divisor' variable to a pre-increment one. Either way, this variable is not used in a calculation in the same line, therefore no impact is produced whether it is pre-incremented or post-incremented.

\section{A.5 Non-Uniform Mutants}

This section lists non-uniform mutants. These are mutants that were not killed, or left alive, by all tests suites.

\begin{tabular}{|ll|} 
UOI10 & Mutated Code \\
\hline $\begin{aligned} \text { if (rates. ContainsKey }(\text { monthOfSecurity) } \\
\text { exchangeRate }=\text { rates[monthOfSecurity]; }\end{aligned}$ & $\begin{array}{r}\text { if (rates.ContainsKey(monthOfSecurity)) } \\
\text { exchangeRate }=- \text { rates [monthOfSecurity]; }\end{array}$ \\
\hline
\end{tabular}




\section{Appendix B Currency Conversion Case Study (Second Approach)}

\section{B.1 Non-Annotated CP Specifications}

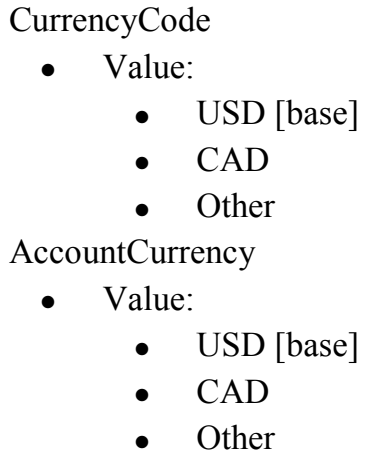

- Value:
- USD [base]
- $\mathrm{CAD}$
- Other

\section{Base-Choice Frames and Test Cases}

Frame 1:

CurrencyCode.Value.USD

AccountCurrency.Value.USD

SecurityMonthlyValue.IsMatchingMonthInRates

.True

Rates.Count.MoreThanOne

Frame 2:

CurrencyCode.Value.CAD

AccountCurrency.Value.USD

SecurityMonthlyValue.IsMatchingMonthInRates

.True

Rates.Count.MoreThanOne

Frame 3:

CurrencyCode.Value.Other

AccountCurrency.Value.USD

SecurityMonthlyValue.IsMatchingMonthInRates

.True

Rates.Count.MoreThanOne

\author{
SecurityMonthlyValue \\ - IsMatchingMonthInRates \\ - True [base] \\ - False \\ Rates \\ - Count \\ - Zero \\ - MoreThanOne [base]
}

Frame 4:

CurrencyCode.Value.USD

AccountCurrency.Value.CAD

SecurityMonthlyValue.IsMatchingMonthInRates

.True

Rates.Count.MoreThanOne

Frame 5:

CurrencyCode.Value.USD

AccountCurrency.Value.Other

SecurityMonthlyValue.IsMatchingMonthInRates

.True

Rates.Count.MoreThanOne

Frame 6:

CurrencyCode.Value.USD

AccountCurrency.Value.USD

SecurityMonthlyValue.IsMatchingMonthInRates

.False

Rates.Count.MoreThanOne 
Frame 7:

CurrencyCode.Value.USD

AccountCurrency.Value.USD
SecurityMonthlyValue.IsMatchingMonthInRates

.True

Rates.Count.Zero

\begin{tabular}{|c|c|c|c|}
\hline Test Case Name & Test Case Value & Expected output & Actual Output \\
\hline Rates_2_TC_1_1_BC & $\begin{array}{l}\text { USD, USD } \\
{[\text { Month=January, BV=10, MV=20] }} \\
{[[\text { Month=January, Rate }=1.5]} \\
\text { [Month=February, Rate }=1.3] \\
\text { [Month=March, Rate=1.2] } \\
\text { [Month=April, Rate1.8] }\end{array}$ & $\mathrm{BV}=14, \mathrm{MV}=30$ & Same \\
\hline Rates_2_TC_2_1_BC & $\begin{array}{l}\text { CAD,USD } \\
{[\text { Month=March, BV=10, MV=20] }} \\
{[\text { Month=January, Rate=1.5] }} \\
{[\text { Month=February, Rate }=1.3]} \\
{[\text { Month=March, Rate }=1.2]} \\
{[\text { Month=April, Rate1.8] }}\end{array}$ & $\mathrm{BV}=10, \mathrm{MV}=20$ & Same \\
\hline Rates_2_TC_3_1_BC & $\begin{array}{l}\text { AA, USD } \\
{[\text { Month=March, BV=10, MV=20] }} \\
{[\text { Month=January, Rate=1.5] }} \\
{[\text { Month=February, Rate }=1.3]} \\
{[\text { Month=March, Rate }=1.2]} \\
{[\text { Month=April, Rate1.8] }}\end{array}$ & Error & Same \\
\hline Rates_2_TC_4_1_BC & $\begin{array}{l}\text { USD,CAD } \\
{[\text { Month=March, BV=10, MV=20] }} \\
{[\text { Month=January, Rate=1.5] }} \\
{[\text { Month=February, Rate=1.3] }} \\
{[\text { Month=March, Rate=1.2] }} \\
{[\text { Month=April, Rate1.8] }}\end{array}$ & $\mathrm{BV}=10, \mathrm{MV}=24$ & Same \\
\hline Rates_2_TC_5_1_BC & $\begin{array}{l}\text { USD,BB } \\
{[\text { Month=JNURY, BV=10, MV=20] }} \\
\text { [Month=January, Rate=1.5] } \\
\text { [Month=February, Rate=1.3] } \\
\text { [Month=March, Rate=1.2] } \\
\text { [Month=April, Rate1.8] }\end{array}$ & Error & Same \\
\hline Rates_2_TC_6_1_BC & $\begin{array}{l}\text { USD, USD } \\
{[\text { Month=JUNRY, BV=10, MV=20] }} \\
{[\text { Month=January, Rate }=1.5]} \\
\text { [Month=February, Rate }=1.3] \\
\text { [Month=March, Rate=1.2] } \\
{[\text { Month=April, Rate1.8] }}\end{array}$ & $\mathrm{BV}=14, \mathrm{MV}=20$ & Same \\
\hline Rates_2_TC_7_1_BC & $\begin{array}{l}\text { USD, USD } \\
\text { [Month=January, BV=10, MV=20] }\end{array}$ & $\mathrm{BV}=10, \mathrm{MV}=20$ & Same \\
\hline
\end{tabular}

Table 29 - Base-Choice Test Cases (Non-Annotated Rates_2) 


\section{Each-Choice Frames and Test Cases}

Frame 1:

CurrencyCode.Value.Other

AccountCurrency.Value.Other

SecurityMonthlyValue.IsMatchingMonthInRates

.True

Rates.Count.Zero

Frame 2:

CurrencyCode.Value.CAD

AccountCurrency.Value.CAD

SecurityMonthlyValue.IsMatchingMonthInRates

.False

Rates.Count.MoreThanOne

\begin{tabular}{|l|l|l|l|}
\hline Test Case Name & Test Case Value & Expected output & Actual Output \\
\hline Rates_2_TC_1_1_EC & $\begin{array}{l}\text { AA,BB } \\
{[\text { Month=April, BV=10, MV=20] }}\end{array}$ & Error & Same \\
\hline Rates_2_TC_2_1_EC & $\begin{array}{l}\text { CAD, CAD } \\
{[\text { Month=AAApl, BV=10, MV=20] }} \\
{[[\text { Month=January, Rate=1.5] }} \\
{[\text { Month=February, Rate=1.3] }} \\
{[\text { Month=March, Rate=1.2] }} \\
{[\text { Month=April, Rate1.8] }}\end{array}$ & BV=10, MV=20 & Same \\
\hline Rates_2_TC_3_1_EC & $\begin{array}{l}\text { USD, USD } \\
{[\text { Month=AAApl, BV=10, MV=20] }}\end{array}$ & & \\
\end{tabular}

Table 30 - Each-Choice Test Cases (Non-Annotated Rates_2)
Frame 3:

CurrencyCode.Value.USD

SecurityMonthlyValue.IsMatchingMonthInRates

.False

Rates.Count.Zero
AccountCurrency.Value.USD 


\section{Pair-Wise Frames and Test Cases}

Frame 1:

CurrencyCode.Value.USD

AccountCurrency.Value.Other

SecurityMonthlyValue.IsMatchingMonthInRates

.False

Rates.Count.Zero

Frame 2:

CurrencyCode.Value.USD

AccountCurrency.Value.USD

SecurityMonthlyValue.IsMatchingMonthInRates

.True

Rates.Count.Zero

Frame 3:

CurrencyCode.Value.Other

AccountCurrency.Value.USD

SecurityMonthlyValue.IsMatchingMonthInRates .False

Rates.Count.MoreThanOne

Frame 4:

CurrencyCode.Value.CAD

AccountCurrency.Value.Other

SecurityMonthlyValue.IsMatchingMonthInRates

.True

Rates.Count.MoreThanOne

Frame 5:

CurrencyCode.Value.USD

AccountCurrency.Value.CAD

SecurityMonthlyValue.IsMatchingMonthInRates

.True

Rates.Count.MoreThanOne
Frame 6:

CurrencyCode.Value.Other

AccountCurrency.Value.Other

SecurityMonthlyValue.IsMatchingMonthInRates

.True

Rates.Count.Zero

Frame 7:

CurrencyCode.Value.Other

AccountCurrency.Value.CAD

SecurityMonthlyValue.IsMatchingMonthInRates .False

Rates.Count.MoreThanOne

Frame 8:

CurrencyCode.Value.CAD

AccountCurrency.Value.CAD

SecurityMonthlyValue.IsMatchingMonthInRates .True

Rates.Count.Zero

Frame 9:

CurrencyCode.Value.CAD

AccountCurrency.Value.USD

SecurityMonthlyValue.IsMatchingMonthInRates .False

Rates.Count.Zero 


\begin{tabular}{|c|c|c|c|}
\hline Test Case Name & Test Case Value & Expected output & Actual Output \\
\hline Rates_2_TC_1_1_PW & $\begin{array}{l}\text { USD,BB, } \\
\text { [Month=Maye, BV=10, MV=20] }\end{array}$ & Error & Same \\
\hline Rates_2_TC_2_1_PW & $\begin{array}{l}\text { USD, USD } \\
\text { [Month=April, BV=10, MV=20] }\end{array}$ & $\mathrm{BV}=10, \mathrm{MV}=20$ & Same \\
\hline Rates_2_TC_3_1_PW & $\begin{array}{l}\text { AA, USD } \\
{[\text { Month=JNURY, BV=10, MV=20] }} \\
{[\text { Month=January, Rate=1.5] }} \\
{[\text { Month=February, Rate }=1.3]} \\
{[\text { Month=March, Rate }=1.2]} \\
{[\text { Month=April, Rate1.8] }}\end{array}$ & Error & Same \\
\hline Rates_2_TC_4_1_PW & $\begin{array}{l}\text { CAD,BB } \\
{[\text { Month=March, BV=10, MV=20] }} \\
{[\text { Month=January, Rate=1.5] }} \\
{[\text { Month=February, Rate=1.3] }} \\
{[\text { Month=March, Rate }=1.2]} \\
{[\text { Month=April, Rate1.8] }}\end{array}$ & Error & Same \\
\hline Rates_2_TC_5_1_PW & $\begin{array}{l}\text { USD, CAD } \\
{[\text { Month=January, BV=10, MV=20] }} \\
{[[\text { Month=January, Rate }=1.5]} \\
{[\text { Month=February, Rate }=1.3]} \\
{[\text { Month=March, Rate }=1.2]} \\
{[\text { Month=April, Rate1.8] }}\end{array}$ & $\mathrm{BV}=10, \mathrm{MV}=30$ & Same \\
\hline Rates_2_TC_6_1_PW & $\begin{array}{l}\mathrm{AA}, \mathrm{BB} \\
{[\mathrm{Month}=\text { January, } \mathrm{BV}=12.35,} \\
\mathrm{MV}=22.30]\end{array}$ & Error & Same \\
\hline Rates_2_TC_7_1_PW & $\begin{array}{l}\text { AA, CAD } \\
{[\text { Month=JANURY, BV }=10, \mathrm{MV}=20]} \\
{[[\text { Month=January, Rate }=1.5]} \\
\text { [Month=February, Rate }=1.3] \\
{[\text { Month=March, Rate }=1.2]} \\
{[\text { Month=April, Rate1.8] }}\end{array}$ & Error & Same \\
\hline Rates_2_TC_8_1_PW & $\begin{array}{l}\text { CAD, CAD } \\
{[\text { Month=May, BV=10, MV=20] }}\end{array}$ & $\mathrm{BV}=10, \mathrm{MV}=20$ & Same \\
\hline Rates_2_TC_9_1_PW & $\begin{array}{l}\text { CAD, USD } \\
{[\text { Month=JANURY, BV=10, MV=20] }}\end{array}$ & $\mathrm{BV}=10, \mathrm{MV}=20$ & Same \\
\hline
\end{tabular}

Table 31 - Pair-Wise Test Cases (Non-Annotated Rates_2) 


\section{B.2 Annotated CP Specifications}

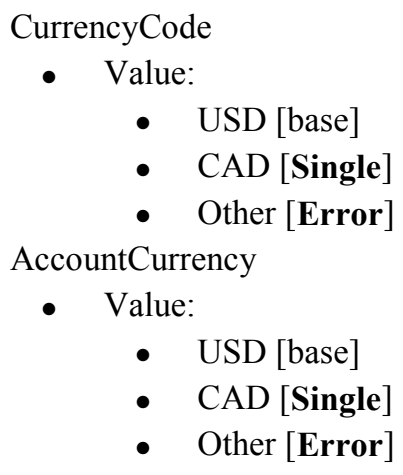

- Value:

- USD [base]

- CAD [Single]

- Other [Error]

AccountCurrency

- Value:

- USD [base]

- CAD [Single]

- Other [Error]

\section{Base-Choice Frames and Test Cases}

Frame 1:

CurrencyCode.Value.USD

AccountCurrency.Value.USD

SecurityMonthlyValue.IsMatchingMonthInRates

.True

Rates.Count.MoreThanOne

Frame 2:

CurrencyCode.Value.CAD

AccountCurrency.Value.USD

SecurityMonthlyValue.IsMatchingMonthInRates

.True

Rates.Count.MoreThanOne

Frame 3:

CurrencyCode.Value.USD

AccountCurrency.Value.USD
SecurityMonthlyValue

- IsMatchingMonthInRates

- True [base]

- False [Single]

Rates

- Count

- Zero [Single]

- MoreThanOne [base]
SecurityMonthlyValue.IsMatchingMonthInRates

.False

Rates.Count.MoreThanOne

Frame 4:

CurrencyCode.Value.USD

AccountCurrency.Value.USD

SecurityMonthlyValue.IsMatchingMonthInRates

.True

Rates.Count.Zero

Frame 5:

CurrencyCode.Value.Other

Frame 6:

AccountCurrency.Value.Other 


\begin{tabular}{|c|c|c|c|}
\hline Test Case Name & Test Case Value & Expected output & Actual Output \\
\hline Rates_2_TC_1_1_BC_Ann & $\begin{array}{l}\text { USD, USD } \\
{[\text { Month=April, BV=10, MV=20] }} \\
{[\text { Month=January, Rate }=1.5]} \\
{[\text { Month=February, Rate=1.3] }} \\
{[\text { Month=March, Rate=1.2] }} \\
{[\text { Month=April, Rate1.8] }}\end{array}$ & $\mathrm{BV}=14, \mathrm{MV}=36$ & Same \\
\hline Rates_2_TC_2_1_BC_Ann & $\begin{array}{l}\text { CAD, USD } \\
{[\text { Month }=\text { April, BV=10, MV=20] }} \\
{[\text { Month=January, Rate }=1.5]} \\
{[\text { Month=February, Rate }=1.3]} \\
{[\text { Month=March, Rate }=1.2]} \\
{[\text { Month=April, Rate1.8] }}\end{array}$ & $\mathrm{BV}=10, \mathrm{MV}=20$ & Same \\
\hline Rates_2_TC_3_1_BC_Ann & $\begin{array}{l}\text { USD, USD } \\
{[\text { Month=JUNRY, BV=10, MV=20] }} \\
\text { [Month=January, Rate=1.5] } \\
\text { [Month=February, Rate=1.3] } \\
\text { [Month=March, Rate=1.2] } \\
\text { [Month=April, Rate1.8] }\end{array}$ & $\mathrm{BV}=10, \mathrm{MV}=20$ & Same \\
\hline Rates_2_TC_4_1_BC_Ann & $\begin{array}{l}\text { USD, USD } \\
{[\text { Month=April, BV=10, MV=20] }}\end{array}$ & $\mathrm{BV}=10, \mathrm{MV}=20$ & Same \\
\hline Rates_2_TC_5_1_BC_Ann & $\begin{array}{l}\text { AA,USD } \\
\text { [Month=JNURY, BV=10, MV=20] } \\
\text { [Month=January, Rate=1.5] }\end{array}$ & Error & Same \\
\hline Rates_2_TC_6_1_BC_Ann & $\begin{array}{l}\text { USD, BB } \\
{[\text { Month=January, BV=10, MV=20] }} \\
\text { [Month=January, Rate=1.5] } \\
\text { [Month=February, Rate=1.3] } \\
\text { [Month=March, Rate=1.2] } \\
{[\text { Month=April, Rate1.8] }}\end{array}$ & Error & Same \\
\hline
\end{tabular}

Table 32 - Base-Choice Test Cases (Annotated Rates_2)

\section{Each-Choice Frames and Test Cases}

Frame 1:

CurrencyCode.Value.USD

AccountCurrency.Value.USD

SecurityMonthlyValue.IsMatchingMonthInRates

.True

Rates.Count.MoreThanOne

Frame 2:

CurrencyCode.Value.CAD
AccountCurrency.Value.USD

SecurityMonthlyValue.IsMatchingMonthInRates

.True

Rates.Count.Zero

Frame 3:

CurrencyCode.Value.USD

AccountCurrency.Value.CAD 
SecurityMonthlyValue.IsMatchingMonthInRates

.False

Rates.Count.MoreThanOne

Frame 4:

\begin{tabular}{|c|c|c|c|}
\hline Test Case Name & Test Case Value & Expected output & Actual Output \\
\hline Rates_2_TC_1_1_EC_Ann & $\begin{array}{l}\text { USD, USD } \\
{[\text { Month=February, BV=10, MV=20] }} \\
{[\text { Month=January, Rate=1.5] }} \\
{[\text { Month=February, Rate=1.3] }} \\
{[\text { Month=March, Rate=1.2] }} \\
{[\text { Month=April, Rate1.8] }}\end{array}$ & $\mathrm{BV}=10, \mathrm{MV}=26$ & Same \\
\hline Rates_2_TC_2_1_EC_Ann & $\begin{array}{l}\text { CAD, USD } \\
{[\text { Month=May, BV=10, MV=20] }}\end{array}$ & $\mathrm{BV}=10, \mathrm{MV}=20$ & Same \\
\hline Rates_2_TC_3_1_EC_Ann & $\begin{array}{l}\text { USD,CAD } \\
\text { [Month=JNURY, BV=10, MV=20] } \\
\text { [Month=January, Rate=1.5] } \\
\text { Month=January, Rate=1.5] } \\
\text { [Month=February, Rate=1.3] } \\
\text { [Month=March, Rate=1.2] } \\
\text { [Month=April, Rate1.8] }\end{array}$ & $\mathrm{BV}=14, \mathrm{MV}=20$ & Same \\
\hline Rates_2_TC_4_1_EC_Ann & $\begin{array}{l}\text { AA, USD } \\
{[\text { Month=January, BV=10, MV=20] }} \\
{[[\text { Month=January, Rate }=1.5]} \\
{[[\text { Month=January, Rate }=1.1]} \\
{[[\text { Month=January, Rate }=1.44]}\end{array}$ & Error & Same \\
\hline Rates_2_TC_5_1_EC_Ann & $\begin{array}{l}\text { USD, BB } \\
{[\text { Month=January, BV=10, MV=20] }} \\
{[[\text { Month=January, Rate }=1.5]} \\
{[[\text { Month=January, Rate }=1.1]} \\
{[[\text { Month=January, Rate }=1.44]}\end{array}$ & Error & Same \\
\hline
\end{tabular}

Table 33 - Each-Choice Test Cases (Annotated Rates_2)
AccountCurrency.Value.Other
CurrencyCode.Value.Other

Frame 5: 


\section{Pair-Wise Frames and Test Cases}

Frame 1:

CurrencyCode.Value.USD

Frame 3:

AccountCurrency.Value.USD

CurrencyCode.Value.CAD

SecurityMonthlyValue.IsMatchingMonthInRates

AccountCurrency.Value.USD

.True

SecurityMonthlyValue.IsMatchingMonthInRates

Rates.Count.MoreThanOne

.True

Rates.Count.Zero

Frame 2:

CurrencyCode.Value.USD

Frame 4:

AccountCurrency.Value.USD

CurrencyCode.Value.Other

SecurityMonthlyValue.IsMatchingMonthInRates

.False

Frame 5:

Rates.Count.MoreThanOne

AccountCurrency.Value.Other

\begin{tabular}{|c|c|c|c|}
\hline Test Case Name & Test Case Value & Expected output & Actual Output \\
\hline Rates_2_TC_1_1_PW_Ann & $\begin{array}{l}\text { USD, USD } \\
{[\text { Month=January, BV=10, MV=20] }} \\
{[\text { Month=January, Rate=1.5] }} \\
{[\text { Month=February, Rate=1.3] }} \\
{[\text { Month=March, Rate }=1.2]} \\
{[\text { Month=April, Rate1.8] }}\end{array}$ & $\mathrm{BV}=14, \mathrm{MV}=30$ & Same \\
\hline Rates_2_TC_2_1_PW_Ann & $\begin{array}{l}\text { USD, USD } \\
{[\text { Month }=\text { JNURY, BV=10, MV=20] }} \\
{[\text { Month=January, Rate }=1.5]} \\
{[\text { Month=February, Rate=1.3] }} \\
{[\text { Month=March, Rate }=1.2]} \\
{[\text { Month=April, Rate1.8] }}\end{array}$ & $\mathrm{BV}=14, \mathrm{MV}=20$ & Same \\
\hline Rates_2_TC_3_1_PW_Ann & $\begin{array}{l}\text { CAD, USD } \\
{[\text { Month }=\text { April, BV=10, MV=20] }}\end{array}$ & $\mathrm{BV}=10, \mathrm{MV}=20$ & Same \\
\hline Rates_2_TC_4_1_PW_Ann & $\begin{array}{l}\text { AA,USD } \\
{[\text { Month }=J \text { NURY, BV }=10, \mathrm{MV}=20]} \\
{[\text { Month=January, Rate }=1.5]}\end{array}$ & Error & Same \\
\hline Rates_2_TC_5_1_PW_Ann & $\begin{array}{l}\text { USD, BB } \\
{[\text { Month=January, BV=10, MV=20] }} \\
{[[\text { Month=January, Rate }=1.5]}\end{array}$ & Error & Same \\
\hline
\end{tabular}

Table 34 - Pair-Wise Test Cases (Annotated Rates_2) 


\section{B.3 List of Live and Killed Mutants}

\begin{tabular}{|c|c|c|c|c|c|c|}
\hline $\begin{array}{l}\text { Mutation } \\
\text { Name }\end{array}$ & $\begin{array}{l}\text { Rates_2_- } \\
\text { BC }\end{array}$ & $\begin{array}{l}\text { Rates_2_- } \\
\text { EC }\end{array}$ & $\begin{array}{l}\text { Rates_2_- } \\
\text { PW }\end{array}$ & $\begin{array}{l}\text { Rates_2 } \\
\text { BC_Ann }\end{array}$ & $\begin{array}{l}\text { Rates_2 } \\
\text { EC_Ann }\end{array}$ & $\begin{array}{l}\text { Rates_2 } \\
\text { PW_Ann }\end{array}$ \\
\hline AOR1 & KILLED & LIVE & LIVE & KILLED & KILLED & KILLED \\
\hline AOR2 & KILLED & LIVE & LIVE & KILLED & KILLED & KILLED \\
\hline AOR3 & KILLED & LIVE & LIVE & KILLED & KILLED & KILLED \\
\hline AOR4 & KILLED & LIVE & LIVE & KILLED & KILLED & KILLED \\
\hline ASR1 & KILLED & LIVE & LIVE & KILLED & KILLED & KILLED \\
\hline ASR2 & KILLED & LIVE & LIVE & KILLED & KILLED & KILLED \\
\hline ASR3 & KILLED & LIVE & LIVE & KILLED & KILLED & KILLED \\
\hline ASR4 & KILLED & LIVE & LIVE & KILLED & KILLED & KILLED \\
\hline EOC1 & LIVE & LIVE & LIVE & LIVE & LIVE & LIVE \\
\hline EOC2 & LIVE & LIVE & LIVE & LIVE & LIVE & LIVE \\
\hline EOC3 & LIVE & LIVE & LIVE & LIVE & LIVE & LIVE \\
\hline EOC4 & LIVE & LIVE & LIVE & LIVE & LIVE & LIVE \\
\hline EOC5 & LIVE & LIVE & LIVE & LIVE & LIVE & LIVE \\
\hline EOC6 & LIVE & LIVE & LIVE & LIVE & LIVE & LIVE \\
\hline IOP1 & LIVE & LIVE & LIVE & LIVE & LIVE & LIVE \\
\hline IOP2 & LIVE & LIVE & LIVE & LIVE & LIVE & LIVE \\
\hline IOP3 & LIVE & LIVE & LIVE & LIVE & LIVE & LIVE \\
\hline IOP4 & LIVE & LIVE & LIVE & LIVE & LIVE & LIVE \\
\hline JTD1 & LIVE & LIVE & LIVE & LIVE & LIVE & LIVE \\
\hline LOR1 & LIVE & LIVE & LIVE & LIVE & LIVE & LIVE \\
\hline LOR2 & LIVE & LIVE & LIVE & LIVE & LIVE & LIVE \\
\hline LOR3 & KILLED & KILLED & KILLED & LIVE & LIVE & LIVE \\
\hline LOR4 & LIVE & LIVE & LIVE & LIVE & LIVE & LIVE \\
\hline PRV1 & KILLED & LIVE & LIVE & KILLED & KILLED & KILLED \\
\hline UOI1 & KILLED & KILLED & KILLED & KILLED & KILLED & KILLED \\
\hline UOI10 & KILLED & LIVE & KILLED & KILLED & KILLED & KILLED \\
\hline UOI11 & LIVE & LIVE & LIVE & LIVE & LIVE & LIVE \\
\hline UOI13 & KILLED & LIVE & LIVE & KILLED & KILLED & KILLED \\
\hline UOI14 & LIVE & LIVE & LIVE & LIVE & LIVE & LIVE \\
\hline UOI16 & LIVE & LIVE & LIVE & LIVE & LIVE & LIVE \\
\hline UOI17 & LIVE & LIVE & LIVE & LIVE & LIVE & LIVE \\
\hline UOI19 & KILLED & KILLED & KILLED & KILLED & KILLED & KILLED \\
\hline UOI2 & LIVE & LIVE & LIVE & LIVE & LIVE & LIVE \\
\hline UOI20 & LIVE & LIVE & LIVE & LIVE & LIVE & LIVE \\
\hline UOI21 & KILLED & KILLED & KILLED & KILLED & KILLED & KILLED \\
\hline UOI22 & KILLED & KILLED & KILLED & KILLED & KILLED & KILLED \\
\hline UOI23 & LIVE & LIVE & LIVE & LIVE & LIVE & LIVE \\
\hline UOI25 & KILLED & KILLED & KILLED & KILLED & KILLED & KILLED \\
\hline
\end{tabular}




\begin{tabular}{|c|c|c|c|c|c|c|}
\hline $\begin{array}{l}\text { Mutation } \\
\text { Name }\end{array}$ & $\begin{array}{l}\text { Rates_2_ } \\
\text { BC }\end{array}$ & $\begin{array}{l}\text { Rates_2_ } \\
\text { EC }\end{array}$ & $\begin{array}{l}\text { Rates_2_ } \\
\text { PW }\end{array}$ & $\begin{array}{l}\text { Rates_2_- } \\
\text { BC_Ann }\end{array}$ & $\begin{array}{l}\text { Rates_2 } \\
\text { EC_Ann }\end{array}$ & $\begin{array}{l}\text { Rates_2_- } \\
\text { PW_AAnn }\end{array}$ \\
\hline UOI26 & LIVE & LIVE & LIVE & LIVE & LIVE & LIVE \\
\hline UOI28 & KILLED & KILLED & KILLED & KILLED & KILLED & KILLED \\
\hline UOI29 & LIVE & LIVE & LIVE & LIVE & LIVE & LIVE \\
\hline UOI31 & KILLED & KILLED & KILLED & KILLED & KILLED & KILLED \\
\hline UOI32 & LIVE & LIVE & LIVE & LIVE & LIVE & LIVE \\
\hline UOI34 & LIVE & LIVE & LIVE & LIVE & LIVE & LIVE \\
\hline UOI35 & LIVE & LIVE & LIVE & LIVE & LIVE & LIVE \\
\hline UOI36 & KILLED & LIVE & LIVE & KILLED & KILLED & KILLED \\
\hline UOI37 & LIVE & LIVE & LIVE & LIVE & LIVE & LIVE \\
\hline UOI38 & LIVE & LIVE & LIVE & LIVE & LIVE & LIVE \\
\hline UOI39 & KILLED & LIVE & LIVE & KILLED & KILLED & KILLED \\
\hline UOI4 & LIVE & LIVE & LIVE & LIVE & LIVE & LIVE \\
\hline UOI40 & KILLED & KILLED & KILLED & KILLED & KILLED & KILLED \\
\hline UOI41 & KILLED & LIVE & KILLED & KILLED & KILLED & KILLED \\
\hline UOI42 & KILLED & LIVE & LIVE & KILLED & KILLED & KILLED \\
\hline UOI43 & KILLED & LIVE & KILLED & KILLED & KILLED & KILLED \\
\hline UOI44 & KILLED & LIVE & KILLED & KILLED & KILLED & KILLED \\
\hline UOI45 & LIVE & LIVE & LIVE & LIVE & LIVE & LIVE \\
\hline UOI46 & LIVE & LIVE & LIVE & LIVE & LIVE & LIVE \\
\hline UOI47 & KILLED & LIVE & KILLED & KILLED & KILLED & KILLED \\
\hline UOI48 & LIVE & LIVE & LIVE & LIVE & LIVE & LIVE \\
\hline UOI49 & LIVE & LIVE & LIVE & LIVE & LIVE & LIVE \\
\hline UOI5 & LIVE & LIVE & LIVE & LIVE & LIVE & LIVE \\
\hline UOI50 & LIVE & LIVE & LIVE & LIVE & LIVE & LIVE \\
\hline UOI51 & KILLED & KILLED & KILLED & KILLED & KILLED & KILLED \\
\hline UOI52 & KILLED & LIVE & KILLED & KILLED & KILLED & KILLED \\
\hline UOI53 & KILLED & KILLED & KILLED & KILLED & KILLED & KILLED \\
\hline UOI7 & LIVE & LIVE & LIVE & LIVE & LIVE & LIVE \\
\hline UOI8 & LIVE & LIVE & LIVE & LIVE & LIVE & LIVE \\
\hline UOR1 & LIVE & LIVE & LIVE & LIVE & LIVE & LIVE \\
\hline UOR2 & KILLED & LIVE & LIVE & KILLED & KILLED & KILLED \\
\hline UOR3 & KILLED & LIVE & LIVE & KILLED & KILLED & KILLED \\
\hline
\end{tabular}

Table 35 - List of all mutants for the Rates_2 case study

\section{B.4 Live Mutants}

In this approach, thirty eight (38) mutants could not be killed by any of the test suites.

These 38 mutants are a subset of the 41 mutants that remained live in Rates_1 case study. 
Therefore, we will not repeat the explanation given as to why these mutants remain live

because this has been done in section A. 4 above. The mutants in Table 36 used to be live uniform mutants in Rates_1 and now killed in Rates_2.

\begin{tabular}{|l|l|l|l|l|l|l|}
\hline $\begin{array}{l}\text { Mutation } \\
\text { Name }\end{array}$ & $\begin{array}{l}\text { Rates_2 } \\
\text { BC }\end{array}$ & $\begin{array}{l}\text { Rates_2_ } \\
\text { EC }\end{array}$ & $\begin{array}{l}\text { Rates_2_ } \\
\text { PW }\end{array}$ & $\begin{array}{l}\text { Rates_2_ } \\
\text { BC_Ann }\end{array}$ & $\begin{array}{l}\text { Rates_2_ } \\
\text { EC_Ann }\end{array}$ & $\begin{array}{l}\text { Rates_2_ } \\
\text { PW_Ann }\end{array}$ \\
\hline AOR3 & KILLED & LIVE & LIVE & KILLED & KILLED & KILLED \\
\hline ASR2 & KILLED & LIVE & LIVE & KILLED & KILLED & KILLED \\
\hline LOR3 & KILLED & KILLED & KILLED & LIVE & LIVE & LIVE \\
\hline
\end{tabular}

Table 36 - Subset of live mutants in Rates_1 killed in Rates_2

\section{B.5 Non-Uniform Mutants}

This section lists non-uniform mutants. These are mutants that were not killed, or left alive, by all tests suites.

\begin{tabular}{|ll|}
\hline AOR1 & \\
\hline Original Code & Mutated Code \\
\hline return (averageRate / divisor); & return (averageRate + divisor); \\
\hline
\end{tabular}

\begin{tabular}{|ll|}
\hline AOR2 & \\
\hline Original Code & Mutated Code \\
\hline return (averageRate / divisor); & return (averageRate - divisor); \\
\hline
\end{tabular}

\begin{tabular}{|ll|}
\hline AOR3 & \\
\hline Original Code & Mutated Code \\
\hline return (averageRate / divisor); & return (averageRate * divisor); \\
\hline
\end{tabular}

\begin{tabular}{|ll|}
\hline AOR4 & \\
\hline Original Code & Mutated Code \\
\hline return (averageRate / divisor); & return (averageRate \% divisor); \\
\hline
\end{tabular}

\begin{tabular}{|ll|}
\hline ASR1 & Mutated Code \\
\hline Original Code & averageRate $-=$ rate; \\
\hline averageRate $+=$ rate; & \\
\hline
\end{tabular}

\begin{tabular}{|ll|}
\hline ASR2 & Mutated Code \\
\hline Original Code & averageRate $=$ rate; \\
\hline averageRate $+=$ rate; & \\
\hline
\end{tabular}

\begin{tabular}{|ll|}
\hline ASR3 & Mutated Code \\
\hline Original Code & averageRate * rate; \\
\hline averageRate $+=$ rate; & \\
\hline
\end{tabular}




\section{ASR4}

Original Code

Mutated Code

averageRate += rate;

averageRate $/=$ rate;

\section{LOR3}

Original Code

Mutated Code

if $($ rates $==$ null $\mid$ rates. Count $==0$ )

if (rates $==$ null $\&$ rates. Count $==0$ )

return 1.0

return 1.0;

\section{PRV1}

Original Code

Mutated Code

averageRate += rate;

averageRate +=_averageExchangeRate;

\section{UOI10}

Original Code

if (rates.ContainsKey(monthOfSecurity))

Mutated Code

exchangeRate $=$ rates $[$ monthOfSecurity $]$;

if (rates.ContainsKey(monthOfSecurity))

exchangeRate = -rates[monthOfSecurity];

\section{UOI13}

Original Code

Mutated Code

divisor++

divisor++;

averageRate $+=$ rate;

averageRate $+=$-rate;

\section{UOI36}

Original Code

Mutated Code

double averageRate $=0$;

double averageRate $=\sim 0$;

\section{UOI39}

Original Code

Mutated Code

int divisor $=0$

int divisor $=\sim 0$;

\section{UOI41}

Original Code

//inside the Intialize method

if (rates != null)

Mutated Code

if (!(rates != null))

\section{UOI42}

Original Code

if

Mutated Code

(transformedXml.SelectSingleNode("TaxSlip/Accoun

(!(transformedXml.SelectSingleNode("TaxSlip/Accou

tData/Currency") != null)

ntData/Currency") != null))

accountCurrency $=$

accountCurrency =

transformedXml.SelectSingleNode("TaxSlip/Account transformedXml.SelectSingleNode("TaxSlip/Account

Data/Currency").InnerText;

Data/Currency").InnerText; 


\section{$\mathrm{UOI} 43$}

Original Code

Mutated Code

//inside the TransformAndSetValues method

if (!(securities != null))

if (securities != null)

\section{$\mathrm{UOI} 44$}

Original Code

Mutated Code

if (sec.SelectSingleNode("CurrencyCode") != null) secCurrency $=$

if (!(sec.SelectSingleNode("CurrencyCode") != null)) secCurrency $=$

sec.SelectSingleNode("CurrencyCode").InnerText; sec.SelectSingleNode("CurrencyCode").InnerText;

\section{UOI47}

Original Code

Mutated Code

if (secCurrency == "USD")

if (!(secCurrency == "USD"))

\section{UOI52}

Original Code

Mutated Code

if (accountCurrency == "USD")

if (!(accountCurrency == "USD"))

\section{UOR2}

Original Code

Mutated Code

divisor++;

--divisor:

\section{UOR3}

Original Code

Mutated Code

divisor++;

divisor--; 


\section{Appendix C Calculation Logic Case Study (First Approach)}

\section{C.1 Non-Annotated CP Specifications}

CountryOfSecurity

- Value

- DifferentForAll

- SameForAll

- Empty

- Missing

\section{AllValuesPresent}

- Value

- False [base]

- True

\section{Base-Choice Test Frames and Test Cases}

Frame 1:

AllValuesPresent.Value.False

CountriesForSecurities.Value.DifferentForAll

Frame 2:

AllValuesPresent.Value.True

CountriesForSecurities.Value.DifferentForAll
Frame 3:

AllValuesPresent.Value.False

CountriesForSecurities.Value.SameForAll

Frame 4:

AllValuesPresent.Value.False

CountriesForSecurities.Value.Empty

Frame 5:

AllValuesPresent.Value.False

CountriesForSecurities.Value.Missing 
Calc_1_TC_1_1_BC

\begin{tabular}{|c|c|c|c|c|c|c|c|c|c|c|c|c|c|c|}
\hline 总 & 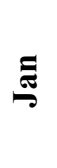 & $\stackrel{0}{0}$ & 竞 & $\overline{\bar{z}}$ & $\sum^{\vec{E}}$ & $\stackrel{\mathscr{\Xi}}{\Xi}$ & $\stackrel{\gtrsim}{\Xi}$ & 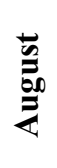 & $\overrightarrow{\vec{a}}$ & $\dot{0}$ & z & ڤ્ઁ & 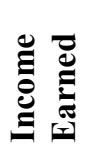 & 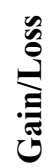 \\
\hline \multirow{2}{*}{ Canada } & & & & & & & 10 & 10 & 10 & 10 & 10 & 10 & \multirow[b]{2}{*}{25} & \multirow{2}{*}{22} \\
\hline & & & & & & & 45 & 34 & 22 & 34 & 87 & 77 & & \\
\hline \multirow{2}{*}{ Canada } & 14 & 14 & 14 & 14 & 14 & 14 & 14 & 14 & & & & & \multirow{2}{*}{11} & \multirow{2}{*}{22} \\
\hline & 14 & 54 & 55 & 45 & 5 & 44 & 71 & 20 & & & & & & \\
\hline \multirow{2}{*}{ Canada } & & & & 33 & 33 & 33 & 33 & 33 & 33 & & & & \multirow[b]{2}{*}{45} & \multirow{2}{*}{44} \\
\hline & & & & 30 & 45 & 66 & 55 & 78 & 79 & & & & & \\
\hline \multirow{2}{*}{ USA } & 25 & 25 & 25 & 25 & 25 & 25 & 25 & 25 & 25 & 25 & & & \multirow{2}{*}{44} & \multirow{2}{*}{55} \\
\hline & 23 & 44 & 24 & 65 & 43 & 24 & 86 & 54 & 22 & 52 & & & & \\
\hline \multirow{2}{*}{ USA } & & & & & & & & & & 45 & 45 & 45 & \multirow{2}{*}{41} & \multirow{2}{*}{42} \\
\hline & & & & & & & & & & 66 & 77 & 88 & & \\
\hline \multirow{2}{*}{ China } & 98 & 98 & 98 & 98 & 98 & 98 & 98 & & & & & & \multirow{2}{*}{23} & \multirow{2}{*}{11} \\
\hline & 45 & 45 & 25 & 78 & 56 & 44 & 57 & & & & & & & \\
\hline \multirow{2}{*}{ China } & & & 56 & 56 & 56 & & & & & & & & \multirow{2}{*}{61} & \multirow{2}{*}{47} \\
\hline & & & 77 & 54 & 36 & & & & & & & & & \\
\hline \multirow{2}{*}{ Mexico } & & & & & & & 23 & 23 & 23 & 23 & 23 & 23 & \multirow{2}{*}{45} & \multirow[b]{2}{*}{30} \\
\hline & & & & & & & 44 & 54 & 23 & 4 & 4 & 33 & & \\
\hline
\end{tabular}

\section{Expected Output:}

\begin{tabular}{|l|l|l|l|l|l|}
\hline $\begin{array}{l}\text { Grouping } \\
\text { Countries }\end{array}$ & $\begin{array}{l}\text { Maximum } \\
\text { Cost }\end{array}$ & $\begin{array}{l}\text { Maximum fair } \\
\text { market value }\end{array}$ & $\begin{array}{l}\text { Fair market } \\
\text { value at year } \\
\text { end }\end{array}$ & $\begin{array}{l}\text { Foreign income } \\
\text { earned or loss }\end{array}$ & $\begin{array}{l}\text { Capital } \\
\text { gain/loss }\end{array}$ \\
\hline CANADA & \multirow{2}{*}{226} & 171 & 77 & 81 & 88 \\
\cline { 1 - 4 } USA & 118 & 88 & 85 & 97 \\
\hline CHINA & 132 & 0 & 84 & 58 \\
\hline MEXICO & 54 & 33 & 45 & 30 \\
\hline
\end{tabular}

\section{Actual Output:}

\begin{tabular}{|l|l|l|l|l|l|}
\hline $\begin{array}{l}\text { Grouping } \\
\text { Countries }\end{array}$ & $\begin{array}{l}\text { Maximum } \\
\text { Cost }\end{array}$ & $\begin{array}{l}\text { Maximum fair } \\
\text { market value }\end{array}$ & $\begin{array}{l}\text { Fair market } \\
\text { value at year } \\
\text { end }\end{array}$ & $\begin{array}{l}\text { Foreign income } \\
\text { earned or loss }\end{array}$ & $\begin{array}{l}\text { Capital } \\
\text { gain/loss }\end{array}$ \\
\cline { 1 - 4 } CANADA & \multirow{2}{*}{226} & 171 & 77 & 81 & 88 \\
\cline { 1 - 4 } USA & 118 & 88 & 85 & 97 \\
\hline CHINA & 132 & 0 & 84 & 58 \\
\hline MEXICO & & 54 & 33 & 45 & 30 \\
\hline
\end{tabular}


Calc_1_TC_2_1_BC

\begin{tabular}{|c|c|c|c|c|c|c|c|c|c|c|c|c|c|c|}
\hline$\stackrel{\Xi}{\Xi}$ & 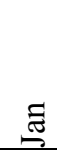 & $\begin{array}{l}0 \\
1\end{array}$ & $\begin{array}{l}\bar{D} \\
\overline{0} \\
\bar{z}\end{array}$ & $\overline{\bar{c}}$ & $\overrightarrow{\mathrm{I}}$ & $\Xi$ & $\vec{\Xi}$ & $\begin{array}{l}\overrightarrow{0} \\
\overrightarrow{0} \\
\stackrel{50}{Z}\end{array}$ & 䒕 & $\tilde{0}$ & $\vec{z}$ & 巳̊ & 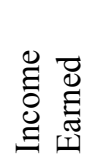 & 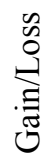 \\
\hline \multirow{2}{*}{ Canada } & 10 & 10 & 10 & 10 & 10 & 10 & 10 & 10 & 10 & 10 & 10 & 10 & \multirow{2}{*}{60} & \multirow{2}{*}{30} \\
\hline & 21 & 22 & 23 & 25 & 22 & 40 & 45 & 34 & 22 & 34 & 87 & 77 & & \\
\hline \multirow{2}{*}{ Canada } & 14 & 14 & 14 & 14 & 14 & 14 & 14 & 14 & 14 & 14 & 14 & 14 & \multirow{2}{*}{40} & \multirow{2}{*}{50} \\
\hline & 14 & 54 & 55 & 45 & 5 & 44 & 71 & 20 & 22 & 24 & 22 & 24 & & \\
\hline \multirow{2}{*}{ USA } & 25 & 25 & 25 & 25 & 25 & 25 & 25 & 25 & 25 & 25 & 25 & 25 & \multirow{2}{*}{45} & \multirow{2}{*}{42} \\
\hline & 23 & 44 & 24 & 65 & 43 & 24 & 86 & 54 & 22 & 52 & 50 & 50 & & \\
\hline \multirow{2}{*}{ USA } & 45 & 45 & 45 & 45 & 45 & 45 & 45 & 45 & 45 & 45 & 45 & 45 & \multirow{2}{*}{65} & \multirow{2}{*}{60} \\
\hline & 45 & 46 & 51 & 53 & 58 & 55 & 59 & 60 & 65 & 66 & 77 & 88 & & \\
\hline \multirow{2}{*}{ China } & 98 & 98 & 98 & 98 & 98 & 98 & 98 & 98 & 98 & 98 & 98 & 98 & \multirow{2}{*}{30} & \multirow{2}{*}{65} \\
\hline & 45 & 45 & 25 & 78 & 56 & 44 & 57 & 55 & 56 & 54 & 53 & 51 & & \\
\hline \multirow{2}{*}{ China } & 56 & 56 & 56 & 56 & 56 & 56 & 56 & 56 & 56 & 56 & 56 & 56 & \multirow{2}{*}{89} & \multirow{2}{*}{12} \\
\hline & 78 & 77 & 77 & 54 & 36 & 36 & 36 & 36 & 36 & 36 & 36 & 36 & & \\
\hline \multirow{2}{*}{ Mexico } & 23 & 23 & 23 & 23 & 23 & 23 & 23 & 23 & 23 & 23 & 23 & 23 & \multirow{2}{*}{45} & \multirow{2}{*}{45} \\
\hline & 44 & 44 & 44 & 44 & 44 & 44 & 44 & 54 & 23 & 4 & 4 & 33 & & \\
\hline
\end{tabular}

\section{Expected Output:}

\begin{tabular}{|l|l|l|l|l|l|}
\hline $\begin{array}{l}\text { Grouping } \\
\text { Countries }\end{array}$ & $\begin{array}{l}\text { Maximum } \\
\text { Cost }\end{array}$ & $\begin{array}{l}\text { Maximum fair } \\
\text { market value }\end{array}$ & $\begin{array}{l}\text { Fair market } \\
\text { value at year end }\end{array}$ & $\begin{array}{l}\text { Foreign income } \\
\text { earned or loss }\end{array}$ & $\begin{array}{l}\text { Capital } \\
\text { gain/loss }\end{array}$ \\
\hline \multirow{3}{*}{ CANADA } & \multirow{3}{*}{271} & 116 & 101 & 100 & 80 \\
\cline { 1 - 5 } USA & 145 & 138 & 110 & 102 \\
\cline { 3 - 5 } CHINA & 132 & 87 & 119 & 77 \\
\cline { 3 - 5 } MEXICO & 54 & 33 & 45 & 45 \\
\hline
\end{tabular}

\section{Actual Output:}

\begin{tabular}{|c|c|c|c|c|c|}
\hline $\begin{array}{l}\text { Grouping } \\
\text { Countries }\end{array}$ & $\begin{array}{l}\text { Maximum } \\
\text { Cost }\end{array}$ & $\begin{array}{l}\text { Maximum fair } \\
\text { market value }\end{array}$ & $\begin{array}{l}\text { Fair market } \\
\text { value at year end }\end{array}$ & $\begin{array}{l}\text { Foreign income } \\
\text { earned or loss }\end{array}$ & $\begin{array}{l}\text { Capital } \\
\text { gain/loss }\end{array}$ \\
\hline CANADA & \multirow{4}{*}{271} & 116 & 101 & 100 & 80 \\
\hline USA & & 145 & 138 & 110 & 102 \\
\hline CHINA & & 132 & 87 & 119 & 77 \\
\hline MEXICO & & 54 & 33 & 45 & 45 \\
\hline
\end{tabular}


Calc_1_TC_3_1_BC

\begin{tabular}{|c|c|c|c|c|c|c|c|c|c|c|c|c|c|c|}
\hline 总 & ప్ & 迹 & $\begin{array}{l}\overline{\overline{0}} \\
\overline{\tilde{m}} \\
\bar{\Sigma}\end{array}$ & 妾 & $\sum_{\Sigma}^{\vec{m}}$ & $\Xi$ & 를 & 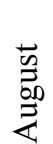 & 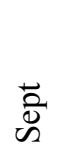 & $\tilde{0}$ & ? & $\stackrel{\mathscr{\nu}}{\triangle}$ & 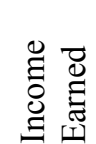 & $\begin{array}{l}\stackrel{0}{0} \\
\stackrel{0}{0} \\
0\end{array}$ \\
\hline \multirow{2}{*}{ Canada } & & & & & & & 10 & 10 & 10 & 10 & 10 & 10 & \multirow{2}{*}{25} & \multirow{2}{*}{22} \\
\hline & & & & & & & 45 & 34 & 22 & 34 & 87 & 77 & & \\
\hline \multirow{2}{*}{ Canada } & 14 & 14 & 14 & 14 & 14 & 14 & 14 & 14 & & & & & \multirow{2}{*}{11} & \multirow{2}{*}{22} \\
\hline & 14 & 54 & 55 & 45 & 5 & 44 & 71 & 20 & & & & & & \\
\hline \multirow{2}{*}{ Canada } & & & & 33 & 33 & 33 & 33 & 33 & 33 & & & & \multirow{2}{*}{45} & \multirow{2}{*}{44} \\
\hline & & & & 30 & 45 & 66 & 55 & 78 & 79 & & & & & \\
\hline \multirow{2}{*}{ Canada } & 25 & 25 & 25 & 25 & 25 & 25 & 25 & 25 & 25 & 25 & & & \multirow{2}{*}{88} & \multirow{2}{*}{98} \\
\hline & 23 & 44 & 24 & 65 & 43 & 24 & 86 & 54 & 22 & 52 & & & & \\
\hline
\end{tabular}

\section{Expected Output:}

\begin{tabular}{|l|l|l|l|l|l|}
\hline $\begin{array}{l}\text { Grouping } \\
\text { Countries }\end{array}$ & $\begin{array}{l}\text { Maximum } \\
\text { Cost }\end{array}$ & $\begin{array}{l}\text { Maximum fair } \\
\text { market value }\end{array}$ & $\begin{array}{l}\text { Fair market } \\
\text { value at year end }\end{array}$ & $\begin{array}{l}\text { Foreign income } \\
\text { earned or loss }\end{array}$ & $\begin{array}{l}\text { Capital } \\
\text { gain/loss }\end{array}$ \\
\hline CANADA & 82 & 257 & 77 & 169 & 186 \\
\hline
\end{tabular}

\section{Actual Output:}

\begin{tabular}{|l|l|l|l|l|l|}
\hline $\begin{array}{l}\text { Grouping } \\
\text { Countries }\end{array}$ & $\begin{array}{l}\text { Maximum } \\
\text { Cost }\end{array}$ & $\begin{array}{l}\text { Maximum fair } \\
\text { market value }\end{array}$ & $\begin{array}{l}\text { Fair market } \\
\text { value at year end }\end{array}$ & $\begin{array}{l}\text { Foreign income } \\
\text { earned or loss }\end{array}$ & $\begin{array}{l}\text { Capital } \\
\text { gain/loss }\end{array}$ \\
\hline CANADA & 82 & 257 & 77 & 169 & 186 \\
\hline
\end{tabular}

Calc_1_TC_4_1_BC

\begin{tabular}{|c|c|c|c|c|c|c|c|c|c|c|c|c|c|c|}
\hline 言 & డే & 离 & $\begin{array}{l}\overline{\bar{c}} \\
\stackrel{\bar{c}}{\bar{w}}\end{array}$ & $\overline{\bar{c}}$ & $\stackrel{\overrightarrow{\mathrm{J}}}{\mathrm{J}^{2}}$ & $\Xi$ & 齐 & 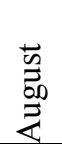 & 营 & $\overrightarrow{0}$ & $\vec{a}$ & ֻั & 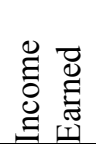 & 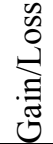 \\
\hline \multirow{2}{*}{ Empty } & & & & & & & 10 & 10 & 10 & 10 & 10 & 10 & \multirow{2}{*}{25} & \multirow{2}{*}{22} \\
\hline & & & & & & & 45 & 34 & 22 & 34 & 87 & 77 & & \\
\hline \multirow{2}{*}{ Empty } & 14 & 14 & 14 & 14 & 14 & 14 & 14 & 14 & & & & & \multirow[b]{2}{*}{11} & \multirow{2}{*}{22} \\
\hline & 14 & 54 & 55 & 45 & 5 & 44 & 71 & 20 & & & & & & \\
\hline \multirow{2}{*}{ Empty } & & & & 33 & 33 & 33 & 33 & 33 & 33 & & & & \multirow{2}{*}{45} & \multirow{2}{*}{44} \\
\hline & & & & 30 & 45 & 66 & 55 & 78 & 79 & & & & & \\
\hline \multirow{2}{*}{ Empty } & 25 & 25 & 25 & 25 & 25 & 25 & 25 & 25 & 25 & 25 & & & \multirow[b]{2}{*}{88} & \multirow{2}{*}{98} \\
\hline & 23 & 44 & 24 & 65 & 43 & 24 & 86 & 54 & 22 & 52 & & & & \\
\hline
\end{tabular}




\section{Expected Output:}

\begin{tabular}{|l|l|l|l|l|l|}
\hline $\begin{array}{l}\text { Grouping } \\
\text { Countries }\end{array}$ & $\begin{array}{l}\text { Maximum } \\
\text { Cost }\end{array}$ & $\begin{array}{l}\text { Maximum fair } \\
\text { market value }\end{array}$ & $\begin{array}{l}\text { Fair market } \\
\text { value at year end }\end{array}$ & $\begin{array}{l}\text { Foreign income } \\
\text { earned or loss }\end{array}$ & $\begin{array}{l}\text { Capital } \\
\text { gain/loss }\end{array}$ \\
\hline Empty & 82 & 257 & 77 & 169 & 186 \\
\hline
\end{tabular}

\section{Actual Output:}

\begin{tabular}{|l|l|l|l|l|l|}
\hline $\begin{array}{l}\text { Grouping } \\
\text { Countries }\end{array}$ & $\begin{array}{l}\text { Maximum } \\
\text { Cost }\end{array}$ & $\begin{array}{l}\text { Maximum fair } \\
\text { market value }\end{array}$ & $\begin{array}{l}\text { Fair market } \\
\text { value at year end }\end{array}$ & $\begin{array}{l}\text { Foreign income } \\
\text { earned or loss }\end{array}$ & $\begin{array}{l}\text { Capital } \\
\text { gain/loss }\end{array}$ \\
\hline Empty & 82 & 257 & 77 & 169 & 186 \\
\hline
\end{tabular}

Calc_1_TC_5_1_BC

\begin{tabular}{|c|c|c|c|c|c|c|c|c|c|c|c|c|c|c|}
\hline 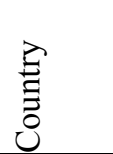 & Е & D & $\begin{array}{l}\overline{0} \\
\bar{c} \\
\bar{\pi}\end{array}$ & $\overline{\bar{z}}$ & $\sum_{\Sigma}^{\pi}$ & $\Xi$ & $\vec{\partial}$ & 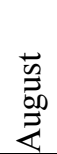 & 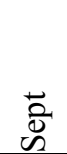 & $\overrightarrow{0}$ & z & 巳̊ల & 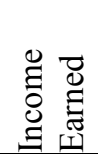 & 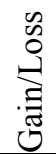 \\
\hline \multirow{2}{*}{ NULL } & & & & & & & 10 & 10 & 10 & 10 & 10 & 10 & \multirow{2}{*}{25} & \multirow{2}{*}{22} \\
\hline & & & & & & & 45 & 34 & 22 & 34 & 87 & 77 & & \\
\hline \multirow{2}{*}{ NULL } & 14 & 14 & 14 & 14 & 14 & 14 & 14 & 14 & & & & & \multirow{2}{*}{11} & \multirow{2}{*}{22} \\
\hline & 14 & 54 & 55 & 45 & 5 & 44 & 71 & 20 & & & & & & \\
\hline \multirow{2}{*}{ NULL } & & & & 33 & 33 & 33 & 33 & 33 & 33 & & & & \multirow{2}{*}{45} & \multirow{2}{*}{44} \\
\hline & & & & 30 & 45 & 66 & 55 & 78 & 79 & & & & & \\
\hline \multirow{2}{*}{ NULL } & 25 & 25 & 25 & 25 & 25 & 25 & 25 & 25 & 25 & 25 & & & \multirow{2}{*}{88} & \multirow{2}{*}{98} \\
\hline & 23 & 44 & 24 & 65 & 43 & 24 & 86 & 54 & 22 & 52 & & & & \\
\hline
\end{tabular}

\section{Expected Output:}

\begin{tabular}{|l|l|l|l|l|l|}
\hline $\begin{array}{l}\text { Grouping } \\
\text { Countries }\end{array}$ & $\begin{array}{l}\text { Maximum } \\
\text { Cost }\end{array}$ & $\begin{array}{l}\text { Maximum fair } \\
\text { market value }\end{array}$ & $\begin{array}{l}\text { Fair market } \\
\text { value at year end }\end{array}$ & $\begin{array}{l}\text { Foreign income } \\
\text { earned or loss }\end{array}$ & $\begin{array}{l}\text { Capital } \\
\text { gain/loss }\end{array}$ \\
\hline Empty & 257 & 82 & 77 & 169 & 186 \\
\hline
\end{tabular}

\section{Actual Output:}

\section{Error}




\section{Each-Choice Test Frames and Test Cases}

Frame 1:

AllValuesPresent.Value.False

CountriesForSecurities.Value.DifferentForAll

Frame 2:

AllValuesPresent.Value.True

CountriesForSecurities.Value.Missing
Frame 3:

AllValuesPresent.Value.False

CountriesForSecurities.Value.SameForAll

Frame 4:

AllValuesPresent.Value.True

CountriesForSecurities.Value.Empty

Calc_1_TC_1_1_EC

\begin{tabular}{|c|c|c|c|c|c|c|c|c|c|c|c|c|c|c|}
\hline 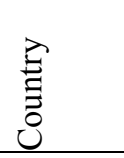 & E & $\begin{array}{l}0 \\
0 \\
0\end{array}$ & 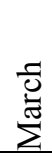 & $\bar{Z}$ & $\vec{\Xi}$ & $\stackrel{\Xi}{\Xi}$ & 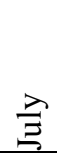 & 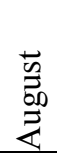 & 苛 & $\overrightarrow{0}$ & $\begin{array}{l}\text { Z } \\
\text { Z }\end{array}$ & 巳̊ & 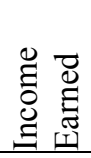 & 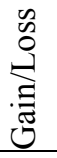 \\
\hline \multirow{2}{*}{ Canada } & & & & & & & 10 & 10 & 10 & 10 & 10 & 10 & \multirow{2}{*}{25} & \multirow{2}{*}{22} \\
\hline & & & & & & & 45 & 34 & 22 & 34 & 87 & 77 & & \\
\hline \multirow{2}{*}{ Canada } & 14 & 14 & 14 & 14 & 14 & 14 & 14 & 14 & & & & & \multirow{2}{*}{11} & \multirow{2}{*}{22} \\
\hline & 14 & 54 & 55 & 45 & 5 & 44 & 71 & 20 & & & & & & \\
\hline \multirow{2}{*}{ Canada } & & & & 33 & 33 & 33 & 33 & 33 & 33 & & & & \multirow{2}{*}{45} & \multirow{2}{*}{44} \\
\hline & & & & 30 & 45 & 66 & 55 & 78 & 79 & & & & & \\
\hline \multirow{2}{*}{ USA } & 25 & 25 & 25 & 25 & 25 & 25 & 25 & 25 & 25 & 25 & & & \multirow{2}{*}{44} & \multirow{2}{*}{55} \\
\hline & 23 & 44 & 24 & 65 & 43 & 24 & 86 & 54 & 22 & 52 & & & & \\
\hline \multirow{2}{*}{ USA } & & & & & & & & & & 45 & 45 & 45 & \multirow{2}{*}{41} & \multirow{2}{*}{42} \\
\hline & & & & & & & & & & 66 & 77 & 88 & & \\
\hline \multirow{2}{*}{ China } & 98 & 98 & 98 & 98 & 98 & 98 & 98 & & & & & & \multirow{2}{*}{23} & \multirow{2}{*}{11} \\
\hline & 45 & 45 & 25 & 78 & 56 & 44 & 57 & & & & & & & \\
\hline \multirow{2}{*}{ China } & & & 56 & 56 & 56 & & & & & & & & \multirow{2}{*}{61} & \multirow{2}{*}{47} \\
\hline & & & 77 & 54 & 36 & & & & & & & & & \\
\hline \multirow{2}{*}{ Mexico } & & & & & & & 23 & 23 & 23 & 23 & 23 & 23 & \multirow{2}{*}{45} & \multirow{2}{*}{30} \\
\hline & & & & & & & 44 & 54 & 23 & 4 & 4 & 33 & & \\
\hline
\end{tabular}

\section{Expected Output:}

\begin{tabular}{|l|l|l|l|l|l|}
\hline $\begin{array}{l}\text { Grouping } \\
\text { Countries }\end{array}$ & $\begin{array}{l}\text { Maximum } \\
\text { Cost }\end{array}$ & $\begin{array}{l}\text { Maximum fair } \\
\text { market value }\end{array}$ & $\begin{array}{l}\text { Fair market } \\
\text { value at year end }\end{array}$ & $\begin{array}{l}\text { Foreign income } \\
\text { earned or loss }\end{array}$ & $\begin{array}{l}\text { Capital } \\
\text { gain/loss }\end{array}$ \\
\hline \multirow{3}{*}{26} & 171 & 77 & 81 & 88 \\
\cline { 1 - 5 } CANADA & 118 & 88 & 85 & 97 \\
\cline { 3 - 6 } USA & 132 & 0 & 84 & 58 \\
\cline { 3 - 6 } CHINA & 54 & 33 & 45 & 30 \\
\hline
\end{tabular}




\section{Actual Output:}

\begin{tabular}{|c|c|c|c|c|c|}
\hline $\begin{array}{l}\text { Grouping } \\
\text { Countries }\end{array}$ & $\begin{array}{l}\text { Maximum } \\
\text { Cost }\end{array}$ & $\begin{array}{l}\text { Maximum fair } \\
\text { market value }\end{array}$ & $\begin{array}{l}\text { Fair market } \\
\text { value at year end }\end{array}$ & $\begin{array}{l}\text { Foreign income } \\
\text { earned or loss }\end{array}$ & $\begin{array}{l}\text { Capital } \\
\text { gain/loss }\end{array}$ \\
\hline CANADA & \multirow{4}{*}{226} & 171 & 77 & 81 & 88 \\
\hline USA & & 118 & 88 & 85 & 97 \\
\hline CHINA & & 132 & 0 & 84 & 58 \\
\hline MEXICO & & 54 & 33 & 45 & 30 \\
\hline
\end{tabular}

Calc_1_TC_2_1_EC

\begin{tabular}{|c|c|c|c|c|c|c|c|c|c|c|c|c|c|c|}
\hline $\begin{array}{l}\vec{E} \\
\Xi \\
0 \\
0\end{array}$ & Еี & $\begin{array}{l}0 \\
0 \\
\end{array}$ & $\begin{array}{l}\bar{J} \\
\text { J } \\
\sum^{\pi}\end{array}$ & $\begin{array}{l}\bar{z} \\
\bar{L}\end{array}$ & $\stackrel{\Xi}{\Xi}$ & $\Xi$ & $\frac{\lambda}{\Xi}$ & 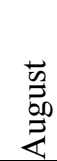 & 苛 & 苑 & z & $\stackrel{\circlearrowright}{0}$ & 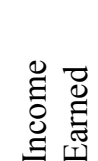 & 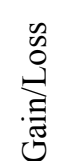 \\
\hline \multirow{2}{*}{ NULL } & 10 & 10 & 10 & 10 & 10 & 10 & 10 & 10 & 10 & 10 & 10 & 10 & \multirow{2}{*}{60} & \multirow{2}{*}{30} \\
\hline & 21 & 22 & 23 & 25 & 22 & 40 & 45 & 34 & 22 & 34 & 87 & 77 & & \\
\hline \multirow{2}{*}{ NULL } & 14 & 14 & 14 & 14 & 14 & 14 & 14 & 14 & 14 & 14 & 14 & 14 & \multirow{2}{*}{90} & \multirow{2}{*}{50} \\
\hline & 14 & 54 & 55 & 45 & 5 & 44 & 71 & 20 & 22 & 24 & 22 & 24 & & \\
\hline \multirow{2}{*}{ NULL } & 25 & 25 & 25 & 25 & 25 & 25 & 25 & 25 & 25 & 25 & 25 & 25 & \multirow{2}{*}{45} & \multirow{2}{*}{42} \\
\hline & 23 & 44 & 24 & 65 & 43 & 24 & 86 & 54 & 22 & 52 & 50 & 50 & & \\
\hline \multirow{2}{*}{ NULL } & 45 & 45 & 45 & 45 & 45 & 45 & 45 & 45 & 45 & 45 & 45 & 45 & \multirow{2}{*}{65} & \multirow{2}{*}{100} \\
\hline & 45 & 46 & 51 & 53 & 58 & 55 & 59 & 60 & 65 & 66 & 77 & 88 & & \\
\hline \multirow{2}{*}{ NULL } & 98 & 98 & 98 & 98 & 98 & 98 & 98 & 98 & 98 & 98 & 98 & 98 & \multirow[b]{2}{*}{98} & \multirow[b]{2}{*}{65} \\
\hline & 45 & 45 & 25 & 78 & 56 & 44 & 57 & 55 & 56 & 54 & 53 & 51 & & \\
\hline \multirow{2}{*}{ NULL } & 56 & 56 & 56 & 56 & 56 & 56 & 56 & 56 & 56 & 56 & 56 & 56 & \multirow{2}{*}{89} & \multirow[b]{2}{*}{12} \\
\hline & 78 & 77 & 77 & 54 & 36 & 36 & 36 & 36 & 36 & 36 & 36 & 36 & & \\
\hline \multirow{2}{*}{ NULL } & 23 & 23 & 23 & 23 & 23 & 23 & 23 & 23 & 23 & 23 & 23 & 23 & \multirow{2}{*}{85} & \multirow{2}{*}{85} \\
\hline & 44 & 44 & 44 & 44 & 44 & 44 & 44 & 54 & 23 & 4 & 4 & 33 & & \\
\hline
\end{tabular}

\section{Expected Output:}

Error

\section{Actual Output:}

\section{Error}


Calc_1_TC_3_1_EC

\begin{tabular}{|c|c|c|c|c|c|c|c|c|c|c|c|c|c|c|}
\hline$\hat{\mathrm{E}}$ & 茞 & 离 & 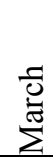 & 妾 & $\stackrel{\vec{\Sigma}}{\Sigma}$ & $\Xi$ & $\vec{\Xi}$ & $\begin{array}{l}\frac{5}{5} \\
\frac{5}{50} \\
z\end{array}$ & 产 & $\tilde{0}$ & 2 & "ू. & 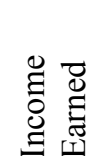 & 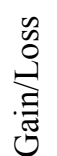 \\
\hline Canada & & & & & & & 10 & 10 & 10 & 10 & 10 & 10 & \multirow{2}{*}{25} & \multirow{2}{*}{22} \\
\hline & & & & & & & 45 & 34 & 22 & 34 & 87 & 77 & & \\
\hline Canada & 14 & 14 & 14 & 14 & 14 & 14 & 14 & 14 & & & & & \multirow{2}{*}{11} & \multirow{2}{*}{22} \\
\hline \multirow[b]{2}{*}{ Canada } & 14 & 54 & 5 & 45 & 5 & 44 & 71 & 20 & & & & & & \\
\hline & & & & 33 & $\frac{33}{45}$ & 33 & $\frac{33}{55}$ & $\frac{33}{78}$ & 33 & & & & 45 & 44 \\
\hline \multirow{2}{*}{ Canada } & 25 & 25 & 25 & 25 & 25 & 25 & 25 & 25 & 25 & 25 & & & \multirow{2}{*}{88} & \multirow{2}{*}{98} \\
\hline & 23 & 44 & 24 & 65 & 43 & 24 & 86 & 54 & 22 & 52 & & & & \\
\hline
\end{tabular}

\section{Expected Output:}

\begin{tabular}{|l|l|l|l|l|l|}
\hline $\begin{array}{l}\text { Grouping } \\
\text { Countries }\end{array}$ & $\begin{array}{l}\text { Maximum } \\
\text { Cost }\end{array}$ & $\begin{array}{l}\text { Maximum fair } \\
\text { market value }\end{array}$ & $\begin{array}{l}\text { Fair market } \\
\text { value at year end }\end{array}$ & $\begin{array}{l}\text { Foreign income } \\
\text { earned or loss }\end{array}$ & $\begin{array}{l}\text { Capital } \\
\text { gain/loss }\end{array}$ \\
\hline CANADA & 82 & 257 & 77 & 169 & 186 \\
\hline
\end{tabular}

\section{Actual Output:}

\begin{tabular}{|l|l|l|l|l|l|}
\hline $\begin{array}{l}\text { Grouping } \\
\text { Countries }\end{array}$ & $\begin{array}{l}\text { Maximum } \\
\text { Cost }\end{array}$ & $\begin{array}{l}\text { Maximum fair } \\
\text { market value }\end{array}$ & $\begin{array}{l}\text { Fair market } \\
\text { value at year end }\end{array}$ & $\begin{array}{l}\text { Foreign income } \\
\text { earned or loss }\end{array}$ & $\begin{array}{l}\text { Capital } \\
\text { gain/loss }\end{array}$ \\
\hline Canada & 82 & 257 & 77 & 169 & 186 \\
\hline
\end{tabular}


Calc_1_TC_4_1_EC

\begin{tabular}{|c|c|c|c|c|c|c|c|c|c|c|c|c|c|c|}
\hline $\begin{array}{l}\text { E } \\
\vdots \\
0 \\
0\end{array}$ & Eี & $\begin{array}{l}0 \\
1\end{array}$ & $\begin{array}{l}\overline{0} \\
\bar{\Xi} \\
\sum_{\Sigma}^{\pi}\end{array}$ & $\overline{\bar{\alpha}}$ & ¿ & $\Xi$ & $\vec{\partial}$ & 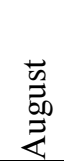 & 苍 & $\overrightarrow{0}$ & z & ల్ల & 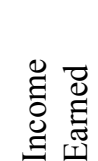 & 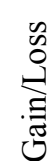 \\
\hline \multirow{2}{*}{ Empty } & 10 & 10 & 10 & 10 & 10 & 10 & 10 & 10 & 10 & 10 & 10 & 10 & \multirow{2}{*}{60} & \multirow{2}{*}{30} \\
\hline & 21 & 22 & 23 & 25 & 22 & 40 & 45 & 34 & 22 & 34 & 87 & 77 & & \\
\hline \multirow{2}{*}{ Empty } & 14 & 14 & 14 & 14 & 14 & 14 & 14 & 14 & 14 & 14 & 14 & 14 & \multirow{2}{*}{40} & \multirow{2}{*}{50} \\
\hline & 14 & 54 & 55 & 45 & 5 & 44 & 71 & 20 & 22 & 24 & 22 & 24 & & \\
\hline \multirow{2}{*}{ Empty } & 25 & 25 & 25 & 25 & 25 & 25 & 25 & 25 & 25 & 25 & 25 & 25 & \multirow{2}{*}{45} & \multirow{2}{*}{42} \\
\hline & 23 & 44 & 24 & 65 & 43 & 24 & 86 & 54 & 22 & 52 & 50 & 50 & & \\
\hline \multirow{2}{*}{ Empty } & 45 & 45 & 45 & 45 & 45 & 45 & 45 & 45 & 45 & 45 & 45 & 45 & \multirow[b]{2}{*}{65} & \multirow[b]{2}{*}{60} \\
\hline & 45 & 46 & 51 & 53 & 58 & 55 & 59 & 60 & 65 & 66 & 77 & 88 & & \\
\hline \multirow{2}{*}{ Empty } & 98 & 98 & 98 & 98 & 98 & 98 & 98 & 98 & 98 & 98 & 98 & 98 & \multirow{2}{*}{30} & \multirow{2}{*}{65} \\
\hline & 45 & 45 & 25 & 78 & 56 & 44 & 57 & 55 & 56 & 54 & 53 & 51 & & \\
\hline \multirow{2}{*}{ Empty } & 56 & 56 & 56 & 56 & 56 & 56 & 56 & 56 & 56 & 56 & 56 & 56 & \multirow{2}{*}{89} & \multirow{2}{*}{12} \\
\hline & 78 & 77 & 77 & 54 & 36 & 36 & 36 & 36 & 36 & 36 & 36 & 36 & & \\
\hline \multirow{2}{*}{ Empty } & 23 & 23 & 23 & 23 & 23 & 23 & 23 & 23 & 23 & 23 & 23 & 23 & \multirow[b]{2}{*}{45} & \multirow{2}{*}{45} \\
\hline & 44 & 44 & 44 & 44 & 44 & 44 & 44 & 54 & 23 & 4 & 4 & 33 & & \\
\hline
\end{tabular}

\section{Expected Output:}

\begin{tabular}{|l|l|l|l|l|l|}
\hline $\begin{array}{l}\text { Grouping } \\
\text { Countries }\end{array}$ & $\begin{array}{l}\text { Maximum } \\
\text { Cost }\end{array}$ & $\begin{array}{l}\text { Maximum fair } \\
\text { market value }\end{array}$ & $\begin{array}{l}\text { Fair market } \\
\text { value at year end }\end{array}$ & $\begin{array}{l}\text { Foreign income } \\
\text { earned or loss }\end{array}$ & $\begin{array}{l}\text { Capital } \\
\text { gain/loss }\end{array}$ \\
\hline Empty & 271 & 398 & 359 & 374 & 304 \\
\hline
\end{tabular}

\section{Actual Output:}

\begin{tabular}{|l|l|l|l|l|l|}
\hline $\begin{array}{l}\text { Grouping } \\
\text { Countries }\end{array}$ & $\begin{array}{l}\text { Maximum } \\
\text { Cost }\end{array}$ & $\begin{array}{l}\text { Maximum fair } \\
\text { market value }\end{array}$ & $\begin{array}{l}\text { Fair market } \\
\text { value at year end }\end{array}$ & $\begin{array}{l}\text { Foreign income } \\
\text { earned or loss }\end{array}$ & $\begin{array}{l}\text { Capital } \\
\text { gain/loss }\end{array}$ \\
\hline Empty & 271 & 398 & 359 & 374 & 304 \\
\hline
\end{tabular}

\section{Pair-Wise Test Frames and Test Cases}

Frame 1:

AllValuesPresent.Value.False

CountriesForSecurities.Value.DifferentForAll

Frame 2:

AllValuesPresent.Value.True

CountriesForSecurities.Value.Missing
Frame 3:

AllValuesPresent.Value.False

CountriesForSecurities.Value.SameForAll

Frame 4:

AllValuesPresent.Value.True

CountriesForSecurities.Value.Empty 
Calc_TC_1_1_PW

\begin{tabular}{|c|c|c|c|c|c|c|c|c|c|c|c|c|c|c|}
\hline 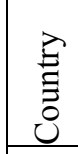 & స్ & $\begin{array}{l}0 \\
0 \\
1\end{array}$ & $\begin{array}{l}\bar{D} \\
\overline{0} \\
\bar{\Sigma}\end{array}$ & $\overline{\overline{2}}$ & $\sum^{\vec{\pi}}$ & $\Xi$ & $\frac{2}{\Xi}$ & $\begin{array}{l}\overrightarrow{0} \\
\overrightarrow{0} \\
\overrightarrow{3} \\
\vec{Z}\end{array}$ & 苍 & 0 & z & $\stackrel{8}{8}$ & 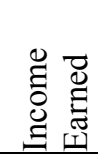 & 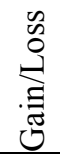 \\
\hline & & & & & & & 10 & 10 & 10 & 10 & 10 & 10 & \multirow{2}{*}{25} & \multirow{2}{*}{22} \\
\hline & & & & & & & 45 & 34 & 22 & 34 & 87 & 77 & & \\
\hline & 14 & 14 & 14 & 14 & 14 & 14 & 14 & 14 & & & & & \multirow{2}{*}{11} & \multirow{2}{*}{22} \\
\hline & 14 & 54 & 55 & 45 & 5 & 44 & 71 & 20 & & & & & & \\
\hline & & & & 33 & 33 & 33 & 33 & 33 & 33 & & & & \multirow[b]{2}{*}{45} & \multirow{2}{*}{44} \\
\hline & & & & 30 & 45 & 66 & 55 & 78 & 79 & & & & & \\
\hline & 25 & 25 & 25 & 25 & 25 & 25 & 25 & 25 & 25 & 25 & & & \multirow[b]{2}{*}{88} & \multirow{2}{*}{98} \\
\hline & 23 & 44 & 24 & 65 & 43 & 24 & 86 & 54 & 22 & 52 & & & & \\
\hline
\end{tabular}

\section{Expected Output:}

\begin{tabular}{|l|l|l|l|l|l|}
\hline $\begin{array}{l}\text { Grouping } \\
\text { Countries }\end{array}$ & $\begin{array}{l}\text { Maximum } \\
\text { Cost }\end{array}$ & $\begin{array}{l}\text { Maximum fair } \\
\text { market value }\end{array}$ & $\begin{array}{l}\text { Fair market } \\
\text { value at year end }\end{array}$ & $\begin{array}{l}\text { Foreign income } \\
\text { earned or loss }\end{array}$ & $\begin{array}{l}\text { Capital } \\
\text { gain/loss }\end{array}$ \\
\hline Empty & 82 & 257 & 77 & 169 & 186 \\
\hline
\end{tabular}

\section{Actual Output:}

\begin{tabular}{|l|l|l|l|l|l|}
\hline $\begin{array}{l}\text { Grouping } \\
\text { Countries }\end{array}$ & $\begin{array}{l}\text { Maximum } \\
\text { Cost }\end{array}$ & $\begin{array}{l}\text { Maximum fair } \\
\text { market value }\end{array}$ & $\begin{array}{l}\text { Fair market } \\
\text { value at year end }\end{array}$ & $\begin{array}{l}\text { Foreign income } \\
\text { earned or loss }\end{array}$ & $\begin{array}{l}\text { Capital } \\
\text { gain/loss }\end{array}$ \\
\hline Empty & 82 & 257 & 77 & 169 & 186 \\
\hline
\end{tabular}

\section{Calc_TC_2_1_PW}

\begin{tabular}{|c|c|c|c|c|c|c|c|c|c|c|c|c|c|c|}
\hline $\begin{array}{l}\hat{E} \\
\text { 吾 }\end{array}$ & Еี & $\begin{array}{l}0 \\
0 \\
\end{array}$ & 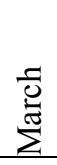 & $\overline{\bar{z}}$ & $\mathrm{~J}^{\mathrm{I}}$ & $\Xi$ & 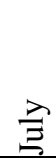 & 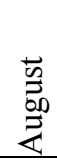 & $\begin{array}{l}\overrightarrow{0} \\
0 \\
0\end{array}$ & $\overrightarrow{0}$ & z & $\stackrel{0}{0}$ & 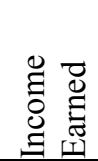 & 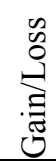 \\
\hline \multirow{2}{*}{ Canada } & & & & & & & 10 & 10 & 10 & 10 & 10 & 10 & \multirow{2}{*}{25} & \multirow{2}{*}{22} \\
\hline & & & & & & & 45 & 34 & 22 & 34 & 87 & 77 & & \\
\hline \multirow{2}{*}{ Canada } & 14 & 14 & 14 & 14 & 14 & 14 & 14 & 14 & & & & & \multirow{2}{*}{11} & \multirow{2}{*}{22} \\
\hline & 14 & 54 & 55 & 45 & 5 & 44 & 71 & 20 & & & & & & \\
\hline \multirow{2}{*}{ Canada } & & & & 33 & 33 & 33 & 33 & 33 & 33 & & & & \multirow{2}{*}{45} & \multirow{2}{*}{44} \\
\hline & & & & 30 & 45 & 66 & 55 & 78 & 79 & & & & & \\
\hline \multirow{2}{*}{ Canada } & 25 & 25 & 25 & 25 & 25 & 25 & 25 & 25 & 25 & 25 & & & \multirow{2}{*}{88} & \multirow{2}{*}{98} \\
\hline & 23 & 44 & 24 & 65 & 43 & 24 & 86 & 54 & 22 & 52 & & & & \\
\hline
\end{tabular}




\section{Expected Output:}

\begin{tabular}{|l|l|l|l|l|l|}
\hline $\begin{array}{l}\text { Grouping } \\
\text { Countries }\end{array}$ & $\begin{array}{l}\text { Maximum } \\
\text { Cost }\end{array}$ & $\begin{array}{l}\text { Maximum fair } \\
\text { market value }\end{array}$ & $\begin{array}{l}\text { Fair market } \\
\text { value at year end }\end{array}$ & $\begin{array}{l}\text { Foreign income } \\
\text { earned or loss }\end{array}$ & $\begin{array}{l}\text { Capital } \\
\text { gain/loss }\end{array}$ \\
\hline CANADA & 82 & 257 & 77 & 169 & 186 \\
\hline
\end{tabular}

\section{Actual Output:}

\begin{tabular}{|l|l|l|l|l|l|}
\hline $\begin{array}{l}\text { Grouping } \\
\text { Countries }\end{array}$ & $\begin{array}{l}\text { Maximum } \\
\text { Cost }\end{array}$ & $\begin{array}{l}\text { Maximum fair } \\
\text { market value }\end{array}$ & $\begin{array}{l}\text { Fair market } \\
\text { value at year end }\end{array}$ & $\begin{array}{l}\text { Foreign income } \\
\text { earned or loss }\end{array}$ & $\begin{array}{l}\text { Capital } \\
\text { gain/loss }\end{array}$ \\
\hline CANADA & 82 & 257 & 77 & 169 & 186 \\
\hline
\end{tabular}

\section{Calc_TC_3_1_PW}

\begin{tabular}{|c|c|c|c|c|c|c|c|c|c|c|c|c|c|c|}
\hline $\begin{array}{l}\stackrel{\Xi}{E} \\
\stackrel{\Xi}{0}\end{array}$ & हี & $\begin{array}{l}0 \\
1\end{array}$ & $\begin{array}{l}\overline{0} \\
\bar{c} \\
\sum^{\pi}\end{array}$ & $\overline{\frac{0}{4}}$ & $\stackrel{\vec{\sigma}}{\Sigma}$ & $\Xi$ & 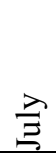 & $\begin{array}{l}\overrightarrow{0} \\
\overrightarrow{50} \\
\vec{Z} \\
\vec{z}\end{array}$ & 苛 & $\ddot{0}$ & z & ڤ̊ & 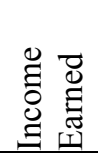 & 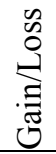 \\
\hline \multirow{2}{*}{ Canada } & 10 & 10 & 10 & 10 & 10 & 10 & 10 & 10 & 10 & 10 & 10 & 10 & \multirow{2}{*}{60} & \multirow{2}{*}{30} \\
\hline & 21 & 22 & 23 & 25 & 22 & 40 & 45 & 34 & 22 & 34 & 87 & 77 & & \\
\hline \multirow{2}{*}{ Canada } & 14 & 14 & 14 & 14 & 14 & 14 & 14 & 14 & 14 & 14 & 14 & 14 & \multirow{2}{*}{40} & \multirow{2}{*}{50} \\
\hline & 14 & 54 & 55 & 45 & 5 & 44 & 71 & 20 & 22 & 24 & 22 & 24 & & \\
\hline \multirow{2}{*}{ USA } & 25 & 25 & 25 & 25 & 25 & 25 & 25 & 25 & 25 & 25 & 25 & 25 & \multirow{2}{*}{45} & \multirow{2}{*}{42} \\
\hline & 23 & 44 & 24 & 65 & 43 & 24 & 86 & 54 & 22 & 52 & 50 & 50 & & \\
\hline \multirow{2}{*}{ USA } & 45 & 45 & 45 & 45 & 45 & 45 & 45 & 45 & 45 & 45 & 45 & 45 & \multirow{2}{*}{65} & \multirow{2}{*}{60} \\
\hline & 45 & 46 & 51 & 53 & 58 & 55 & 59 & 60 & 65 & 66 & 77 & 88 & & \\
\hline \multirow{2}{*}{ China } & 98 & 98 & 98 & 98 & 98 & 98 & 98 & 98 & 98 & 98 & 98 & 98 & \multirow{2}{*}{30} & \multirow{2}{*}{65} \\
\hline & 45 & 45 & 25 & 78 & 56 & 44 & 57 & 55 & 56 & 54 & 53 & 51 & & \\
\hline \multirow{2}{*}{ China } & 56 & 56 & 56 & 56 & 56 & 56 & 56 & 56 & 56 & 56 & 56 & 56 & \multirow{2}{*}{89} & \multirow{2}{*}{12} \\
\hline & 78 & 77 & 77 & 54 & 36 & 36 & 36 & 36 & 36 & 36 & 36 & 36 & & \\
\hline \multirow{2}{*}{ Mexico } & 23 & 23 & 23 & 23 & 23 & 23 & 23 & 23 & 23 & 23 & 23 & 23 & \multirow{2}{*}{45} & \multirow{2}{*}{45} \\
\hline & 44 & 44 & 44 & 44 & 44 & 44 & 44 & 54 & 23 & 4 & 4 & 33 & & \\
\hline
\end{tabular}

\section{Expected Output:}

\begin{tabular}{|l|l|l|l|l|l|}
\hline $\begin{array}{l}\text { Grouping } \\
\text { Countries }\end{array}$ & $\begin{array}{l}\text { Maximum } \\
\text { Cost }\end{array}$ & $\begin{array}{l}\text { Maximum fair } \\
\text { market value }\end{array}$ & $\begin{array}{l}\text { Fair market } \\
\text { value at year end }\end{array}$ & $\begin{array}{l}\text { Foreign income } \\
\text { earned or loss }\end{array}$ & $\begin{array}{l}\text { Capital } \\
\text { gain/loss }\end{array}$ \\
\hline CANADA & \multirow{3}{*}{271} & 116 & 101 & 100 & 80 \\
\cline { 4 - 6 } & & 145 & 138 & 110 & 102 \\
\cline { 4 - 6 } USA & 132 & 87 & 119 & 77 \\
\cline { 3 - 5 } CHINA & 54 & 33 & 45 & 45 \\
\hline MEXICO & & & & \\
\hline
\end{tabular}




\section{Actual Output:}

\begin{tabular}{|l|l|l|l|l|l|}
\hline $\begin{array}{l}\text { Grouping } \\
\text { Countries }\end{array}$ & \multirow{2}{*}{$\begin{array}{l}\text { Maximum } \\
\text { Cost }\end{array}$} & $\begin{array}{l}\text { Maximum fair } \\
\text { market value }\end{array}$ & $\begin{array}{l}\text { Fair market } \\
\text { value at year end }\end{array}$ & $\begin{array}{l}\text { Foreign income } \\
\text { earned or loss }\end{array}$ & $\begin{array}{l}\text { Capital } \\
\text { gain/loss }\end{array}$ \\
\hline \multirow{3}{*}{ CANADA } & \multirow{3}{*}{271} & 116 & 101 & 100 & 80 \\
\cline { 3 - 6 } & 145 & 138 & 110 & 102 \\
\cline { 3 - 6 } USA & 132 & 87 & 119 & 77 \\
\cline { 3 - 6 } CHINA & 54 & 33 & 45 & 45 \\
\hline MEXICO & & & & \\
\hline
\end{tabular}

\section{Calc_TC_4_1_PW}

\begin{tabular}{|c|c|c|c|c|c|c|c|c|c|c|c|c|c|c|}
\hline $\begin{array}{l}\hat{E} \\
\text { 吾 }\end{array}$ & 토 & $\begin{array}{l}0 \\
0\end{array}$ & 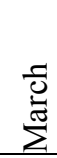 & $\overline{\bar{z}}$ & $\sum^{\vec{\sigma}}$ & $\Xi$ & $\stackrel{\lambda}{\Xi}$ & 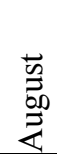 & 菅 & $\overrightarrow{0}$ & z & : & 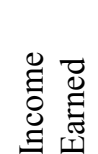 & 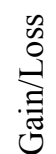 \\
\hline \multirow{2}{*}{ Empty } & 10 & 10 & 10 & 10 & 10 & 10 & 10 & 10 & 10 & 10 & 10 & 10 & \multirow{2}{*}{60} & \multirow{2}{*}{30} \\
\hline & 21 & 22 & 23 & 25 & 22 & 40 & 45 & 34 & 22 & 34 & 87 & 77 & & \\
\hline \multirow{2}{*}{ Empty } & 14 & 14 & 14 & 14 & 14 & 14 & 14 & 14 & 14 & 14 & 14 & 14 & \multirow{2}{*}{40} & \multirow{2}{*}{50} \\
\hline & 14 & 54 & 55 & 45 & 5 & 44 & 71 & 20 & 22 & 24 & 22 & 24 & & \\
\hline \multirow{2}{*}{ Empty } & 25 & 25 & 25 & 25 & 25 & 25 & 25 & 25 & 25 & 25 & 25 & 25 & \multirow{2}{*}{45} & \multirow{2}{*}{42} \\
\hline & 23 & 44 & 24 & 65 & 43 & 24 & 86 & 54 & 22 & 52 & 50 & 50 & & \\
\hline \multirow{2}{*}{ Empty } & 45 & 45 & 45 & 45 & 45 & 45 & 45 & 45 & 45 & 45 & 45 & 45 & \multirow{2}{*}{65} & \multirow{2}{*}{60} \\
\hline & 45 & 46 & 51 & 53 & 58 & 55 & 59 & 60 & 65 & 66 & 77 & 88 & & \\
\hline \multirow{2}{*}{ Empty } & 98 & 98 & 98 & 98 & 98 & 98 & 98 & 98 & 98 & 98 & 98 & 98 & \multirow{2}{*}{30} & \multirow{2}{*}{65} \\
\hline & 45 & 45 & 25 & 78 & 56 & 44 & 57 & 55 & 56 & 54 & 53 & 51 & & \\
\hline \multirow{2}{*}{ Empty } & 56 & 56 & 56 & 56 & 56 & 56 & 56 & 56 & 56 & 56 & 56 & 56 & \multirow{2}{*}{89} & \multirow{2}{*}{12} \\
\hline & 78 & 77 & 77 & 54 & 36 & 36 & 36 & 36 & 36 & 36 & 36 & 36 & & \\
\hline \multirow{2}{*}{ Empty } & 23 & 23 & 23 & 23 & 23 & 23 & 23 & 23 & 23 & 23 & 23 & 23 & \multirow{2}{*}{45} & \multirow{2}{*}{45} \\
\hline & 44 & 44 & 44 & 44 & 44 & 44 & 44 & 54 & 23 & 4 & 4 & 33 & & \\
\hline
\end{tabular}

\section{Expected Output:}

\begin{tabular}{|l|l|l|l|l|l|}
\hline $\begin{array}{l}\text { Grouping } \\
\text { Countries }\end{array}$ & $\begin{array}{l}\text { Maximum } \\
\text { Cost }\end{array}$ & $\begin{array}{l}\text { Maximum fair } \\
\text { market value }\end{array}$ & $\begin{array}{l}\text { Fair market } \\
\text { value at year end }\end{array}$ & $\begin{array}{l}\text { Foreign income } \\
\text { earned or loss }\end{array}$ & $\begin{array}{l}\text { Capital } \\
\text { gain/loss }\end{array}$ \\
\hline Empty & 271 & 398 & 359 & 374 & 304 \\
\hline
\end{tabular}

\section{Actual Output:}

\begin{tabular}{|l|l|l|l|l|l|}
\hline $\begin{array}{l}\text { Grouping } \\
\text { Countries }\end{array}$ & $\begin{array}{l}\text { Maximum } \\
\text { Cost }\end{array}$ & $\begin{array}{l}\text { Maximum fair } \\
\text { market value }\end{array}$ & $\begin{array}{l}\text { Fair market } \\
\text { value at year end }\end{array}$ & $\begin{array}{l}\text { Foreign income } \\
\text { earned or loss }\end{array}$ & $\begin{array}{l}\text { Capital } \\
\text { gain/loss }\end{array}$ \\
\hline Empty & 271 & 398 & 359 & 374 & 304 \\
\hline
\end{tabular}


Calc_TC_5_1_PW

\begin{tabular}{|c|c|c|c|c|c|c|c|c|c|c|c|c|c|c|}
\hline $\begin{array}{l}\stackrel{\Xi}{\Xi} \\
\text { 己 }\end{array}$ & పี & 过 & 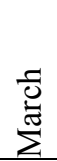 & 妾 & $\sum^{\circledR}$ & $\stackrel{\Xi}{\Xi}$ & $\vec{\Xi}$ & 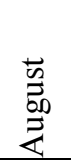 & $\begin{array}{l}\overrightarrow{0} \\
\text { हू } \\
\ddot{n}\end{array}$ & $\overrightarrow{0}$ & zे & ֻٌ & 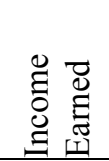 & 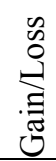 \\
\hline \multirow{2}{*}{ Canada } & 10 & 10 & 10 & 10 & 10 & 10 & 10 & 10 & 10 & 10 & 10 & 10 & \multirow{2}{*}{60} & \multirow{2}{*}{30} \\
\hline & 21 & 22 & 23 & 25 & 22 & 40 & 45 & 34 & 22 & 34 & 87 & 77 & & \\
\hline \multirow{2}{*}{ Canada } & 14 & 14 & 14 & 14 & 14 & 14 & 14 & 14 & 14 & 14 & 14 & 14 & \multirow{2}{*}{40} & \multirow{2}{*}{50} \\
\hline & 14 & 54 & 55 & 45 & 5 & 44 & 71 & 20 & 22 & 24 & 22 & 24 & & \\
\hline \multirow{2}{*}{ Canada } & 25 & 25 & 25 & 25 & 25 & 25 & 25 & 25 & 25 & 25 & 25 & 25 & \multirow{2}{*}{45} & \multirow{2}{*}{42} \\
\hline & 23 & 44 & 24 & 65 & 43 & 24 & 86 & 54 & 22 & 52 & 50 & 50 & & \\
\hline \multirow{2}{*}{ Canada } & 45 & 45 & 45 & 45 & 45 & 45 & 45 & 45 & 45 & 45 & 45 & 45 & \multirow{2}{*}{65} & \multirow{2}{*}{60} \\
\hline & 45 & 46 & 51 & 53 & 58 & 55 & 59 & 60 & 65 & 66 & 77 & 88 & & \\
\hline \multirow{2}{*}{ Canada } & 98 & 98 & 98 & 98 & 98 & 98 & 98 & 98 & 98 & 98 & 98 & 98 & \multirow{2}{*}{30} & \multirow{2}{*}{65} \\
\hline & 45 & 45 & 25 & 78 & 56 & 44 & 57 & 55 & 56 & 54 & 53 & 51 & & \\
\hline \multirow{2}{*}{ Canada } & 56 & 56 & 56 & 56 & 56 & 56 & 56 & 56 & 56 & 56 & 56 & 56 & \multirow{2}{*}{89} & \multirow{2}{*}{12} \\
\hline & 78 & 77 & 77 & 54 & 36 & 36 & 36 & 36 & 36 & 36 & 36 & 36 & & \\
\hline \multirow{2}{*}{ Canada } & 23 & 23 & 23 & 23 & 23 & 23 & 23 & 23 & 23 & 23 & 23 & 23 & \multirow{2}{*}{45} & \multirow{2}{*}{45} \\
\hline & 44 & 44 & 44 & 44 & 44 & 44 & 44 & 54 & 23 & 4 & 4 & 33 & & \\
\hline
\end{tabular}

\section{Expected Output:}

\begin{tabular}{|l|l|l|l|l|l|}
\hline $\begin{array}{l}\text { Grouping } \\
\text { Countries }\end{array}$ & $\begin{array}{l}\text { Maximum } \\
\text { Cost }\end{array}$ & $\begin{array}{l}\text { Maximum fair } \\
\text { market value }\end{array}$ & $\begin{array}{l}\text { Fair market } \\
\text { value at year end }\end{array}$ & $\begin{array}{l}\text { Foreign income } \\
\text { earned or loss }\end{array}$ & $\begin{array}{l}\text { Capital } \\
\text { gain/loss }\end{array}$ \\
\hline CANADA & 271 & 398 & 359 & 374 & 304 \\
\hline
\end{tabular}

\section{Actual Output:}

\begin{tabular}{|l|l|l|l|l|l|}
\hline $\begin{array}{l}\text { Grouping } \\
\text { Countries }\end{array}$ & $\begin{array}{l}\text { Maximum } \\
\text { Cost }\end{array}$ & $\begin{array}{l}\text { Maximum fair } \\
\text { market value }\end{array}$ & $\begin{array}{l}\text { Fair market } \\
\text { value at year end }\end{array}$ & $\begin{array}{l}\text { Foreign income } \\
\text { earned or loss }\end{array}$ & $\begin{array}{l}\text { Capital } \\
\text { gain/loss }\end{array}$ \\
\hline CANADA & 271 & 398 & 359 & 532 & 384 \\
\hline
\end{tabular}


Calc_TC_6_1_PW

\begin{tabular}{|c|c|c|c|c|c|c|c|c|c|c|c|c|c|c|}
\hline $\begin{array}{l}\hat{\theta} \\
\text { 吾 }\end{array}$ & 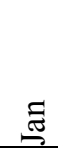 & 这 & 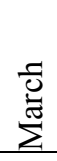 & 容 & $\stackrel{\vec{z}}{\Sigma^{2}}$ & $\underline{\Xi}$ & $\vec{\Xi}$ & 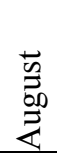 & $\begin{array}{l}\text { ठे } \\
\stackrel{n}{n}\end{array}$ & $\ddot{0}$ & za & ֻั & 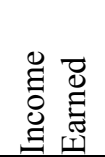 & 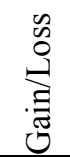 \\
\hline NULL & & & & & & & 10 & 10 & 10 & 10 & 10 & 10 & \multirow{2}{*}{25} & \multirow{2}{*}{22} \\
\hline \multirow{3}{*}{ NULL } & & & & & & & 45 & 34 & 22 & 34 & 87 & 77 & & \\
\hline & 14 & 14 & 14 & 14 & 14 & 14 & 14 & 14 & & & & & \multirow{2}{*}{11} & \multirow{2}{*}{22} \\
\hline & 14 & 54 & 55 & 45 & 5 & 44 & 71 & 20 & & & & & & \\
\hline NULL & & & & 33 & 33 & 33 & 33 & 33 & 33 & & & & \multirow{2}{*}{45} & \multirow{2}{*}{44} \\
\hline \multirow[b]{2}{*}{ NULL } & & & & 30 & 45 & 66 & 55 & 78 & 79 & & & & & \\
\hline & 23 & $\frac{25}{44}$ & $\frac{25}{24}$ & $\frac{25}{65}$ & $\frac{25}{43}$ & $\frac{25}{24}$ & 23 & 25 & 25 & $\frac{25}{52}$ & & & 88 & 98 \\
\hline
\end{tabular}

\section{Expected Output:}

\begin{tabular}{|l|l|l|l|l|l|}
\hline $\begin{array}{l}\text { Grouping } \\
\text { Countries }\end{array}$ & $\begin{array}{l}\text { Maximum } \\
\text { Cost }\end{array}$ & $\begin{array}{l}\text { Maximum fair } \\
\text { market value }\end{array}$ & $\begin{array}{l}\text { Fair market } \\
\text { value at year end }\end{array}$ & $\begin{array}{l}\text { Foreign income } \\
\text { earned or loss }\end{array}$ & $\begin{array}{l}\text { Capital } \\
\text { gain/loss }\end{array}$ \\
\hline Empty & 257 & 82 & 77 & 169 & 186 \\
\hline
\end{tabular}

\section{Actual Output:}

\section{Error}


Calc_TC_7_1_PW

\begin{tabular}{|c|c|c|c|c|c|c|c|c|c|c|c|c|c|c|}
\hline $\begin{array}{l}\stackrel{\Xi}{\Xi} \\
\text { ठ }\end{array}$ & Е్ & $\begin{array}{l}0 \\
0 \\
\end{array}$ & 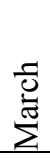 & $\overline{\bar{z}}$ & $\sum^{\pi}$ & $\Xi$ & $\frac{\lambda}{3}$ & $\begin{array}{l}\overrightarrow{0} \\
\overrightarrow{0} \\
\stackrel{50}{Z}\end{array}$ & 䒕 & $\ddot{0}$ & z & ڤ్ల & 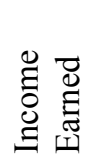 & 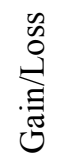 \\
\hline \multirow{2}{*}{ NULL } & 10 & 10 & 10 & 10 & 10 & 10 & 10 & 10 & 10 & 10 & 10 & 10 & \multirow{2}{*}{60} & \multirow{2}{*}{30} \\
\hline & 21 & 22 & 23 & 25 & 22 & 40 & 45 & 34 & 22 & 34 & 87 & 77 & & \\
\hline \multirow{2}{*}{ NULL } & 14 & 14 & 14 & 14 & 14 & 14 & 14 & 14 & 14 & 14 & 14 & 14 & \multirow{2}{*}{90} & \multirow{2}{*}{50} \\
\hline & 14 & 54 & 55 & 45 & 5 & 44 & 71 & 20 & 22 & 24 & 22 & 24 & & \\
\hline \multirow{2}{*}{ NULL } & 25 & 25 & 25 & 25 & 25 & 25 & 25 & 25 & 25 & 25 & 25 & 25 & \multirow{2}{*}{45} & \multirow{2}{*}{42} \\
\hline & 23 & 44 & 24 & 65 & 43 & 24 & 86 & 54 & 22 & 52 & 50 & 50 & & \\
\hline \multirow{2}{*}{ NULL } & 45 & 45 & 45 & 45 & 45 & 45 & 45 & 45 & 45 & 45 & 45 & 45 & \multirow{2}{*}{65} & \multirow{2}{*}{100} \\
\hline & 45 & 46 & 51 & 53 & 58 & 55 & 59 & 60 & 65 & 66 & 77 & 88 & & \\
\hline \multirow{2}{*}{ NULL } & 98 & 98 & 98 & 98 & 98 & 98 & 98 & 98 & 98 & 98 & 98 & 98 & \multirow{2}{*}{98} & \multirow{2}{*}{65} \\
\hline & 45 & 45 & 25 & 78 & 56 & 44 & 57 & 55 & 56 & 54 & 53 & 51 & & \\
\hline \multirow{2}{*}{ NULL } & 56 & 56 & 56 & 56 & 56 & 56 & 56 & 56 & 56 & 56 & 56 & 56 & \multirow{2}{*}{89} & \multirow{2}{*}{12} \\
\hline & 78 & 77 & 77 & 54 & 36 & 36 & 36 & 36 & 36 & 36 & 36 & 36 & & \\
\hline \multirow{2}{*}{ NULL } & 23 & 23 & 23 & 23 & 23 & 23 & 23 & 23 & 23 & 23 & 23 & 23 & \multirow{2}{*}{85} & \multirow{2}{*}{85} \\
\hline & 44 & 44 & 44 & 44 & 44 & 44 & 44 & 54 & 23 & 4 & 4 & 33 & & \\
\hline
\end{tabular}

\section{Expected Output:}

Error

Actual Output:

Error 
Calc_TC_8_1_PW

\begin{tabular}{|c|c|c|c|c|c|c|c|c|c|c|c|c|c|c|}
\hline $\begin{array}{l}\hat{\theta} \\
\hat{0}\end{array}$ & 寻 & 8 & 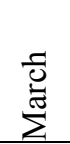 & 安 & $\sum^{\mathrm{m}}$ & 意 & 를 & 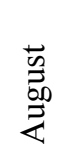 & పे & $\overline{0}$ & z & $\ddot{\mathscr{~}}$ & 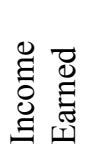 & 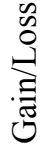 \\
\hline \multirow{2}{*}{ Canada } & & & & & & & 10 & 10 & 10 & 10 & 10 & 10 & \multirow{2}{*}{25} & \multirow{2}{*}{22} \\
\hline & & & & & & & 45 & 34 & 22 & 34 & 87 & 77 & & \\
\hline \multirow{2}{*}{ Canada } & 14 & 14 & 14 & 14 & 14 & 14 & 14 & 14 & & & & & \multirow{2}{*}{11} & \multirow{2}{*}{22} \\
\hline & 14 & 54 & 55 & 45 & 5 & 44 & 71 & 20 & & & & & & \\
\hline \multirow{2}{*}{ Canada } & & & & 33 & 33 & 33 & 33 & 33 & 33 & & & & \multirow{2}{*}{45} & \multirow{2}{*}{44} \\
\hline & & & & 30 & 45 & 66 & 55 & 78 & 79 & & & & & \\
\hline \multirow{2}{*}{ USA } & 25 & 25 & 25 & 25 & 25 & 25 & 25 & 25 & 25 & 25 & & & \multirow{2}{*}{44} & \multirow{2}{*}{55} \\
\hline & 23 & 44 & 24 & 65 & 43 & 24 & 86 & 54 & 22 & 52 & & & & \\
\hline \multirow{2}{*}{ USA } & & & & & & & & & & 45 & 45 & 45 & \multirow{2}{*}{41} & \multirow{2}{*}{42} \\
\hline & & 08 & & 0 & 0 & & 80 & & & 66 & 77 & 88 & & \\
\hline China & 45 & 45 & 25 & 78 & 56 & 44 & 57 & & & & & & 23 & 11 \\
\hline \multirow{2}{*}{ China } & & & 56 & 56 & 56 & & & & & & & & \multirow{2}{*}{61} & \multirow{2}{*}{47} \\
\hline & & & 77 & 54 & 36 & & & & & & & & & \\
\hline \multirow{2}{*}{ Mexico } & & & & & & & 23 & 23 & 23 & 23 & 23 & 23 & \multirow{2}{*}{45} & \multirow{2}{*}{30} \\
\hline & & & & & & & 44 & 54 & 23 & 4 & 4 & 33 & & \\
\hline
\end{tabular}

\section{Expected Output:}

\begin{tabular}{|l|l|l|l|l|l|}
\hline $\begin{array}{l}\text { Grouping } \\
\text { Countries }\end{array}$ & $\begin{array}{l}\text { Maximum } \\
\text { Cost }\end{array}$ & $\begin{array}{l}\text { Maximum fair } \\
\text { market value }\end{array}$ & $\begin{array}{l}\text { Fair market } \\
\text { value at year end }\end{array}$ & $\begin{array}{l}\text { Foreign income } \\
\text { earned or loss }\end{array}$ & $\begin{array}{l}\text { Capital } \\
\text { gain/loss }\end{array}$ \\
\hline \multirow{3}{*}{ CANADA } & \multirow{3}{*}{26} & 171 & 77 & 81 & 88 \\
\cline { 1 - 5 } & & 118 & 88 & 82 & 97 \\
\cline { 3 - 6 } USA & 132 & 0 & 84 & 58 \\
\cline { 3 - 6 } CHINA & 54 & 33 & 45 & 30 \\
\hline MEXICO & & & & \\
\hline
\end{tabular}

\section{Actual Output:}

\begin{tabular}{|c|c|c|c|c|c|}
\hline $\begin{array}{l}\text { Grouping } \\
\text { Countries }\end{array}$ & $\begin{array}{l}\text { Maximum } \\
\text { Cost }\end{array}$ & $\begin{array}{l}\text { Maximum fair } \\
\text { market value }\end{array}$ & $\begin{array}{l}\text { Fair market } \\
\text { value at year end }\end{array}$ & $\begin{array}{l}\text { Foreign income } \\
\text { earned or loss }\end{array}$ & $\begin{array}{l}\text { Capital } \\
\text { gain/loss }\end{array}$ \\
\hline CANADA & \multirow{4}{*}{226} & 171 & 77 & 81 & 88 \\
\hline USA & & 118 & 88 & 85 & 97 \\
\hline CHINA & & 132 & 0 & 84 & 58 \\
\hline MEXICO & & 54 & 33 & 45 & 30 \\
\hline
\end{tabular}




\section{C.2 Annotated CP Specifications}

\section{CountryOfSecurity}

- Value
- DifferentForAll
- SameForAll
$\circ \quad$ Empty [Single]
○ Missing [Error]

\section{Base-Choice Test Frames and Test Cases}

Frame 1:

AllValuesPresent.Value.False

CountriesForSecurities.Value.DifferentForAll

Frame 2:

AllValuesPresent.Value.True

CountriesForSecurities.Value.DifferentForAll
Frame 3:

AllValuesPresent.Value.False

CountriesForSecurities.Value.SameForAll

Frame 4:

AllValuesPresent.Value.False

CountriesForSecurities.Value.Empty

Frame 5:

CountriesForSecurities.Value.Missing 
Calc_1_TC_1_1_BC_Ann

\begin{tabular}{|c|c|c|c|c|c|c|c|c|c|c|c|c|c|c|}
\hline $\begin{array}{l}\vec{E} \\
\text { 吾 } \\
\text { U }\end{array}$ & 寻 & $\begin{array}{l}0 \\
0 \\
\end{array}$ & $\begin{array}{l}\text { D̃ } \\
\sum^{\pi}\end{array}$ & $\bar{z}$ & $\stackrel{\vec{\pi}}{\mathrm{\Sigma}}$ & $\Xi$ & $\frac{\lambda}{\Xi}$ & 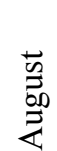 & 苍 & $\overrightarrow{0}$ & $\vec{z}$ & ச̊ & 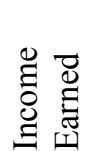 & 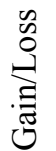 \\
\hline \multirow{2}{*}{ Canada } & & & & & & & 10 & 10 & 10 & 10 & 10 & 10 & \multirow{2}{*}{25} & \multirow{2}{*}{22} \\
\hline & & & & & & & 45 & 34 & 22 & 34 & 87 & 77 & & \\
\hline \multirow{2}{*}{ Canada } & 14 & 14 & 14 & 14 & 14 & 14 & 14 & 14 & & & & & \multirow[b]{2}{*}{11} & \multirow{2}{*}{22} \\
\hline & 14 & 54 & 55 & 45 & 5 & 44 & 71 & 20 & & & & & & \\
\hline \multirow{2}{*}{ Canada } & & & & 33 & 33 & 33 & 33 & 33 & 33 & & & & \multirow{2}{*}{45} & \multirow{2}{*}{44} \\
\hline & & & & 30 & 45 & 66 & 55 & 78 & 79 & & & & & \\
\hline \multirow{2}{*}{ USA } & 25 & 25 & 25 & 25 & 25 & 25 & 25 & 25 & 25 & 25 & & & \multirow{2}{*}{44} & \multirow{2}{*}{55} \\
\hline & 23 & 44 & 24 & 65 & 43 & 24 & 86 & 54 & 22 & 52 & & & & \\
\hline \multirow{2}{*}{ USA } & & & & & & & & & & 45 & 45 & 45 & \multirow{2}{*}{41} & \multirow{2}{*}{42} \\
\hline & & & & & & & & & & 66 & 77 & 88 & & \\
\hline \multirow{2}{*}{ China } & 98 & 98 & 98 & 98 & 98 & 98 & 98 & & & & & & \multirow{2}{*}{23} & \multirow{2}{*}{11} \\
\hline & 45 & 45 & 25 & 78 & 56 & 44 & 57 & & & & & & & \\
\hline \multirow{2}{*}{ China } & & & 56 & 56 & 56 & & & & & & & & \multirow{2}{*}{61} & \multirow{2}{*}{47} \\
\hline & & & 77 & 54 & 36 & & & & & & & & & \\
\hline \multirow{2}{*}{ Mexico } & & & & & & & 23 & 23 & 23 & 23 & 23 & 23 & \multirow{2}{*}{45} & \multirow{2}{*}{30} \\
\hline & & & & & & & 44 & 54 & 23 & 4 & 4 & 33 & & \\
\hline
\end{tabular}

\section{Expected Output:}

\begin{tabular}{|l|l|l|l|l|l|}
\hline $\begin{array}{l}\text { Grouping } \\
\text { Countries }\end{array}$ & $\begin{array}{l}\text { Maximum } \\
\text { Cost }\end{array}$ & $\begin{array}{l}\text { Maximum fair } \\
\text { market value }\end{array}$ & $\begin{array}{l}\text { Fair market } \\
\text { value at year end }\end{array}$ & $\begin{array}{l}\text { Foreign income } \\
\text { earned or loss }\end{array}$ & $\begin{array}{l}\text { Capital } \\
\text { gain/loss }\end{array}$ \\
\hline \multirow{3}{*}{ CANADA } & \multirow{3}{*}{26} & 171 & 77 & 81 & 88 \\
\cline { 1 - 5 } USA & 118 & 88 & 85 & 97 \\
\cline { 3 - 6 } CHINA & 132 & 0 & 84 & 58 \\
\hline MEXICO & & 54 & 33 & 45 & 30 \\
\cline { 3 - 5 } & & & & \\
\hline
\end{tabular}

\section{Actual Output:}

\begin{tabular}{|l|l|l|l|l|l|}
\hline $\begin{array}{l}\text { Grouping } \\
\text { Countries }\end{array}$ & $\begin{array}{l}\text { Maximum } \\
\text { Cost }\end{array}$ & $\begin{array}{l}\text { Maximum fair } \\
\text { market value }\end{array}$ & $\begin{array}{l}\text { Fair market } \\
\text { value at year end }\end{array}$ & $\begin{array}{l}\text { Foreign income } \\
\text { earned or loss }\end{array}$ & $\begin{array}{l}\text { Capital } \\
\text { gain/loss }\end{array}$ \\
\hline \multirow{3}{*}{ CANADA } & \multirow{3}{*}{26} & 171 & 77 & 81 & 88 \\
\cline { 1 - 5 } USA & 118 & 88 & 85 & 97 \\
\cline { 3 - 6 } CHINA & 132 & 0 & 84 & 58 \\
\cline { 3 - 6 } & & 54 & 33 & 45 & 30 \\
\hline
\end{tabular}


Calc_1_TC_2_1_BC_Ann

\begin{tabular}{|c|c|c|c|c|c|c|c|c|c|c|c|c|c|c|}
\hline $\begin{array}{l}\hat{E} \\
\text { 吾 }\end{array}$ & E్ & $\begin{array}{l}0 \\
0 \\
\end{array}$ & $\begin{array}{l}\bar{D} \\
\bar{\Xi} \\
\Sigma\end{array}$ & $\overline{\frac{2}{4}}$ & $\stackrel{\overrightarrow{\mathrm{I}}}{\mathrm{z}}$ & $\Xi$ & $\frac{\lambda}{3}$ & $\begin{array}{l}\vec{w} \\
\overrightarrow{0} \\
\overrightarrow{0} \\
\vec{Z}\end{array}$ & 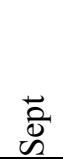 & $\overrightarrow{0}$ & z & ڤ̈ & 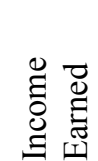 & 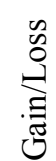 \\
\hline \multirow{2}{*}{ Canada } & 10 & 10 & 10 & 10 & 10 & 10 & 10 & 10 & 10 & 10 & 10 & 10 & \multirow{2}{*}{60} & \multirow{2}{*}{30} \\
\hline & 21 & 22 & 23 & 25 & 22 & 40 & 45 & 34 & 22 & 34 & 87 & 77 & & \\
\hline \multirow{2}{*}{ Canada } & 14 & 14 & 14 & 14 & 14 & 14 & 14 & 14 & 14 & 14 & 14 & 14 & \multirow{2}{*}{40} & \multirow{2}{*}{50} \\
\hline & 14 & 54 & 55 & 45 & 5 & 44 & 71 & 20 & 22 & 24 & 22 & 24 & & \\
\hline \multirow{2}{*}{ USA } & 25 & 25 & 25 & 25 & 25 & 25 & 25 & 25 & 25 & 25 & 25 & 25 & \multirow{2}{*}{45} & \multirow{2}{*}{42} \\
\hline & 23 & 44 & 24 & 65 & 43 & 24 & 86 & 54 & 22 & 52 & 50 & 50 & & \\
\hline \multirow{2}{*}{ USA } & 45 & 45 & 45 & 45 & 45 & 45 & 45 & 45 & 45 & 45 & 45 & 45 & \multirow{2}{*}{65} & \multirow{2}{*}{60} \\
\hline & 45 & 46 & 51 & 53 & 58 & 55 & 59 & 60 & 65 & 66 & 77 & 88 & & \\
\hline \multirow{2}{*}{ China } & 98 & 98 & 98 & 98 & 98 & 98 & 98 & 98 & 98 & 98 & 98 & 98 & \multirow{2}{*}{30} & \multirow{2}{*}{65} \\
\hline & 45 & 45 & 25 & 78 & 56 & 44 & 57 & 55 & 56 & 54 & 53 & 51 & & \\
\hline \multirow{2}{*}{ China } & 56 & 56 & 56 & 56 & 56 & 56 & 56 & 56 & 56 & 56 & 56 & 56 & \multirow[b]{2}{*}{89} & \multirow[b]{2}{*}{12} \\
\hline & 78 & 77 & 77 & 54 & 36 & 36 & 36 & 36 & 36 & 36 & 36 & 36 & & \\
\hline \multirow{2}{*}{ Mexico } & 23 & 23 & 23 & 23 & 23 & 23 & 23 & 23 & 23 & 23 & 23 & 23 & \multirow{2}{*}{45} & \multirow{2}{*}{45} \\
\hline & 44 & 44 & 44 & 44 & 44 & 44 & 44 & 54 & 23 & 4 & 4 & 33 & & \\
\hline
\end{tabular}

\section{Expected Output:}

\begin{tabular}{|l|l|l|l|l|l|}
\hline $\begin{array}{l}\text { Grouping } \\
\text { Countries }\end{array}$ & \multirow{2}{*}{$\begin{array}{l}\text { Maximum } \\
\text { Cost }\end{array}$} & $\begin{array}{l}\text { Maximum fair } \\
\text { market value }\end{array}$ & $\begin{array}{l}\text { Fair market } \\
\text { value at year end }\end{array}$ & $\begin{array}{l}\text { Foreign income } \\
\text { earned or loss }\end{array}$ & $\begin{array}{l}\text { Capital } \\
\text { gain/loss }\end{array}$ \\
\hline \multirow{3}{*}{ CANADA } & \multirow{3}{*}{271} & 116 & 101 & 100 & 80 \\
\cline { 1 - 4 } USA & 145 & 138 & 110 & 102 \\
\cline { 3 - 6 } CHINA & 132 & 87 & 119 & 77 \\
\hline MEXICO & 54 & 33 & 45 & 45 \\
\cline { 3 - 5 } & & & & \\
\hline
\end{tabular}

\section{Actual Output:}

\begin{tabular}{|l|l|l|l|l|l|}
\hline $\begin{array}{l}\text { Grouping } \\
\text { Countries }\end{array}$ & \multirow{2}{*}{$\begin{array}{l}\text { Maximum } \\
\text { Cost }\end{array}$} & $\begin{array}{l}\text { Maximum fair } \\
\text { market value }\end{array}$ & $\begin{array}{l}\text { Fair market } \\
\text { value at year end }\end{array}$ & $\begin{array}{l}\text { Foreign income } \\
\text { earned or loss }\end{array}$ & $\begin{array}{l}\text { Capital } \\
\text { gain/loss }\end{array}$ \\
\hline \multirow{3}{*}{ CANADA } & \multirow{3}{*}{271} & 116 & 101 & 100 & 80 \\
\cline { 1 - 5 } USA & 145 & 138 & 110 & 102 \\
\cline { 3 - 5 } CHINA & 132 & 87 & 119 & 77 \\
\cline { 3 - 5 } MEXICO & 54 & 33 & 45 & 45 \\
\hline
\end{tabular}


Calc_1_TC_3_1_BC_Ann

\begin{tabular}{|c|c|c|c|c|c|c|c|c|c|c|c|c|c|c|}
\hline $\begin{array}{l}0 \\
0 \\
0 \\
0\end{array}$ & Еี & 这 & 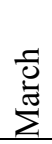 & 言 & $\sum_{i}^{\mathrm{g}}$ & 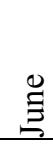 & $\vec{\Xi}$ & $\begin{array}{l}\frac{5}{5} \\
500 \\
z \\
\end{array}$ & 苛 & $\ddot{0}$ & $\vec{z}$ & $\ddot{\Xi}$ & 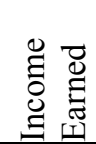 & 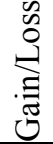 \\
\hline Canada & & & & & & & $\frac{10}{45}$ & 10 & 10 & 10 & 10 & $\frac{10}{77}$ & 25 & \multirow{2}{*}{22} \\
\hline \multirow{2}{*}{ Canada } & 14 & 14 & 14 & 14 & 14 & 14 & $\frac{45}{14}$ & $\frac{34}{14}$ & & & 01 & 11 & \multirow[b]{2}{*}{11} & \\
\hline & 14 & 54 & 55 & 45 & 5 & 44 & 71 & 20 & & & & & & 22 \\
\hline \multirow{2}{*}{ Canada } & & & & 33 & 33 & 33 & 33 & 33 & 33 & & & & \multirow{2}{*}{45} & \multirow{2}{*}{44} \\
\hline & & & & 30 & 45 & 66 & 55 & 78 & 79 & & & & & \\
\hline \multirow{2}{*}{ Canada } & 25 & 25 & 25 & 25 & 25 & 25 & 25 & 25 & 25 & 25 & & & \multirow{2}{*}{88} & \multirow{2}{*}{98} \\
\hline & 23 & 44 & 24 & 65 & 43 & 24 & 86 & 54 & 22 & 52 & & & & \\
\hline
\end{tabular}

\section{Expected Output:}

\begin{tabular}{|l|l|l|l|l|l|}
\hline $\begin{array}{l}\text { Grouping } \\
\text { Countries }\end{array}$ & $\begin{array}{l}\text { Maximum } \\
\text { Cost }\end{array}$ & $\begin{array}{l}\text { Maximum fair } \\
\text { market value }\end{array}$ & $\begin{array}{l}\text { Fair market } \\
\text { value at year end }\end{array}$ & $\begin{array}{l}\text { Foreign income } \\
\text { earned or loss }\end{array}$ & $\begin{array}{l}\text { Capital } \\
\text { gain/loss }\end{array}$ \\
\hline CANADA & 82 & 257 & 77 & 169 & 186 \\
\hline
\end{tabular}

\section{Actual Output:}

\begin{tabular}{|l|l|l|l|l|l|}
\hline $\begin{array}{l}\text { Grouping } \\
\text { Countries }\end{array}$ & $\begin{array}{l}\text { Maximum } \\
\text { Cost }\end{array}$ & $\begin{array}{l}\text { Maximum fair } \\
\text { market value }\end{array}$ & $\begin{array}{l}\text { Fair market } \\
\text { value at year end }\end{array}$ & $\begin{array}{l}\text { Foreign income } \\
\text { earned or loss }\end{array}$ & $\begin{array}{l}\text { Capital } \\
\text { gain/loss }\end{array}$ \\
\hline CANADA & 82 & 257 & 77 & 169 & 186 \\
\hline
\end{tabular}

Calc_1_TC_4_1_BC_Ann

\begin{tabular}{|c|c|c|c|c|c|c|c|c|c|c|c|c|c|c|}
\hline 㝵 & ⿷్ & 屋 & $\begin{array}{l}\overline{0} \\
\overline{0} \\
\Sigma\end{array}$ & 焉 & $\sum^{\mathrm{m}}$ & 莺 & $\overrightarrow{2}$ & 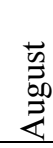 & $\begin{array}{l}\overrightarrow{0} \\
\ddot{0} \\
\ddot{n}\end{array}$ & 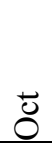 & zo & $\ddot{\Xi}$ & 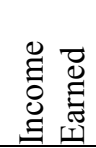 & $\begin{array}{l}\text {. } \\
\stackrel{0}{0} \\
\stackrel{0}{0}\end{array}$ \\
\hline \multirow{2}{*}{ Empty } & & & & & & & 10 & 10 & 10 & 10 & 10 & 10 & \multirow{2}{*}{25} & \multirow{2}{*}{22} \\
\hline & & & & & & & 45 & 34 & 22 & 34 & 87 & 77 & & \\
\hline \multirow{2}{*}{ Empty } & 14 & 14 & 14 & 14 & 14 & 14 & 14 & 14 & & & & & \multirow{2}{*}{11} & \multirow{2}{*}{22} \\
\hline & 14 & 54 & 55 & 45 & 5 & 44 & 71 & 20 & & & & & & \\
\hline Empty & & & & 33 & 33 & 33 & 33 & 33 & 33 & & & & 45 & 44 \\
\hline \multirow[b]{2}{*}{ Empty } & 25 & 25 & 25 & 25 & $\frac{75}{25}$ & 25 & 25 & 25 & 25 & 25 & & & \multirow[b]{2}{*}{8} & \multirow[b]{2}{*}{98} \\
\hline & 23 & 44 & 24 & 65 & 43 & 24 & 86 & 54 & 22 & 52 & & & & \\
\hline
\end{tabular}




\section{Expected Output:}

\begin{tabular}{|l|l|l|l|l|l|}
\hline $\begin{array}{l}\text { Grouping } \\
\text { Countries }\end{array}$ & $\begin{array}{l}\text { Maximum } \\
\text { Cost }\end{array}$ & $\begin{array}{l}\text { Maximum fair } \\
\text { market value }\end{array}$ & $\begin{array}{l}\text { Fair market } \\
\text { value at year end }\end{array}$ & $\begin{array}{l}\text { Foreign income } \\
\text { earned or loss }\end{array}$ & $\begin{array}{l}\text { Capital } \\
\text { gain/loss }\end{array}$ \\
\hline Empty & 82 & 257 & 77 & 169 & 186 \\
\hline
\end{tabular}

\section{Actual Output:}

\begin{tabular}{|l|l|l|l|l|l|}
\hline $\begin{array}{l}\text { Grouping } \\
\text { Countries }\end{array}$ & $\begin{array}{l}\text { Maximum } \\
\text { Cost }\end{array}$ & $\begin{array}{l}\text { Maximum fair } \\
\text { market value }\end{array}$ & $\begin{array}{l}\text { Fair market } \\
\text { value at year end }\end{array}$ & $\begin{array}{l}\text { Foreign income } \\
\text { earned or loss }\end{array}$ & $\begin{array}{l}\text { Capital } \\
\text { gain/loss }\end{array}$ \\
\hline Empty & 82 & 257 & 77 & 169 & 186 \\
\hline
\end{tabular}

Calc_1_TC_5_1_BC_Ann

\begin{tabular}{|c|c|c|c|c|c|c|c|c|c|c|c|c|c|c|}
\hline $\begin{array}{l}\text { 音 } \\
\text { 己 }\end{array}$ & 胥 & $\begin{array}{l}0 \\
0\end{array}$ & $\begin{array}{l}\text { ग्र } \\
\stackrel{\Xi}{\pi}\end{array}$ & $\overline{\bar{z}}$ & $\stackrel{\vec{\lambda}}{\Sigma}$ & $\stackrel{\Xi}{\Xi}$ & $\vec{\Xi}$ & 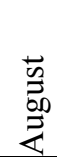 & $\begin{array}{l}\overrightarrow{0} 0 \\
0 \\
0\end{array}$ & $\overrightarrow{0}$ & z & $\ddot{\mathscr{N}}$ & 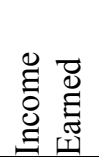 & 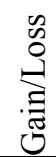 \\
\hline \multirow{2}{*}{ NULL } & & & & & & & 10 & 10 & 10 & 10 & 10 & 10 & \multirow[b]{2}{*}{25} & \multirow[b]{2}{*}{22} \\
\hline & & & & & & & 45 & 34 & 22 & 34 & 87 & 77 & & \\
\hline \multirow[b]{2}{*}{ NULL } & 14 & 14 & 14 & 14 & 14 & 14 & 14 & 14 & & & & & \multirow[b]{2}{*}{11} & \multirow[b]{2}{*}{22} \\
\hline & 14 & 54 & 55 & 45 & 5 & 44 & 71 & 20 & & & & & & \\
\hline \multirow{2}{*}{ NULL } & & & & 33 & 33 & 33 & 33 & 33 & 33 & & & & \multirow{2}{*}{45} & \multirow{2}{*}{44} \\
\hline & & & & 30 & 45 & 66 & 55 & 78 & 79 & & & & & \\
\hline \multirow{2}{*}{ NULL } & 25 & 25 & 25 & 25 & 25 & 25 & 25 & 25 & 25 & 25 & & & \multirow{2}{*}{88} & \multirow{2}{*}{98} \\
\hline & 23 & 44 & 24 & 65 & 43 & 24 & 86 & 54 & 22 & 52 & & & & \\
\hline
\end{tabular}

\section{Expected Output:}

Error

\section{Actual Output:}

Error 


\section{Each-Choice Test Frames and Test Cases}

Frame 1:

AllValuesPresent.Value.False

CountriesForSecurities.Value.DifferentForAll

Frame 2:

AllValuesPresent.Value.True

CountriesForSecurities. Value.SameForAll
Frame 3:

AllValuesPresent.Value.False

CountriesForSecurities.Value.Empty

Frame 4:

CountriesForSecurities.Value.Missing

Calc_1_TC_1_1_EC_Ann

\begin{tabular}{|c|c|c|c|c|c|c|c|c|c|c|c|c|c|c|}
\hline 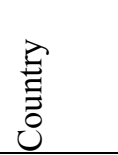 & E & $\begin{array}{l}0 \\
0 \\
1\end{array}$ & $\begin{array}{l}\frac{1}{0} \\
\stackrel{\pi}{ \pm}\end{array}$ & 竞 & $\stackrel{\vec{J}}{\Sigma}$ & $\stackrel{\Xi}{\Xi}$ & $\underline{\Xi}$ & 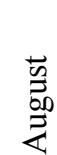 & 苍 & $\overleftarrow{\circlearrowright}$ & zo & ڤ్ల & 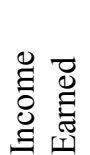 & 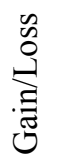 \\
\hline \multirow{2}{*}{ Canada } & & & & & & & 10 & 10 & 10 & 10 & 10 & 10 & \multirow{2}{*}{25} & \multirow{2}{*}{22} \\
\hline & & & & & & & 45 & 34 & 22 & 34 & 87 & 77 & & \\
\hline \multirow{2}{*}{ Canada } & 14 & 14 & 14 & 14 & 14 & 14 & 14 & 14 & & & & & \multirow{2}{*}{11} & \multirow{2}{*}{22} \\
\hline & 14 & 54 & 55 & 45 & 5 & 44 & 71 & 20 & & & & & & \\
\hline \multirow{2}{*}{ Canada } & & & & 33 & 33 & 33 & 33 & 33 & 33 & & & & \multirow{2}{*}{45} & \multirow{2}{*}{44} \\
\hline & & & & 30 & 45 & 66 & 55 & 78 & 79 & & & & & \\
\hline \multirow{2}{*}{ USA } & 25 & 25 & 25 & 25 & 25 & 25 & 25 & 25 & 25 & 25 & & & \multirow{2}{*}{44} & \multirow{2}{*}{55} \\
\hline & 23 & 44 & 24 & 65 & 43 & 24 & 86 & 54 & 22 & 52 & & & & \\
\hline \multirow{2}{*}{ USA } & & & & & & & & & & 45 & 45 & 45 & \multirow{2}{*}{41} & \multirow{2}{*}{42} \\
\hline & & & & & & & & & & 66 & 77 & 88 & & \\
\hline \multirow{2}{*}{ China } & 98 & 98 & 98 & 98 & 98 & 98 & 98 & & & & & & \multirow{2}{*}{23} & \multirow{2}{*}{11} \\
\hline & 45 & 45 & 25 & 78 & 56 & 44 & 57 & & & & & & & \\
\hline \multirow{2}{*}{ China } & & & 56 & 56 & 56 & & & & & & & & \multirow{2}{*}{61} & \multirow{2}{*}{47} \\
\hline & & & 77 & 54 & 36 & & & & & & & & & \\
\hline \multirow{2}{*}{ Mexico } & & & & & & & 23 & 23 & 23 & 23 & 23 & 23 & \multirow{2}{*}{45} & \multirow{2}{*}{30} \\
\hline & & & & & & & 44 & 54 & 23 & 4 & 4 & 33 & & \\
\hline
\end{tabular}

\section{Expected Output:}

\begin{tabular}{|l|l|l|l|l|l|}
\hline $\begin{array}{l}\text { Grouping } \\
\text { Countries }\end{array}$ & $\begin{array}{l}\text { Maximum } \\
\text { Cost }\end{array}$ & $\begin{array}{l}\text { Maximum fair } \\
\text { market value }\end{array}$ & $\begin{array}{l}\text { Fair market } \\
\text { value at year end }\end{array}$ & $\begin{array}{l}\text { Foreign income } \\
\text { earned or loss }\end{array}$ & $\begin{array}{l}\text { Capital } \\
\text { gain/loss }\end{array}$ \\
\hline \multirow{2}{*}{ CANADA } & \multirow{3}{*}{226} & 171 & 77 & 81 & 88 \\
\cline { 3 - 6 } USA & 118 & 88 & 85 & 97 \\
\cline { 3 - 6 } CHINA & 132 & 0 & 84 & 58 \\
\cline { 3 - 6 } MEXICO & 54 & 33 & 45 & 30 \\
\hline
\end{tabular}




\section{Actual Output:}

\begin{tabular}{|l|l|l|l|l|l|}
\hline $\begin{array}{l}\text { Grouping } \\
\text { Countries }\end{array}$ & \multirow{2}{*}{$\begin{array}{l}\text { Maximum } \\
\text { Cost }\end{array}$} & $\begin{array}{l}\text { Maximum fair } \\
\text { market value }\end{array}$ & $\begin{array}{l}\text { Fair market } \\
\text { value at year end }\end{array}$ & $\begin{array}{l}\text { Foreign income } \\
\text { earned or loss }\end{array}$ & $\begin{array}{l}\text { Capital } \\
\text { gain/loss }\end{array}$ \\
\hline \multirow{3}{*}{ CANADA } & \multirow{3}{*}{26} & 171 & 77 & 81 & 88 \\
\cline { 3 - 6 } USA & 118 & 88 & 85 & 97 \\
\cline { 3 - 6 } CHINA & 132 & 0 & 84 & 58 \\
\cline { 3 - 6 } MEXICO & 54 & 33 & 45 & 30 \\
\hline
\end{tabular}

Calc_1_TC_2_1_EC_Ann

\begin{tabular}{|c|c|c|c|c|c|c|c|c|c|c|c|c|c|c|}
\hline $\begin{array}{l}\stackrel{\vec{E}}{\Xi} \\
\stackrel{\Xi}{0}\end{array}$ & స్ & $\begin{array}{l}80 \\
1 \\
\end{array}$ & 总 & $\overline{\bar{z}}$ & 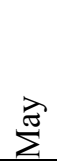 & $\Xi$ & $\frac{\lambda}{3}$ & 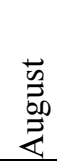 & 苛 & $\ddot{0}$ & zे & : & 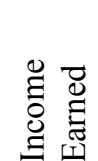 & 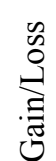 \\
\hline \multirow{2}{*}{ Canada } & 10 & 10 & 10 & 10 & 10 & 10 & 10 & 10 & 10 & 10 & 10 & 10 & \multirow{2}{*}{60} & \multirow{2}{*}{30} \\
\hline & 21 & 22 & 23 & 25 & 22 & 40 & 45 & 34 & 22 & 34 & 87 & 77 & & \\
\hline \multirow{2}{*}{ Canada } & 14 & 14 & 14 & 14 & 14 & 14 & 14 & 14 & 14 & 14 & 14 & 14 & \multirow{2}{*}{40} & \multirow{2}{*}{50} \\
\hline & 14 & 54 & 55 & 45 & 5 & 44 & 71 & 20 & 22 & 24 & 22 & 24 & & \\
\hline \multirow{2}{*}{ Canada } & 25 & 25 & 25 & 25 & 25 & 25 & 25 & 25 & 25 & 25 & 25 & 25 & \multirow{2}{*}{45} & \multirow{2}{*}{42} \\
\hline & 23 & 44 & 24 & 65 & 43 & 24 & 86 & 54 & 22 & 52 & 50 & 50 & & \\
\hline \multirow{2}{*}{ Canada } & 45 & 45 & 45 & 45 & 45 & 45 & 45 & 45 & 45 & 45 & 45 & 45 & \multirow{2}{*}{65} & \multirow{2}{*}{60} \\
\hline & 45 & 46 & 51 & 53 & 58 & 55 & 59 & 60 & 65 & 66 & 77 & 88 & & \\
\hline \multirow{2}{*}{ Canada } & 98 & 98 & 98 & 98 & 98 & 98 & 98 & 98 & 98 & 98 & 98 & 98 & \multirow{2}{*}{30} & \multirow{2}{*}{65} \\
\hline & 45 & 45 & 25 & 78 & 56 & 44 & 57 & 55 & 56 & 54 & 53 & 51 & & \\
\hline \multirow{2}{*}{ Canada } & 56 & 56 & 56 & 56 & 56 & 56 & 56 & 56 & 56 & 56 & 56 & 56 & \multirow{2}{*}{89} & \multirow{2}{*}{12} \\
\hline & 78 & 77 & 77 & 54 & 36 & 36 & 36 & 36 & 36 & 36 & 36 & 36 & & \\
\hline \multirow{2}{*}{ Canada } & 23 & 23 & 23 & 23 & 23 & 23 & 23 & 23 & 23 & 23 & 23 & 23 & \multirow{2}{*}{45} & \multirow{2}{*}{45} \\
\hline & 44 & 44 & 44 & 44 & 44 & 44 & 44 & 54 & 23 & 4 & 4 & 33 & & \\
\hline
\end{tabular}

\section{Expected Output:}

\begin{tabular}{|l|l|l|l|l|l|}
\hline $\begin{array}{l}\text { Grouping } \\
\text { Countries }\end{array}$ & $\begin{array}{l}\text { Maximum } \\
\text { Cost }\end{array}$ & $\begin{array}{l}\text { Maximum fair } \\
\text { market value }\end{array}$ & $\begin{array}{l}\text { Fair market } \\
\text { value at year end }\end{array}$ & $\begin{array}{l}\text { Foreign income } \\
\text { earned or loss }\end{array}$ & $\begin{array}{l}\text { Capital } \\
\text { gain/loss }\end{array}$ \\
\hline CANADA & 271 & 398 & 359 & 374 & 304 \\
\hline
\end{tabular}

\section{Actual Output:}

\begin{tabular}{|l|l|l|l|l|l|}
\hline $\begin{array}{l}\text { Grouping } \\
\text { Countries }\end{array}$ & $\begin{array}{l}\text { Maximum } \\
\text { Cost }\end{array}$ & $\begin{array}{l}\text { Maximum fair } \\
\text { market value }\end{array}$ & $\begin{array}{l}\text { Fair market } \\
\text { value at year end }\end{array}$ & $\begin{array}{l}\text { Foreign income } \\
\text { earned or loss }\end{array}$ & $\begin{array}{l}\text { Capital } \\
\text { gain/loss }\end{array}$ \\
\hline CANADA & 271 & 398 & 359 & 374 & 304 \\
\hline
\end{tabular}


Calc_1_TC_3_1_EC_Ann

\begin{tabular}{|c|c|c|c|c|c|c|c|c|c|c|c|c|c|c|}
\hline 言 & 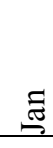 & 屏 & $\begin{array}{l}\bar{E} \\
\overline{\tilde{J}} \\
\Sigma\end{array}$ & 运 & $\sum^{\mathrm{\Xi}}$ & 怘 & 齐 & 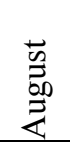 & $\begin{array}{l}0 \\
\overline{0} \\
\ddot{n}\end{array}$ & 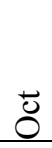 & zُ & $\stackrel{\mathscr{\Xi}}{\varrho}$ & 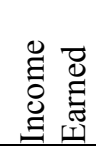 & 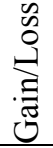 \\
\hline \multirow{2}{*}{ Empty } & & & & & & & 10 & 10 & 10 & 10 & 10 & 10 & \multirow{2}{*}{25} & \multirow{2}{*}{22} \\
\hline & 14 & 14 & 14 & 11 & 1 & 14 & $\frac{45}{14}$ & $\frac{34}{14}$ & 22 & 34 & 87 & 77 & & \\
\hline Empty & 14 & 54 & 55 & 45 & 5 & $\frac{14}{44}$ & $\frac{14}{71}$ & $\frac{14}{20}$ & & & & & 11 & 22 \\
\hline \multirow{2}{*}{ Empty } & & & & 33 & 33 & 33 & 33 & 33 & 33 & & & & \multirow[b]{2}{*}{45} & \multirow[b]{2}{*}{44} \\
\hline & & & & 30 & 45 & 66 & 55 & 78 & 79 & & & & & \\
\hline \multirow{2}{*}{ Empty } & 25 & 25 & 25 & 25 & 25 & 25 & 25 & 25 & 25 & 25 & & & \multirow{2}{*}{88} & \multirow{2}{*}{98} \\
\hline & 23 & 44 & 24 & 65 & 43 & 24 & 86 & 54 & 22 & 52 & & & & \\
\hline
\end{tabular}

\section{Expected Output:}

\begin{tabular}{|l|l|l|l|l|l|}
\hline $\begin{array}{l}\text { Grouping } \\
\text { Countries }\end{array}$ & $\begin{array}{l}\text { Maximum } \\
\text { Cost }\end{array}$ & $\begin{array}{l}\text { Maximum fair } \\
\text { market value }\end{array}$ & $\begin{array}{l}\text { Fair market } \\
\text { value at year end }\end{array}$ & $\begin{array}{l}\text { Foreign income } \\
\text { earned or loss }\end{array}$ & $\begin{array}{l}\text { Capital } \\
\text { gain/loss }\end{array}$ \\
\hline Empty & 82 & 257 & 77 & 169 & 186 \\
\hline
\end{tabular}

\section{Actual Output:}

\begin{tabular}{|l|l|l|l|l|l|}
\hline $\begin{array}{l}\text { Grouping } \\
\text { Countries }\end{array}$ & $\begin{array}{l}\text { Maximum } \\
\text { Cost }\end{array}$ & $\begin{array}{l}\text { Maximum fair } \\
\text { market value }\end{array}$ & $\begin{array}{l}\text { Fair market } \\
\text { value at year end }\end{array}$ & $\begin{array}{l}\text { Foreign income } \\
\text { earned or loss }\end{array}$ & $\begin{array}{l}\text { Capital } \\
\text { gain/loss }\end{array}$ \\
\hline Empty & 82 & 257 & 77 & 169 & 186 \\
\hline
\end{tabular}

Calc_1_TC_4_1_EC_Ann

\begin{tabular}{|c|c|c|c|c|c|c|c|c|c|c|c|c|c|c|}
\hline 害 & ప్ & 迹 & 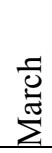 & 容 & $\sum_{\Sigma}^{\overparen{m}}$ & $\Xi$ & $\frac{2}{\Xi}$ & 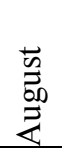 & 气̆ & $\overrightarrow{0}$ & $\vec{z}$ & هั & 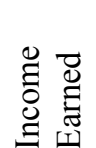 & 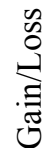 \\
\hline NULL & & & & & & & $\frac{10}{45}$ & $\frac{10}{34}$ & $\frac{10}{20}$ & $\frac{10}{34}$ & $\frac{10}{87}$ & $\frac{10}{77}$ & 25 & 22 \\
\hline \multirow{2}{*}{ NULL } & 14 & 14 & 14 & 14 & 14 & 14 & $\frac{45}{14}$ & $\begin{array}{l}34 \\
14\end{array}$ & & & & & \multirow{2}{*}{11} & \multirow{2}{*}{22} \\
\hline & 14 & 54 & 55 & 45 & 5 & 44 & 71 & 20 & & & & & & \\
\hline \multirow{2}{*}{ NULL } & & & & 33 & 33 & 33 & 33 & 33 & 33 & & & & \multirow{2}{*}{45} & \multirow{2}{*}{44} \\
\hline & & & & 30 & 45 & 66 & 55 & 78 & 79 & & & & & \\
\hline \multirow{2}{*}{ NULL } & 25 & 25 & 25 & 25 & 25 & 25 & 25 & 25 & 25 & 25 & & & \multirow{2}{*}{88} & \multirow{2}{*}{98} \\
\hline & 23 & 44 & 24 & 65 & 43 & 24 & 86 & 54 & 22 & 52 & & & & \\
\hline
\end{tabular}




\section{Expected Output:}

Error

\section{Actual Output:}

Error

\section{Pair-Wise Test Frames and Test Cases}

Frame 1:

AllValuesPresent.Value.True

CountriesForSecurities.Value.SameForAll

Frame 2:

AllValuesPresent.Value.True

CountriesForSecurities.Value.DifferentForAll

Frame 3:

AllValuesPresent.Value.False

CountriesForSecurities.Value.DifferentForAll
Frame 4:

AllValuesPresent.Value.False

CountriesForSecurities.Value.SameForAll

Frame 5:

AllValuesPresent.Value.False

CountriesForSecurities.Value.Empty

Frame 6:

CountriesForSecurities.Value.Missing

Calc_1_TC_1_1_PW_Ann

\begin{tabular}{|c|c|c|c|c|c|c|c|c|c|c|c|c|c|c|}
\hline $\begin{array}{l}\vec{E} \\
\stackrel{\Xi}{0}\end{array}$ & Eี & $\begin{array}{l}0 \\
0 \\
1\end{array}$ & 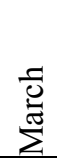 & $\overline{\bar{z}}$ & $\sum^{\circledR}$ & $\Xi$ & 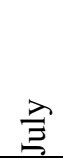 & 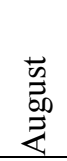 & 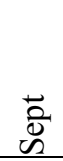 & $\tilde{0}$ & z & $\stackrel{8}{8}$ & 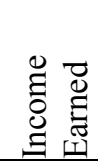 & $\begin{array}{l}\infty \\
0 \\
0 \\
0 \\
0 \\
0 \\
0\end{array}$ \\
\hline \multirow{2}{*}{ Canada } & 10 & 10 & 10 & 10 & 10 & 10 & 10 & 10 & 10 & 10 & 10 & 10 & \multirow{2}{*}{60} & \multirow{2}{*}{30} \\
\hline & 21 & 22 & 23 & 25 & 22 & 40 & 45 & 34 & 22 & 34 & 87 & 77 & & \\
\hline \multirow{2}{*}{ Canada } & 14 & 14 & 14 & 14 & 14 & 14 & 14 & 14 & 14 & 14 & 14 & 14 & \multirow{2}{*}{40} & \multirow{2}{*}{50} \\
\hline & 14 & 54 & 55 & 45 & 5 & 44 & 71 & 20 & 22 & 24 & 22 & 24 & & \\
\hline \multirow{2}{*}{ Canada } & 25 & 25 & 25 & 25 & 25 & 25 & 25 & 25 & 25 & 25 & 25 & 25 & \multirow{2}{*}{45} & \multirow{2}{*}{42} \\
\hline & 23 & 44 & 24 & 65 & 43 & 24 & 86 & 54 & 22 & 52 & 50 & 50 & & \\
\hline \multirow{2}{*}{ Canada } & 45 & 45 & 45 & 45 & 45 & 45 & 45 & 45 & 45 & 45 & 45 & 45 & \multirow{2}{*}{65} & \multirow{2}{*}{60} \\
\hline & 45 & 46 & 51 & 53 & 58 & 55 & 59 & 60 & 65 & 66 & 77 & 88 & & \\
\hline \multirow{2}{*}{ Canada } & 98 & 98 & 98 & 98 & 98 & 98 & 98 & 98 & 98 & 98 & 98 & 98 & \multirow{2}{*}{30} & \multirow{2}{*}{65} \\
\hline & 45 & 45 & 25 & 78 & 56 & 44 & 57 & 55 & 56 & 54 & 53 & 51 & & \\
\hline \multirow{2}{*}{ Canada } & 56 & 56 & 56 & 56 & 56 & 56 & 56 & 56 & 56 & 56 & 56 & 56 & \multirow{2}{*}{89} & \multirow{2}{*}{12} \\
\hline & 78 & 77 & 77 & 54 & 36 & 36 & 36 & 36 & 36 & 36 & 36 & 36 & & \\
\hline \multirow{2}{*}{ Canada } & 23 & 23 & 23 & 23 & 23 & 23 & 23 & 23 & 23 & 23 & 23 & 23 & \multirow{2}{*}{45} & \multirow[b]{2}{*}{4} \\
\hline & 44 & 44 & 44 & 44 & 44 & 44 & 44 & 54 & 23 & 4 & 4 & 33 & & \\
\hline
\end{tabular}




\section{Expected Output:}

\begin{tabular}{|l|l|l|l|l|l|}
\hline $\begin{array}{l}\text { Grouping } \\
\text { Countries }\end{array}$ & $\begin{array}{l}\text { Maximum } \\
\text { Cost }\end{array}$ & $\begin{array}{l}\text { Maximum fair } \\
\text { market value }\end{array}$ & $\begin{array}{l}\text { Fair market } \\
\text { value at year end }\end{array}$ & $\begin{array}{l}\text { Foreign income } \\
\text { earned or loss }\end{array}$ & $\begin{array}{l}\text { Capital } \\
\text { gain/loss }\end{array}$ \\
\hline CANADA & 271 & 398 & 359 & 374 & 304 \\
\hline
\end{tabular}

\section{Actual Output:}

\begin{tabular}{|l|l|l|l|l|l|}
\hline $\begin{array}{l}\text { Grouping } \\
\text { Countries }\end{array}$ & $\begin{array}{l}\text { Maximum } \\
\text { Cost }\end{array}$ & $\begin{array}{l}\text { Maximum fair } \\
\text { market value }\end{array}$ & $\begin{array}{l}\text { Fair market } \\
\text { value at year end }\end{array}$ & $\begin{array}{l}\text { Foreign income } \\
\text { earned or loss }\end{array}$ & $\begin{array}{l}\text { Capital } \\
\text { gain/loss }\end{array}$ \\
\hline CANADA & 271 & 398 & 359 & 374 & 304 \\
\hline
\end{tabular}

Calc_1_TC_2_1_PW_Ann

\begin{tabular}{|c|c|c|c|c|c|c|c|c|c|c|c|c|c|c|}
\hline 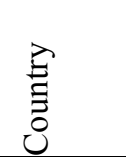 & ్ㅗ & e & $\begin{array}{l}\frac{\sigma}{0} \\
\bar{E} \\
\sum\end{array}$ & $\bar{z}$ & $\stackrel{\vec{\Sigma}}{\mathrm{J}}$ & $\Xi$ & $\frac{\lambda}{3}$ & 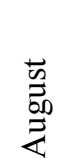 & 苍 & U & z & ֻั & 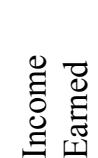 & 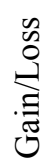 \\
\hline \multirow{2}{*}{ Canada } & 10 & 10 & 10 & 10 & 10 & 10 & 10 & 10 & 10 & 10 & 10 & 10 & \multirow{2}{*}{60} & \multirow{2}{*}{30} \\
\hline & 21 & 22 & 23 & 25 & 22 & 40 & 45 & 34 & 22 & 34 & 87 & 77 & & \\
\hline \multirow{2}{*}{ Canada } & 14 & 14 & 14 & 14 & 14 & 14 & 14 & 14 & 14 & 14 & 14 & 14 & \multirow{2}{*}{40} & \multirow{2}{*}{50} \\
\hline & 14 & 54 & 55 & 45 & 5 & 44 & 71 & 20 & 22 & 24 & 22 & 24 & & \\
\hline \multirow{2}{*}{ USA } & 25 & 25 & 25 & 25 & 25 & 25 & 25 & 25 & 25 & 25 & 25 & 25 & \multirow{2}{*}{45} & \multirow{2}{*}{42} \\
\hline & 23 & 44 & 24 & 65 & 43 & 24 & 86 & 54 & 22 & 52 & 50 & 50 & & \\
\hline \multirow{2}{*}{ USA } & 45 & 45 & 45 & 45 & 45 & 45 & 45 & 45 & 45 & 45 & 45 & 45 & \multirow{2}{*}{65} & \multirow[b]{2}{*}{60} \\
\hline & 45 & 46 & 51 & 53 & 58 & 55 & 59 & 60 & 65 & 66 & 77 & 88 & & \\
\hline \multirow{2}{*}{ China } & 98 & 98 & 98 & 98 & 98 & 98 & 98 & 98 & 98 & 98 & 98 & 98 & \multirow{2}{*}{30} & \multirow{2}{*}{65} \\
\hline & 45 & 45 & 25 & 78 & 56 & 44 & 57 & 55 & 56 & 54 & 53 & 51 & & \\
\hline \multirow{2}{*}{ China } & 56 & 56 & 56 & 56 & 56 & 56 & 56 & 56 & 56 & 56 & 56 & 56 & \multirow[b]{2}{*}{89} & \multirow{2}{*}{12} \\
\hline & 78 & 77 & 77 & 54 & 36 & 36 & 36 & 36 & 36 & 36 & 36 & 36 & & \\
\hline \multirow{2}{*}{ Mexico } & 23 & 23 & 23 & 23 & 23 & 23 & 23 & 23 & 23 & 23 & 23 & 23 & \multirow{2}{*}{45} & \multirow[b]{2}{*}{45} \\
\hline & 44 & 44 & 44 & 44 & 44 & 44 & 44 & 54 & 23 & 4 & 4 & 33 & & \\
\hline
\end{tabular}

\section{Expected Output:}

\begin{tabular}{|l|l|l|l|l|l|}
\hline $\begin{array}{l}\text { Grouping } \\
\text { Countries }\end{array}$ & $\begin{array}{l}\text { Maximum } \\
\text { Cost }\end{array}$ & $\begin{array}{l}\text { Maximum fair } \\
\text { market value }\end{array}$ & $\begin{array}{l}\text { Fair market } \\
\text { value at year end }\end{array}$ & $\begin{array}{l}\text { Foreign income } \\
\text { earned or loss }\end{array}$ & $\begin{array}{l}\text { Capital } \\
\text { gain/loss }\end{array}$ \\
\hline CANADA & \multirow{3}{*}{271} & 116 & 101 & 100 & 80 \\
\cline { 3 - 6 } & 145 & 138 & 110 & 102 \\
\hline USA & 132 & 87 & 119 & 77 \\
\cline { 3 - 6 } CHINA & 54 & 33 & 45 & 45 \\
\hline MEXICO & & & & \\
\hline
\end{tabular}




\section{Actual Output:}

\begin{tabular}{|l|l|l|l|l|l|}
\hline $\begin{array}{l}\text { Grouping } \\
\text { Countries }\end{array}$ & \multirow{2}{*}{$\begin{array}{l}\text { Maximum } \\
\text { Cost }\end{array}$} & $\begin{array}{l}\text { Maximum fair } \\
\text { market value }\end{array}$ & $\begin{array}{l}\text { Fair market } \\
\text { value at year end }\end{array}$ & $\begin{array}{l}\text { Foreign income } \\
\text { earned or loss }\end{array}$ & $\begin{array}{l}\text { Capital } \\
\text { gain/loss }\end{array}$ \\
\hline \multirow{3}{*}{ CANADA } & \multirow{3}{*}{271} & 116 & 101 & 100 & 80 \\
\cline { 3 - 6 } & 145 & 138 & 110 & 102 \\
\cline { 3 - 6 } USA & 132 & 87 & 119 & 77 \\
\cline { 3 - 6 } CHINA & 54 & 33 & 45 & 45 \\
\hline MEXICO & & & & \\
\hline
\end{tabular}

\section{Calc_1_TC_3_1_PW_Ann}

\begin{tabular}{|c|c|c|c|c|c|c|c|c|c|c|c|c|c|c|}
\hline $\begin{array}{l}\stackrel{\hat{\Xi}}{\Xi} \\
\stackrel{\Xi}{0}\end{array}$ & E్త్ & 过 & 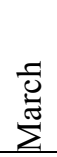 & $\overline{\vec{z}}$ & $\stackrel{\Xi}{\Sigma}$ & $\Xi$ & 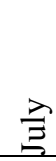 & $\begin{array}{l}\bar{n} \\
\overrightarrow{0} \\
\vec{Z}\end{array}$ & 苛 & $\tilde{0}$ & $\vec{z}$ & $\stackrel{8}{0}$ & 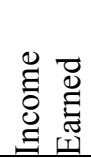 & $\begin{array}{l}\text { D } \\
0 \\
\stackrel{0}{1} \\
\stackrel{\Xi}{\mathbb{E}} \\
0\end{array}$ \\
\hline \multirow{2}{*}{ Canada } & & & & & & & 10 & 10 & 10 & 10 & 10 & 10 & \multirow{2}{*}{25} & \multirow{2}{*}{22} \\
\hline & & & & & & & 45 & 34 & 22 & 34 & 87 & 77 & & \\
\hline \multirow{2}{*}{ Canada } & 14 & 14 & 14 & 14 & 14 & 14 & 14 & 14 & & & & & \multirow{2}{*}{11} & \multirow{2}{*}{22} \\
\hline & 14 & 54 & 55 & 45 & 5 & 44 & 71 & 20 & & & & & & \\
\hline \multirow{2}{*}{ Canada } & & & & 33 & 33 & 33 & 33 & 33 & 33 & & & & \multirow{2}{*}{45} & \multirow{2}{*}{44} \\
\hline & & & & 30 & 45 & 66 & 55 & 78 & 79 & & & & & \\
\hline \multirow{2}{*}{ USA } & 25 & 25 & 25 & 25 & 25 & 25 & 25 & 25 & 25 & 25 & & & \multirow[b]{2}{*}{44} & \multirow{2}{*}{55} \\
\hline & 23 & 44 & 24 & 65 & 43 & 24 & 86 & 54 & 22 & 52 & & & & \\
\hline \multirow{2}{*}{ USA } & & & & & & & & & & 45 & 45 & 45 & \multirow{2}{*}{41} & \multirow{2}{*}{42} \\
\hline & & & & & & & & & & 66 & 77 & 88 & & \\
\hline \multirow{2}{*}{ China } & 98 & 98 & 98 & 98 & 98 & 98 & 98 & & & & & & \multirow{2}{*}{23} & \multirow{2}{*}{11} \\
\hline & 45 & 45 & 25 & 78 & 56 & 44 & 57 & & & & & & & \\
\hline \multirow{2}{*}{ China } & & & 56 & 56 & 56 & & & & & & & & \multirow{2}{*}{61} & \multirow{2}{*}{47} \\
\hline & & & 77 & 54 & 36 & & & & & & & & & \\
\hline \multirow{2}{*}{ Mexico } & & & & & & & 23 & 23 & 23 & 23 & 23 & 23 & \multirow[b]{2}{*}{45} & \multirow{2}{*}{30} \\
\hline & & & & & & & 44 & 54 & 23 & 4 & 4 & 33 & & \\
\hline
\end{tabular}

\section{Expected Output:}

\begin{tabular}{|l|l|l|l|l|l|}
\hline $\begin{array}{l}\text { Grouping } \\
\text { Countries }\end{array}$ & \multirow{2}{*}{$\begin{array}{l}\text { Maximum } \\
\text { Cost }\end{array}$} & $\begin{array}{l}\text { Maximum fair } \\
\text { market value }\end{array}$ & $\begin{array}{l}\text { Fair market } \\
\text { value at year end }\end{array}$ & $\begin{array}{l}\text { Foreign income } \\
\text { earned or loss }\end{array}$ & $\begin{array}{l}\text { Capital } \\
\text { gain/loss }\end{array}$ \\
\hline \multirow{3}{*}{ CANADA } & \multirow{3}{*}{26} & 171 & 77 & 81 & 88 \\
\cline { 1 - 4 } USA & 118 & 88 & 85 & 97 \\
\cline { 3 - 6 } CHINA & & 0 & 84 & 58 \\
\cline { 3 - 6 } MEXICO & 132 & 33 & 45 & 30 \\
\cline { 3 - 5 } & 54 & & \\
\hline
\end{tabular}




\section{Actual Output:}

\begin{tabular}{|l|l|l|l|l|l|}
\hline $\begin{array}{l}\text { Grouping } \\
\text { Countries }\end{array}$ & \multirow{2}{*}{$\begin{array}{l}\text { Maximum } \\
\text { Cost }\end{array}$} & $\begin{array}{l}\text { Maximum fair } \\
\text { market value }\end{array}$ & $\begin{array}{l}\text { Fair market } \\
\text { value at year end }\end{array}$ & $\begin{array}{l}\text { Foreign income } \\
\text { earned or loss }\end{array}$ & $\begin{array}{l}\text { Capital } \\
\text { gain/loss }\end{array}$ \\
\hline \multirow{3}{*}{ CANADA } & \multirow{3}{*}{26} & 171 & 77 & 81 & 88 \\
\cline { 3 - 6 } USA & 118 & 88 & 85 & 97 \\
\cline { 3 - 6 } CHINA & 132 & 0 & 84 & 58 \\
\cline { 3 - 6 } MEXICO & 54 & 33 & 45 & 30 \\
\hline
\end{tabular}

\section{Calc_1_TC_4_1_PW_Ann}

\begin{tabular}{|c|c|c|c|c|c|c|c|c|c|c|c|c|c|c|}
\hline $\begin{array}{l}\stackrel{\hat{\Xi}}{\Xi} \\
\stackrel{\Xi}{0}\end{array}$ & $\stackrel{\Xi}{\Xi}$ & $\begin{array}{l}0 \\
1\end{array}$ & $\begin{array}{l}\overline{\overline{0}} \\
\bar{\Xi} \\
\Sigma\end{array}$ & $\overline{\bar{z}}$ & $\stackrel{\vec{J}}{\Sigma}$ & $\Xi$ & 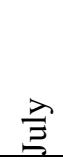 & 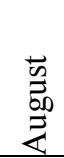 & 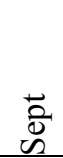 & $\overrightarrow{0}$ & z & $\stackrel{8}{8}$ & 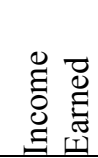 & : \\
\hline \multirow{2}{*}{ Canada } & & & & & & & 10 & 10 & 10 & 10 & 10 & 10 & \multirow{2}{*}{25} & \multirow{2}{*}{22} \\
\hline & & & & & & & 45 & 34 & 22 & 34 & 87 & 77 & & \\
\hline \multirow{2}{*}{ Canada } & 14 & 14 & 14 & 14 & 14 & 14 & 14 & 14 & & & & & \multirow{2}{*}{11} & \multirow{2}{*}{22} \\
\hline & 14 & 54 & 55 & 45 & 5 & 44 & 71 & 20 & & & & & & \\
\hline \multirow{2}{*}{ Canada } & & & & 33 & 33 & 33 & 33 & 33 & 33 & & & & \multirow{2}{*}{45} & \multirow{2}{*}{44} \\
\hline & & & & 30 & 45 & 66 & 55 & 78 & 79 & & & & & \\
\hline \multirow{2}{*}{ Canada } & 25 & 25 & 25 & 25 & 25 & 25 & 25 & 25 & 25 & 25 & & & \multirow{2}{*}{88} & \multirow{2}{*}{98} \\
\hline & 23 & 44 & 24 & 65 & 43 & 24 & 86 & 54 & 22 & 52 & & & & \\
\hline
\end{tabular}

\section{Expected Output:}

\begin{tabular}{|l|l|l|l|l|l|}
\hline $\begin{array}{l}\text { Grouping } \\
\text { Countries }\end{array}$ & $\begin{array}{l}\text { Maximum } \\
\text { Cost }\end{array}$ & $\begin{array}{l}\text { Maximum fair } \\
\text { market value }\end{array}$ & $\begin{array}{l}\text { Fair market } \\
\text { value at year end }\end{array}$ & $\begin{array}{l}\text { Foreign income } \\
\text { earned or loss }\end{array}$ & $\begin{array}{l}\text { Capital } \\
\text { gain/loss }\end{array}$ \\
\hline CANADA & 82 & 257 & 77 & 169 & 186 \\
\hline
\end{tabular}

\section{Actual Output:}

\begin{tabular}{|l|l|l|l|l|l|}
\hline $\begin{array}{l}\text { Grouping } \\
\text { Countries }\end{array}$ & $\begin{array}{l}\text { Maximum } \\
\text { Cost }\end{array}$ & $\begin{array}{l}\text { Maximum fair } \\
\text { market value }\end{array}$ & $\begin{array}{l}\text { Fair market } \\
\text { value at year end }\end{array}$ & $\begin{array}{l}\text { Foreign income } \\
\text { earned or loss }\end{array}$ & $\begin{array}{l}\text { Capital } \\
\text { gain/loss }\end{array}$ \\
\hline CANADA & 82 & 257 & 77 & 169 & 186 \\
\hline
\end{tabular}


Calc_1_TC_5_1_PW_Ann

\begin{tabular}{|c|c|c|c|c|c|c|c|c|c|c|c|c|c|c|}
\hline 总 & శ్ & 这 & 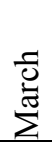 & 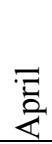 & $\sum^{\mathrm{\sigma}}$ & 吾 & 글 & z & 产 & $\tilde{0}$ & ? & $\ddot{\Xi}$ & 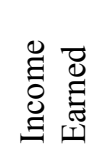 & $\begin{array}{l}0 \\
\stackrel{0}{0} \\
\stackrel{0}{0}\end{array}$ \\
\hline \multirow{2}{*}{ Empty } & & & & & & & 10 & 10 & 10 & 10 & 10 & 10 & \multirow{2}{*}{25} & \multirow{2}{*}{22} \\
\hline & & & & & & & 45 & 34 & 22 & 34 & 87 & 77 & & \\
\hline \multirow{2}{*}{ Empty } & 14 & 14 & 14 & 14 & 14 & 14 & 14 & 14 & & & & & \multirow{2}{*}{11} & \multirow{2}{*}{22} \\
\hline & 14 & 54 & 55 & 45 & 5 & 44 & 71 & 20 & & & & & & \\
\hline \multirow{2}{*}{ Empty } & & & & 33 & 33 & 33 & 33 & 33 & 33 & & & & \multirow{2}{*}{45} & \multirow{2}{*}{44} \\
\hline & & & & 30 & 45 & 66 & 55 & 78 & 79 & & & & & \\
\hline \multirow{2}{*}{ Empty } & 25 & 25 & 25 & $\frac{25}{65}$ & 25 & 25 & 25 & 23 & & 25 & & & \multirow{2}{*}{8} & \multirow{2}{*}{98} \\
\hline & 23 & 44 & 24 & 65 & 43 & 24 & 8 & 54 & 22 & 52 & & & & \\
\hline
\end{tabular}

\section{Expected Output:}

\begin{tabular}{|l|l|l|l|l|l|}
\hline $\begin{array}{l}\text { Grouping } \\
\text { Countries }\end{array}$ & $\begin{array}{l}\text { Maximum } \\
\text { Cost }\end{array}$ & $\begin{array}{l}\text { Maximum fair } \\
\text { market value }\end{array}$ & $\begin{array}{l}\text { Fair market } \\
\text { value at year end }\end{array}$ & $\begin{array}{l}\text { Foreign income } \\
\text { earned or loss }\end{array}$ & $\begin{array}{l}\text { Capital } \\
\text { gain/loss }\end{array}$ \\
\hline Empty & 82 & 257 & 77 & 169 & 186 \\
\hline
\end{tabular}

\section{Actual Output:}

\begin{tabular}{|l|l|l|l|l|l|}
\hline $\begin{array}{l}\text { Grouping } \\
\text { Countries }\end{array}$ & $\begin{array}{l}\text { Maximum } \\
\text { Cost }\end{array}$ & $\begin{array}{l}\text { Maximum fair } \\
\text { market value }\end{array}$ & $\begin{array}{l}\text { Fair market } \\
\text { value at year end }\end{array}$ & $\begin{array}{l}\text { Foreign income } \\
\text { earned or loss }\end{array}$ & $\begin{array}{l}\text { Capital } \\
\text { gain/loss }\end{array}$ \\
\hline Empty & 82 & 257 & 77 & 169 & 186 \\
\hline
\end{tabular}

\section{Calc_1_TC_6_1_PW_Ann}

\begin{tabular}{|c|c|c|c|c|c|c|c|c|c|c|c|c|c|c|}
\hline 音 & శ్ & 这 & $\begin{array}{l}\overline{0} \\
\overline{0} \\
\Sigma\end{array}$ & 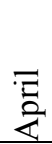 & $\sum^{m}$ & $\Xi$ & 齐 & 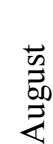 & ڤँ & $\ddot{0}$ & z & $\ddot{\Xi}$ & 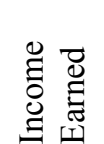 & 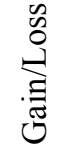 \\
\hline \multirow{2}{*}{ NULL } & & & & & & & 10 & 10 & 10 & 10 & 10 & 10 & \multirow{2}{*}{25} & \multirow{2}{*}{22} \\
\hline & & & & & & & 45 & 34 & 22 & 34 & 87 & 77 & & \\
\hline \multirow{2}{*}{ NULL } & 14 & 14 & 14 & 14 & 14 & 14 & 14 & 14 & & & & & \multirow{2}{*}{11} & \multirow{2}{*}{22} \\
\hline & 14 & 54 & 55 & 45 & 5 & 44 & 71 & 20 & & & & & & \\
\hline \multirow{2}{*}{ NULL } & & & & 33 & 33 & 33 & 33 & 33 & 33 & & & & \multirow{2}{*}{45} & \multirow{2}{*}{44} \\
\hline & & & & 30 & 45 & 66 & 55 & 78 & 79 & & & & & \\
\hline \multirow{2}{*}{ NULL } & 25 & 25 & 25 & 25 & 25 & 25 & 25 & 25 & 25 & 25 & & & \multirow{2}{*}{88} & \multirow{2}{*}{98} \\
\hline & 23 & 44 & 24 & 65 & 43 & 24 & 86 & 54 & 22 & 52 & & & & \\
\hline
\end{tabular}




\section{Expected Output:}

Error

\section{Actual Output:}

Error

\section{C.3 List of Live and Killed Mutants}

\begin{tabular}{|c|c|c|c|c|c|c|}
\hline $\begin{array}{l}\text { Mutation } \\
\text { Name }\end{array}$ & Calc_1_BC & Calc_1_EC & Calc_1_PW & $\begin{array}{l}\text { Calc_1_- } \\
\text { BC_Ann }\end{array}$ & $\begin{array}{l}\text { Calc_1_- } \\
\text { EC_Ann }\end{array}$ & $\begin{array}{l}\text { Calc_1_- } \\
\text { PW_Ann }\end{array}$ \\
\hline D1 & LIVE & LIVE & LIVE & LIVE & LIVE & LIVE \\
\hline D2 & LIVE & LIVE & LIVE & LIVE & LIVE & LIVE \\
\hline EOC1 & LIVE & LIVE & LIVE & LIVE & LIVE & LIVE \\
\hline EOC2 & LIVE & LIVE & LIVE & LIVE & LIVE & LIVE \\
\hline JID1 & LIVE & LIVE & LIVE & LIVE & LIVE & LIVE \\
\hline LCR1 & LIVE & LIVE & LIVE & LIVE & LIVE & LIVE \\
\hline LCR2 & LIVE & LIVE & LIVE & LIVE & LIVE & LIVE \\
\hline LCR3 & LIVE & LIVE & LIVE & LIVE & LIVE & LIVE \\
\hline LCR4 & LIVE & LIVE & LIVE & LIVE & LIVE & LIVE \\
\hline UOI1 & KILLED & KILLED & KILLED & KILLED & KILLED & KILLED \\
\hline UOI10 & KILLED & KILLED & KILLED & KILLED & KILLED & KILLED \\
\hline UOI11 & KILLED & KILLED & KILLED & KILLED & KILLED & KILLED \\
\hline UOI12 & KILLED & KILLED & KILLED & KILLED & KILLED & KILLED \\
\hline UOI13 & KILLED & KILLED & KILLED & KILLED & KILLED & KILLED \\
\hline UOI14 & KILLED & KILLED & KILLED & KILLED & KILLED & KILLED \\
\hline UOI15 & KILLED & KILLED & KILLED & KILLED & KILLED & KILLED \\
\hline UOI16 & KILLED & KILLED & KILLED & KILLED & KILLED & KILLED \\
\hline UOI17 & LIVE & LIVE & LIVE & LIVE & LIVE & LIVE \\
\hline UOI18 & LIVE & LIVE & LIVE & LIVE & LIVE & LIVE \\
\hline UOI19 & LIVE & LIVE & LIVE & LIVE & LIVE & LIVE \\
\hline UOI2 & LIVE & LIVE & LIVE & LIVE & LIVE & LIVE \\
\hline UOI20 & KILLED & KILLED & KILLED & KILLED & KILLED & KILLED \\
\hline UOI3 & LIVE & LIVE & LIVE & LIVE & LIVE & LIVE \\
\hline UOI4 & LIVE & LIVE & LIVE & LIVE & LIVE & LIVE \\
\hline UOI5 & KILLED & KILLED & KILLED & KILLED & KILLED & KILLED \\
\hline UOI6 & KILLED & KILLED & KILLED & KILLED & KILLED & KILLED \\
\hline UOI7 & KILLED & KILLED & KILLED & KILLED & KILLED & KILLED \\
\hline UOI8 & KILLED & KILLED & KILLED & KILLED & KILLED & KILLED \\
\hline UOI9 & KILLED & KILLED & KILLED & KILLED & KILLED & KILLED \\
\hline
\end{tabular}




\section{C.4 Live Mutants}

\begin{tabular}{|ll|}
\hline D1 & Mutated Code \\
\hline Original Code & No Details for confidentiality reasons. \\
\hline No Details for confidentiality reasons. & N
\end{tabular}

D1 is a manually injected mutant. No details can be provided for confidentiality reasons.

\begin{tabular}{|ll|}
\hline D2 & Mutated Code \\
\hline Original Code & No Details for confidentiality reasons. \\
\hline No Details for confidentiality reasons. & Notitis
\end{tabular}

D2 is also a manually created defect. No details can be provided for confidentiality reasons.

\begin{tabular}{|c|c|}
\hline EOC1 & \\
\hline Original Code & Mutated Code \\
\hline $\begin{array}{c}\text { if (bundle. } \text { ReportData }==\text { null) } \\
\text { return; }\end{array}$ & $\begin{array}{c}\text { if (bundle.ReportData.Equals(null)) } \\
\text { return; }\end{array}$ \\
\hline
\end{tabular}

\begin{tabular}{|l} 
EOC2 \\
\hline \begin{tabular}{rl|} 
Original Code & Mutated Code \\
\hline $\begin{array}{r}\text { if (bundle }==\text { null) } \\
\text { throw new }\end{array}$ & $\begin{array}{c}\text { if (bundle.Equals(null)) } \\
\text { throw new }\end{array}$ \\
$\begin{array}{l}\text { ArgumentNullException("Null T1135 } \\
\text { bundle."); }\end{array}$ & $\begin{array}{l}\text { ArgumentNullException("Null T1135 } \\
\text { bundle."); }\end{array}$ \\
\hline
\end{tabular}
\end{tabular}

EOC1 and EOC2 mutant do not change the system behavior. Therefore, they cannot be killed by any test case input.

\begin{tabular}{ll|}
\hline JID1 & \\
\hline Original Code & Mutated Code \\
\hline public readonly string[] MONTHS = & public readonly string[] MONTHS; \\
"January", "February", "March", "April", \\
"May", "June", "July", "August", \\
"Septembe", "October", "November", \\
"December" \};
\end{tabular}


JID1 mutates unused code. This is an array containing months names. It is not used anywhere else in the code, therefore changes to it do not affect the system's behavior.

\begin{tabular}{|ll|}
\hline LCR1 & Mutated Code \\
\hline Original Code & if (bundle.ReportData $!=$ null $\|$ \\
\hline $\begin{array}{l}\text { if (bundle.ReportData } !=\text { null \&\& } \\
\text { bundle. ReportData.Count }>0)\end{array}$ & bundle. ReportData.Count $>0$ ) \\
\hline
\end{tabular}

LCR1 introduces a change to an area that, whether executed or not, will not have an impact on the test's output. The portion of code enclosed by above if-statement sets values at the report level which we are not checking to pass/fail our tests. Therefore, where it executes or not, a test case output is not affected.

\begin{tabular}{|c|c|}
\hline Original Code & Mutated Code \\
\hline $\begin{array}{l}\text { if (bundle.BookValueSecuritiesMonthlyGrandTotal != } \\
\text { null \&\& } \\
\text { bundle.BookValueSecuritiesMonthlyGrandTotal.Count } \\
\text { != 0) }\end{array}$ & $\begin{array}{l}\text { if (bundle.BookValueSecuritiesMonthlyGrandTotal != } \\
\text { null || } \\
\text { bundle.BookValueSecuritiesMonthlyGrandTotal.Count } \\
\text { !=0) }\end{array}$ \\
\hline bundle. MaximumCost $=$ & bundle. MaximumCost $=$ \\
\hline $\begin{array}{l}\text { bundle.BookValueSecuritiesMonthlyGrandTotal.Max( } \\
\text { a => a.Value); }\end{array}$ & $\begin{array}{l}\text { bundle.BookValueSecuritiesMonthlyGrandTotal.Max( } \\
\text { a => a.Value); }\end{array}$ \\
\hline
\end{tabular}

LCR2 actually loosens the condition of the if-statement by replacing the AND with an OR. Also, because of the logic in the code, invoking the method where this mutant is always comes after calculating the BV totals. Therefore whether the condition is loosened or removed all together, it should always execute the body of the if-statement.

\begin{tabular}{|ll|}
\hline LCR3 & Mutated Code \\
\hline Original Code & if \\
\hline if & (bundle.BookValueSecuritiesMonthlySubTot \\
(bundle.BookValueSecuritiesMonthlySubTot & al != null || \\
al != null \&\& & bundle.BookValueSecuritiesMonthlySubTota \\
bundle.BookValueSecuritiesMonthlySubTota & l.Keys.Count $>0$ ) \\
l.Keys.Count $>0$ ) & \\
\hline
\end{tabular}




\begin{tabular}{|ll|}
\hline LCR4 & Mutated Code \\
\hline Original Code & if \\
\hline if & (bundle. MarketValueSecuritiesMonthlySubT \\
(bundle.MarketValueSecuritiesMonthlySubT & otal $!=$ null $\|$ \\
otal $!=$ null \&\& & bundle.MarketValueSecuritiesMonthlySubTo \\
bundle.MarketValueSecuritiesMonthlySubTo & tal.Keys.Count $>\theta)$ \\
tal.Keys.Count $>\theta)$ & \\
\hline
\end{tabular}

Both LCR3 and LCR4 are in the method CalculateMonthlyGrandTotalsForAllCountries, and like the case in LCR2, this method is only invoked after the BV and MV monthly totals are calculated. These two mutants loosen the if-statement condition by replacing the AND with an OR. Given that the monthly totals are always available, the changes by LCR3 and LCR4 have no impact.

\begin{tabular}{|ll|}
\hline UOI17 & Mutated Code \\
\hline Original Code & if \\
\hline if & (! (bundle.MarketValueSecuritiesMonthlySu \\
(bundle.MarketValueSecuritiesMonthlySubT & bTotal != null) \&\& \\
otal != null \&\& & bundle.MarketValueSecuritiesMonthlySubTo \\
bundle.MarketValueSecuritiesMonthlySubTo & tal.Keys.Count $>0$ ) \\
tal.Keys.Count $>0$ ) & \\
\hline
\end{tabular}

\begin{tabular}{|ll|}
\hline UOI18 & Mutated Code \\
\hline Original Code & if \\
\hline if & (bundle.MarketValueSecuritiesMonthlySubTo \\
(bundle.MarketValueSecuritiesMonthlySub & tal != null \&\& \\
Total != null \&\& & ! (bundle.MarketValueSecuritiesMonthlySubT \\
bundle.MarketValueSecuritiesMonthlySubT & otal.Keys.Count $>0$ )) \\
otal.Keys.Count $>0$ ) & \\
\hline
\end{tabular}

\begin{tabular}{|ll|}
\hline UOl19 & \\
\hline Original Code & Mutated Code \\
\hline if & if \\
(bundle.MarketValueSecuritiesMonthlySubT & (! (bundle.MarketValueSecuritiesMonthlySu \\
otal != null \&\& & bTotal != null \&\& \\
bundle.MarketValueSecuritiesMonthlySubTo & bundle.MarketValueSecuritiesMonthlySubTo \\
tal.Keys.Count $>0)$ & tal.Keys.Count $>0)$ ) \\
\hline
\end{tabular}

UOI17, UOI18, and UOI19 all impact the condition of an if-statement whose body, whether executed or not, has no impact on the output of test cases. The reason for this is 
that because the piece of the code guarded by this condition set values at the report level which we are not checking in our test cases to pass/fail them.

\section{UOI2}

Original Code

Mutated Code

if (bundle.ReportData $!=$ null \&\& if (! (bundle. ReportData $!=$ null) $\& \&$

bundle. ReportData.Count $>0$ ) bundle.ReportData.Count >0)

\begin{tabular}{|ll}
\hline UOI3 & Mutated Code \\
Original Code & if (bundle. ReportData $!=$ null \&\& \\
\hline $\begin{array}{l}\text { if (bundle.ReportData } !=\text { null \&\& } \\
\text { bundle.ReportData.Count }>0)\end{array}$ & !(bundle. ReportData.Count $>0$ )) \\
\hline
\end{tabular}

\section{$\mathrm{UOI} 4$}

Original Code

Mutated Code

if (bundle. ReportData != null \&\&

bundle. ReportData.Count $>0$ )

if ! ((bundle. ReportData != null \&\&

bundle. ReportData.Count $>0)$ )

Just like the previous set of mutants, UOI3, UOI3, and UOI4 impact the condition of an

if-statement that sets values at the report level which we are not checking to pass/fail our test cases. 


\section{C.5 Non-Uniform Mutants}

All mutants were uniform across all selection criteria and both the annotated and nonannotated approach. 


\section{Appendix D Calculation Logic Case Study (Second Approach)}

\section{D.1 Non-Annotated CP Specifications}

Countries

- Casing
- Consistent [base]
- Inconsistent

- Similarity

$\begin{array}{ll}\circ & \text { False [base] } \\ \circ \text { True }\end{array}$

SecurityValue

- PlaceOfHighestSummedUpValue
- OtherMonths [base]
- December
- IncomeEarnedOrCapitalGain

\section{Base-Choice Test Frames and Test Cases}

Frame 1:

Countries.Casing.Consistent

Countries.AreSimilar.False

Countries.HaveEmpty.False

Countries.HaveMissing.False

SecurityValues.PlaceOfHighestSummedUpValu

e.OtherMonths

Frame 2:

Countries.Casing.Inconsistent

Countries.AreSimilar.False

Countries.HaveEmpty.False

Countries.HaveMissing.False

SecurityValues.PlaceOfHighestSummedUpValu

e.OtherMonths
- HaveEmpty

$\circ \quad$ False [base]

○ True

- HaveMissing

- False [base]

○ True
Frame 3:

Countries.Casing.Consistent

Countries.AreSimilar.True

Countries.HaveEmpty.False

Countries.HaveMissing.False

SecurityValues.PlaceOfHighestSummedUpValu

e.OtherMonths

Frame 4:

Countries.Casing.Consistent

Countries.AreSimilar.False

Countries.HaveEmpty.True

Countries.HaveMissing.False

SecurityValues.PlaceOfHighestSummedUpValu

e.OtherMonths 
Frame 5:

Countries.Casing.Consistent

Countries.AreSimilar.False

Countries.HaveEmpty.False

Countries.HaveMissing.True

SecurityValues.PlaceOfHighestSummedUpValu

e.OtherMonths

Frame 6:

Countries.Casing.Consistent

Countries.AreSimilar.False

Countries.HaveEmpty.False

Countries.HaveMissing.False

SecurityValues.PlaceOfHighestSummedUpValu

e.December
Frame 7:

Countries.Casing.Consistent

Countries.AreSimilar.False

Countries.HaveEmpty.False

Countries.HaveMissing.False

SecurityValues.PlaceOfHighestSummedUpValu

e.IncomeEarnedOrCapitalGain

Calc_2_TC_1_1_BC

We can choose any month other than December to have the highest MV values. Here we choose 'January'

\begin{tabular}{|c|c|c|c|c|c|c|c|c|c|c|c|c|c|c|}
\hline 㝵 & E & 这 & $\begin{array}{l}\overline{\bar{U}} \\
\overline{\tilde{J}}\end{array}$ & 产 & $\stackrel{\overparen{\pi}}{\Sigma}$ & 䄈 & 3 & 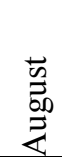 & 㐔 & $\bar{o}$ & ฉá & $\stackrel{\mathscr{N}}{0}$ & 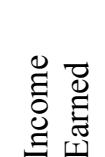 & 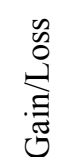 \\
\hline \multirow{2}{*}{ Canada } & 10 & 10 & 10 & 10 & 10 & 10 & 10 & 10 & 10 & 10 & 10 & 10 & \multirow{2}{*}{60} & \multirow{2}{*}{30} \\
\hline & 210 & 22 & 23 & 25 & 22 & 40 & 45 & 34 & 22 & 34 & 87 & 77 & & \\
\hline \multirow{2}{*}{ Canada } & 14 & 14 & 14 & 14 & 14 & 14 & 14 & 14 & \begin{tabular}{|l|l|}
14 \\
\end{tabular} & 14 & 14 & 14 & \multirow{2}{*}{90} & \multirow{2}{*}{50} \\
\hline & 140 & 54 & 55 & 45 & 5 & 44 & 71 & 20 & 22 & 24 & 22 & 24 & & \\
\hline \multirow{2}{*}{ USA } & 25 & 25 & 25 & 25 & 25 & 25 & 25 & 25 & 25 & 25 & 25 & 25 & \multirow{2}{*}{4} & \multirow{2}{*}{42} \\
\hline & 230 & 44 & 24 & 65 & 43 & 24 & 86 & 54 & 22 & 52 & 50 & 50 & & \\
\hline \multirow{2}{*}{ USA } & 45 & 45 & 45 & 45 & 45 & 45 & 45 & 45 & 45 & 45 & 45 & 45 & \multirow[b]{2}{*}{65} & \multirow{2}{*}{100} \\
\hline & 450 & 46 & 51 & 53 & 58 & 55 & 59 & 60 & 65 & 66 & 77 & 88 & & \\
\hline \multirow{2}{*}{ China } & 98 & \begin{tabular}{|l|l|}
98 \\
\end{tabular} & 98 & 98 & 98 & 98 & 98 & 98 & \begin{tabular}{|l|l|}
98 \\
\end{tabular} & 98 & 98 & 98 & \multirow[b]{2}{*}{98} & \multirow{2}{*}{65} \\
\hline & 450 & 45 & 25 & 78 & 56 & 44 & 57 & 55 & 56 & 54 & 53 & 51 & & \\
\hline \multirow{2}{*}{ China } & 56 & 56 & 56 & 56 & 56 & 56 & 56 & 56 & 56 & 56 & 56 & 56 & & \multirow{2}{*}{12} \\
\hline & 780 & 77 & 77 & 54 & 36 & 36 & 36 & 36 & 36 & 36 & 36 & 36 & & \\
\hline \multirow{2}{*}{ Mexico } & 23 & 23 & 23 & 23 & 23 & 23 & 23 & 23 & 23 & 23 & 23 & 23 & \multirow[b]{2}{*}{8} & \multirow{2}{*}{85} \\
\hline & 440 & 44 & 44 & 44 & 44 & 44 & 44 & 54 & 23 & 4 & 4 & 33 & & \\
\hline
\end{tabular}




\section{Expected Output:}

\begin{tabular}{|c|c|c|c|c|c|}
\hline $\begin{array}{l}\text { Grouping } \\
\text { Countries }\end{array}$ & $\begin{array}{l}\text { Maximum } \\
\text { Cost }\end{array}$ & $\begin{array}{l}\text { Maximum fair } \\
\text { market value }\end{array}$ & $\begin{array}{l}\text { Fair market } \\
\text { value at year end }\end{array}$ & $\begin{array}{l}\text { Foreign income } \\
\text { earned or loss }\end{array}$ & $\begin{array}{l}\text { Capital } \\
\text { gain/loss }\end{array}$ \\
\hline CANADA & \multirow{4}{*}{271} & 350 & 101 & 150 & 80 \\
\hline USA & & 680 & 138 & 110 & 142 \\
\hline CHINA & & 1230 & 87 & 187 & 77 \\
\hline MEXICO & & 440 & 33 & 85 & 85 \\
\hline
\end{tabular}

\section{Actual Output:}

\begin{tabular}{|l|l|l|l|l|l|}
\hline $\begin{array}{l}\text { Grouping } \\
\text { Countries }\end{array}$ & \multirow{2}{*}{$\begin{array}{l}\text { Maximum } \\
\text { Cost }\end{array}$} & $\begin{array}{l}\text { Maximum fair } \\
\text { market value }\end{array}$ & $\begin{array}{l}\text { Fair market } \\
\text { value at year end }\end{array}$ & $\begin{array}{l}\text { Foreign income } \\
\text { earned or loss }\end{array}$ & $\begin{array}{l}\text { Capital } \\
\text { gain/loss }\end{array}$ \\
\hline \multirow{3}{*}{ CANADA } & \multirow{3}{*}{271} & 350 & 101 & 150 & 80 \\
\cline { 1 - 5 } USA & 680 & 138 & 110 & 142 \\
\cline { 3 - 6 } CHINA & 1230 & 87 & 187 & 77 \\
\cline { 3 - 5 } MEXICO & 440 & 33 & 85 & 85 \\
\hline
\end{tabular}

\section{Calc_2_TC_2_1_BC}

We can choose any month other than December to have the highest MV values. Here we choose 'January'

\begin{tabular}{|c|c|c|c|c|c|c|c|c|c|c|c|c|c|c|}
\hline 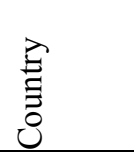 & పี & $\begin{array}{l}0 \\
0 \\
\end{array}$ & 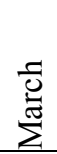 & $\overline{\bar{c}}$ & $\stackrel{\vec{J}}{\Sigma}$ & $\Xi$ & $\frac{\lambda}{\Xi}$ & 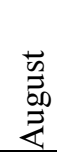 & $\begin{array}{l}\overrightarrow{0} 0 \\
0 \\
\end{array}$ & $\overrightarrow{0}$ & z & ڤ̊ & 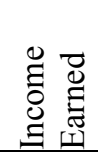 & 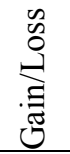 \\
\hline \multirow{2}{*}{ Canada } & 10 & 10 & 10 & 10 & 10 & 10 & 10 & 10 & 10 & 10 & 10 & 10 & \multirow{2}{*}{60} & \multirow{2}{*}{30} \\
\hline & 210 & 22 & 23 & 25 & 22 & 40 & 45 & 34 & 22 & 34 & 87 & 77 & & \\
\hline \multirow{2}{*}{ CanadA } & 14 & 14 & 14 & 14 & 14 & 14 & 14 & 14 & 14 & 14 & 14 & 14 & \multirow{2}{*}{90} & \multirow{2}{*}{50} \\
\hline & 140 & 54 & 55 & 45 & 5 & 44 & 71 & 20 & 22 & 24 & 22 & 24 & & \\
\hline \multirow{2}{*}{ USA } & 25 & 25 & 25 & 25 & 25 & 25 & 25 & 25 & 25 & 25 & 25 & 25 & \multirow{2}{*}{45} & \multirow{2}{*}{42} \\
\hline & 230 & 44 & 24 & 65 & 43 & 24 & 86 & 54 & 22 & 52 & 50 & 50 & & \\
\hline \multirow{2}{*}{ USA } & 45 & 45 & 45 & 45 & 45 & 45 & 45 & 45 & 45 & 45 & 45 & 45 & \multirow{2}{*}{65} & \multirow{2}{*}{100} \\
\hline & 450 & 46 & 51 & 53 & 58 & 55 & 59 & 60 & 65 & 66 & 77 & 88 & & \\
\hline \multirow{2}{*}{ China } & 98 & 98 & 98 & 98 & 98 & 98 & 98 & 98 & 98 & 98 & 98 & 98 & \multirow{2}{*}{98} & \multirow{2}{*}{65} \\
\hline & 450 & 45 & 25 & 78 & 56 & 44 & 57 & 55 & 56 & 54 & 53 & 51 & & \\
\hline \multirow{2}{*}{ China } & 56 & 56 & 56 & 56 & 56 & 56 & 56 & 56 & 56 & 56 & 56 & 56 & \multirow{2}{*}{89} & \multirow{2}{*}{12} \\
\hline & 780 & 77 & 77 & 54 & 36 & 36 & 36 & 36 & 36 & 36 & 36 & 36 & & \\
\hline \multirow{2}{*}{ Mexico } & 23 & 23 & 23 & 23 & 23 & 23 & 23 & 23 & 23 & 23 & 23 & 23 & \multirow{2}{*}{85} & \multirow{2}{*}{85} \\
\hline & 440 & 44 & 44 & 44 & 44 & 44 & 44 & 54 & 23 & 4 & 4 & 33 & & \\
\hline
\end{tabular}




\section{Expected Output:}

\begin{tabular}{|l|l|l|l|l|l|}
\hline $\begin{array}{l}\text { Grouping } \\
\text { Countries }\end{array}$ & \multirow{2}{*}{$\begin{array}{l}\text { Maximum } \\
\text { Cost }\end{array}$} & $\begin{array}{l}\text { Maximum fair } \\
\text { market value }\end{array}$ & $\begin{array}{l}\text { Fair market } \\
\text { value at year end }\end{array}$ & $\begin{array}{l}\text { Foreign income } \\
\text { earned or loss }\end{array}$ & $\begin{array}{l}\text { Capital } \\
\text { gain/loss }\end{array}$ \\
\hline \multirow{3}{*}{ CANADA } & \multirow{3}{*}{271} & 350 & 101 & 150 & 80 \\
\cline { 3 - 6 } & 680 & 138 & 110 & 142 \\
\cline { 3 - 6 } USA & 1230 & 87 & 187 & 77 \\
\cline { 3 - 6 } CHINA & 440 & 33 & 85 & 85 \\
\hline MEXICO & & & & \\
\hline
\end{tabular}

\section{Actual Output:}

\begin{tabular}{|l|l|l|l|l|l|}
\hline $\begin{array}{l}\text { Grouping } \\
\text { Countries }\end{array}$ & $\begin{array}{l}\text { Maximum } \\
\text { Cost }\end{array}$ & $\begin{array}{l}\text { Maximum fair } \\
\text { market value }\end{array}$ & $\begin{array}{l}\text { Fair market } \\
\text { value at year end }\end{array}$ & $\begin{array}{l}\text { Foreign income } \\
\text { earned or loss }\end{array}$ & $\begin{array}{l}\text { Capital } \\
\text { gain/loss }\end{array}$ \\
\hline CANADA & \multirow{3}{*}{271} & 350 & 101 & 150 & 80 \\
\cline { 1 - 5 } USA & 680 & 138 & 110 & 142 \\
\cline { 3 - 6 } CHINA & 1230 & 87 & 187 & 77 \\
\cline { 3 - 6 } & & 440 & 33 & 85 & 85 \\
\hline
\end{tabular}

Calc_2_TC_3_1_BC

\begin{tabular}{|c|c|c|c|c|c|c|c|c|c|c|c|c|c|c|}
\hline 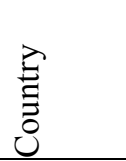 & 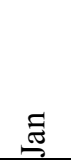 & $\begin{array}{l}0 \\
0\end{array}$ & $\begin{array}{l}\text { D. } \\
\sum^{\pi}\end{array}$ & 容 & $\sum^{\grave{\lambda}}$ & $\Xi$ & $\vec{\partial}$ & 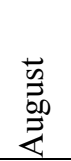 & $\begin{array}{l}\overrightarrow{0} \\
\text { के }\end{array}$ & $\overrightarrow{0}$ & z & ֶ๊̊ & 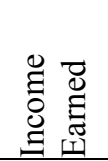 & 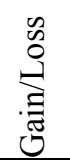 \\
\hline \multirow{2}{*}{ Canada } & 10 & 10 & 10 & 10 & 10 & 10 & 10 & 10 & 10 & 10 & 10 & 10 & \multirow{2}{*}{60} & \multirow{2}{*}{30} \\
\hline & 210 & 22 & 23 & 25 & 22 & 40 & 45 & 34 & 22 & 34 & 87 & 77 & & \\
\hline \multirow{2}{*}{ Canada } & 14 & 14 & 14 & 14 & 14 & 14 & 14 & 14 & 14 & 14 & 14 & 14 & \multirow{2}{*}{90} & \multirow{2}{*}{50} \\
\hline & 140 & 54 & 55 & 45 & 5 & 44 & 71 & 20 & 22 & 24 & 22 & 24 & & \\
\hline \multirow{2}{*}{ Canada } & 25 & 25 & 25 & 25 & 25 & 25 & 25 & 25 & 25 & 25 & 25 & 25 & \multirow{2}{*}{45} & \multirow{2}{*}{42} \\
\hline & 230 & 44 & 24 & 65 & 43 & 24 & 86 & 54 & 22 & 52 & 50 & 50 & & \\
\hline \multirow{2}{*}{ Canada } & 45 & 45 & 45 & 45 & 45 & 45 & 45 & 45 & 45 & 45 & 45 & 45 & \multirow{2}{*}{65} & \multirow{2}{*}{100} \\
\hline & 450 & 46 & 51 & 53 & 58 & 55 & 59 & 60 & 65 & 66 & 77 & 88 & & \\
\hline \multirow{2}{*}{ Canada } & 98 & 98 & 98 & 98 & 98 & 98 & 98 & 98 & 98 & 98 & 98 & 98 & \multirow{2}{*}{98} & \multirow{2}{*}{65} \\
\hline & 450 & 45 & 25 & 78 & 56 & 44 & 57 & 55 & 56 & 54 & 53 & 51 & & \\
\hline \multirow{2}{*}{ Canada } & 56 & 56 & 56 & 56 & 56 & 56 & 56 & 56 & 56 & 56 & 56 & 56 & \multirow{2}{*}{89} & \multirow{2}{*}{12} \\
\hline & 780 & 77 & 77 & 54 & 36 & 36 & 36 & 36 & 36 & 36 & 36 & 36 & & \\
\hline \multirow{2}{*}{ Canada } & 23 & 23 & 23 & 23 & 23 & 23 & 23 & 23 & 23 & 23 & 23 & 23 & \multirow{2}{*}{85} & \multirow{2}{*}{85} \\
\hline & 440 & 44 & 44 & 44 & 44 & 44 & 44 & 54 & 23 & 4 & 4 & 33 & & \\
\hline
\end{tabular}

\section{Expected Output:}

\begin{tabular}{|l|l|l|l|l|l|}
\hline $\begin{array}{l}\text { Grouping } \\
\text { Countries }\end{array}$ & $\begin{array}{l}\text { Maximum } \\
\text { Cost }\end{array}$ & $\begin{array}{l}\text { Maximum fair } \\
\text { market value }\end{array}$ & $\begin{array}{l}\text { Fair market } \\
\text { value at year end }\end{array}$ & $\begin{array}{l}\text { Foreign income } \\
\text { earned or loss }\end{array}$ & $\begin{array}{l}\text { Capital } \\
\text { gain/loss }\end{array}$ \\
\hline CANADA & 271 & 2700 & 359 & 532 & 384 \\
\hline
\end{tabular}




\section{Actual Output:}

\begin{tabular}{|l|l|l|l|l|l|}
\hline $\begin{array}{l}\text { Grouping } \\
\text { Countries }\end{array}$ & $\begin{array}{l}\text { Maximum } \\
\text { Cost }\end{array}$ & $\begin{array}{l}\text { Maximum fair } \\
\text { market value }\end{array}$ & $\begin{array}{l}\text { Fair market } \\
\text { value at year end }\end{array}$ & $\begin{array}{l}\text { Foreign income } \\
\text { earned or loss }\end{array}$ & $\begin{array}{l}\text { Capital } \\
\text { gain/loss }\end{array}$ \\
\hline CANADA & 271 & 2700 & 359 & 532 & 384 \\
\hline
\end{tabular}

\section{Calc_2_TC_4_1_BC}

An empty value here is represented by double quotes(“"').

\begin{tabular}{|c|c|c|c|c|c|c|c|c|c|c|c|c|c|c|}
\hline $\begin{array}{l}\stackrel{\vec{E}}{\Xi} \\
\stackrel{0}{0}\end{array}$ & ప్ & 过 & 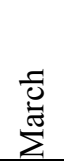 & 苞 & $\stackrel{\vec{\Xi}}{\Sigma}$ & $\Xi$ & $\vec{\Xi}$ & 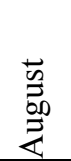 & $\begin{array}{l}\overrightarrow{0} \\
\stackrel{0}{0}\end{array}$ & $\overrightarrow{0}$ & zo & Оू & 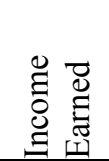 & 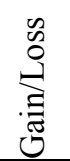 \\
\hline \multirow{2}{*}{ Canada } & 10 & 10 & 10 & 10 & 10 & 10 & 10 & 10 & 10 & 10 & 10 & 10 & \multirow{2}{*}{60} & \multirow{2}{*}{30} \\
\hline & 210 & 22 & 23 & 25 & 22 & 40 & 45 & 34 & 22 & 34 & 87 & 77 & & \\
\hline \multirow{2}{*}{ Canada } & 14 & 14 & 14 & 14 & 14 & 14 & 14 & 14 & 14 & 14 & 14 & 14 & \multirow{2}{*}{90} & \multirow{2}{*}{50} \\
\hline & 140 & 54 & 55 & 45 & 5 & 44 & 71 & 20 & 22 & 24 & 22 & 24 & & \\
\hline \multirow{2}{*}{ USA } & 25 & 25 & 25 & 25 & 25 & 25 & 25 & 25 & 25 & 25 & 25 & 25 & \multirow{2}{*}{45} & \multirow{2}{*}{42} \\
\hline & 230 & 44 & 24 & 65 & 43 & 24 & 86 & 54 & 22 & 52 & 50 & 50 & & \\
\hline \multirow{2}{*}{ USA } & 45 & 45 & 45 & 45 & 45 & 45 & 45 & 45 & 45 & 45 & 45 & 45 & \multirow{2}{*}{65} & \multirow{2}{*}{100} \\
\hline & 450 & 46 & 51 & 53 & 58 & 55 & 59 & 60 & 65 & 66 & 77 & 88 & & \\
\hline \multirow{2}{*}{ China } & 98 & 98 & 98 & 98 & 98 & 98 & 98 & 98 & 98 & 98 & 98 & 98 & \multirow{2}{*}{98} & \multirow{2}{*}{65} \\
\hline & 450 & 45 & 25 & 78 & 56 & 44 & 57 & 55 & 56 & 54 & 53 & 51 & & \\
\hline \multirow{2}{*}{ China } & 56 & 56 & 56 & 56 & 56 & 56 & 56 & 56 & 56 & 56 & 56 & 56 & \multirow{2}{*}{89} & \multirow{2}{*}{12} \\
\hline & 780 & 77 & 77 & 54 & 36 & 36 & 36 & 36 & 36 & 36 & 36 & 36 & & \\
\hline \multirow[t]{2}{*}{ ،" } & 23 & 23 & 23 & 23 & 23 & 23 & 23 & 23 & 23 & 23 & 23 & 23 & \multirow{2}{*}{85} & \multirow[b]{2}{*}{85} \\
\hline & 440 & 44 & 44 & 44 & 44 & 44 & 44 & 54 & 23 & 4 & 4 & 33 & & \\
\hline
\end{tabular}

\section{Expected Output:}

\begin{tabular}{|l|l|l|l|l|l|}
\hline $\begin{array}{l}\text { Grouping } \\
\text { Countries }\end{array}$ & $\begin{array}{l}\text { Maximum } \\
\text { Cost }\end{array}$ & $\begin{array}{l}\text { Maximum fair } \\
\text { market value }\end{array}$ & $\begin{array}{l}\text { Fair market } \\
\text { value at year end }\end{array}$ & $\begin{array}{l}\text { Foreign income } \\
\text { earned or loss }\end{array}$ & $\begin{array}{l}\text { Capital } \\
\text { gain/loss }\end{array}$ \\
\hline \multirow{3}{*}{ CANADA } & \multirow{3}{*}{271} & 350 & 101 & 150 & 80 \\
\cline { 3 - 6 } & 680 & 138 & 110 & 142 \\
\cline { 3 - 6 } USA & 1230 & 87 & 187 & 77 \\
\cline { 3 - 5 } CHINA & 440 & 33 & 85 & 85 \\
\hline "'" & & & & \\
\hline
\end{tabular}

\section{Actual Output:}

\begin{tabular}{|l|l|l|l|l|l|}
\hline $\begin{array}{l}\text { Grouping } \\
\text { Countries }\end{array}$ & $\begin{array}{l}\text { Maximum } \\
\text { Cost }\end{array}$ & $\begin{array}{l}\text { Maximum fair } \\
\text { market value }\end{array}$ & $\begin{array}{l}\text { Fair market } \\
\text { value at year end }\end{array}$ & $\begin{array}{l}\text { Foreign income } \\
\text { earned or loss }\end{array}$ & $\begin{array}{l}\text { Capital } \\
\text { gain/loss }\end{array}$ \\
\hline CANADA & \multirow{3}{*}{271} & 350 & 101 & 150 & 80 \\
\cline { 1 - 4 } & & 680 & 138 & 110 & 142 \\
\cline { 3 - 6 } USA & 1230 & 87 & 187 & 77 \\
\cline { 3 - 5 } CHINA & 440 & 33 & 85 & 85 \\
\hline “'” & & & & \\
\hline
\end{tabular}


Calc_2_TC_4_2_BC

This is another test case under Frame number 4 to test for more than on empty country

\begin{tabular}{|c|c|c|c|c|c|c|c|c|c|c|c|c|c|c|}
\hline$\stackrel{8}{0}$ & 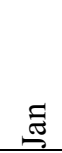 & 业 & $\begin{array}{l}\overline{\bar{J}} \\
\sum_{\bar{\pi}}\end{array}$ & 荌 & $\sum^{\mathrm{m}}$ & $\underline{\Xi}$ & $\frac{\lambda}{\Xi}$ & $\begin{array}{l}\frac{\vec{v}}{5} \\
\frac{b_{0}}{z}\end{array}$ & है & $\overline{0}$ & $\vec{z}$ & ஜू & 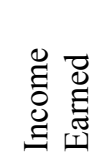 & 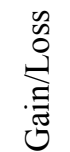 \\
\hline \multirow[t]{2}{*}{ “" } & & & & & & & 10 & 10 & 10 & 10 & 10 & 10 & \multirow{2}{*}{25} & \multirow{2}{*}{22} \\
\hline & & & & & & & 450 & 34 & 22 & 34 & 87 & 77 & & \\
\hline \multirow[t]{2}{*}{ ("), } & 14 & 14 & 14 & 14 & 14 & 14 & 14 & 14 & & & & & \multirow{2}{*}{11} & \multirow{2}{*}{22} \\
\hline & 14 & 54 & 55 & 45 & 5 & 44 & 710 & 20 & & & & & & \\
\hline \multirow[t]{2}{*}{ "', } & & & & 33 & 33 & 33 & 33 & 33 & 33 & & & & \multirow{2}{*}{45} & \multirow{2}{*}{44} \\
\hline & & & & 30 & 45 & 66 & 550 & 78 & 79 & & & & & \\
\hline \multirow{2}{*}{ USA } & 25 & 25 & 25 & 25 & 25 & 25 & 25 & 25 & 25 & 25 & & & \multirow{2}{*}{88} & \multirow{2}{*}{98} \\
\hline & 23 & 44 & 24 & 65 & 43 & 24 & 860 & 54 & 22 & 52 & & & & \\
\hline \multirow{2}{*}{ USA } & & & & & & & & & & 45 & 45 & 45 & \multirow{2}{*}{41} & \multirow{2}{*}{42} \\
\hline & & & & & & & & & & 66 & 77 & 88 & & \\
\hline \multirow{2}{*}{ China } & 98 & 98 & 98 & 98 & 98 & 98 & 98 & & & & & & \multirow{2}{*}{234} & \multirow{2}{*}{11} \\
\hline & 45 & 45 & 25 & 78 & 56 & 44 & 570 & & & & & & & \\
\hline China & & & 56 & 56 & 56 & & & & & & & & 61 & 47 \\
\hline \multirow[b]{2}{*}{ Mexico } & & & 77 & 54 & 36 & & 23 & 23 & 23 & 23 & 23 & 23 & \multirow[b]{2}{*}{45} & \multirow[b]{2}{*}{676} \\
\hline & & & & & & & 440 & 54 & 23 & 4 & 4 & 33 & & \\
\hline
\end{tabular}

\section{Expected Output:}

\begin{tabular}{|l|l|l|l|l|l|}
\hline $\begin{array}{l}\text { Grouping } \\
\text { Countries }\end{array}$ & $\begin{array}{l}\text { Maximum } \\
\text { Cost }\end{array}$ & $\begin{array}{l}\text { Maximum fair } \\
\text { market value }\end{array}$ & $\begin{array}{l}\text { Fair market } \\
\text { value at year end }\end{array}$ & $\begin{array}{l}\text { Foreign income } \\
\text { earned or loss }\end{array}$ & $\begin{array}{l}\text { Capital } \\
\text { gain/loss }\end{array}$ \\
\hline \multirow{3}{*}{226} & 1710 & 77 & 81 & 88 \\
\cline { 1 - 4 } & & 860 & 88 & 129 & 140 \\
\cline { 3 - 6 } & & 570 & 0 & 295 & 58 \\
\cline { 3 - 5 } CHINA & 440 & 33 & 45 & 676 \\
\hline MEXICO & & & & \\
\hline
\end{tabular}

\section{Actual Output:}

\begin{tabular}{|l|l|l|l|l|l|}
\hline $\begin{array}{l}\text { Grouping } \\
\text { Countries }\end{array}$ & $\begin{array}{l}\text { Maximum } \\
\text { Cost }\end{array}$ & $\begin{array}{l}\text { Maximum fair } \\
\text { market value }\end{array}$ & $\begin{array}{l}\text { Fair market } \\
\text { value at year end }\end{array}$ & $\begin{array}{l}\text { Foreign income } \\
\text { earned or loss }\end{array}$ & $\begin{array}{l}\text { Capital } \\
\text { gain/loss }\end{array}$ \\
\hline \multirow{3}{*}{ “'” } & \multirow{3}{*}{26} & 1710 & 77 & 81 & 88 \\
\cline { 1 - 4 } USA & 860 & 88 & 129 & 140 \\
\cline { 3 - 6 } & & 570 & 0 & 295 & 58 \\
\cline { 3 - 5 } CHINA & 440 & 33 & 45 & 676 \\
\hline MEXICO & & & & \\
\hline
\end{tabular}


Calc_2_TC_5_1_BC

A missing country is represented by a NULL value in the country field.

\begin{tabular}{|c|c|c|c|c|c|c|c|c|c|c|c|c|c|c|}
\hline 音 & Еี & 退 & $\begin{array}{l}\bar{D} \\
\bar{d} \\
\Sigma \\
\Sigma\end{array}$ & $\overline{\frac{2}{4}}$ & 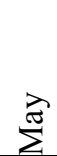 & $\Xi$ & $\vec{\Xi}$ & 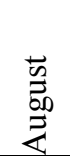 & 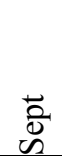 & $\overline{0}$ & $\vec{z}$ & $\ddot{~}$ & 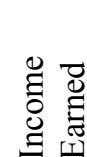 & 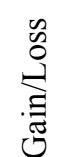 \\
\hline \multirow{2}{*}{ Canada } & 10 & 10 & 10 & 10 & 10 & 10 & 10 & 10 & 10 & 10 & 10 & 10 & \multirow{2}{*}{60} & \multirow{2}{*}{30} \\
\hline & 210 & 22 & 23 & 25 & 22 & 40 & 45 & 34 & 22 & 34 & 87 & 77 & & \\
\hline \multirow{2}{*}{ Canada } & 14 & 14 & 14 & 14 & 14 & 14 & 14 & 14 & 14 & 14 & 14 & 14 & \multirow[b]{2}{*}{0} & \multirow{2}{*}{50} \\
\hline & 140 & 54 & 55 & 45 & 5 & 44 & 71 & 20 & 22 & 24 & 22 & 24 & & \\
\hline \multirow{2}{*}{ USA } & 25 & 25 & 25 & 25 & 25 & 25 & 25 & 25 & 25 & 25 & 25 & 25 & \multirow[b]{2}{*}{45} & \multirow{2}{*}{42} \\
\hline & 230 & 44 & 24 & 65 & 43 & 24 & 86 & 54 & 22 & 52 & 50 & 50 & & \\
\hline \multirow{2}{*}{ USA } & 45 & 45 & 45 & 45 & 45 & 45 & 45 & 45 & 45 & 45 & 45 & 45 & \multirow{2}{*}{65} & \multirow{2}{*}{100} \\
\hline & 450 & 46 & 51 & 53 & 58 & 55 & 59 & 60 & 65 & 66 & 77 & 88 & & \\
\hline \multirow{2}{*}{ China } & 98 & 98 & 98 & 98 & 98 & 98 & 98 & 98 & 98 & 98 & 98 & 98 & \multirow{2}{*}{98} & \multirow{2}{*}{65} \\
\hline & 450 & 45 & 25 & 78 & 56 & 44 & 57 & 55 & 56 & 54 & 53 & 51 & & \\
\hline \multirow{2}{*}{ China } & 56 & 56 & 56 & 56 & 56 & 56 & 56 & 56 & 56 & 56 & 56 & 56 & \multirow[b]{2}{*}{89} & \multirow{2}{*}{12} \\
\hline & 780 & 77 & 77 & 54 & 36 & 36 & 36 & 36 & 36 & 36 & 36 & 36 & & \\
\hline \multirow{2}{*}{ NULL } & 23 & 23 & 23 & 23 & 23 & 23 & 23 & 23 & 23 & 23 & 23 & 23 & \multirow[b]{2}{*}{85} & \multirow{2}{*}{85} \\
\hline & 440 & 44 & 44 & 44 & 44 & 44 & 44 & 54 & 23 & 4 & 4 & 33 & & \\
\hline
\end{tabular}

\section{Expected Output:}

Error

\section{Actual Output:}

Error 
Calc_2_TC_6_1_BC

\begin{tabular}{|c|c|c|c|c|c|c|c|c|c|c|c|c|c|c|}
\hline $\begin{array}{l}\stackrel{\Xi}{\Xi} \\
0 \\
0\end{array}$ & ప్ & $\begin{array}{l}0 \\
11\end{array}$ & $\begin{array}{l}\overline{\overline{0}} \\
\bar{\pi}\end{array}$ & $\bar{z}$ & $\sum_{\Sigma}^{\nexists ~}$ & $\Xi$ & $\frac{\lambda}{\Xi}$ & 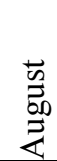 & 苋 & $\tilde{0}$ & z & ల్ల & 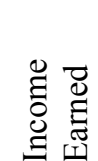 & $\begin{array}{l}\text { D) } \\
\stackrel{0}{\Theta} \\
\stackrel{\Xi}{\mathbb{E}} \\
0\end{array}$ \\
\hline \multirow{2}{*}{ Canada } & 10 & 10 & 10 & 10 & 10 & 10 & 10 & 10 & 10 & 10 & 10 & 10 & \multirow{2}{*}{60} & \multirow{2}{*}{30} \\
\hline & 21 & 22 & 23 & 25 & 22 & 40 & 45 & 34 & 22 & 34 & 87 & 770 & & \\
\hline \multirow{2}{*}{ Canada } & 14 & 14 & 14 & 14 & 14 & 14 & 14 & 14 & 14 & 14 & 14 & 14 & \multirow{2}{*}{90} & \multirow{2}{*}{50} \\
\hline & 14 & 54 & 55 & 45 & 5 & 44 & 71 & 20 & 22 & 24 & 22 & 240 & & \\
\hline \multirow{2}{*}{ USA } & 25 & 25 & 25 & 25 & 25 & 25 & 25 & 25 & 25 & 25 & 25 & 25 & \multirow{2}{*}{45} & \multirow{2}{*}{42} \\
\hline & 23 & 44 & 24 & 65 & 43 & 24 & 86 & 54 & 22 & 52 & 50 & 500 & & \\
\hline \multirow{2}{*}{ USA } & 45 & 45 & 45 & 45 & 45 & 45 & 45 & 45 & 45 & 45 & 45 & 45 & \multirow{2}{*}{65} & \multirow{2}{*}{100} \\
\hline & 45 & 46 & 51 & 53 & 58 & 55 & 59 & 60 & 65 & 66 & 77 & 880 & & \\
\hline \multirow{2}{*}{ China } & 98 & 98 & 98 & 98 & 98 & 98 & 98 & 98 & 98 & 98 & 98 & 98 & \multirow{2}{*}{98} & \multirow{2}{*}{65} \\
\hline & 45 & 45 & 25 & 78 & 56 & 44 & 57 & 55 & 56 & 54 & 53 & 510 & & \\
\hline \multirow{2}{*}{ China } & 56 & 56 & 56 & 56 & 56 & 56 & 56 & 56 & 56 & 56 & 56 & 56 & \multirow{2}{*}{89} & \multirow{2}{*}{12} \\
\hline & 78 & 77 & 77 & 54 & 36 & 36 & 36 & 36 & 36 & 36 & 36 & 360 & & \\
\hline \multirow{2}{*}{ Mexico } & 23 & 23 & 23 & 23 & 23 & 23 & 23 & 23 & 23 & 23 & 23 & 23 & \multirow{2}{*}{85} & \multirow{2}{*}{85} \\
\hline & 44 & 44 & 44 & 44 & 44 & 44 & 44 & 54 & 23 & 4 & 4 & 330 & & \\
\hline
\end{tabular}

\section{Expected Output:}

\begin{tabular}{|l|l|l|l|l|l|}
\hline $\begin{array}{l}\text { Grouping } \\
\text { Countries }\end{array}$ & $\begin{array}{l}\text { Maximum } \\
\text { Cost }\end{array}$ & $\begin{array}{l}\text { Maximum fair } \\
\text { market value }\end{array}$ & $\begin{array}{l}\text { Fair market } \\
\text { value at year end }\end{array}$ & $\begin{array}{l}\text { Foreign income } \\
\text { earned or loss }\end{array}$ & $\begin{array}{l}\text { Capital } \\
\text { gain/loss }\end{array}$ \\
\hline \multirow{3}{*}{ CANADA } & \multirow{3}{*}{271} & 1010 & 1010 & 150 & 80 \\
\cline { 1 - 5 } USA & 1380 & 1380 & 110 & 142 \\
\cline { 3 - 6 } CHINA & 870 & 870 & 187 & 77 \\
\cline { 3 - 5 } & & 330 & 330 & 85 & 85 \\
\hline
\end{tabular}

\section{Actual Output:}

\begin{tabular}{|l|l|l|l|l|l|}
\hline $\begin{array}{l}\text { Grouping } \\
\text { Countries }\end{array}$ & $\begin{array}{l}\text { Maximum } \\
\text { Cost }\end{array}$ & $\begin{array}{l}\text { Maximum fair } \\
\text { market value }\end{array}$ & $\begin{array}{l}\text { Fair market } \\
\text { value at year end }\end{array}$ & $\begin{array}{l}\text { Foreign income } \\
\text { earned or loss }\end{array}$ & $\begin{array}{l}\text { Capital } \\
\text { gain/loss }\end{array}$ \\
\hline \multirow{3}{*}{ CANADA } & \multirow{3}{*}{271} & 1010 & 1010 & 150 & 80 \\
\cline { 1 - 4 } USA & 1380 & 1380 & 110 & 142 \\
\cline { 4 - 6 } CHINA & 870 & 870 & 187 & 77 \\
\cline { 3 - 6 } & & 330 & 330 & 85 & 85 \\
\hline
\end{tabular}


Calc_2_TC_7_1_BC

\begin{tabular}{|c|c|c|c|c|c|c|c|c|c|c|c|c|c|c|}
\hline $\begin{array}{l}\hat{E} \\
\hat{0}\end{array}$ & Eี & e & 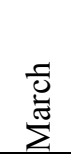 & $\overline{\bar{c}}$ & $\stackrel{\Xi}{\Xi}$ & $\Xi$ & $\frac{\lambda}{3}$ & 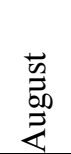 & $\begin{array}{l}\overrightarrow{0} 0 \\
\ddot{n}\end{array}$ & $\ddot{0}$ & ż & ஜ̈ & 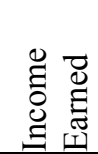 & 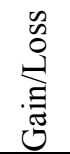 \\
\hline \multirow{2}{*}{ Canada } & 10 & 10 & 10 & 10 & 10 & 10 & 10 & 10 & 10 & 10 & 10 & 10 & \multirow{2}{*}{600} & \multirow{2}{*}{30} \\
\hline & 21 & 22 & 23 & 25 & 22 & 40 & 45 & 34 & 22 & 34 & 87 & 77 & & \\
\hline \multirow{2}{*}{ Canada } & 14 & 14 & 14 & 14 & 14 & 14 & 14 & 14 & 14 & 14 & 14 & 14 & \multirow{2}{*}{900} & \multirow{2}{*}{50} \\
\hline & 14 & 54 & 55 & 45 & 5 & 44 & 71 & 20 & 22 & 24 & 22 & 24 & & \\
\hline \multirow{2}{*}{ USA } & 25 & 25 & 25 & 25 & 25 & 25 & 25 & 25 & 25 & 25 & 25 & 25 & \multirow{2}{*}{450} & \multirow{2}{*}{42} \\
\hline & 23 & 44 & 24 & 65 & 43 & 24 & 86 & 54 & 22 & 52 & 50 & 50 & & \\
\hline \multirow{2}{*}{ USA } & 45 & 45 & 45 & 45 & 45 & 45 & 45 & 45 & 45 & 45 & 45 & 45 & \multirow{2}{*}{650} & \multirow{2}{*}{100} \\
\hline & 45 & 46 & 51 & 53 & 58 & 55 & 59 & 60 & 65 & 66 & 77 & 88 & & \\
\hline \multirow{2}{*}{ China } & 98 & 98 & 98 & 98 & 98 & 98 & 98 & 98 & 98 & 98 & 98 & 98 & \multirow{2}{*}{980} & \multirow{2}{*}{65} \\
\hline & 45 & 45 & 25 & 78 & 56 & 44 & 57 & 55 & 56 & 54 & 53 & 51 & & \\
\hline \multirow{2}{*}{ China } & 56 & 56 & 56 & 56 & 56 & 56 & 56 & 56 & 56 & 56 & 56 & 56 & \multirow{2}{*}{890} & \multirow{2}{*}{12} \\
\hline & 78 & 77 & \begin{tabular}{|l|}
77 \\
\end{tabular} & 54 & 36 & 36 & 36 & 36 & 36 & 36 & 36 & 36 & & \\
\hline \multirow{2}{*}{ Mexico } & 23 & 23 & 23 & 23 & 23 & 23 & 23 & 23 & 23 & 23 & 23 & 23 & \multirow{2}{*}{850} & \multirow{2}{*}{85} \\
\hline & 44 & 44 & 44 & 44 & 44 & 44 & 44 & 54 & 23 & 4 & 4 & 33 & & \\
\hline
\end{tabular}

\section{Expected Output:}

\begin{tabular}{|l|l|l|l|l|l|}
\hline $\begin{array}{l}\text { Grouping } \\
\text { Countries }\end{array}$ & $\begin{array}{l}\text { Maximum } \\
\text { Cost }\end{array}$ & $\begin{array}{l}\text { Maximum fair } \\
\text { market value }\end{array}$ & $\begin{array}{l}\text { Fair market } \\
\text { value at year end }\end{array}$ & $\begin{array}{l}\text { Foreign income } \\
\text { earned or loss }\end{array}$ & $\begin{array}{l}\text { Capital } \\
\text { gain/loss }\end{array}$ \\
\hline \multirow{3}{*}{ CANADA } & \multirow{3}{*}{271} & 116 & 101 & 1500 & 80 \\
\cline { 1 - 5 } USA & 145 & 138 & 1100 & 142 \\
\cline { 3 - 6 } CHINA & 132 & 87 & 1870 & 77 \\
\cline { 3 - 5 } MEXICO & 54 & 33 & 850 & 85 \\
\hline
\end{tabular}

\section{Actual Output:}

\begin{tabular}{|c|c|c|c|c|c|}
\hline $\begin{array}{l}\text { Grouping } \\
\text { Countries }\end{array}$ & $\begin{array}{l}\text { Maximum } \\
\text { Cost }\end{array}$ & $\begin{array}{l}\text { Maximum fair } \\
\text { market value }\end{array}$ & $\begin{array}{l}\text { Fair market } \\
\text { value at year end }\end{array}$ & $\begin{array}{l}\text { Foreign income } \\
\text { earned or loss }\end{array}$ & $\begin{array}{l}\text { Capital } \\
\text { gain/loss }\end{array}$ \\
\hline CANADA & \multirow{4}{*}{271} & 116 & 101 & 1500 & 80 \\
\hline USA & & 145 & 138 & 1100 & 142 \\
\hline CHINA & & 132 & 87 & 1870 & 77 \\
\hline MEXICO & & 54 & 33 & 850 & 85 \\
\hline
\end{tabular}




\section{Each-Choice Test Frames and Test Cases}

Frame 1:

Countries.Casing.Consistent

Countries.AreSimilar.True

Countries.HaveEmpty.False

Countries.HaveMissing.True

SecurityValues.PlaceOfHighestSummedUpValu

e.December

Frame 2:

Countries.Casing.Inconsistent

Countries.AreSimilar.False

Countries.HaveEmpty.True
Countries.HaveMissing.False

SecurityValues.PlaceOfHighestSummedUpValu

e.IncomeEarnedOrCapitalGain

Frame 3:

Countries.Casing.Inconsistent

Countries.AreSimilar.False

Countries.HaveEmpty.False

Countries.HaveMissing.False

SecurityValues.PlaceOfHighestSummedUpValu

e.OtherMonths

Calc_2_TC_1_1_EC

\begin{tabular}{|c|c|c|c|c|c|c|c|c|c|c|c|c|c|c|}
\hline $\begin{array}{l}\stackrel{\lambda}{\Xi} \\
ٍ \\
0\end{array}$ & 胥 & $\begin{array}{l}\text { eे } \\
\text { e }\end{array}$ & 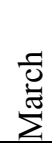 & 胥 & $\sum_{i}^{\vec{\pi}}$ & $\stackrel{\Xi}{\Xi}$ & $\frac{\lambda}{\Xi}$ & 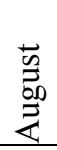 & 苛 & $\ddot{0}$ & $\begin{array}{l}z \\
\text { Z }\end{array}$ & 巳̊ & 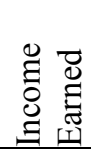 & 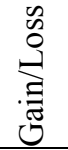 \\
\hline \multirow{2}{*}{ Canada } & 10 & 10 & 10 & 10 & 10 & 10 & 10 & 10 & 10 & 10 & 10 & 10 & \multirow{2}{*}{60} & \multirow{2}{*}{30} \\
\hline & 21 & 22 & 23 & 25 & 22 & 40 & 45 & 34 & 22 & 34 & 87 & 770 & & \\
\hline \multirow{2}{*}{ Canada } & 14 & 14 & 14 & 14 & 14 & 14 & 14 & 14 & 14 & 14 & 14 & 14 & \multirow{2}{*}{90} & \multirow{2}{*}{50} \\
\hline & 14 & 54 & 55 & 45 & 5 & 44 & 71 & 20 & 22 & 24 & 22 & 240 & & \\
\hline \multirow{2}{*}{ NULL } & 25 & 25 & 25 & 25 & 25 & 25 & 25 & 25 & 25 & 25 & 25 & 25 & \multirow{2}{*}{45} & \multirow{2}{*}{42} \\
\hline & 23 & 44 & 24 & 65 & 43 & 24 & 86 & 54 & 22 & 52 & 50 & 500 & & \\
\hline \multirow{2}{*}{ NULL } & 45 & 45 & 45 & 45 & 45 & 45 & 45 & 45 & 45 & 45 & 45 & 45 & \multirow{2}{*}{65} & \multirow{2}{*}{100} \\
\hline & 45 & 46 & 51 & 53 & 58 & 55 & 59 & 60 & 65 & 66 & 77 & 880 & & \\
\hline
\end{tabular}

\section{Expected Output:}

Error

\section{Actual Output:}

Error 
Calc_2_TC_2_1_EC

\begin{tabular}{|c|c|c|c|c|c|c|c|c|c|c|c|c|c|c|}
\hline $\begin{array}{l}\hat{E} \\
\overline{0}\end{array}$ & డ్ & లి & 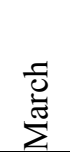 & $\overline{\bar{c}}$ & 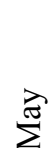 & $\Xi$ & 공 & $\begin{array}{l}\frac{5}{5} \\
\frac{0}{00} \\
\end{array}$ & 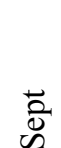 & $\overline{8}$ & ? & $\ddot{\Xi}$ & 兽 : & 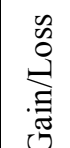 \\
\hline \multirow{2}{*}{ Canada } & 10 & 10 & 10 & 10 & 10 & 10 & 10 & 10 & 10 & 10 & 10 & 10 & \multirow{2}{*}{600} & \multirow{2}{*}{30} \\
\hline & 21 & 22 & 23 & 25 & 22 & 40 & 45 & 34 & 22 & 34 & 87 & 77 & & \\
\hline \multirow{2}{*}{ CanadA } & 14 & 14 & 14 & 14 & 14 & 14 & 14 & 14 & 14 & 14 & 14 & 14 & \multirow{2}{*}{900} & \multirow{2}{*}{50} \\
\hline & 14 & 54 & 55 & 45 & 5 & 44 & 71 & 20 & 22 & 24 & 22 & 24 & & \\
\hline \multirow{2}{*}{ Mexico } & 23 & 23 & 23 & 23 & 23 & 23 & 23 & 23 & 23 & 23 & 23 & 23 & \multirow{2}{*}{850} & \multirow{2}{*}{85} \\
\hline & 44 & 44 & 44 & 44 & 44 & 44 & 44 & 54 & 23 & 4 & 4 & 33 & & \\
\hline
\end{tabular}

\section{Expected Output:}

\begin{tabular}{|l|l|l|l|l|l|}
\hline $\begin{array}{l}\text { Grouping } \\
\text { Countries }\end{array}$ & $\begin{array}{l}\text { Maximum } \\
\text { Cost }\end{array}$ & $\begin{array}{l}\text { Maximum fair } \\
\text { market value }\end{array}$ & $\begin{array}{l}\text { Fair market } \\
\text { value at year end }\end{array}$ & $\begin{array}{l}\text { Foreign income } \\
\text { earned or loss }\end{array}$ & $\begin{array}{l}\text { Capital } \\
\text { gain/loss }\end{array}$ \\
\hline CANADA & \multirow{2}{*}{47} & 116 & 101 & 1500 & 80 \\
\cline { 3 - 6 } MEXICO & 54 & 33 & 850 & 85 \\
\hline
\end{tabular}

\section{Actual Output:}

\begin{tabular}{|l|l|l|l|l|l|}
\hline $\begin{array}{l}\text { Grouping } \\
\text { Countries }\end{array}$ & $\begin{array}{l}\text { Maximum } \\
\text { Cost }\end{array}$ & $\begin{array}{l}\text { Maximum fair } \\
\text { market value }\end{array}$ & $\begin{array}{l}\text { Fair market } \\
\text { value at year end }\end{array}$ & $\begin{array}{l}\text { Foreign income } \\
\text { earned or loss }\end{array}$ & $\begin{array}{l}\text { Capital } \\
\text { gain/loss }\end{array}$ \\
\hline CANADA & \multirow{2}{*}{47} & 116 & 101 & 1500 & 80 \\
\cline { 3 - 6 } MEXICO & & 54 & 33 & 850 & 85 \\
\hline
\end{tabular}


Calc_2_TC_3_1_EC

\begin{tabular}{|c|c|c|c|c|c|c|c|c|c|c|c|c|c|c|}
\hline $\begin{array}{l}\stackrel{\Xi}{\Xi} \\
0 \\
0\end{array}$ & పี & $\begin{array}{l}00 \\
11\end{array}$ & $\begin{array}{l}\overline{0} \\
\overline{\tilde{J}} \\
\sum^{2}\end{array}$ & $\overline{\bar{c}}$ & $\sum_{\Sigma}^{\grave{J}}$ & $\Xi$ & $\vec{\partial}$ & $\begin{array}{l}\overrightarrow{0} \\
\stackrel{0}{0} \\
\stackrel{0}{Z}\end{array}$ & $\begin{array}{l}\overrightarrow{0} \\
\text { है }\end{array}$ & $\overrightarrow{0}$ & z & $\stackrel{\mathscr{U}}{0}$ & 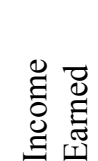 & 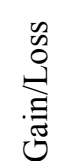 \\
\hline \multirow{2}{*}{ Canada } & 10 & 10 & 10 & 10 & 10 & 10 & 10 & 10 & 10 & 10 & 10 & 10 & \multirow{2}{*}{60} & \multirow{2}{*}{30} \\
\hline & 210 & 22 & 23 & 25 & 22 & 40 & 45 & 34 & 22 & 34 & 87 & 77 & & \\
\hline \multirow{2}{*}{ CanadA } & 14 & 14 & 14 & 14 & 14 & 14 & 14 & 14 & 14 & 14 & 14 & 14 & \multirow{2}{*}{90} & \multirow{2}{*}{50} \\
\hline & 140 & 54 & 55 & 45 & 5 & 44 & 71 & 20 & 22 & 24 & 22 & 24 & & \\
\hline \multirow{2}{*}{ USA } & 25 & 25 & 25 & 25 & 25 & 25 & 25 & 25 & 25 & 25 & 25 & 25 & \multirow{2}{*}{45} & \multirow{2}{*}{42} \\
\hline & 230 & 44 & 24 & 65 & 43 & 24 & 86 & 54 & 22 & 52 & 50 & 50 & & \\
\hline \multirow{2}{*}{ USA } & 45 & 45 & 45 & 45 & 45 & 45 & 45 & 45 & 45 & 45 & 45 & 45 & \multirow{2}{*}{65} & \multirow{2}{*}{100} \\
\hline & 450 & 46 & 51 & 53 & 58 & 55 & 59 & 60 & 65 & 66 & 77 & 88 & & \\
\hline \multirow{2}{*}{ China } & 98 & 98 & 98 & 98 & 98 & 98 & 98 & 98 & 98 & 98 & 98 & 98 & \multirow{2}{*}{98} & \multirow{2}{*}{65} \\
\hline & 450 & 45 & 25 & 78 & 56 & 44 & 57 & 55 & 56 & 54 & 53 & 51 & & \\
\hline \multirow{2}{*}{ China } & 56 & 56 & 56 & 56 & 56 & 56 & 56 & 56 & 56 & 56 & 56 & 56 & \multirow{2}{*}{89} & \multirow{2}{*}{12} \\
\hline & 780 & 77 & 77 & 54 & 36 & 36 & 36 & 36 & 36 & 36 & 36 & 36 & & \\
\hline \multirow{2}{*}{ Mexico } & 23 & 23 & 23 & 23 & 23 & 23 & 23 & 23 & 23 & 23 & 23 & 23 & \multirow[b]{2}{*}{8} & \multirow[b]{2}{*}{85} \\
\hline & 440 & 44 & 44 & 44 & 44 & 44 & 44 & 54 & 23 & 4 & 4 & 33 & & \\
\hline
\end{tabular}

\section{Expected Output:}

We expect the 'Canada' securities to be grouped under the country 'Canada' using any variation of it spelling.

\begin{tabular}{|l|l|l|l|l|l|}
\hline $\begin{array}{l}\text { Grouping } \\
\text { Countries }\end{array}$ & $\begin{array}{l}\text { Maximum } \\
\text { Cost }\end{array}$ & $\begin{array}{l}\text { Maximum fair } \\
\text { market value }\end{array}$ & $\begin{array}{l}\text { Fair market } \\
\text { value at year end }\end{array}$ & $\begin{array}{l}\text { Foreign income } \\
\text { earned or loss }\end{array}$ & $\begin{array}{l}\text { Capital } \\
\text { gain/loss }\end{array}$ \\
\hline \multirow{3}{*}{ CANADA } & \multirow{3}{*}{271} & 350 & 101 & 150 & 80 \\
\cline { 1 - 4 } USA & 680 & 138 & 110 & 142 \\
\cline { 3 - 6 } CHINA & & 87 & 187 & 77 \\
\cline { 3 - 6 } MEXICO & 1230 & 33 & 85 & 85 \\
\cline { 3 - 5 } & 440 & & \\
\hline
\end{tabular}

\section{Actual Output:}

\begin{tabular}{|l|l|l|l|l|l|}
\hline $\begin{array}{l}\text { Grouping } \\
\text { Countries }\end{array}$ & \multirow{2}{*}{$\begin{array}{l}\text { Maximum } \\
\text { Cost }\end{array}$} & $\begin{array}{l}\text { Maximum fair } \\
\text { market value }\end{array}$ & $\begin{array}{l}\text { Fair market } \\
\text { value at year end }\end{array}$ & $\begin{array}{l}\text { Foreign income } \\
\text { earned or loss }\end{array}$ & $\begin{array}{l}\text { Capital } \\
\text { gain/loss }\end{array}$ \\
\hline \multirow{3}{*}{ CANADA } & \multirow{3}{*}{271} & 350 & 101 & 150 & 80 \\
\cline { 1 - 5 } USA & 680 & 138 & 110 & 142 \\
\cline { 3 - 5 } CHINA & 1230 & 87 & 187 & 77 \\
\cline { 3 - 5 } MEXICO & 440 & 33 & 85 & 85 \\
\hline
\end{tabular}




\section{Pair-Wise Test Frames and Test Cases}

Frame 1:

Countries.Casing.Consistent

Countries.AreSimilar.True

Countries.HaveEmpty.True

Countries.HaveMissing.True

SecurityValues.PlaceOfHighestSummedUpValu

e.December

Frame 2:

Countries.Casing.Consistent

Countries.AreSimilar.False

Countries.HaveEmpty.False

Countries.HaveMissing.True

SecurityValues.PlaceOfHighestSummedUpValu

e.OtherMonths

Frame 3:

Countries.Casing.Inconsistent

Countries.AreSimilar.False

Countries.HaveEmpty.False

Countries.HaveMissing.False

SecurityValues.PlaceOfHighestSummedUpValu

e.December
Frame 4:

Countries.Casing.Inconsistent

Countries.AreSimilar.True

Countries.HaveEmpty.False

Countries.HaveMissing.True

SecurityValues.PlaceOfHighestSummedUpValu

e.IncomeEarnedOrCapitalGain

Frame 5:

Countries.Casing.Inconsistent

Countries.AreSimilar.True

Countries.HaveEmpty.True

Countries.HaveMissing.False

SecurityValues.PlaceOfHighestSummedUpValu

e.OtherMonths

Frame 6:

Countries.Casing.Consistent

Countries.AreSimilar.False

Countries.HaveEmpty.True

Countries.HaveMissing.False

SecurityValues.PlaceOfHighestSummedUpValu e.IncomeEarnedOrCapitalGain

\section{Calc_2_TC_1_1_PW}

\begin{tabular}{|c|c|c|c|c|c|c|c|c|c|c|c|c|c|c|}
\hline $\begin{array}{l}\stackrel{\vec{E}}{\Xi} \\
\stackrel{\Xi}{0}\end{array}$ & 胥 & $\begin{array}{l}0 \\
0 \\
1\end{array}$ & $\begin{array}{l}\overline{0} \\
\bar{\Xi} \\
\Sigma\end{array}$ & $\overline{\bar{z}}$ & $\sum_{\Sigma}^{\vec{\epsilon}}$ & $\Xi$ & $\vec{\partial}$ & $\begin{array}{l}\vec{n} \\
\overrightarrow{0} \\
\stackrel{0}{Z}\end{array}$ & $\begin{array}{l}\overrightarrow{0} 0 \\
0 \\
\tilde{n}\end{array}$ & $\overline{0}$ & zo & ల్ల & 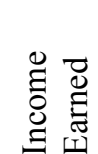 & 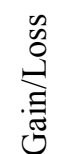 \\
\hline \multirow{2}{*}{ NULL } & 10 & 10 & 10 & 10 & 10 & 10 & 10 & 10 & 10 & 10 & 10 & 10 & \multirow{2}{*}{60} & \multirow{2}{*}{30} \\
\hline & 21 & 22 & 23 & 25 & 22 & 40 & 45 & 34 & 22 & 34 & 87 & 770 & & \\
\hline \multirow[t]{2}{*}{ “"” } & 14 & 14 & 14 & 14 & 14 & 14 & 14 & 14 & 14 & 14 & 14 & 14 & \multirow{2}{*}{90} & \multirow{2}{*}{50} \\
\hline & 14 & 54 & 55 & 45 & 5 & 44 & 71 & 20 & 22 & 24 & 22 & 240 & & \\
\hline \multirow{2}{*}{ USA } & 25 & 25 & 25 & 25 & 25 & 25 & 25 & 25 & 25 & 25 & 25 & 25 & \multirow{2}{*}{45} & \multirow{2}{*}{42} \\
\hline & 23 & 44 & 24 & 65 & 43 & 24 & 86 & 54 & 22 & 52 & 50 & 500 & & \\
\hline \multirow{2}{*}{ USA } & 45 & 45 & 45 & 45 & 45 & 45 & 45 & 45 & 45 & 45 & 45 & 45 & \multirow{2}{*}{65} & \multirow{2}{*}{100} \\
\hline & 45 & 46 & 51 & 53 & 58 & 55 & 59 & 60 & 65 & 66 & 77 & 880 & & \\
\hline
\end{tabular}




\section{Expected Output:}

Error

\section{Actual Output:}

Error

Calc_2_TC_2_1_PW

\begin{tabular}{|c|c|c|c|c|c|c|c|c|c|c|c|c|c|c|}
\hline 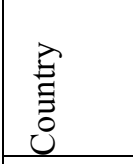 & Е్త్ & 过 & 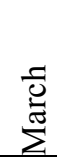 & $\overline{\bar{z}}$ & $\sum_{\Sigma}^{\mathrm{J}}$ & $\Xi$ & $\overrightarrow{3}$ & $\begin{array}{l}\vec{n} \\
\vec{z} \\
\overrightarrow{00} \\
\vec{Z}\end{array}$ & 离 & $\ddot{0}$ & z & $\stackrel{\mathscr{U}}{0}$ & 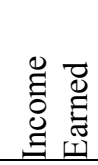 & 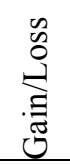 \\
\hline \multirow{2}{*}{ Canada } & 10 & 10 & 10 & 10 & 10 & 10 & 10 & 10 & 10 & 10 & 10 & 10 & \multirow{2}{*}{60} & \multirow{2}{*}{30} \\
\hline & 210 & 22 & 23 & 25 & 22 & 40 & 45 & 34 & 22 & 34 & 87 & 77 & & \\
\hline \multirow{2}{*}{ Canada } & 14 & 14 & 14 & 14 & 14 & 14 & 14 & 14 & 14 & 14 & 14 & 14 & \multirow{2}{*}{90} & \multirow{2}{*}{50} \\
\hline & 140 & 54 & 55 & 45 & 5 & 44 & 71 & 20 & 22 & 24 & 22 & 24 & & \\
\hline \multirow[b]{2}{*}{ USA } & 25 & 25 & 25 & 25 & 25 & 25 & 25 & 25 & 25 & 25 & 25 & 25 & \multirow{2}{*}{45} & \multirow[b]{2}{*}{42} \\
\hline & 230 & 44 & 24 & 65 & 43 & 24 & 86 & 54 & 22 & 52 & 50 & 50 & & \\
\hline \multirow{2}{*}{ USA } & 45 & 45 & 45 & 45 & 45 & 45 & 45 & 45 & 45 & 45 & 45 & 45 & \multirow{2}{*}{65} & \multirow{2}{*}{100} \\
\hline & 450 & 46 & 51 & 53 & 58 & 55 & 59 & 60 & 65 & 66 & 77 & 88 & & \\
\hline \multirow{2}{*}{ China } & 98 & 98 & 98 & 98 & 98 & 98 & 98 & 98 & 98 & 98 & 98 & 98 & \multirow{2}{*}{98} & \multirow[b]{2}{*}{65} \\
\hline & 450 & 45 & 25 & 78 & 56 & 44 & 57 & 55 & 56 & 54 & 53 & 51 & & \\
\hline \multirow{2}{*}{ China } & 56 & 56 & 56 & 56 & 56 & 56 & 56 & 56 & 56 & 56 & 56 & 56 & \multirow{2}{*}{89} & \multirow{2}{*}{12} \\
\hline & 780 & 77 & 77 & 54 & 36 & 36 & 36 & 36 & 36 & 36 & 36 & 36 & & \\
\hline \multirow{2}{*}{ NULL } & 23 & 23 & 23 & 23 & 23 & 23 & 23 & 23 & 23 & 23 & 23 & 23 & \multirow{2}{*}{85} & \multirow[b]{2}{*}{85} \\
\hline & 440 & 44 & 44 & 44 & 44 & 44 & 44 & 54 & 23 & 4 & 4 & 33 & & \\
\hline
\end{tabular}

\section{Expected Output:}

Error

\section{Actual Output:}

Error 
Calc_2_TC_3_1_PW

\begin{tabular}{|c|c|c|c|c|c|c|c|c|c|c|c|c|c|c|}
\hline $\begin{array}{l}\stackrel{\Xi}{\Xi} \\
\text { 己 }\end{array}$ & Eี & 邁 & $\begin{array}{l}\text { D̃ } \\
\sum_{\Sigma}^{\pi}\end{array}$ & $\overline{\vec{z}}$ & $\stackrel{\nexists}{\Xi}$ & $\Xi$ & $\vec{\partial}$ & 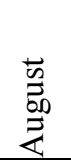 & $\begin{array}{l}\overrightarrow{0} \\
\text { हू }\end{array}$ & $\overrightarrow{0}$ & z & $\stackrel{\mathscr{N}}{0}$ & 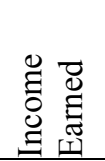 & 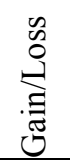 \\
\hline \multirow{2}{*}{ Canada } & 10 & 10 & 10 & 10 & 10 & 10 & 10 & 10 & 10 & 10 & 10 & 10 & \multirow{2}{*}{60} & \multirow{2}{*}{30} \\
\hline & 21 & 22 & 23 & 25 & 22 & 40 & 45 & 34 & 22 & 34 & 87 & 770 & & \\
\hline \multirow{2}{*}{ CanadA } & 14 & 14 & 14 & 14 & 14 & 14 & 14 & 14 & 14 & 14 & 14 & 14 & \multirow{2}{*}{90} & \multirow{2}{*}{50} \\
\hline & 14 & 54 & 55 & 45 & 5 & 44 & 71 & 20 & 22 & 24 & 22 & 240 & & \\
\hline \multirow{2}{*}{ USA } & 25 & 25 & 25 & 25 & 25 & 25 & 25 & 25 & 25 & 25 & 25 & 25 & \multirow{2}{*}{45} & \multirow{2}{*}{42} \\
\hline & 23 & 44 & 24 & 65 & 43 & 24 & 86 & 54 & 22 & 52 & 50 & 500 & & \\
\hline \multirow{2}{*}{ USA } & 45 & 45 & 45 & 45 & 45 & 45 & 45 & 45 & 45 & 45 & 45 & 45 & \multirow{2}{*}{65} & \multirow{2}{*}{100} \\
\hline & 45 & 46 & 51 & 53 & 58 & 55 & 59 & 60 & 65 & 66 & 77 & 880 & & \\
\hline \multirow{2}{*}{ China } & 98 & 98 & 98 & 98 & 98 & 98 & 98 & 98 & 98 & 98 & 98 & 98 & \multirow{2}{*}{98} & \multirow{2}{*}{65} \\
\hline & 45 & 45 & 25 & 78 & 56 & 44 & 57 & 55 & 56 & 54 & 53 & 510 & & \\
\hline \multirow{2}{*}{ China } & 56 & 56 & 56 & 56 & 56 & 56 & 56 & 56 & 56 & 56 & 56 & 56 & \multirow{2}{*}{89} & \multirow{2}{*}{12} \\
\hline & 78 & 77 & 77 & 54 & 36 & 36 & 36 & 36 & 36 & 36 & 36 & 360 & & \\
\hline \multirow{2}{*}{ Mexico } & 23 & 23 & 23 & 23 & 23 & 23 & 23 & 23 & 23 & 23 & 23 & 23 & \multirow{2}{*}{85} & \multirow{2}{*}{85} \\
\hline & 44 & 44 & 44 & 44 & 44 & 44 & 44 & 54 & 23 & 4 & 4 & 330 & & \\
\hline
\end{tabular}

\section{Expected Output:}

\begin{tabular}{|l|l|l|l|l|l|}
\hline $\begin{array}{l}\text { Grouping } \\
\text { Countries }\end{array}$ & $\begin{array}{l}\text { Maximum } \\
\text { Cost }\end{array}$ & $\begin{array}{l}\text { Maximum fair } \\
\text { market value }\end{array}$ & $\begin{array}{l}\text { Fair market } \\
\text { value at year end }\end{array}$ & $\begin{array}{l}\text { Foreign income } \\
\text { earned or loss }\end{array}$ & $\begin{array}{l}\text { Capital } \\
\text { gain/loss }\end{array}$ \\
\hline \multirow{3}{*}{ CANADA } & \multirow{3}{*}{271} & 1010 & 1010 & 150 & 80 \\
\cline { 1 - 5 } USA & 1380 & 1380 & 110 & 142 \\
\cline { 3 - 6 } CHINA & 870 & 870 & 187 & 77 \\
\cline { 3 - 5 } MEXICO & 330 & 330 & 85 & 85 \\
\hline
\end{tabular}

\section{Actual Output:}

\begin{tabular}{|l|l|l|l|l|l|}
\hline $\begin{array}{l}\text { Grouping } \\
\text { Countries }\end{array}$ & $\begin{array}{l}\text { Maximum } \\
\text { Cost }\end{array}$ & $\begin{array}{l}\text { Maximum fair } \\
\text { market value }\end{array}$ & $\begin{array}{l}\text { Fair market } \\
\text { value at year end }\end{array}$ & $\begin{array}{l}\text { Foreign income } \\
\text { earned or loss }\end{array}$ & $\begin{array}{l}\text { Capital } \\
\text { gain/loss }\end{array}$ \\
\hline \multirow{3}{*}{ CANADA } & \multirow{3}{*}{271} & 1010 & 1010 & 150 & 80 \\
\cline { 1 - 4 } USA & 1380 & 1380 & 110 & 142 \\
\cline { 4 - 6 } CHINA & 870 & 870 & 187 & 77 \\
\cline { 3 - 6 } & & 330 & 330 & 85 & 85 \\
\hline
\end{tabular}




\section{Calc_2_TC_4_1_PW}

We can choose any month other than December to have the highest MV values. Here we choose 'January'

\begin{tabular}{|c|c|c|c|c|c|c|c|c|c|c|c|c|c|c|}
\hline 音 & 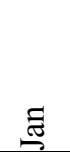 & 这 & 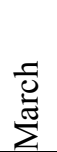 & 家 & $\sum^{e}$ & $\Xi$ & 齐 & $\frac{50}{2}$ & 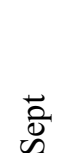 & $\overrightarrow{0}$ & $\vec{a}$ & $\ddot{\mathscr{I}}$ & 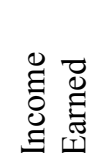 & 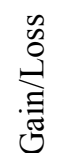 \\
\hline \multirow{2}{*}{ Canada } & 10 & 10 & 10 & 10 & 10 & 10 & 10 & 10 & 10 & 10 & 10 & 10 & \multirow{2}{*}{60} & \multirow{2}{*}{30} \\
\hline & 210 & 22 & 23 & 25 & 22 & 40 & 45 & 34 & 22 & 34 & 87 & 77 & & \\
\hline \multirow{2}{*}{ CanadA } & 14 & 14 & 14 & 14 & 14 & 14 & 14 & 14 & 14 & 14 & 14 & 14 & \multirow{2}{*}{90} & \multirow{2}{*}{50} \\
\hline & 140 & 54 & 55 & 45 & 5 & 44 & 71 & 20 & 22 & 24 & 22 & 24 & & \\
\hline \multirow{2}{*}{ NULL } & 23 & 23 & 23 & 23 & 23 & 23 & 23 & 23 & 23 & 23 & 23 & 23 & \multirow[b]{2}{*}{85} & \multirow{2}{*}{85} \\
\hline & 440 & 44 & 44 & 44 & 44 & 44 & 44 & 54 & 23 & 4 & 4 & 33 & & \\
\hline
\end{tabular}

\section{Expected Output:}

Error

\section{Actual Output:}

Error

\section{Calc_2_TC_5_1_PW}

We can choose any month other than December to have the highest MV values. Here we choose 'January'

\begin{tabular}{|c|c|c|c|c|c|c|c|c|c|c|c|c|c|c|}
\hline $\begin{array}{l}\hat{\theta} \\
\hat{0}\end{array}$ & 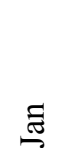 & 这 & $\begin{array}{l}\overline{0} \\
\overline{0} \\
\Sigma\end{array}$ & $\overline{\bar{c}}$ & 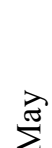 & $\Xi$ & 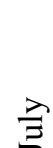 & 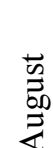 & 흠 & $\overline{0}$ & ? & $\ddot{\Perp}$ & 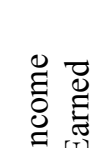 & 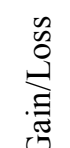 \\
\hline \multirow{2}{*}{ Canada } & 10 & 10 & 10 & 10 & 10 & 10 & 10 & 10 & 10 & 10 & 10 & 10 & \multirow{2}{*}{60} & \multirow{2}{*}{30} \\
\hline & 210 & 22 & 23 & 25 & 22 & 40 & 45 & 34 & 22 & 34 & 87 & 77 & & \\
\hline \multirow{2}{*}{ CanadA } & 14 & 14 & 14 & 14 & 14 & 14 & 14 & 14 & 14 & 14 & 14 & 14 & \multirow{2}{*}{90} & \multirow{2}{*}{50} \\
\hline & 140 & 54 & 55 & 45 & 5 & 44 & 71 & 20 & 22 & 24 & 22 & 24 & & \\
\hline \multirow[t]{2}{*}{ "', } & 25 & 25 & 25 & 25 & 25 & 25 & 25 & 25 & 25 & 25 & 25 & 25 & \multirow{2}{*}{45} & \multirow{2}{*}{42} \\
\hline & 230 & 44 & 24 & 65 & 43 & 24 & 86 & 54 & 22 & 52 & 50 & 50 & & \\
\hline \multirow[t]{2}{*}{ “" } & 45 & 45 & 45 & 45 & 45 & 45 & 45 & 45 & 45 & 45 & 45 & 45 & \multirow{2}{*}{65} & \multirow{2}{*}{100} \\
\hline & 450 & 46 & 51 & 53 & 58 & 55 & 59 & 60 & 65 & 66 & 77 & 88 & & \\
\hline
\end{tabular}




\section{Expected Output:}

\begin{tabular}{|l|l|l|l|l|l|}
\hline $\begin{array}{l}\text { Grouping } \\
\text { Countries }\end{array}$ & $\begin{array}{l}\text { Maximum } \\
\text { Cost }\end{array}$ & $\begin{array}{l}\text { Maximum fair } \\
\text { market value }\end{array}$ & $\begin{array}{l}\text { Fair market } \\
\text { value at year end }\end{array}$ & $\begin{array}{l}\text { Foreign income } \\
\text { earned or loss }\end{array}$ & $\begin{array}{l}\text { Capital } \\
\text { gain/loss }\end{array}$ \\
\hline CANADA & \multirow{2}{*}{94} & 350 & 101 & 150 & 80 \\
\cline { 3 - 6 } & 64 & 680 & 138 & 110 & 142 \\
\hline
\end{tabular}

\section{Actual Output:}

\begin{tabular}{|l|l|l|l|l|l|}
\hline $\begin{array}{l}\text { Grouping } \\
\text { Countries }\end{array}$ & $\begin{array}{l}\text { Maximum } \\
\text { Cost }\end{array}$ & $\begin{array}{l}\text { Maximum fair } \\
\text { market value }\end{array}$ & $\begin{array}{l}\text { Fair market } \\
\text { value at year end }\end{array}$ & $\begin{array}{l}\text { Foreign income } \\
\text { earned or loss }\end{array}$ & $\begin{array}{l}\text { Capital } \\
\text { gain/loss }\end{array}$ \\
\hline CANADA & \multirow{2}{*}{94} & 350 & 101 & 150 & 80 \\
\cline { 3 - 6 } “'” & 680 & 138 & 110 & 142 \\
\hline
\end{tabular}

Calc_2_TC_6_1_PW

\begin{tabular}{|c|c|c|c|c|c|c|c|c|c|c|c|c|c|c|}
\hline $\begin{array}{l}\stackrel{.}{\Xi} \\
\stackrel{\Xi}{0}\end{array}$ & Еี & 过 & 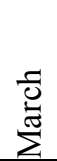 & $\bar{z}$ & $\stackrel{\vec{\Xi}}{\Sigma}$ & $\stackrel{\Xi}{\Xi}$ & $\vec{\Xi}$ & 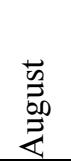 & $\begin{array}{l}\overrightarrow{0} \\
\stackrel{0}{n} \\
\ddot{n}\end{array}$ & $\overrightarrow{0}$ & zे & $\stackrel{\mathscr{\nu}}{\varrho}$ & 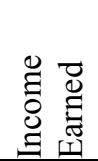 & 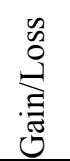 \\
\hline \multirow{2}{*}{ Canada } & 10 & 10 & 10 & 10 & 10 & 10 & 10 & 10 & 10 & 10 & 10 & 10 & \multirow{2}{*}{600} & \multirow{2}{*}{30} \\
\hline & 21 & 22 & 23 & 25 & 22 & 40 & 45 & 34 & 22 & 34 & 87 & 77 & & \\
\hline \multirow{2}{*}{ Canada } & 14 & 14 & 14 & 14 & 14 & 14 & 14 & 14 & 14 & 14 & 14 & 14 & \multirow{2}{*}{900} & \multirow{2}{*}{50} \\
\hline & 14 & 54 & 55 & 45 & 5 & 44 & 71 & 20 & 22 & 24 & 22 & 24 & & \\
\hline \multirow{2}{*}{ USA } & 25 & 25 & 25 & 25 & 25 & 25 & 25 & 25 & 25 & 25 & 25 & 25 & \multirow{2}{*}{450} & \multirow{2}{*}{42} \\
\hline & 23 & 44 & 24 & 65 & 43 & 24 & 86 & 54 & 22 & 52 & 50 & 50 & & \\
\hline \multirow{2}{*}{ USA } & 45 & 45 & 45 & 45 & 45 & 45 & 45 & 45 & 45 & 45 & 45 & 45 & \multirow{2}{*}{650} & \multirow{2}{*}{100} \\
\hline & 45 & 46 & 51 & 53 & 58 & 55 & 59 & 60 & 65 & 66 & 77 & 88 & & \\
\hline \multirow[t]{2}{*}{ “"” } & 98 & 98 & 98 & 98 & 98 & 98 & 98 & 98 & 98 & 98 & 98 & 98 & \multirow{2}{*}{980} & \multirow{2}{*}{65} \\
\hline & 45 & 45 & 25 & 78 & 56 & 44 & 57 & 55 & 56 & 54 & 53 & 51 & & \\
\hline \multirow[t]{2}{*}{ ،"” } & 56 & 56 & 56 & 56 & 56 & 56 & 56 & 56 & 56 & 56 & 56 & 56 & \multirow{2}{*}{890} & \multirow{2}{*}{12} \\
\hline & 78 & 77 & 77 & 54 & 36 & 36 & 36 & 36 & 36 & 36 & 36 & 36 & & \\
\hline \multirow{2}{*}{ Mexico } & 23 & 23 & 23 & 23 & 23 & 23 & 23 & 23 & 23 & 23 & 23 & 23 & \multirow{2}{*}{850} & \multirow[b]{2}{*}{85} \\
\hline & 44 & 44 & 44 & 44 & 44 & 44 & 44 & 54 & 23 & 4 & 4 & 33 & & \\
\hline
\end{tabular}

\section{Expected Output:}

\begin{tabular}{|l|l|l|l|l|l|}
\hline $\begin{array}{l}\text { Grouping } \\
\text { Countries }\end{array}$ & \multirow{2}{*}{$\begin{array}{l}\text { Maximum } \\
\text { Cost }\end{array}$} & $\begin{array}{l}\text { Maximum fair } \\
\text { market value }\end{array}$ & $\begin{array}{l}\text { Fair market } \\
\text { value at year end }\end{array}$ & $\begin{array}{l}\text { Foreign income } \\
\text { earned or loss }\end{array}$ & $\begin{array}{l}\text { Capital } \\
\text { gain/loss }\end{array}$ \\
\hline \multirow{3}{*}{ CANADA } & \multirow{3}{*}{271} & 116 & 101 & 1500 & 80 \\
\cline { 1 - 5 } & 145 & 138 & 1100 & 142 \\
\cline { 3 - 6 } USA & 132 & 87 & 1870 & 77 \\
\hline "'? & 54 & 33 & 850 & 85 \\
\hline MEXICO & & & & \\
\hline
\end{tabular}




\section{Actual Output:}

\begin{tabular}{|l|l|l|l|l|l|}
\hline $\begin{array}{l}\text { Grouping } \\
\text { Countries }\end{array}$ & $\begin{array}{l}\text { Maximum } \\
\text { Cost }\end{array}$ & $\begin{array}{l}\text { Maximum fair } \\
\text { market value }\end{array}$ & $\begin{array}{l}\text { Fair market } \\
\text { value at year end }\end{array}$ & $\begin{array}{l}\text { Foreign income } \\
\text { earned or loss }\end{array}$ & $\begin{array}{l}\text { Capital } \\
\text { gain/loss }\end{array}$ \\
\hline \multirow{2}{*}{ CANADA } & \multirow{3}{*}{271} & 116 & 101 & 1500 & 80 \\
\cline { 3 - 6 } & 145 & 138 & 1100 & 142 \\
\cline { 3 - 6 } USA & 132 & 87 & 1870 & 77 \\
\cline { 3 - 6 } & & 34 & 850 & 85 \\
\hline MEXICO & & & & \\
\hline
\end{tabular}

\section{D.2 Annotated CP Specifications}

\section{Countries}

- Casing

- Consistent [base]

- Inconsistent [Single]

- Similarity

- False [base]

- True [Single]
- HaveEmpty

$\circ$ False [base]

- True [single]

- HaveMissing

- False [base]

- True [Error]

SecurityValue

- PlaceOfHighestSummedUpValue

- OtherMonths [base]

- December

- IncomeEarnedOrCapitalGain [Single]

\section{Base-Choice Test Frames}

Frame 1:

Countries.Casing.Consistent

Countries.AreSimilar.False

Countries.HaveEmpty.False

Countries.HaveMissing.False

SecurityValues.PlaceOfHighestSummedUpValu

e.OtherMonths
Frame 2:

Countries.Casing.Consistent

Countries.AreSimilar.False

Countries.HaveEmpty.False

Countries.HaveMissing.False

SecurityValues.PlaceOfHighestSummedUpValu

e.December 
Frame 3:

Countries.Casing.Inconsistent

Countries.AreSimilar.False

Countries.HaveEmpty.False

Countries.HaveMissing.False

SecurityValues.PlaceOfHighestSummedUpValu

e.OtherMonths

Frame 4:

Countries.Casing.Consistent

Countries.AreSimilar.True

Countries.HaveEmpty.False

Countries.HaveMissing.False

SecurityValues.PlaceOfHighestSummedUpValu

e.OtherMonths
Frame 5:

Countries.Casing.Consistent

Countries.AreSimilar.False

Countries.HaveEmpty.True

Countries.HaveMissing.False

SecurityValues.PlaceOfHighestSummedUpValu

e.OtherMonths

Frame 6:

Countries.Casing.Consistent

Countries.AreSimilar.False

Countries.HaveEmpty.False

Countries.HaveMissing.False

SecurityValues.PlaceOfHighestSummedUpValu

e.IncomeEarnedOrCapitalGain

Frame 7:

Countries.HaveMissing. True

Calc_2_TC_1_1_BC_Ann

We can randomly choose any month other than December to have the highest MV values. Here we choose 'January'

\begin{tabular}{|c|c|c|c|c|c|c|c|c|c|c|c|c|c|c|}
\hline $\begin{array}{l}\hat{\Xi} \\
\stackrel{\Xi}{\Xi} \\
0 \\
\end{array}$ & 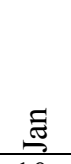 & $\begin{array}{l}0 \\
0 \\
\end{array}$ & $\begin{array}{l}\overline{0} \\
\overline{0} \\
\bar{\Sigma}\end{array}$ & $\overline{\bar{z}}$ & $\sum^{\pi}$ & $\Xi$ & $\vec{\Xi}$ & 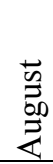 & $\begin{array}{l}0 \\
0 \\
\ddot{n}\end{array}$ & $\overrightarrow{0}$ & z & $\stackrel{\mathscr{\Xi}}{\varrho}$ & 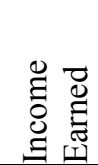 & 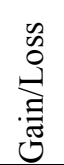 \\
\hline \multirow{2}{*}{ Canada } & 10 & 10 & 10 & 10 & 10 & 10 & 10 & 10 & 10 & 10 & 10 & 10 & \multirow{2}{*}{60} & \multirow{2}{*}{30} \\
\hline & 210 & 22 & 23 & 25 & 22 & 40 & 45 & 34 & 22 & 34 & 87 & 77 & & \\
\hline \multirow{2}{*}{ Canada } & 14 & 14 & 14 & 14 & 14 & 14 & 14 & 14 & 14 & 14 & 14 & 14 & \multirow{2}{*}{90} & \multirow{2}{*}{50} \\
\hline & 140 & 54 & 55 & 45 & 5 & 44 & 71 & 20 & 22 & 24 & 22 & 24 & & \\
\hline \multirow{2}{*}{ USA } & 25 & 25 & 25 & 25 & 25 & 25 & 25 & 25 & 25 & 25 & 25 & 25 & \multirow{2}{*}{45} & \multirow[b]{2}{*}{42} \\
\hline & 230 & 44 & 24 & 65 & 43 & 24 & 86 & 54 & 22 & 52 & 50 & 50 & & \\
\hline \multirow{2}{*}{ USA } & 45 & 45 & 45 & 45 & 45 & 45 & 45 & 45 & 45 & 45 & 45 & 45 & \multirow{2}{*}{65} & \multirow[b]{2}{*}{100} \\
\hline & 450 & 46 & 51 & 53 & 58 & 55 & 59 & 60 & 65 & 66 & 77 & 88 & & \\
\hline \multirow{2}{*}{ China } & 98 & 98 & 98 & 98 & 98 & 98 & 98 & 98 & 98 & 98 & 98 & 98 & \multirow{2}{*}{98} & \multirow{2}{*}{65} \\
\hline & 450 & 45 & 25 & 78 & 56 & 44 & 57 & 55 & 56 & 54 & 53 & 51 & & \\
\hline \multirow{2}{*}{ China } & 56 & 56 & 56 & 56 & 56 & 56 & 56 & 56 & 56 & 56 & 56 & 56 & \multirow{2}{*}{89} & \multirow{2}{*}{12} \\
\hline & 780 & 77 & 77 & 54 & 36 & 36 & 36 & 36 & 36 & 36 & 36 & 36 & & \\
\hline \multirow{2}{*}{ Mexico } & 23 & 23 & 23 & 23 & 23 & 23 & 23 & 23 & 23 & 23 & 23 & 23 & \multirow{2}{*}{85} & \multirow{2}{*}{85} \\
\hline & 440 & 44 & 44 & 44 & 44 & 44 & 44 & 54 & 23 & 4 & 4 & 33 & & \\
\hline
\end{tabular}




\section{Expected Output:}

\begin{tabular}{|l|l|l|l|l|l|}
\hline $\begin{array}{l}\text { Grouping } \\
\text { Countries }\end{array}$ & $\begin{array}{l}\text { Maximum } \\
\text { Cost }\end{array}$ & $\begin{array}{l}\text { Maximum fair } \\
\text { market value }\end{array}$ & $\begin{array}{l}\text { Fair market } \\
\text { value at year end }\end{array}$ & $\begin{array}{l}\text { Foreign income } \\
\text { earned or loss }\end{array}$ & $\begin{array}{l}\text { Capital } \\
\text { gain/loss }\end{array}$ \\
\hline \multirow{3}{*}{ CANADA } & \multirow{3}{*}{271} & 350 & 101 & 150 & 80 \\
\cline { 1 - 5 } & 680 & 138 & 110 & 142 \\
\cline { 3 - 6 } USA & 1230 & 87 & 187 & 77 \\
\cline { 3 - 5 } CHINA & 440 & 33 & 85 & 85 \\
\hline MEXICO & & & & \\
\hline
\end{tabular}

\section{Actual Output:}

\begin{tabular}{|l|l|l|l|l|l|}
\hline $\begin{array}{l}\text { Grouping } \\
\text { Countries }\end{array}$ & $\begin{array}{l}\text { Maximum } \\
\text { Cost }\end{array}$ & $\begin{array}{l}\text { Maximum fair } \\
\text { market value }\end{array}$ & $\begin{array}{l}\text { Fair market } \\
\text { value at year end }\end{array}$ & $\begin{array}{l}\text { Foreign income } \\
\text { earned or loss }\end{array}$ & $\begin{array}{l}\text { Capital } \\
\text { gain/loss }\end{array}$ \\
\hline \multirow{2}{*}{ CANADA } & \multirow{3}{*}{271} & 350 & 101 & 150 & 80 \\
\cline { 1 - 4 } & & 680 & 138 & 110 & 142 \\
\cline { 3 - 6 } USA & 1230 & 87 & 187 & 77 \\
\cline { 3 - 6 } CHINA & 440 & 33 & 85 & 85 \\
\hline MEXICO & & & & \\
\hline
\end{tabular}

Calc_2_TC_2_1_BC_Ann

\begin{tabular}{|c|c|c|c|c|c|c|c|c|c|c|c|c|c|c|}
\hline $\begin{array}{l}\stackrel{E}{E} \\
\stackrel{\Xi}{0}\end{array}$ & E్త్ & 过 & 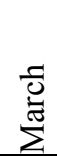 & $\bar{z}$ & $\stackrel{\Xi}{\Xi}$ & 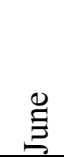 & $\overrightarrow{3}$ & 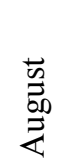 & $\begin{array}{l}\overrightarrow{0} \\
0 \\
\ddot{n}\end{array}$ & ర0 & z & $\stackrel{8}{0}$ & 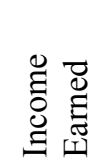 & 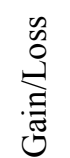 \\
\hline \multirow{2}{*}{ Canada } & 10 & 10 & 10 & 10 & 10 & 10 & 10 & 10 & 10 & 10 & 10 & 10 & \multirow{2}{*}{60} & \multirow{2}{*}{30} \\
\hline & 21 & 22 & 23 & 25 & 22 & 40 & 45 & 34 & 22 & 34 & 87 & 770 & & \\
\hline \multirow{2}{*}{ Canada } & 14 & 14 & 14 & 14 & 14 & 14 & 14 & 14 & 14 & 14 & 14 & 14 & \multirow{2}{*}{90} & \multirow{2}{*}{50} \\
\hline & 14 & 54 & 55 & 45 & 5 & 44 & 71 & 20 & 22 & 24 & 22 & 240 & & \\
\hline \multirow{2}{*}{ USA } & 25 & 25 & 25 & 25 & 25 & 25 & 25 & 25 & 25 & 25 & 25 & 25 & \multirow{2}{*}{45} & \multirow{2}{*}{42} \\
\hline & 23 & 44 & 24 & 65 & 43 & 24 & 86 & 54 & 22 & 52 & 50 & 500 & & \\
\hline \multirow{2}{*}{ USA } & 45 & 45 & 45 & 45 & 45 & 45 & 45 & 45 & 45 & 45 & 45 & 45 & \multirow[b]{2}{*}{65} & \multirow{2}{*}{100} \\
\hline & 45 & 46 & 51 & 53 & 58 & 55 & 59 & 60 & 65 & 66 & 77 & 880 & & \\
\hline \multirow{2}{*}{ China } & 98 & 98 & 98 & 98 & 98 & 98 & 98 & 98 & 98 & 98 & 98 & 98 & \multirow{2}{*}{98} & \multirow{2}{*}{65} \\
\hline & 45 & 45 & 25 & 78 & 56 & 44 & 57 & 55 & 56 & 54 & 53 & 510 & & \\
\hline \multirow{2}{*}{ China } & 56 & 56 & 56 & 56 & 56 & 56 & 56 & 56 & 56 & 56 & 56 & 56 & \multirow{2}{*}{89} & \multirow{2}{*}{12} \\
\hline & 78 & 77 & 77 & 54 & 36 & 36 & 36 & 36 & 36 & 36 & 36 & 360 & & \\
\hline \multirow{2}{*}{ Mexico } & 23 & 23 & 23 & 23 & 23 & 23 & 23 & 23 & 23 & 23 & 23 & 23 & \multirow[b]{2}{*}{8} & \multirow{2}{*}{85} \\
\hline & 44 & 44 & 44 & 44 & 44 & 44 & 44 & 54 & 23 & 4 & 4 & 330 & & \\
\hline
\end{tabular}

\section{Expected Output:}

\begin{tabular}{|l|l|l|l|l|l|}
\hline $\begin{array}{l}\text { Grouping } \\
\text { Countries }\end{array}$ & $\begin{array}{l}\text { Maximum } \\
\text { Cost }\end{array}$ & $\begin{array}{l}\text { Maximum fair } \\
\text { market value }\end{array}$ & $\begin{array}{l}\text { Fair market } \\
\text { value at year end }\end{array}$ & $\begin{array}{l}\text { Foreign income } \\
\text { earned or loss }\end{array}$ & $\begin{array}{l}\text { Capital } \\
\text { gain/loss }\end{array}$ \\
\hline CANADA & & 1010 & 1010 & 150 & 80 \\
\hline
\end{tabular}




\begin{tabular}{|l|l|l|l|l|l|}
\hline USA & \multirow{2}{*}{271} & 1380 & 1380 & 110 & 142 \\
\cline { 1 - 4 } CHINA & 870 & 870 & 187 & 77 \\
\cline { 3 - 6 } & & 330 & 330 & 85 & 85 \\
\hline
\end{tabular}

\section{Actual Output:}

\begin{tabular}{|l|l|l|l|l|l|}
\hline $\begin{array}{l}\text { Grouping } \\
\text { Countries }\end{array}$ & $\begin{array}{l}\text { Maximum } \\
\text { Cost }\end{array}$ & $\begin{array}{l}\text { Maximum fair } \\
\text { market value }\end{array}$ & $\begin{array}{l}\text { Fair market } \\
\text { value at year end }\end{array}$ & $\begin{array}{l}\text { Foreign income } \\
\text { earned or loss }\end{array}$ & $\begin{array}{l}\text { Capital } \\
\text { gain/loss }\end{array}$ \\
\hline \multirow{3}{*}{ CANADA } & \multirow{3}{*}{271} & 1010 & 1010 & 150 & 80 \\
\cline { 1 - 5 } USA & 1380 & 1380 & 110 & 142 \\
\cline { 3 - 6 } CHINA & 870 & 870 & 187 & 77 \\
\cline { 3 - 5 } & & 330 & 330 & 85 & 85 \\
\hline
\end{tabular}

\section{Calc_2_TC_3_1_BC_Ann}

We can choose any month other than December to have the highest MV values. Here we choose 'January'

\begin{tabular}{|c|c|c|c|c|c|c|c|c|c|c|c|c|c|c|}
\hline $\begin{array}{l}\stackrel{\vec{E}}{\Xi} \\
\stackrel{\Xi}{0}\end{array}$ & స్ & e & $\begin{array}{l}\bar{J} \\
\bar{\pi} \\
\bar{\Sigma}\end{array}$ & $\overline{\bar{z}}$ & $\sum_{\Sigma}^{\mathrm{m}}$ & $\Xi$ & $\frac{\lambda}{3}$ & $\begin{array}{l}\overrightarrow{0} \\
\overrightarrow{0} \\
\vec{z} \\
\vec{Z}\end{array}$ & $\begin{array}{l}\overrightarrow{0} 0 \\
0 \\
\tilde{n}\end{array}$ & $\overrightarrow{0}$ & z & $\stackrel{\mathscr{N}}{0}$ & 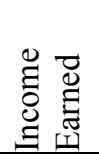 & 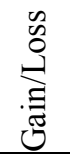 \\
\hline \multirow{2}{*}{ Canada } & 10 & 10 & 10 & 10 & 10 & 10 & 10 & 10 & 10 & 10 & 10 & 10 & \multirow{2}{*}{60} & \multirow{2}{*}{30} \\
\hline & 210 & 22 & 23 & 25 & 22 & 40 & 45 & 34 & 22 & 34 & 87 & 77 & & \\
\hline \multirow{2}{*}{ CanadA } & 14 & 14 & 14 & 14 & 14 & 14 & 14 & 14 & 14 & 14 & 14 & 14 & \multirow{2}{*}{90} & \multirow[b]{2}{*}{50} \\
\hline & 140 & 54 & 55 & 45 & 5 & 44 & 71 & 20 & 22 & 24 & 22 & 24 & & \\
\hline \multirow{2}{*}{ USA } & 25 & 25 & 25 & 25 & 25 & 25 & 25 & 25 & 25 & 25 & 25 & 25 & \multirow{2}{*}{45} & \multirow{2}{*}{42} \\
\hline & 230 & 44 & 24 & 65 & 43 & 24 & 86 & 54 & 22 & 52 & 50 & 50 & & \\
\hline \multirow{2}{*}{ USA } & 45 & 45 & 45 & 45 & 45 & 45 & 45 & 45 & 45 & 45 & 45 & 45 & \multirow{2}{*}{65} & \multirow{2}{*}{100} \\
\hline & 450 & 46 & 51 & 53 & 58 & 55 & 59 & 60 & 65 & 66 & 77 & 88 & & \\
\hline \multirow{2}{*}{ China } & 98 & 98 & 98 & 98 & 98 & 98 & 98 & 98 & 98 & 98 & 98 & 98 & \multirow{2}{*}{98} & \multirow{2}{*}{65} \\
\hline & 450 & 45 & 25 & 78 & 56 & 44 & 57 & 55 & 56 & 54 & 53 & 51 & & \\
\hline \multirow{2}{*}{ China } & 56 & 56 & 56 & 56 & 56 & 56 & 56 & 56 & 56 & 56 & 56 & 56 & \multirow{2}{*}{89} & \multirow{2}{*}{12} \\
\hline & 780 & 77 & 77 & 54 & 36 & 36 & 36 & 36 & 36 & 36 & 36 & 36 & & \\
\hline \multirow{2}{*}{ Mexico } & 23 & 23 & 23 & 23 & 23 & 23 & 23 & 23 & 23 & 23 & 23 & 23 & \multirow{2}{*}{85} & \multirow{2}{*}{85} \\
\hline & 440 & 44 & 44 & 44 & 44 & 44 & 44 & 54 & 23 & 4 & 4 & 33 & & \\
\hline
\end{tabular}

\section{Expected Output:}

\begin{tabular}{|c|c|c|c|c|c|}
\hline $\begin{array}{l}\text { Grouping } \\
\text { Countries }\end{array}$ & $\begin{array}{l}\text { Maximum } \\
\text { Cost }\end{array}$ & $\begin{array}{l}\text { Maximum fair } \\
\text { market value }\end{array}$ & $\begin{array}{l}\text { Fair market } \\
\text { value at year end }\end{array}$ & $\begin{array}{l}\text { Foreign income } \\
\text { earned or loss }\end{array}$ & $\begin{array}{l}\text { Capital } \\
\text { gain/loss }\end{array}$ \\
\hline CANADA & \multirow{4}{*}{271} & 350 & 101 & 150 & 80 \\
\hline USA & & 680 & 138 & 110 & 142 \\
\hline CHINA & & 1230 & 87 & 187 & 77 \\
\hline MEXICO & & 440 & 33 & 85 & 85 \\
\hline
\end{tabular}




\section{Actual Output:}

\begin{tabular}{|l|l|l|l|l|l|}
\hline $\begin{array}{l}\text { Grouping } \\
\text { Countries }\end{array}$ & $\begin{array}{l}\text { Maximum } \\
\text { Cost }\end{array}$ & $\begin{array}{l}\text { Maximum fair } \\
\text { market value }\end{array}$ & $\begin{array}{l}\text { Fair market } \\
\text { value at year end }\end{array}$ & $\begin{array}{l}\text { Foreign income } \\
\text { earned or loss }\end{array}$ & $\begin{array}{l}\text { Capital } \\
\text { gain/loss }\end{array}$ \\
\hline \multirow{3}{*}{ CANADA } & \multirow{3}{*}{271} & 350 & 101 & 150 & 80 \\
\cline { 4 - 6 } & & 680 & 138 & 110 & 142 \\
\cline { 3 - 6 } USA & 1230 & 87 & 187 & 77 \\
\cline { 3 - 6 } CHINA & 440 & 33 & 85 & 85 \\
\hline MEXICO & & & & \\
\hline
\end{tabular}

Calc_2_TC_4_1_BC_Ann

\begin{tabular}{|c|c|c|c|c|c|c|c|c|c|c|c|c|c|c|}
\hline 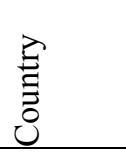 & 跑 & $\begin{array}{l}0 \\
0 \\
\end{array}$ & 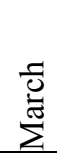 & $\overline{\bar{z}}$ & 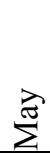 & $\Xi$ & $\vec{\Xi}$ & $\begin{array}{l}\overrightarrow{0} \\
\overrightarrow{5} \\
\vec{z}\end{array}$ & 䒕 & 0 & z & ڤ્ & 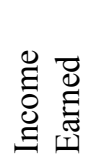 & 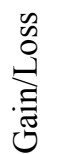 \\
\hline \multirow{2}{*}{ Canada } & 10 & 10 & 10 & 10 & 10 & 10 & 10 & 10 & 10 & 10 & 10 & 10 & \multirow{2}{*}{60} & \multirow{2}{*}{30} \\
\hline & 210 & 22 & 23 & 25 & 22 & 40 & 45 & 34 & 22 & 34 & 87 & 77 & & \\
\hline \multirow{2}{*}{ Canada } & 14 & 14 & 14 & 14 & 14 & 14 & 14 & 14 & 14 & 14 & 14 & 14 & \multirow{2}{*}{90} & \multirow{2}{*}{50} \\
\hline & 140 & 54 & 55 & 45 & 5 & 44 & 71 & 20 & 22 & 24 & 22 & 24 & & \\
\hline \multirow{2}{*}{ Canada } & 25 & 25 & 25 & 25 & 25 & 25 & 25 & 25 & 25 & 25 & 25 & 25 & \multirow{2}{*}{45} & \multirow{2}{*}{42} \\
\hline & 230 & 44 & 24 & 65 & 43 & 24 & 86 & 54 & 22 & 52 & 50 & 50 & & \\
\hline \multirow{2}{*}{ Canada } & 45 & 45 & 45 & 45 & 45 & 45 & 45 & 45 & 45 & 45 & 45 & 45 & \multirow{2}{*}{65} & \multirow{2}{*}{100} \\
\hline & 450 & 46 & 51 & 53 & 58 & 55 & 59 & 60 & 65 & 66 & 77 & 88 & & \\
\hline \multirow{2}{*}{ Canada } & 98 & 98 & 98 & 98 & 98 & 98 & 98 & 98 & 98 & 98 & 98 & 98 & \multirow{2}{*}{98} & \multirow{2}{*}{65} \\
\hline & 450 & 45 & 25 & 78 & 56 & 44 & 57 & 55 & 56 & 54 & 53 & 51 & & \\
\hline \multirow{2}{*}{ Canada } & 56 & 56 & 56 & 56 & 56 & 56 & 56 & 56 & 56 & 56 & 56 & 56 & \multirow{2}{*}{89} & \multirow{2}{*}{12} \\
\hline & 780 & 77 & 77 & 54 & 36 & 36 & 36 & 36 & 36 & 36 & 36 & 36 & & \\
\hline \multirow{2}{*}{ Canada } & 23 & 23 & 23 & 23 & 23 & 23 & 23 & 23 & 23 & 23 & 23 & 23 & \multirow{2}{*}{85} & \multirow{2}{*}{85} \\
\hline & 440 & 44 & 44 & 44 & 44 & 44 & 44 & 54 & 23 & 4 & 4 & 33 & & \\
\hline
\end{tabular}

\section{Expected Output:}

\begin{tabular}{|l|l|l|l|l|l|}
\hline $\begin{array}{l}\text { Grouping } \\
\text { Countries }\end{array}$ & $\begin{array}{l}\text { Maximum } \\
\text { Cost }\end{array}$ & $\begin{array}{l}\text { Maximum fair } \\
\text { market value }\end{array}$ & $\begin{array}{l}\text { Fair market } \\
\text { value at year end }\end{array}$ & $\begin{array}{l}\text { Foreign income } \\
\text { earned or loss }\end{array}$ & $\begin{array}{l}\text { Capital } \\
\text { gain/loss }\end{array}$ \\
\hline CANADA & 271 & 2700 & 359 & 532 & 384 \\
\hline
\end{tabular}

\section{Actual Output:}

\begin{tabular}{|l|l|l|l|l|l|}
\hline $\begin{array}{l}\text { Grouping } \\
\text { Countries }\end{array}$ & $\begin{array}{l}\text { Maximum } \\
\text { Cost }\end{array}$ & $\begin{array}{l}\text { Maximum fair } \\
\text { market value }\end{array}$ & $\begin{array}{l}\text { Fair market } \\
\text { value at year end }\end{array}$ & $\begin{array}{l}\text { Foreign income } \\
\text { earned or loss }\end{array}$ & $\begin{array}{l}\text { Capital } \\
\text { gain/loss }\end{array}$ \\
\hline CANADA & 271 & 2700 & 359 & 532 & 384 \\
\hline
\end{tabular}


Calc_2_TC_5_1_BC_Ann

An empty value here is represented by double quotes("')).

\begin{tabular}{|c|c|c|c|c|c|c|c|c|c|c|c|c|c|c|}
\hline $\begin{array}{l}\stackrel{\Xi}{\Xi} \\
\stackrel{\Xi}{0}\end{array}$ & 点 & $\begin{array}{l}0 \\
0\end{array}$ & 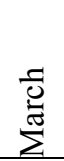 & $\overline{\bar{z}}$ & $\stackrel{\text { ¿ }}{\mathrm{\Sigma}}$ & $\Xi$ & $\vec{\Xi}$ & 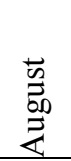 & $\begin{array}{l}\overrightarrow{0} \\
\stackrel{0}{n}\end{array}$ & $\overrightarrow{0}$ & zo & ڤ̊ల & 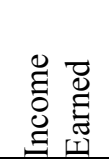 & 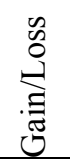 \\
\hline \multirow{2}{*}{ Canada } & 10 & 10 & 10 & 10 & 10 & 10 & 10 & 10 & 10 & 10 & 10 & 10 & \multirow{2}{*}{60} & \multirow{2}{*}{30} \\
\hline & 210 & 22 & 23 & 25 & 22 & 40 & 45 & 34 & 22 & 34 & 87 & 77 & & \\
\hline \multirow{2}{*}{ Canada } & 14 & 14 & 14 & 14 & 14 & 14 & 14 & 14 & 14 & 14 & 14 & 14 & \multirow{2}{*}{90} & \multirow{2}{*}{50} \\
\hline & 140 & 54 & 55 & 45 & 5 & 44 & 71 & 20 & 22 & 24 & 22 & 24 & & \\
\hline \multirow{2}{*}{ USA } & 25 & 25 & 25 & 25 & 25 & 25 & 25 & 25 & 25 & 25 & 25 & 25 & \multirow{2}{*}{45} & \multirow{2}{*}{42} \\
\hline & 230 & 44 & 24 & 65 & 43 & 24 & 86 & 54 & 22 & 52 & 50 & 50 & & \\
\hline \multirow{2}{*}{ USA } & 45 & 45 & 45 & 45 & 45 & 45 & 45 & 45 & 45 & 45 & 45 & 45 & \multirow{2}{*}{65} & \multirow{2}{*}{100} \\
\hline & 450 & 46 & 51 & 53 & 58 & 55 & 59 & 60 & 65 & 66 & 77 & 88 & & \\
\hline \multirow{2}{*}{ China } & 98 & 98 & 98 & 98 & 98 & 98 & 98 & 98 & 98 & 98 & 98 & 98 & \multirow{2}{*}{98} & \multirow{2}{*}{65} \\
\hline & 450 & 45 & 25 & 78 & 56 & 44 & 57 & 55 & 56 & 54 & 53 & 51 & & \\
\hline \multirow{2}{*}{ China } & 56 & 56 & 56 & 56 & 56 & 56 & 56 & 56 & 56 & 56 & 56 & 56 & \multirow{2}{*}{89} & \multirow{2}{*}{12} \\
\hline & 780 & 77 & 77 & 54 & 36 & 36 & 36 & 36 & 36 & 36 & 36 & 36 & & \\
\hline \multirow[t]{2}{*}{ “"” } & 23 & 23 & 23 & 23 & 23 & 23 & 23 & 23 & 23 & 23 & 23 & 23 & \multirow{2}{*}{85} & \multirow{2}{*}{85} \\
\hline & 440 & 44 & 44 & 44 & 44 & 44 & 44 & 54 & 23 & 4 & 4 & 33 & & \\
\hline
\end{tabular}

\section{Expected Output:}

\begin{tabular}{|c|c|c|c|c|c|}
\hline $\begin{array}{l}\text { Grouping } \\
\text { Countries }\end{array}$ & $\begin{array}{l}\text { Maximum } \\
\text { Cost }\end{array}$ & $\begin{array}{l}\text { Maximum fair } \\
\text { market value }\end{array}$ & $\begin{array}{l}\text { Fair market } \\
\text { value at year end }\end{array}$ & $\begin{array}{l}\text { Foreign income } \\
\text { earned or loss }\end{array}$ & $\begin{array}{l}\text { Capital } \\
\text { gain/loss }\end{array}$ \\
\hline CANADA & \multirow{4}{*}{271} & 350 & 101 & 150 & 80 \\
\hline USA & & 680 & 138 & 110 & 142 \\
\hline CHINA & & 1230 & 87 & 187 & 77 \\
\hline “"” & & 440 & 33 & 85 & 85 \\
\hline
\end{tabular}

\section{Actual Output:}

\begin{tabular}{|c|c|c|c|c|c|}
\hline $\begin{array}{l}\text { Grouping } \\
\text { Countries }\end{array}$ & $\begin{array}{l}\text { Maximum } \\
\text { Cost }\end{array}$ & $\begin{array}{l}\text { Maximum fair } \\
\text { market value }\end{array}$ & $\begin{array}{l}\text { Fair market } \\
\text { value at year end }\end{array}$ & $\begin{array}{l}\text { Foreign income } \\
\text { earned or loss }\end{array}$ & $\begin{array}{l}\text { Capital } \\
\text { gain/loss }\end{array}$ \\
\hline CANADA & \multirow{4}{*}{271} & 350 & 101 & 150 & 80 \\
\hline USA & & 680 & 138 & 110 & 142 \\
\hline CHINA & & 1230 & 87 & 187 & 77 \\
\hline “'" & & 440 & 33 & 85 & 85 \\
\hline
\end{tabular}


Calc_2_TC_6_1_BC_Ann

\begin{tabular}{|c|c|c|c|c|c|c|c|c|c|c|c|c|c|c|}
\hline$\stackrel{\Xi}{\Xi}$ & 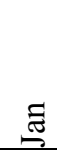 & $\begin{array}{l}0 \\
0 \\
\end{array}$ & 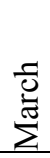 & $\overline{\bar{z}}$ & $\sum^{\pi}$ & $\Xi$ & $\frac{\lambda}{3}$ & $\begin{array}{l}\overrightarrow{0} \\
\overrightarrow{0} \\
\stackrel{50}{Z}\end{array}$ & 䒕 & $\ddot{0}$ & z & ڤ్ల & 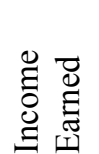 & 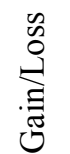 \\
\hline \multirow{2}{*}{ Canada } & 10 & 10 & 10 & 10 & 10 & 10 & 10 & 10 & 10 & 10 & 10 & 10 & \multirow{2}{*}{600} & \multirow{2}{*}{30} \\
\hline & 21 & 22 & 23 & 25 & 22 & 40 & 45 & 34 & 22 & 34 & 87 & 77 & & \\
\hline \multirow{2}{*}{ Canada } & 14 & 14 & 14 & 14 & 14 & 14 & 14 & 14 & 14 & 14 & 14 & 14 & \multirow{2}{*}{900} & \multirow{2}{*}{50} \\
\hline & 14 & 54 & 55 & 45 & 5 & 44 & 71 & 20 & 22 & 24 & 22 & 24 & & \\
\hline \multirow{2}{*}{ USA } & 25 & 25 & 25 & 25 & 25 & 25 & 25 & 25 & 25 & 25 & 25 & 25 & \multirow{2}{*}{450} & \multirow{2}{*}{42} \\
\hline & 23 & 44 & 24 & 65 & 43 & 24 & 86 & 54 & 22 & 52 & 50 & 50 & & \\
\hline \multirow{2}{*}{ USA } & 45 & 45 & 45 & 45 & 45 & 45 & 45 & 45 & 45 & 45 & 45 & 45 & \multirow{2}{*}{650} & \multirow{2}{*}{100} \\
\hline & 45 & 46 & 51 & 53 & 58 & 55 & 59 & 60 & 65 & 66 & 77 & 88 & & \\
\hline \multirow{2}{*}{ China } & 98 & 98 & 98 & 98 & 98 & 98 & 98 & 98 & 98 & 98 & 98 & 98 & \multirow{2}{*}{980} & \multirow{2}{*}{65} \\
\hline & 45 & 45 & 25 & 78 & 56 & 44 & 57 & 55 & 56 & 54 & 53 & 51 & & \\
\hline \multirow{2}{*}{ China } & 56 & 56 & 56 & 56 & 56 & 56 & 56 & 56 & 56 & 56 & 56 & 56 & \multirow{2}{*}{890} & \multirow{2}{*}{12} \\
\hline & 78 & 77 & 77 & 54 & 36 & 36 & 36 & 36 & 36 & 36 & 36 & 36 & & \\
\hline \multirow{2}{*}{ Mexico } & 23 & 23 & 23 & 23 & 23 & 23 & 23 & 23 & 23 & 23 & 23 & 23 & \multirow{2}{*}{850} & \multirow{2}{*}{85} \\
\hline & 44 & 44 & 44 & 44 & 44 & 44 & 44 & 54 & 23 & 4 & 4 & 33 & & \\
\hline
\end{tabular}

\section{Expected Output:}

\begin{tabular}{|l|l|l|l|l|l|}
\hline $\begin{array}{l}\text { Grouping } \\
\text { Countries }\end{array}$ & $\begin{array}{l}\text { Maximum } \\
\text { Cost }\end{array}$ & $\begin{array}{l}\text { Maximum fair } \\
\text { market value }\end{array}$ & $\begin{array}{l}\text { Fair market } \\
\text { value at year end }\end{array}$ & $\begin{array}{l}\text { Foreign income } \\
\text { earned or loss }\end{array}$ & $\begin{array}{l}\text { Capital } \\
\text { gain/loss }\end{array}$ \\
\hline \multirow{3}{*}{ CANADA } & \multirow{3}{*}{271} & 116 & 101 & 1500 & 80 \\
\cline { 1 - 5 } USA & 145 & 138 & 1100 & 142 \\
\cline { 3 - 5 } CHINA & 132 & 87 & 1870 & 77 \\
\cline { 3 - 5 } MEXICO & 54 & 33 & 850 & 85 \\
\hline
\end{tabular}

\section{Actual Output:}

\begin{tabular}{|c|c|c|c|c|c|}
\hline $\begin{array}{l}\text { Grouping } \\
\text { Countries }\end{array}$ & $\begin{array}{l}\text { Maximum } \\
\text { Cost }\end{array}$ & $\begin{array}{l}\text { Maximum fair } \\
\text { market value }\end{array}$ & $\begin{array}{l}\text { Fair market } \\
\text { value at year end }\end{array}$ & $\begin{array}{l}\text { Foreign income } \\
\text { earned or loss }\end{array}$ & $\begin{array}{l}\text { Capital } \\
\text { gain/loss }\end{array}$ \\
\hline CANADA & \multirow{4}{*}{271} & 116 & 101 & 1500 & 80 \\
\hline USA & & 145 & 138 & 1100 & 142 \\
\hline CHINA & & 132 & 87 & 1870 & 77 \\
\hline MEXICO & & 54 & 33 & 850 & 85 \\
\hline
\end{tabular}


Calc_2_TC_7_1_BC_Ann

A missing country is represented by a NULL value in the country field.

\begin{tabular}{|c|c|c|c|c|c|c|c|c|c|c|c|c|c|c|}
\hline 急 & Еี & 这 & $\begin{array}{l}\overline{\bar{D}} \\
\sum_{\Sigma}^{\pi}\end{array}$ & $\frac{\bar{c}}{4}$ & $\sum_{2}^{m}$ & 窇 & 齐 & 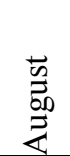 & 高 & $\ddot{0}$ & $\vec{z}$ & $\stackrel{\mathscr{u}}{0}$ & 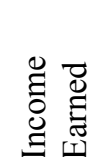 & 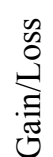 \\
\hline \multirow{2}{*}{ China } & 98 & 98 & 98 & 98 & 98 & 98 & 98 & 98 & 98 & 98 & 98 & 98 & \multirow{2}{*}{98} & \multirow{2}{*}{65} \\
\hline & 450 & 45 & 25 & 78 & 56 & 44 & 57 & 55 & 56 & 54 & 53 & 51 & & \\
\hline \multirow{2}{*}{ China } & 56 & 56 & 56 & 56 & 56 & 56 & 56 & 56 & 56 & 56 & 56 & 56 & \multirow{2}{*}{89} & \multirow{2}{*}{12} \\
\hline & 780 & 77 & 77 & 54 & 36 & 36 & 36 & 36 & 36 & 36 & 36 & 36 & & \\
\hline \multirow{2}{*}{ NULL } & 23 & 23 & 23 & 23 & 23 & 23 & 23 & 23 & 23 & 23 & 23 & 23 & \multirow[b]{2}{*}{8} & \multirow[b]{2}{*}{85} \\
\hline & 440 & 44 & 44 & 44 & 44 & 44 & 44 & 54 & 23 & 4 & 4 & 33 & & \\
\hline
\end{tabular}

\section{Expected Output:}

Error

\section{Actual Output:}

Error

\section{Each-Choice Test Frames and Test Cases}

Frame 1:

Countries.Casing.Consistent

Countries.AreSimilar.False

Countries.HaveEmpty.False

Countries.HaveMissing.False

SecurityValues.PlaceOfHighestSummedUpValu

e.December
Frame 2:

Countries.Casing.Consistent

Countries.AreSimilar.False

Countries.HaveEmpty.False

Countries.HaveMissing.False

SecurityValues.PlaceOfHighestSummedUpValu

e.OtherMonths 
Frame 3:

Countries.Casing.Inconsistent

Countries.AreSimilar.True

Countries.HaveEmpty.False

Countries.HaveMissing.False

SecurityValues.PlaceOfHighestSummedUpValu

e.IncomeEarnedOrCapitalGain
Frame 4:

Countries.Casing.Consistent

Countries.AreSimilar.True

Countries.HaveEmpty.True

Countries.HaveMissing.False

SecurityValues.PlaceOfHighestSummedUpValu

e.OtherMonths

Frame 5:

Countries.HaveMissing.True

Calc_2_TC_1_1_EC_An

\begin{tabular}{|c|c|c|c|c|c|c|c|c|c|c|c|c|c|c|}
\hline 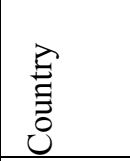 & E్త్ & $\begin{array}{l}0 \\
0 \\
\end{array}$ & $\begin{array}{l}\bar{e} \\
\dot{0} \\
\sum_{\Sigma}^{\pi}\end{array}$ & $\overline{\vec{c}}$ & $\stackrel{\Xi}{\Sigma}$ & $\Xi$ & 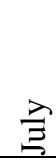 & $\begin{array}{l}\overrightarrow{\tilde{n}} \\
\overrightarrow{50} \\
\vec{Z}\end{array}$ & $\begin{array}{l}\overrightarrow{0} \\
\ddot{2}\end{array}$ & 0 & z & $\stackrel{8}{0}$ & 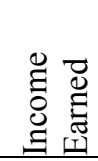 & 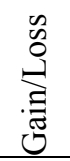 \\
\hline \multirow{2}{*}{ Canada } & 10 & 10 & 10 & 10 & 10 & 10 & 10 & 10 & 10 & 10 & 10 & 10 & \multirow{2}{*}{60} & \multirow{2}{*}{30} \\
\hline & 21 & 22 & 23 & 25 & 22 & 40 & 45 & 34 & 22 & 34 & 87 & 770 & & \\
\hline \multirow{2}{*}{ Canada } & 14 & 14 & 14 & 14 & 14 & 14 & 14 & 14 & 14 & 14 & 14 & 14 & \multirow{2}{*}{90} & \multirow{2}{*}{50} \\
\hline & 14 & 54 & 55 & 45 & 5 & 44 & 71 & 20 & 22 & 24 & 22 & 240 & & \\
\hline \multirow{2}{*}{ USA } & 25 & 25 & 25 & 25 & 25 & 25 & 25 & 25 & 25 & 25 & 25 & 25 & \multirow{2}{*}{45} & \multirow{2}{*}{42} \\
\hline & 23 & 44 & 24 & 65 & 43 & 24 & 86 & 54 & 22 & 52 & 50 & 500 & & \\
\hline \multirow{2}{*}{ USA } & 45 & 45 & 45 & 45 & 45 & 45 & 45 & 45 & 45 & 45 & 45 & 45 & \multirow{2}{*}{65} & \multirow{2}{*}{100} \\
\hline & 45 & 46 & 51 & 53 & 58 & 55 & 59 & 60 & 65 & 66 & 77 & 880 & & \\
\hline \multirow{2}{*}{ China } & 98 & 98 & 98 & 98 & 98 & 98 & 98 & 98 & 98 & 98 & 98 & 98 & \multirow{2}{*}{98} & \multirow{2}{*}{65} \\
\hline & 45 & 45 & 25 & 78 & 56 & 44 & 57 & 55 & 56 & 54 & 53 & 510 & & \\
\hline \multirow{2}{*}{ China } & 56 & 56 & 56 & 56 & 56 & 56 & 56 & 56 & 56 & 56 & 56 & 56 & \multirow{2}{*}{89} & \multirow{2}{*}{12} \\
\hline & 78 & 77 & 77 & 54 & 36 & 36 & 36 & 36 & 36 & 36 & 36 & 360 & & \\
\hline \multirow{2}{*}{ Mexico } & 23 & 23 & 23 & 23 & 23 & 23 & 23 & 23 & 23 & 23 & 23 & 23 & \multirow{2}{*}{85} & \multirow{2}{*}{85} \\
\hline & 44 & 44 & 44 & 44 & 44 & 44 & 44 & 54 & 23 & 4 & 4 & 330 & & \\
\hline
\end{tabular}

\section{Expected Output:}

\begin{tabular}{|l|l|l|l|l|l|}
\hline $\begin{array}{l}\text { Grouping } \\
\text { Countries }\end{array}$ & $\begin{array}{l}\text { Maximum } \\
\text { Cost }\end{array}$ & $\begin{array}{l}\text { Maximum fair } \\
\text { market value }\end{array}$ & $\begin{array}{l}\text { Fair market } \\
\text { value at year end }\end{array}$ & $\begin{array}{l}\text { Foreign income } \\
\text { earned or loss }\end{array}$ & $\begin{array}{l}\text { Capital } \\
\text { gain/loss }\end{array}$ \\
\cline { 1 - 4 } CANADA & \multirow{3}{*}{271} & 1010 & 1010 & 150 & 80 \\
\cline { 1 - 4 } USA & 1380 & 1380 & 110 & 142 \\
\cline { 3 - 6 } CHINA & 870 & 870 & 187 & 77 \\
\cline { 3 - 5 } MEXICO & 330 & 330 & 85 & 85 \\
\hline
\end{tabular}




\section{Actual Output:}

\begin{tabular}{|l|l|l|l|l|l|}
\hline $\begin{array}{l}\text { Grouping } \\
\text { Countries }\end{array}$ & \multirow{2}{*}{$\begin{array}{l}\text { Maximum } \\
\text { Cost }\end{array}$} & $\begin{array}{l}\text { Maximum fair } \\
\text { market value }\end{array}$ & $\begin{array}{l}\text { Fair market } \\
\text { value at year end }\end{array}$ & $\begin{array}{l}\text { Foreign income } \\
\text { earned or loss }\end{array}$ & $\begin{array}{l}\text { Capital } \\
\text { gain/loss }\end{array}$ \\
\hline \multirow{3}{*}{ CANADA } & \multirow{3}{*}{271} & 1010 & 1010 & 150 & 80 \\
\cline { 1 - 5 } & 1380 & 1380 & 110 & 142 \\
\cline { 3 - 6 } USA & 870 & 870 & 187 & 77 \\
\cline { 3 - 6 } CHINA & 330 & 330 & 85 & 85 \\
\hline MEXICO & & & & \\
\hline
\end{tabular}

Calc_2_TC_2_1_EC_An

We can choose any month other than December to have the highest MV values. Here we choose 'January'

\begin{tabular}{|c|c|c|c|c|c|c|c|c|c|c|c|c|c|c|}
\hline $\begin{array}{l}\text { E } \\
\text { 吾 }\end{array}$ & స్ & $\begin{array}{l}0 \\
0 \\
\end{array}$ & $\begin{array}{l}\overline{0} \\
\stackrel{0}{\pi} \\
\end{array}$ & $\overline{\bar{z}}$ & $\stackrel{\overrightarrow{\mathrm{J}}}{\mathrm{\Sigma}}$ & $\Xi$ & 主 & 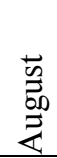 & 䒕 & $\ddot{0}$ & z & ڤ̊ & 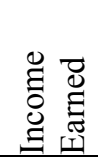 & 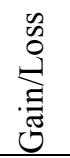 \\
\hline \multirow{2}{*}{ Canada } & 10 & 10 & 10 & 10 & 10 & 10 & 10 & 10 & 10 & 10 & 10 & 10 & \multirow{2}{*}{60} & \multirow{2}{*}{30} \\
\hline & 210 & 22 & 23 & 25 & 22 & 40 & 45 & 34 & 22 & 34 & 87 & 77 & & \\
\hline \multirow{2}{*}{ Canada } & 14 & 14 & 14 & 14 & 14 & 14 & 14 & 14 & 14 & 14 & 14 & 14 & \multirow{2}{*}{90} & \multirow{2}{*}{50} \\
\hline & 140 & 54 & 55 & 45 & 5 & 44 & 71 & 20 & 22 & 24 & 22 & 24 & & \\
\hline \multirow{2}{*}{ USA } & 25 & 25 & 25 & 25 & 25 & 25 & 25 & 25 & 25 & 25 & 25 & 25 & \multirow{2}{*}{45} & \multirow{2}{*}{42} \\
\hline & 230 & 44 & 24 & 65 & 43 & 24 & 86 & 54 & 22 & 52 & 50 & 50 & & \\
\hline \multirow{2}{*}{ USA } & 45 & 45 & 45 & 45 & 45 & 45 & 45 & 45 & 45 & 45 & 45 & 45 & \multirow{2}{*}{65} & \multirow{2}{*}{100} \\
\hline & 450 & 46 & 51 & 53 & 58 & 55 & 59 & 60 & 65 & 66 & 77 & 88 & & \\
\hline \multirow{2}{*}{ China } & 98 & 98 & 98 & 98 & 98 & 98 & 98 & 98 & 98 & 98 & 98 & 98 & \multirow{2}{*}{98} & \multirow{2}{*}{65} \\
\hline & 450 & 45 & 25 & 78 & 56 & 44 & 57 & 55 & 56 & 54 & 53 & 51 & & \\
\hline \multirow{2}{*}{ China } & 56 & 56 & 56 & 56 & 56 & 56 & 56 & 56 & 56 & 56 & 56 & 56 & \multirow{2}{*}{89} & \multirow{2}{*}{12} \\
\hline & 780 & 77 & 77 & 54 & 36 & 36 & 36 & 36 & 36 & 36 & 36 & 36 & & \\
\hline \multirow{2}{*}{ Mexico } & 23 & 23 & 23 & 23 & 23 & 23 & 23 & 23 & 23 & 23 & 23 & 23 & \multirow{2}{*}{85} & \multirow{2}{*}{85} \\
\hline & 440 & 44 & 44 & 44 & 44 & 44 & 44 & 54 & 23 & 4 & 4 & 33 & & \\
\hline
\end{tabular}

\section{Expected Output:}

\begin{tabular}{|c|c|c|c|c|c|}
\hline $\begin{array}{l}\text { Grouping } \\
\text { Countries }\end{array}$ & $\begin{array}{l}\text { Maximum } \\
\text { Cost }\end{array}$ & $\begin{array}{l}\text { Maximum fair } \\
\text { market value }\end{array}$ & $\begin{array}{l}\text { Fair market } \\
\text { value at year end }\end{array}$ & $\begin{array}{l}\text { Foreign income } \\
\text { earned or loss }\end{array}$ & $\begin{array}{l}\text { Capital } \\
\text { gain/loss }\end{array}$ \\
\hline CANADA & \multirow{4}{*}{271} & 350 & 101 & 150 & 80 \\
\hline USA & & 680 & 138 & 110 & 142 \\
\hline CHINA & & 1230 & 87 & 187 & 77 \\
\hline MEXICO & & 440 & 33 & 85 & 85 \\
\hline
\end{tabular}




\section{Actual Output:}

\begin{tabular}{|l|l|l|l|l|l|}
\hline $\begin{array}{l}\text { Grouping } \\
\text { Countries }\end{array}$ & \multirow{2}{*}{$\begin{array}{l}\text { Maximum } \\
\text { Cost }\end{array}$} & $\begin{array}{l}\text { Maximum fair } \\
\text { market value }\end{array}$ & $\begin{array}{l}\text { Fair market } \\
\text { value at year end }\end{array}$ & $\begin{array}{l}\text { Foreign income } \\
\text { earned or loss }\end{array}$ & $\begin{array}{l}\text { Capital } \\
\text { gain/loss }\end{array}$ \\
\hline \multirow{3}{*}{ CANADA } & \multirow{3}{*}{271} & 350 & 101 & 150 & 80 \\
\cline { 3 - 6 } & 680 & 138 & 110 & 142 \\
\cline { 3 - 6 } USA & 1230 & 87 & 187 & 77 \\
\cline { 3 - 6 } CHINA & 440 & 33 & 85 & 85 \\
\hline MEXICO & & & & \\
\hline
\end{tabular}

Calc_2_TC_3_1_EC_An

\begin{tabular}{|c|c|c|c|c|c|c|c|c|c|c|c|c|c|c|}
\hline $\begin{array}{l}\stackrel{\Xi}{\Xi} \\
\stackrel{\Xi}{0}\end{array}$ & Еี & 0 & $\begin{array}{l}= \\
0 \\
\bar{d}\end{array}$ & $\overline{\bar{z}}$ & $\sum^{\pi}$ & $\Xi$ & 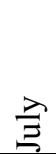 & $\begin{array}{l}\vec{W} \\
\overrightarrow{2} \\
\stackrel{2}{2}\end{array}$ & 苍 & $\overrightarrow{0}$ & z & 巳̊ & 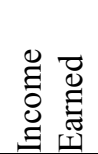 & 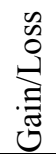 \\
\hline \multirow{2}{*}{ Canada } & 10 & 10 & 10 & 10 & 10 & 10 & 10 & 10 & 10 & 10 & 10 & 10 & \multirow{2}{*}{600} & \multirow{2}{*}{30} \\
\hline & 21 & 22 & 23 & 25 & 22 & 40 & 45 & 34 & 22 & 34 & 87 & 77 & & \\
\hline \multirow{2}{*}{ CanadA } & 14 & 14 & 14 & 14 & 14 & 14 & 14 & 14 & 14 & 14 & 14 & 14 & \multirow{2}{*}{900} & \multirow{2}{*}{50} \\
\hline & 14 & 54 & 55 & 45 & 5 & 44 & 71 & 20 & 22 & 24 & 22 & 24 & & \\
\hline
\end{tabular}

\section{Expected Output:}

\begin{tabular}{|l|l|l|l|l|l|}
\hline $\begin{array}{l}\text { Grouping } \\
\text { Countries }\end{array}$ & $\begin{array}{l}\text { Maximum } \\
\text { Cost }\end{array}$ & $\begin{array}{l}\text { Maximum fair } \\
\text { market value }\end{array}$ & $\begin{array}{l}\text { Fair market } \\
\text { value at year end }\end{array}$ & $\begin{array}{l}\text { Foreign income } \\
\text { earned or loss }\end{array}$ & $\begin{array}{l}\text { Capital } \\
\text { gain/loss }\end{array}$ \\
\hline CANADA & 24 & 116 & 101 & 1500 & 80 \\
\hline
\end{tabular}

\section{Actual Output:}

\begin{tabular}{|l|l|l|l|l|l|}
\hline $\begin{array}{l}\text { Grouping } \\
\text { Countries }\end{array}$ & $\begin{array}{l}\text { Maximum } \\
\text { Cost }\end{array}$ & $\begin{array}{l}\text { Maximum fair } \\
\text { market value }\end{array}$ & $\begin{array}{l}\text { Fair market } \\
\text { value at year end }\end{array}$ & $\begin{array}{l}\text { Foreign income } \\
\text { earned or loss }\end{array}$ & $\begin{array}{l}\text { Capital } \\
\text { gain/loss }\end{array}$ \\
\hline CANADA & 24 & 116 & 101 & 1500 & 80 \\
\hline
\end{tabular}


Calc_2_TC_4_1_EC_An

\begin{tabular}{|c|c|c|c|c|c|c|c|c|c|c|c|c|c|c|}
\hline 竞 & 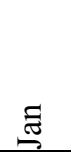 & 这 & 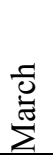 & 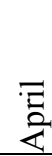 & $\sum_{2}^{m}$ & $\Xi$ & 츨 & 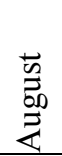 & 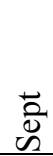 & $\overline{0}$ & ? & $\stackrel{\mathscr{8}}{0}$ & 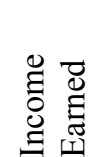 & 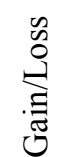 \\
\hline \multirow{2}{*}{ Canada } & 10 & 10 & 10 & 10 & 10 & 10 & 10 & 10 & 10 & 10 & 10 & 10 & \multirow[b]{2}{*}{60} & \multirow{2}{*}{30} \\
\hline & 210 & 22 & 23 & 25 & 22 & 40 & 45 & 34 & 22 & 34 & 87 & 77 & & \\
\hline \multirow{2}{*}{ CanadA } & 14 & 14 & 14 & 14 & 14 & 14 & 14 & 14 & 14 & 14 & 14 & 14 & \multirow{2}{*}{90} & \multirow{2}{*}{50} \\
\hline & 140 & 54 & 55 & 45 & 5 & 44 & 71 & 20 & 22 & 24 & 22 & 24 & & \\
\hline \multirow{2}{*}{ “" } & 25 & 25 & 25 & 25 & 25 & 25 & 25 & 25 & 25 & 25 & 25 & 25 & \multirow{2}{*}{45} & \multirow{2}{*}{42} \\
\hline & 230 & 44 & 24 & 65 & 43 & 24 & 86 & 54 & 22 & 52 & 50 & 50 & & \\
\hline \multirow[t]{2}{*}{ “" } & 45 & 45 & 45 & 45 & 45 & 45 & 45 & 45 & 45 & 45 & 45 & 45 & \multirow[b]{2}{*}{65} & \multirow{2}{*}{100} \\
\hline & 450 & 46 & 51 & 53 & 58 & 55 & 59 & 60 & 65 & 66 & 77 & 88 & & \\
\hline
\end{tabular}

\section{Expected Output:}

\begin{tabular}{|l|l|l|l|l|l|}
\hline $\begin{array}{l}\text { Grouping } \\
\text { Countries }\end{array}$ & $\begin{array}{l}\text { Maximum } \\
\text { Cost }\end{array}$ & $\begin{array}{l}\text { Maximum fair } \\
\text { market value }\end{array}$ & $\begin{array}{l}\text { Fair market } \\
\text { value at year end }\end{array}$ & $\begin{array}{l}\text { Foreign income } \\
\text { earned or loss }\end{array}$ & $\begin{array}{l}\text { Capital } \\
\text { gain/loss }\end{array}$ \\
\hline CANADA & \multirow{2}{*}{94} & 350 & 101 & 150 & 80 \\
\cline { 3 - 6 } & 64 & 680 & 138 & 110 & 142 \\
\hline
\end{tabular}

\section{Actual Output:}

\begin{tabular}{|c|c|c|c|c|c|}
\hline $\begin{array}{l}\text { Grouping } \\
\text { Countries }\end{array}$ & $\begin{array}{l}\text { Maximum } \\
\text { Cost }\end{array}$ & $\begin{array}{l}\text { Maximum fair } \\
\text { market value }\end{array}$ & $\begin{array}{l}\text { Fair market } \\
\text { value at year end }\end{array}$ & $\begin{array}{l}\text { Foreign income } \\
\text { earned or loss }\end{array}$ & $\begin{array}{l}\text { Capital } \\
\text { gain/loss }\end{array}$ \\
\hline CANADA & \multirow[b]{2}{*}{94} & 350 & 101 & 150 & 80 \\
\hline “" & & 680 & 138 & 110 & 142 \\
\hline
\end{tabular}

Calc_2_TC_5_1_EC_An

A missing country is represented by a NULL value in the country field.

\begin{tabular}{|c|c|c|c|c|c|c|c|c|c|c|c|c|c|c|}
\hline 音 & Е & 这 & 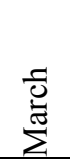 & $\overline{\bar{c}}$ & $\sum^{\mathrm{\sigma}}$ & 吾 & $\vec{\partial}$ & 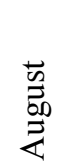 & है & $\overrightarrow{0}$ & za & $\stackrel{\mathscr{D}}{\triangle}$ & 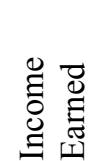 & 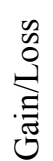 \\
\hline \multirow{2}{*}{ China } & 98 & 98 & 98 & 98 & 98 & 98 & 98 & 98 & 98 & 98 & 98 & $\overline{98}$ & \multirow{2}{*}{98} & \multirow{2}{*}{65} \\
\hline & 450 & 45 & 25 & 78 & 56 & 44 & 57 & 55 & 56 & 54 & 53 & 51 & & \\
\hline \multirow{2}{*}{ China } & 56 & 56 & 56 & 56 & 56 & 56 & 56 & 56 & 56 & 56 & 56 & 56 & \multirow[b]{2}{*}{89} & \multirow{2}{*}{12} \\
\hline & 780 & 77 & 77 & 54 & 36 & 36 & 36 & 36 & 36 & 36 & 36 & 36 & & \\
\hline \multirow{2}{*}{ NULL } & 23 & 23 & 23 & 23 & 23 & 23 & 23 & 23 & 23 & 23 & 23 & 23 & \multirow[b]{2}{*}{85} & \multirow[b]{2}{*}{85} \\
\hline & 440 & 44 & 44 & 44 & 44 & 44 & 44 & 54 & 23 & 4 & 4 & 33 & & \\
\hline
\end{tabular}




\section{Expected Output:}

Error

\section{Actual Output:}

Error

\section{Pair-Wise Test Frames and Test Cases}

Frame 1:

Countries.Casing.Consistent

Countries.AreSimilar.False

Countries.HaveEmpty.False

Countries.HaveMissing.False

SecurityValues.PlaceOfHighestSummedUpValu

e.OtherMonths

Frame 2:

Countries.Casing.Consistent

Countries.AreSimilar.False

Countries.HaveEmpty.False

Countries.HaveMissing.False

SecurityValues.PlaceOfHighestSummedUpValu

e.December
Frame 3:

Countries.Casing.Consistent

Countries.AreSimilar.False

Countries.HaveEmpty.True

Countries.HaveMissing.False

SecurityValues.PlaceOfHighestSummedUpValu

e.IncomeEarnedOrCapitalGain

Frame 4:

Countries.Casing.Inconsistent

Countries.AreSimilar.True

Countries.HaveEmpty.True

Countries.HaveMissing.False

SecurityValues.PlaceOfHighestSummedUpValu

e.OtherMonths

Frame 5:

Countries.HaveMissing.True 
Calc_2_TC_1_1_PW_An

We can choose any month other than December to have the highest MV values. Here we choose 'January'

\begin{tabular}{|c|c|c|c|c|c|c|c|c|c|c|c|c|c|c|}
\hline $\begin{array}{l}\vec{E} \\
\stackrel{\Xi}{0}\end{array}$ & ప్ & $\begin{array}{l}0 \\
0 \\
1\end{array}$ & 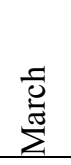 & $\overline{\bar{z}}$ & $\stackrel{\mathrm{I}}{\mathrm{I}}^{\mathrm{d}}$ & $\Xi$ & $\stackrel{\lambda}{\Xi}$ & 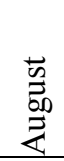 & $\begin{array}{l}\overrightarrow{0} \\
0 \\
\tilde{0}\end{array}$ & $\overrightarrow{0}$ & $\vec{z}$ & ̊̊. & 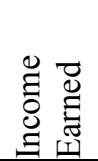 & 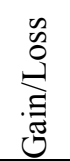 \\
\hline \multirow{2}{*}{ Canada } & 10 & 10 & 10 & 10 & 10 & 10 & 10 & 10 & 10 & 10 & 10 & 10 & \multirow{2}{*}{60} & \multirow{2}{*}{30} \\
\hline & 210 & 22 & 23 & 25 & 22 & 40 & 45 & 34 & 22 & 34 & 87 & 77 & & \\
\hline \multirow{2}{*}{ Canada } & 14 & 14 & 14 & 14 & 14 & 14 & 14 & 14 & 14 & 14 & 14 & 14 & \multirow{2}{*}{90} & \multirow{2}{*}{50} \\
\hline & 140 & 54 & 55 & 45 & 5 & 44 & 71 & 20 & 22 & 24 & 22 & 24 & & \\
\hline \multirow{2}{*}{ USA } & 25 & 25 & 25 & 25 & 25 & 25 & 25 & 25 & 25 & 25 & 25 & 25 & \multirow{2}{*}{45} & \multirow{2}{*}{42} \\
\hline & 230 & 44 & 24 & 65 & 43 & 24 & 86 & 54 & 22 & 52 & 50 & 50 & & \\
\hline \multirow{2}{*}{ USA } & 45 & 45 & 45 & 45 & 45 & 45 & 45 & 45 & 45 & 45 & 45 & 45 & \multirow{2}{*}{65} & \multirow{2}{*}{100} \\
\hline & 450 & 46 & 51 & 53 & 58 & 55 & 59 & 60 & 65 & 66 & 77 & 88 & & \\
\hline \multirow{2}{*}{ China } & 98 & 98 & 98 & 98 & 98 & 98 & 98 & 98 & 98 & 98 & 98 & 98 & \multirow{2}{*}{98} & \multirow{2}{*}{65} \\
\hline & 450 & 45 & 25 & 78 & 56 & 44 & 57 & 55 & 56 & 54 & 53 & 51 & & \\
\hline \multirow{2}{*}{ China } & 56 & 56 & 56 & 56 & 56 & 56 & 56 & 56 & 56 & 56 & 56 & 56 & \multirow[b]{2}{*}{89} & \multirow{2}{*}{12} \\
\hline & 780 & 77 & 77 & 54 & 36 & 36 & 36 & 36 & 36 & 36 & 36 & 36 & & \\
\hline \multirow{2}{*}{ Mexico } & 23 & 23 & 23 & 23 & 23 & 23 & 23 & 23 & 23 & 23 & 23 & 23 & \multirow[b]{2}{*}{8} & \multirow{2}{*}{85} \\
\hline & 440 & 44 & 44 & 44 & 44 & 44 & 44 & 54 & 23 & 4 & 4 & 33 & & \\
\hline
\end{tabular}

\section{Expected Output:}

\begin{tabular}{|l|l|l|l|l|l|}
\hline $\begin{array}{l}\text { Grouping } \\
\text { Countries }\end{array}$ & $\begin{array}{l}\text { Maximum } \\
\text { Cost }\end{array}$ & $\begin{array}{l}\text { Maximum fair } \\
\text { market value }\end{array}$ & $\begin{array}{l}\text { Fair market } \\
\text { value at year end }\end{array}$ & $\begin{array}{l}\text { Foreign income } \\
\text { earned or loss }\end{array}$ & $\begin{array}{l}\text { Capital } \\
\text { gain/loss }\end{array}$ \\
\hline \multirow{2}{*}{ CANADA } & \multirow{3}{*}{271} & 350 & 101 & 150 & 80 \\
\cline { 1 - 4 } USA & 680 & 138 & 110 & 142 \\
\cline { 4 - 6 } & & 1230 & 87 & 187 & 77 \\
\cline { 3 - 5 } CHINA & 440 & 33 & 85 & 85 \\
\hline MEXICO & & & & \\
\hline
\end{tabular}

\section{Actual Output:}

\begin{tabular}{|l|l|l|l|l|l|}
\hline $\begin{array}{l}\text { Grouping } \\
\text { Countries }\end{array}$ & \multirow{2}{*}{$\begin{array}{l}\text { Maximum } \\
\text { Cost }\end{array}$} & $\begin{array}{l}\text { Maximum fair } \\
\text { market value }\end{array}$ & $\begin{array}{l}\text { Fair market } \\
\text { value at year end }\end{array}$ & $\begin{array}{l}\text { Foreign income } \\
\text { earned or loss }\end{array}$ & $\begin{array}{l}\text { Capital } \\
\text { gain/loss }\end{array}$ \\
\hline \multirow{3}{*}{ CANADA } & \multirow{3}{*}{271} & 350 & 101 & 150 & 80 \\
\cline { 1 - 5 } USA & 680 & 138 & 110 & 142 \\
\cline { 3 - 5 } CHINA & 1230 & 87 & 187 & 77 \\
\cline { 3 - 5 } MEXICO & 440 & 33 & 85 & 85 \\
\hline
\end{tabular}


Calc_2_TC_2_1_PW_An

\begin{tabular}{|c|c|c|c|c|c|c|c|c|c|c|c|c|c|c|}
\hline $\begin{array}{l}\stackrel{\vec{E}}{\Xi} \\
\stackrel{\Xi}{0}\end{array}$ & 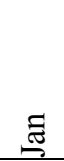 & 0 & $\begin{array}{l}\overline{0} \\
\dot{\pi} \\
\Sigma\end{array}$ & $\overline{\vec{z}}$ & ¿ & $\Xi$ & $\vec{\Xi}$ & $\begin{array}{l}\overrightarrow{0} \\
\stackrel{0}{0} \\
\stackrel{0}{E}\end{array}$ & $\begin{array}{l}\overrightarrow{0} 0 \\
0 \\
0\end{array}$ & $\overrightarrow{0}$ & $\vec{z}$ & ֻั & 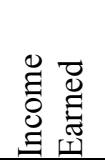 & 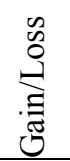 \\
\hline \multirow{2}{*}{ Canada } & 10 & 10 & 10 & 10 & 10 & 10 & 10 & 10 & 10 & 10 & 10 & 10 & \multirow{2}{*}{60} & \multirow{2}{*}{30} \\
\hline & 21 & 22 & 23 & 25 & 22 & 40 & 45 & 34 & 22 & 34 & 87 & 770 & & \\
\hline \multirow{2}{*}{ Canada } & 14 & 14 & 14 & 14 & 14 & 14 & 14 & 14 & 14 & 14 & 14 & 14 & \multirow{2}{*}{90} & \multirow{2}{*}{50} \\
\hline & 14 & 54 & 55 & 45 & 5 & 44 & 71 & 20 & 22 & 24 & 22 & 240 & & \\
\hline \multirow{2}{*}{ USA } & 25 & 25 & 25 & 25 & 25 & 25 & 25 & 25 & 25 & 25 & 25 & 25 & \multirow{2}{*}{45} & \multirow{2}{*}{42} \\
\hline & 23 & 44 & 24 & 65 & 43 & 24 & 86 & 54 & 22 & 52 & 50 & 500 & & \\
\hline \multirow{2}{*}{ USA } & 45 & 45 & 45 & 45 & 45 & 45 & 45 & 45 & 45 & 45 & 45 & 45 & \multirow{2}{*}{65} & \multirow{2}{*}{100} \\
\hline & 45 & 46 & 51 & 53 & 58 & 55 & 59 & 60 & 65 & 66 & 77 & 880 & & \\
\hline \multirow{2}{*}{ China } & 98 & 98 & 98 & 98 & 98 & 98 & 98 & 98 & 98 & 98 & 98 & 98 & \multirow{2}{*}{98} & \multirow{2}{*}{65} \\
\hline & 45 & 45 & 25 & 78 & 56 & 44 & 57 & 55 & 56 & 54 & 53 & 510 & & \\
\hline \multirow{2}{*}{ China } & 56 & 56 & 56 & 56 & 56 & 56 & 56 & 56 & 56 & 56 & 56 & 56 & \multirow{2}{*}{89} & \multirow{2}{*}{12} \\
\hline & 78 & 77 & 77 & 54 & 36 & 36 & 36 & 36 & 36 & 36 & 36 & 360 & & \\
\hline \multirow{2}{*}{ Mexico } & 23 & 23 & 23 & 23 & 23 & 23 & 23 & 23 & 23 & 23 & 23 & 23 & \multirow{2}{*}{85} & \multirow[b]{2}{*}{85} \\
\hline & 44 & 44 & 44 & 44 & 44 & 44 & 44 & 54 & 23 & 4 & 4 & 330 & & \\
\hline
\end{tabular}

\section{Expected Output:}

\begin{tabular}{|l|l|l|l|l|l|}
\hline $\begin{array}{l}\text { Grouping } \\
\text { Countries }\end{array}$ & $\begin{array}{l}\text { Maximum } \\
\text { Cost }\end{array}$ & $\begin{array}{l}\text { Maximum fair } \\
\text { market value }\end{array}$ & $\begin{array}{l}\text { Fair market } \\
\text { value at year end }\end{array}$ & $\begin{array}{l}\text { Foreign income } \\
\text { earned or loss }\end{array}$ & $\begin{array}{l}\text { Capital } \\
\text { gain/loss }\end{array}$ \\
\hline \multirow{3}{*}{ CANADA } & \multirow{3}{*}{271} & 1010 & 1010 & 150 & 80 \\
\cline { 1 - 5 } USA & 1380 & 1380 & 110 & 142 \\
\cline { 3 - 6 } CHINA & 870 & 870 & 187 & 77 \\
\cline { 3 - 5 } & & 330 & 330 & 85 & 85 \\
\hline
\end{tabular}

\section{Actual Output:}

\begin{tabular}{|l|l|l|l|l|l|}
\hline $\begin{array}{l}\text { Grouping } \\
\text { Countries }\end{array}$ & $\begin{array}{l}\text { Maximum } \\
\text { Cost }\end{array}$ & $\begin{array}{l}\text { Maximum fair } \\
\text { market value }\end{array}$ & $\begin{array}{l}\text { Fair market } \\
\text { value at year end }\end{array}$ & $\begin{array}{l}\text { Foreign income } \\
\text { earned or loss }\end{array}$ & $\begin{array}{l}\text { Capital } \\
\text { gain/loss }\end{array}$ \\
\hline \multirow{3}{*}{ CANADA } & \multirow{3}{*}{271} & 1010 & 1010 & 150 & 80 \\
\cline { 1 - 5 } USA & 1380 & 1380 & 110 & 142 \\
\cline { 3 - 6 } CHINA & 870 & 870 & 187 & 77 \\
\cline { 3 - 5 } MEXICO & 330 & 330 & 85 & 85 \\
\hline
\end{tabular}


Calc_2_TC_3_1_PW_An

\begin{tabular}{|c|c|c|c|c|c|c|c|c|c|c|c|c|c|c|}
\hline $\begin{array}{l}\stackrel{\vec{E}}{\Xi} \\
\stackrel{\Xi}{0}\end{array}$ & 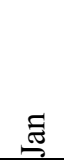 & $\begin{array}{l}0 \\
0\end{array}$ & $\begin{array}{l}\frac{\pi}{0} \\
\tilde{\pi} \\
\Sigma\end{array}$ & $\overline{\vec{z}}$ & $\sum^{\grave{\Xi}}$ & $\Xi$ & $\vec{\Xi}$ & 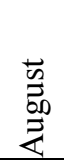 & $\begin{array}{l}\overrightarrow{0} \\
\text { 。 } \\
\ddot{n}\end{array}$ & $\overrightarrow{0}$ & $\vec{z}$ & ڤ̈ & 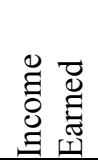 & 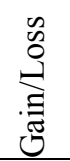 \\
\hline \multirow{2}{*}{ Canada } & 10 & 10 & 10 & 10 & 10 & 10 & 10 & 10 & 10 & 10 & 10 & 10 & \multirow{2}{*}{600} & \multirow{2}{*}{30} \\
\hline & 21 & 22 & 23 & 25 & 22 & 40 & 45 & 34 & 22 & 34 & 87 & 77 & & \\
\hline \multirow{2}{*}{ Canada } & 14 & 14 & 14 & 14 & 14 & 14 & 14 & 14 & 14 & 14 & 14 & 14 & \multirow{2}{*}{900} & \multirow{2}{*}{50} \\
\hline & 14 & 54 & 55 & 45 & 5 & 44 & 71 & 20 & 22 & 24 & 22 & 24 & & \\
\hline \multirow{2}{*}{ USA } & 25 & 25 & 25 & 25 & 25 & 25 & 25 & 25 & 25 & 25 & 25 & 25 & \multirow{2}{*}{450} & \multirow{2}{*}{42} \\
\hline & 23 & 44 & 24 & 65 & 43 & 24 & 86 & 54 & 22 & 52 & 50 & 50 & & \\
\hline \multirow{2}{*}{ USA } & 45 & 45 & 45 & 45 & 45 & 45 & 45 & 45 & 45 & 45 & 45 & 45 & \multirow{2}{*}{650} & \multirow{2}{*}{100} \\
\hline & 45 & 46 & 51 & 53 & 58 & 55 & 59 & 60 & 65 & 66 & 77 & 88 & & \\
\hline \multirow[t]{2}{*}{ “"” } & 98 & 98 & 98 & 98 & 98 & 98 & 98 & 98 & 98 & 98 & 98 & 98 & \multirow{2}{*}{980} & \multirow{2}{*}{65} \\
\hline & 45 & 45 & 25 & 78 & 56 & 44 & 57 & 55 & 56 & 54 & 53 & 51 & & \\
\hline \multirow[t]{2}{*}{ ،"” } & 56 & 56 & 56 & 56 & 56 & 56 & 56 & 56 & 56 & 56 & 56 & 56 & \multirow{2}{*}{890} & \multirow{2}{*}{12} \\
\hline & 78 & 77 & 77 & 54 & 36 & 36 & 36 & 36 & 36 & 36 & 36 & 36 & & \\
\hline \multirow{2}{*}{ Mexico } & 23 & 23 & 23 & 23 & 23 & 23 & 23 & 23 & 23 & 23 & 23 & 23 & \multirow{2}{*}{850} & \multirow[b]{2}{*}{85} \\
\hline & 44 & 44 & 44 & 44 & 44 & 44 & 44 & 54 & 23 & 4 & 4 & 33 & & \\
\hline
\end{tabular}

\section{Expected Output:}

\begin{tabular}{|l|l|l|l|l|l|}
\hline $\begin{array}{l}\text { Grouping } \\
\text { Countries }\end{array}$ & \multirow{2}{*}{$\begin{array}{l}\text { Maximum } \\
\text { Cost }\end{array}$} & $\begin{array}{l}\text { Maximum fair } \\
\text { market value }\end{array}$ & $\begin{array}{l}\text { Fair market } \\
\text { value at year end }\end{array}$ & $\begin{array}{l}\text { Foreign income } \\
\text { earned or loss }\end{array}$ & $\begin{array}{l}\text { Capital } \\
\text { gain/loss }\end{array}$ \\
\hline \multirow{3}{*}{ CANADA } & \multirow{3}{*}{271} & 116 & 101 & 1500 & 80 \\
\cline { 3 - 6 } & 145 & 138 & 1100 & 142 \\
\cline { 3 - 6 } USA & 132 & 87 & 1870 & 77 \\
\cline { 3 - 6 } & & 54 & 33 & 850 & 85 \\
\hline MEXICO & & & & \\
\hline
\end{tabular}

\section{Actual Output:}

\begin{tabular}{|c|c|c|c|c|c|}
\hline $\begin{array}{l}\text { Grouping } \\
\text { Countries }\end{array}$ & $\begin{array}{l}\text { Maximum } \\
\text { Cost }\end{array}$ & $\begin{array}{l}\text { Maximum fair } \\
\text { market value }\end{array}$ & $\begin{array}{l}\text { Fair market } \\
\text { value at year end }\end{array}$ & $\begin{array}{l}\text { Foreign income } \\
\text { earned or loss }\end{array}$ & $\begin{array}{l}\text { Capital } \\
\text { gain/loss }\end{array}$ \\
\hline CANADA & \multirow{4}{*}{271} & 116 & 101 & 1500 & 80 \\
\hline USA & & 145 & 138 & 1100 & 142 \\
\hline “" & & 132 & 87 & 1870 & 77 \\
\hline MEXICO & & 54 & 33 & 850 & 85 \\
\hline
\end{tabular}


Calc_2_TC_4_1_PW_An

We can choose any month other than December to have the highest MV values. Here we choose 'January'

\begin{tabular}{|c|c|c|c|c|c|c|c|c|c|c|c|c|c|c|}
\hline $\begin{array}{l}\stackrel{E}{\Xi} \\
\dot{0}\end{array}$ & $\underset{\Xi}{\mathbb{E}}$ & $\begin{array}{l}0 \\
0 \\
1\end{array}$ & $\begin{array}{l}\frac{1}{0} \\
\vdots \\
\end{array}$ & $\overline{\bar{c}}$ & $\sum^{\grave{\Xi}}$ & $\Xi$ & $\vec{\partial}$ & $\begin{array}{l}\overrightarrow{5} \\
\stackrel{5}{5} \\
\stackrel{2}{2}\end{array}$ & $\begin{array}{l}\overrightarrow{0} \\
\ddot{0}\end{array}$ & E & $\vec{z}$ & 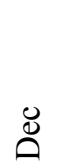 & 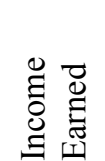 & 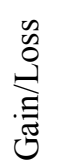 \\
\hline \multirow{2}{*}{ Canada } & 10 & 10 & 10 & 10 & 10 & 10 & 10 & 10 & 10 & 10 & 10 & 10 & \multirow{2}{*}{60} & \multirow{2}{*}{30} \\
\hline & 210 & 22 & 23 & 25 & 22 & 40 & 45 & 34 & 22 & 34 & 87 & 77 & & \\
\hline \multirow{2}{*}{ CanadA } & 14 & 14 & 14 & 14 & 14 & 14 & 14 & 14 & 14 & 14 & 14 & 14 & \multirow{2}{*}{90} & \multirow{2}{*}{50} \\
\hline & 140 & 54 & 55 & 45 & 5 & 44 & 71 & 20 & 22 & 24 & 22 & 24 & & \\
\hline \multirow{2}{*}{ “"” } & 25 & 25 & 25 & 25 & 25 & 25 & 25 & 25 & 25 & 25 & 25 & 25 & \multirow{2}{*}{45} & \multirow{2}{*}{42} \\
\hline & 230 & 44 & 24 & 65 & 43 & 24 & 86 & 54 & 22 & 52 & 50 & 50 & & \\
\hline \multirow[t]{2}{*}{ ،"” } & 45 & 45 & 45 & 45 & 45 & 45 & 45 & 45 & 45 & 45 & 45 & 45 & \multirow{2}{*}{65} & \multirow{2}{*}{100} \\
\hline & 450 & 46 & 51 & 53 & 58 & 55 & 59 & 60 & 65 & 66 & 77 & 88 & & \\
\hline
\end{tabular}

\section{Expected Output:}

\begin{tabular}{|l|l|l|l|l|l|}
\hline $\begin{array}{l}\text { Grouping } \\
\text { Countries }\end{array}$ & $\begin{array}{l}\text { Maximum } \\
\text { Cost }\end{array}$ & $\begin{array}{l}\text { Maximum fair } \\
\text { market value }\end{array}$ & $\begin{array}{l}\text { Fair market } \\
\text { value at year end }\end{array}$ & $\begin{array}{l}\text { Foreign income } \\
\text { earned or loss }\end{array}$ & $\begin{array}{l}\text { Capital } \\
\text { gain/loss }\end{array}$ \\
\hline CANADA & & 350 & 101 & 150 & 80 \\
\hline “'” & 94 & 680 & 138 & 110 & 142 \\
\hline
\end{tabular}

\section{Actual Output:}

\begin{tabular}{|l|l|l|l|l|l|}
\hline $\begin{array}{l}\text { Grouping } \\
\text { Countries }\end{array}$ & $\begin{array}{l}\text { Maximum } \\
\text { Cost }\end{array}$ & $\begin{array}{l}\text { Maximum fair } \\
\text { market value }\end{array}$ & $\begin{array}{l}\text { Fair market } \\
\text { value at year end }\end{array}$ & $\begin{array}{l}\text { Foreign income } \\
\text { earned or loss }\end{array}$ & $\begin{array}{l}\text { Capital } \\
\text { gain/loss }\end{array}$ \\
\hline CANADA & \multirow{2}{*}{94} & 350 & 101 & 150 & 80 \\
\cline { 3 - 6 } & 64 & 680 & 138 & 110 & 142 \\
\hline
\end{tabular}




\section{Calc_2_TC_5_1_PW_An}

A missing country is represented by a NULL value in the country field.

\begin{tabular}{|c|c|c|c|c|c|c|c|c|c|c|c|c|c|c|}
\hline $\begin{array}{l}\vec{\Xi} \\
\stackrel{\Xi}{0}\end{array}$ & ప్త్ & 过 & $\begin{array}{l}\frac{1}{0} \\
\text { 节 }\end{array}$ & $\overline{\bar{z}}$ & $\stackrel{\overrightarrow{\mathrm{c}}}{\mathrm{d}}$ & $\Xi$ & $\frac{\lambda}{\Xi}$ & 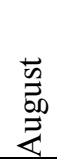 & 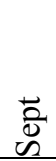 & $\overrightarrow{\tilde{U}}$ & z & ்ֻ & 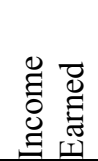 & 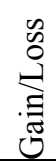 \\
\hline \multirow{2}{*}{ China } & 98 & $\overline{98}$ & 98 & 98 & 98 & 98 & 98 & 98 & 98 & 98 & 98 & 98 & \multirow{2}{*}{98} & \multirow{2}{*}{65} \\
\hline & 450 & 45 & 25 & 78 & 56 & 44 & 57 & 55 & 56 & 54 & 53 & 51 & & \\
\hline \multirow{2}{*}{ China } & 56 & 56 & 56 & 56 & 56 & 56 & 56 & 56 & 56 & 56 & 56 & 56 & \multirow{2}{*}{89} & \multirow{2}{*}{12} \\
\hline & 780 & 77 & 77 & 54 & 36 & 36 & 36 & 36 & 36 & 36 & 36 & 36 & & \\
\hline \multirow{2}{*}{ NULL } & 23 & 23 & 23 & 23 & 23 & 23 & 23 & 23 & 23 & 23 & 23 & 23 & \multirow{2}{*}{85} & \multirow{2}{*}{85} \\
\hline & 440 & 44 & 44 & 44 & 44 & 44 & 44 & 54 & 23 & 4 & 4 & 33 & & \\
\hline
\end{tabular}

\section{Expected Output:}

Error

\section{Actual Output:}

Error 


\section{D.3 List of Live and Killed Mutants}

\begin{tabular}{|c|c|c|c|c|c|c|}
\hline $\begin{array}{l}\text { Mutation } \\
\text { Name }\end{array}$ & Calc_1_BC & Calc_1_EC & Calc_1_PW & $\begin{array}{l}\text { Calc_1_- } \\
\text { BC_Ann }\end{array}$ & $\begin{array}{l}\text { Calc_1_- } \\
\text { EC_Ann }\end{array}$ & $\begin{array}{l}\text { Calc_1_ } \\
\text { PW_Ann }\end{array}$ \\
\hline D1 & KILLED & KILLED & KILLED & KILLED & KILLED & KILLED \\
\hline D2 & KILLED & KILLED & KILLED & KILLED & KILLED & KILLED \\
\hline EOC1 & LIVE & LIVE & LIVE & LIVE & LIVE & LIVE \\
\hline EOC2 & LIVE & LIVE & LIVE & LIVE & LIVE & LIVE \\
\hline JID1 & LIVE & LIVE & LIVE & LIVE & LIVE & LIVE \\
\hline LCR1 & LIVE & LIVE & LIVE & LIVE & LIVE & LIVE \\
\hline LCR2 & LIVE & LIVE & LIVE & LIVE & LIVE & LIVE \\
\hline LCR3 & LIVE & LIVE & LIVE & LIVE & LIVE & LIVE \\
\hline LCR4 & LIVE & LIVE & LIVE & LIVE & LIVE & LIVE \\
\hline UOI1 & KILLED & KILLED & KILLED & KILLED & KILLED & KILLED \\
\hline UOI10 & KILLED & KILLED & KILLED & KILLED & KILLED & KILLED \\
\hline UOI11 & KILLED & KILLED & KILLED & KILLED & KILLED & KILLED \\
\hline UOI12 & KILLED & KILLED & KILLED & KILLED & KILLED & KILLED \\
\hline UOI13 & KILLED & KILLED & KILLED & KILLED & KILLED & KILLED \\
\hline UOI14 & KILLED & KILLED & KILLED & KILLED & KILLED & KILLED \\
\hline UOI15 & KILLED & KILLED & KILLED & KILLED & KILLED & KILLED \\
\hline UOI16 & KILLED & KILLED & KILLED & KILLED & KILLED & KILLED \\
\hline UOI17 & LIVE & LIVE & LIVE & LIVE & LIVE & LIVE \\
\hline UOI18 & LIVE & LIVE & LIVE & LIVE & LIVE & LIVE \\
\hline UOI19 & LIVE & LIVE & LIVE & LIVE & LIVE & LIVE \\
\hline UOI2 & LIVE & LIVE & LIVE & LIVE & LIVE & LIVE \\
\hline UOI20 & KILLED & KILLED & KILLED & KILLED & KILLED & KILLED \\
\hline UOI3 & LIVE & LIVE & LIVE & LIVE & LIVE & LIVE \\
\hline UOI4 & LIVE & LIVE & LIVE & LIVE & LIVE & LIVE \\
\hline UOI5 & KILLED & KILLED & KILLED & KILLED & KILLED & KILLED \\
\hline UOI6 & KILLED & KILLED & KILLED & KILLED & KILLED & KILLED \\
\hline UOI7 & KILLED & KILLED & KILLED & KILLED & KILLED & KILLED \\
\hline UOI8 & KILLED & KILLED & KILLED & KILLED & KILLED & KILLED \\
\hline UOI9 & KILLED & KILLED & KILLED & KILLED & KILLED & KILLED \\
\hline
\end{tabular}




\section{D.4 Live Mutants}

Same as section C.4 except that D1 and D2 and are now killed by all test suites in Calc_2.

\section{D.5 Non-Uniform Mutants}

None. 